REPORT TITLE: Treatment of Produced Oil and Gas Waters with SurfactantModified Zeolite

REPORT TYPE: Final Technical Report

REPORT PERIOD: 1 October 1999 - 31 September 2003

PRINCIPAL AUTHORS: Lynn E. Katz, R.S. Bowman, E.J. Sullivan

REPORT ISSUE DATE: November 2003

DOE AWARD NUMBER: DE-AC26-99BC15221 


\section{Treatment of Produced Oil and Gas Waters with Surfactant-Modified Zeolite}

Final Technical Report

1 October 1999 - 31 September 2003

DOE AWARD NUMBER: DE-AC26-99BC15221

DISCLAIMER: This report was prepared as an account of work sponsored by an agency of the United States Government. Neither the United States Government nor any agency thereof, nor any of their employees, makes any warranty, express or implied, or assumes any legal liability or responsibility for the accuracy, completeness, or usefulness of any information, apparatus, product, or process disclosed, or represents that its use would not infringe privately owned rights. Reference herein to any specific commercial product, process, or service by trade name, trademark, manufacturer, or otherwise does not necessarily constitute or imply its endorsement, recommendation, or favoring by the United States Government or any agency thereof. The views and opinions of authors expressed herein do not necessarily state or reflect those of the United States Government or any agency thereof.

\section{Lynn E. Katz}




\begin{abstract}
Co-produced water from the oil and gas industry accounts for a significant waste stream in the United States. It is by some estimates the largest single waste stream in the country, aside from nonhazardous industrial wastes. Characteristics of produced water include high total dissolved solids content, dissolved organic constituents such as benzene and toluene, an oil and grease component, and chemicals added during the oilproduction process. While most of the produced water is disposed via reinjection, some must be treated to remove organic constituents before the water is discharged. Current treatment options are successful in reducing the organic content; however, they cannot always meet the levels of current or proposed regulations for discharged water. Therefore, an efficient, cost-effective treatment technology is needed. Surfactantmodified zeolite (SMZ) has been used successfully to treat contaminated ground water for organic and inorganic constituents. In addition, the low cost of natural zeolites makes their use attractive in water-treatment applications.

This report summarizes the work and results of this four-year project. We tested the effectiveness of surfactant-modified zeolite (SMZ) for removal of BTEX with batch and column experiments using waters with BTEX concentrations that are comparable to those of produced waters. The data from our experimental investigations showed that BTEX sorption to $\mathrm{SMZ}$ can be described by a linear isotherm model, and competitive effects between compounds were not significant. The SMZ can be readily regenerated using air stripping. We field-tested a prototype SMZ-based water treatment system at produced water treatment facilities and found that the SMZ successfully removes BTEX from produced waters as predicted by laboratory studies. When compared to other existing treatment technologies, the cost of the SMZ system is very competitive. Furthermore, the SMZ system is relatively compact, does not require the storage of potentially hazardous chemicals, and could be readily adapted to an automated system.
\end{abstract}




\section{Table of Contents}

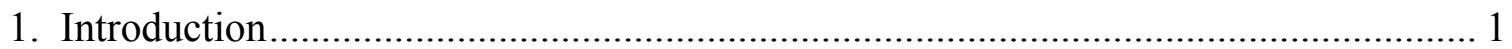

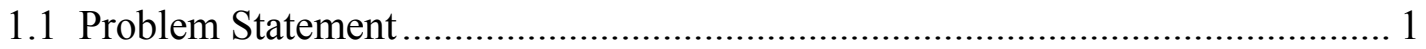

1.2 Objectives and Approach......................................................................... 2

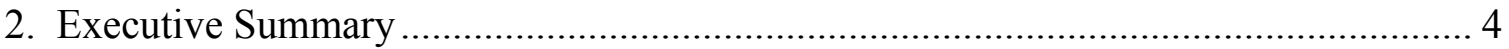

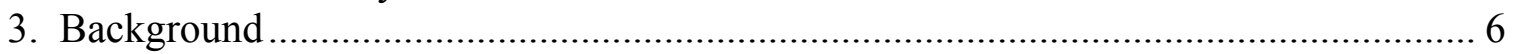

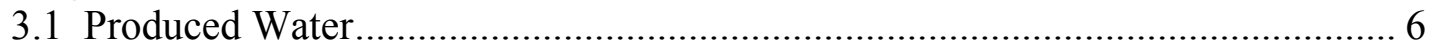

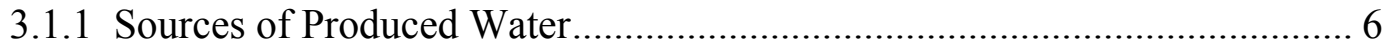

3.1.2 Produced Water Characterization ………………................................... 7

3.1.3 Regulation of Produced Water Disposal........................................................ 8

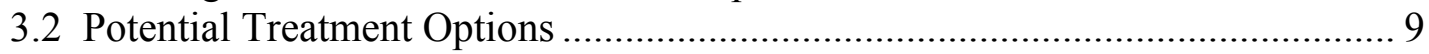

3.2.1 Current Treatment Methods .............................................................. 9

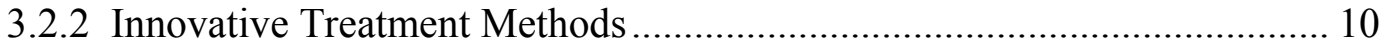

3.2.2.1 Bubble Separation of Hydrocarbons................................................ 10

3.2.2.2 Oxidation of Organic Compounds …………...................................... 11

3.2.2.3 Phytoremediation of Produced Water ...................................................... 11

3.2.2.4 Sorption of Produced Water by Commercially Available Sorbents .... 12

3.2.3 Surfactant Modified Zeolite .................................................................... 14

3.2.3.1 Zeolite Properties ....................................................................... 16

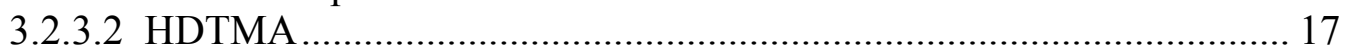

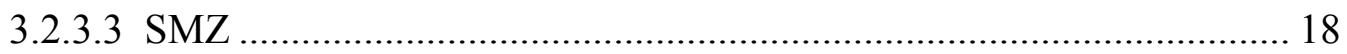

3.2.3.3 Sorption Mechanisms and Predictive Models........................................ 20

3.2.3.4 Long Term Stability of SMZ ………………….............................. 27

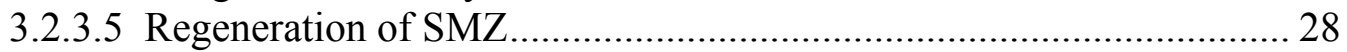

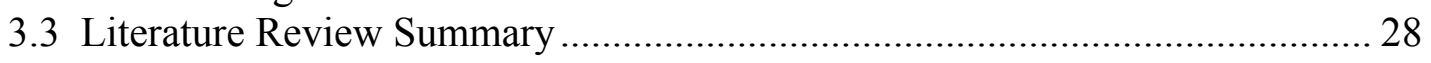

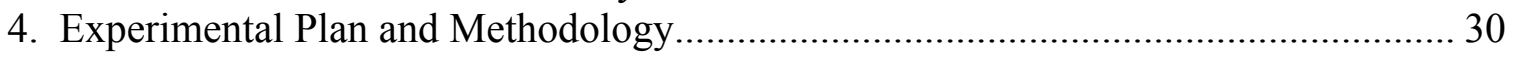

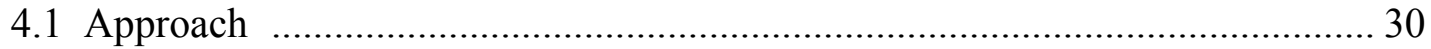

4.1.1 Batch Studies ..................................................................................... 30

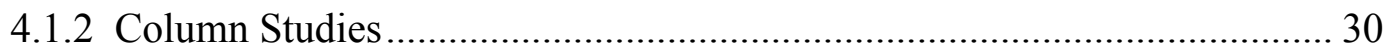

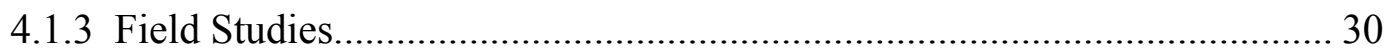

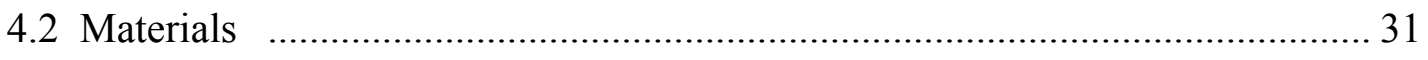

4.2.1 BTEX compounds.............................................................................. 31

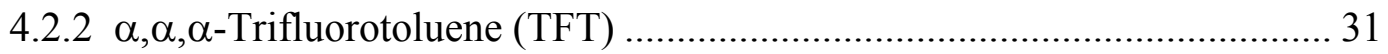

4.2.3 Electrolytes for Saline Water Preparation................................................ 31

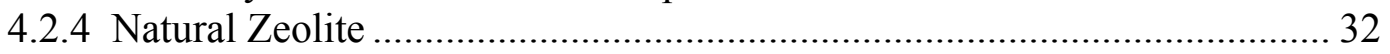

4.2.5 Hexadecyltrimethylammonium Surfactant ............................................... 32

4.2.6 Hexadecyltrimethylammonium Surfactant Modification of Zeolite............ 32

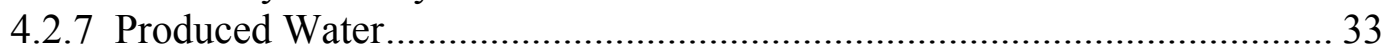

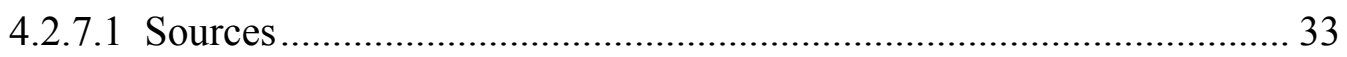

4.2.7.2 Sample Collection........................................................................ 33

4.2.7.3 Characterization of Field Samples .................................................... 34

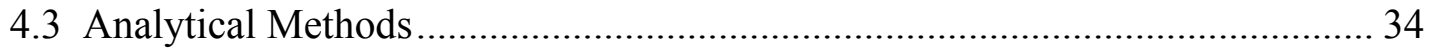

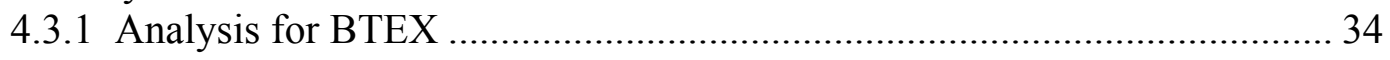


4.3.2 Preparation of Standards for BTEX Analysis ......................................... 37

4.3.3 Analysis for Metals and Semi-Volatiles ................................................. 40

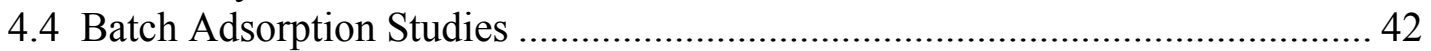

4.4.1 Single- and Multi-Solute Batch Experiments ........................................ 42

4.4.2 Ionic Strength Effects Batch Experiments ............................................. 45

4.4.3 Temperature Effect Batch Studies ..................................................... 47

4.4.4 Batch Studies with Produced Water ...................................................... 49

4.4.5 Statistical Analyses for Batch Experiments ......................................... 50

4.5 Column Adsorption Studies ........................................................................... 52

4.5.1 Single- and Multi-Solute Column Experiments.................................... 54

4.5.2 Column Study in Saline Water Background............................................5 56

4.5.3 Column Study in Produced Water Background........................................ 56

4.5.4 Regeneration Tests.............................................................................. 57

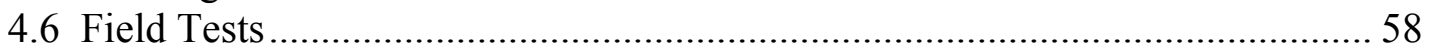

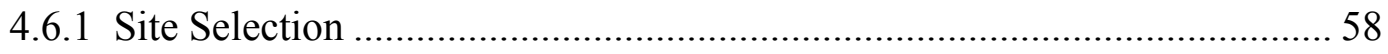

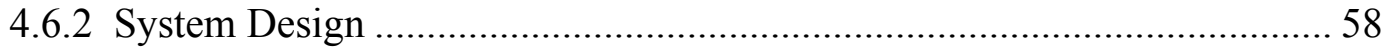

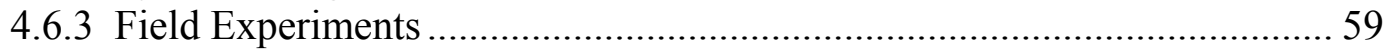

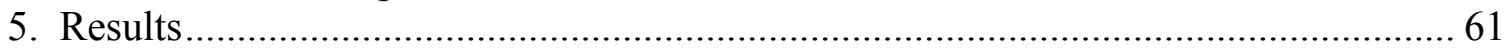

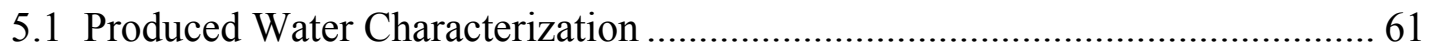

5.1.1 Phillips Petroleum Offshore Sample .................................................... 61

5.1.2 MCA Petroleum Corporation Onshore Samples....................................... 62

5.1.3 Produced Water from BC Technologies Wamsutter Treatment Facility.... 64

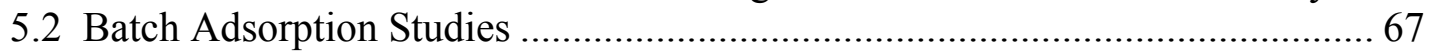

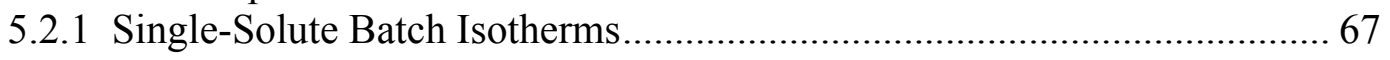

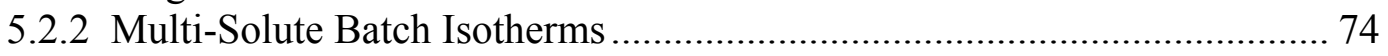

5.2.3 Batch Studies in High Salinity Background Water................................... 77

5.2.3.1 Benzene Sorption onto SMZ in the Presence of Different Salt

Concentrations .................................................................................. 78

5.2.3.2 Multi-Solute BTEX Sorption onto SMZ in Salt Solutions ................. 80

5.2.3.3 Predictive and Empirical Descriptions of BTEX Sorption in Saline

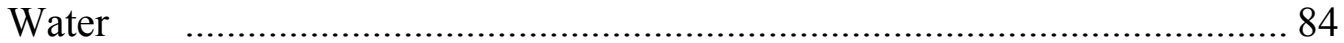

5.2.3.4 Conclusions for Sorption of BTEX in Saline Solutions ..................... 89

5.2.4 Effect of Temperature on BTEX Sorption to SMZ ................................. 89

5.2.4.1 Comparison of Sorption Enthalpy Change with Published Data........ 92

5.2.4.2 Hypothesized Mechanism of Sorption.............................................. 95

5.2.4.3 Conclusions Derived from the BTEX Sorption Temperature Study ... 99

5.2.5 Studies with Produced Water ............................................................ 100

5.2.6 Batch Studies with Different Size SMZ Particles................................... 101

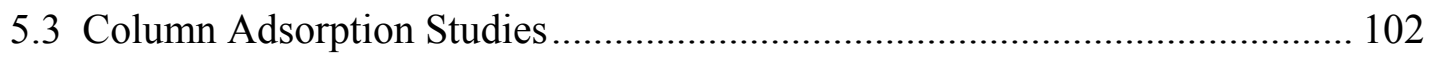

5.3.1 Column Study in Ultrapure Water Background..................................... 102

5.3.2 Column Study in Saline Water Background........................................... 104

5.3.3 Column Study in Produced Water Background...................................... 106

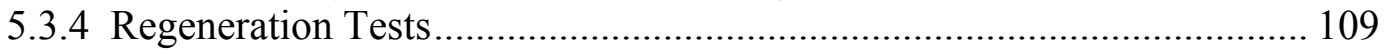

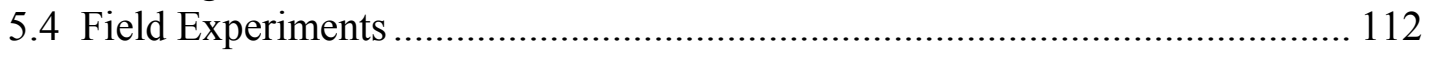

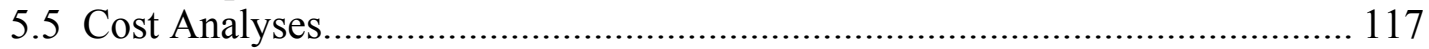

5.5.1 Cost Analysis for Industrial Scale SMZ System................................. 118 


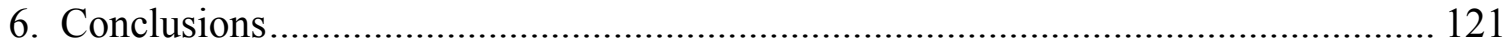

6.1 Batch Equilibrium Studies .............................................................................. 121

6.1.1 Batch Equilibrium Sorption Studies Conducted in Ultrapure Water........ 121

6.1.2 Batch Equilibrium Sorption Studies Conducted in Saline Solutions........ 121

6.1.3 Batch Equilibrium Sorption Studies Conducted in Produced Water ........ 122

6.1.4 Studies of Temperature Effects on Batch Equilibrium Sorption ............... 122

6.2 Laboratory Scale Column Studies and Field Studies...................................... 123

6.2.1 Column Studies with Ultrapure Water, Saline Water, and Produced Water

6.2.1 Regeneration Studies with Ultrapure Water

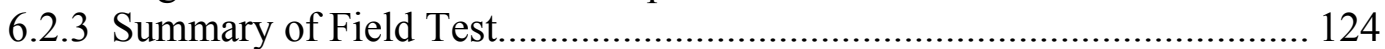

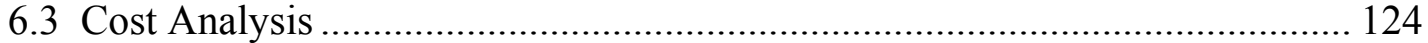

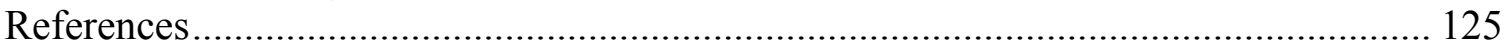

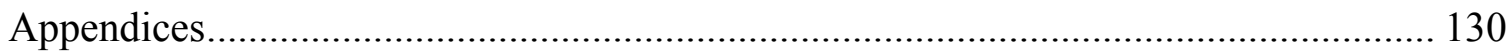

Appendix A: Input and Output Files in Column Studies....................................... 130

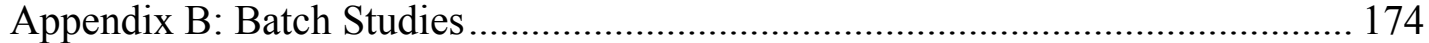

Appendix C: Column Studies ........................................................................ 183

Appendix D: Averages and Standard Deviations for BTEX Sorption Study in

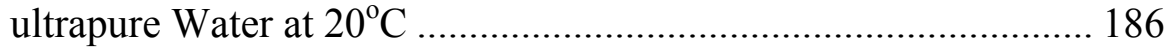




\section{List of Figures}

Figure 3-1 Crystal Structure for Clinoptilolite (adapted from Manley and Holmes, 1989, Minerals with Natural Advantage, New Scientist, March 25, 1989, pp. 39-43) ....... 17

Figure 3.2 HDTMA Sorption to Zeolite

Figure 4.1 Standard Curve for Benzene in Wamsutter Site Holding Pond Produced Water

Figure 4.2 Diagram of Laboratory Column Adsorption System ….............................. 55

Figure 4.3 Diagram of Laboratory Column Regeneration System ................................ 58

Figure 4.4 Testing of a prototype SMZ-based water treatment column at a water treatment facility near Wamsutter, WY.: (a) a SMZ column connected to waste water storage tanks at the treatment site; (b) an enlarged view of the SMZ column with sampling valves.

Figure 5.1 Produced Water Outfall for MCA Petroleum Corp..................................... 64

Figure 5.2 Single-Solute Sorption Isotherm for Benzene on SMZ in Ultrapure Water (a)

Logarithmic $\left(\mathrm{q}_{\mathrm{e}}=\mathrm{K}_{\mathrm{d}} \mathrm{C}_{\mathrm{e}}\right.$ with $95 \%$ Confidence Limits for $\mathrm{K}_{\mathrm{d}}(\mathrm{L} / \mathrm{g} \mathrm{SMZ})$ in

Parentheses); (b) Linear (95\% Confidence Limits for Data Shown by Dashed Lines)

Figure 5.3 Single-Solute Sorption Isotherm for Toluene on SMZ in Ultrapure Water (a)

Logarithmic $\left(\mathrm{q}_{\mathrm{e}}=\mathrm{K}_{\mathrm{d}} \mathrm{C}_{\mathrm{e}}\right.$ with $95 \%$ Confidence Limits for $\mathrm{K}_{\mathrm{d}}(\mathrm{L} / \mathrm{g} \mathrm{SMZ})$ in

Parentheses); (b) Linear (95\% Confidence Limits for Data Shown by Dashed Lines)

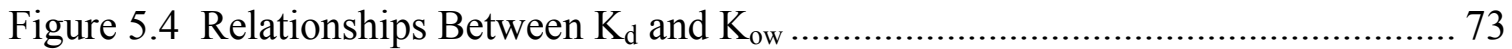

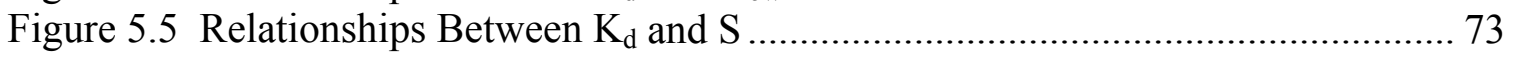

Figure 5.6 Multi-Solute Sorption Isotherms for BTEX on SMZ in ultrapure Water ...... 75

Figure 5.7 Benzene Sorption Isotherm in Presence of Other BTEX Compounds with

95\% Confidence Limits on Data (shown in dashed lines) and y-Intercept.............. 75

Figure 5.8 Benzene Sorption Isotherms at Differing Solution Salinities........................ 79

Figure 5.9 Benzene Sorption Isotherms at Differing Solution Salinities and in the

Presence of the Remaining BTEX Compounds................................................... 81

Figure 5.10 Toluene Sorption Isotherms at Differing Solution Salinities and in the

Presence of the Remaining BTEX Compounds................................................ 81

Figure 5.11 Distribution Coefficient as a Function of Salinity for BTEX Compounds

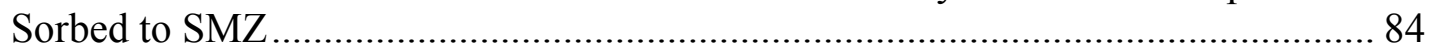

Figure 5.12 Observed and Predicted Distribution Coefficient Values for Benzene in

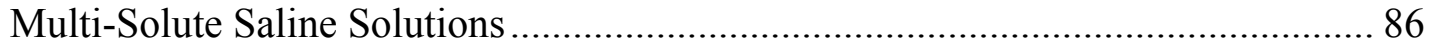

Figure 5.13 Observed and Predicted Distribution Coefficient Values for Toluene in

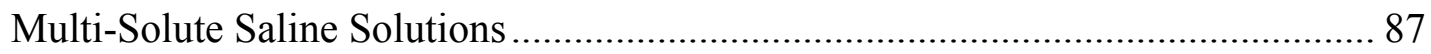

Figure 5.14 Data Used in $\log \mathrm{K}_{\mathrm{d} \text {,salt }}-[\mathrm{salt}]_{\mathrm{M}}$ Regressions....................................... 88

Figure 5.15 Sorption Isotherm for Toluene on SMZ in Ultrapure Water at 20oC- (a)

Linear scale showing data and regression equation (b) Logarithmic scale showing

data and $95 \%$ confidence limits on the regression line.

Figure 5.16 Van't Hoff Plots of SMZ Equilibrium Partitioning for Benzene and Toluene.

Solid lines are regression lines. Bars indicate standard error bars........................ 93

Figure 5.17 Van't Hoff Plots of SMZ Equilibrium Partitioning for Ethylbenzene, m, p-

Xylene, and o-Xylene. Solid Lines are Regression Lines. Bars Indicate Standard Errors 
Figure 5.18 Comparison of BTEX sorption onto SMZ vs. BTEX solubility (Benzene solubility data are from May et al. (1983) and toluene and ethylbenzene solubility data are from Sawamura et al. 2001).

Figure 5.19 Sorption Isotherms for BTEX Compounds in a Produced Water Matrix .. 100

Figure 5.20 Breakthrough Curves for BTEX Sorbed onto SMZ in Ultrapure Water (The column flowrate was $22 \mathrm{~mL} / \mathrm{min}$, the porosity was 0.52 , and the bulk density of the $\mathrm{SMZ}$ was $1 \mathrm{~g} / \mathrm{cm}^{3}$ ) 103

Figure 5.21 Comparison of Breakthrough Curves from Column Data and CXTFIT2 Predictions. Solid lines are from CXTFIT2 Predictions. 103

Figure 5.22 Breakthrough Curves for BTEX Sorbed onto SMZ in 100,000 Saline Water

Figure 5.23 Breakthrough Curves for BTEX sorbed onto SMZ in Produced Water.... 107

Figure 5.24 BTEX Breakthrough in a Laboratory Column Packed with Virgin SMZ.. 109

Figure 5.25 BTEX Mass Removed from SMZ in the Lab Column by Air-Sparging.... 110

Figure 5.26 BTEX Breakthrough in the Lab Column with Regenerated SMZ 111

Figure 5.27 Comparison of Benzene Breakthrough in Lab Column for Virgin and Regenerated SMZ

Figure 5.28 BTEX Breakthrough in the 14-inch Field Column with Virgin SMZ........ 113 Figure 5.29 Comparison of Benzene Breakthrough in Lab Column with Virgin SMZ and

14-inch Field Column with Virgin SMZ. 114

Figure 5.30 Comparison of Toluene Breakthrough in Lab Column with Virgin SMZ and

12-inch Field Column with Virgin SMZ 114

Figure 5.31 BTEX Mass Removed from SMZ in 14-inch Field Column by Air-sparging.

Figure 5.32 BTEX Breakthrough in 14-inch Field Column with Regenerated SMZ ... 116

Figure 5.33 Comparison of Toluene Breakthrough in 14-inch Field Column with Virgin

SMZ and 14-inch Field Column with Regenerated SMZ 


\section{List of Tables}

Table 3.1 Representative BTEX and TDS Concentrations for Produced Water .............. 7

Table 3.2 Distribution Coefficients Determined by Neel and Bowman (1991) ............. 21

Table 3.3 Published Correlations Relating $\mathrm{K}_{\mathrm{oc}}, \mathrm{K}_{\mathrm{om}}, \mathrm{K}_{\mathrm{ow}}$, and $\mathrm{S}$................................ 23

Table 3.4 Effect of Temperature on Sediment/Water Linear Partitioning Coefficients .. 26

Table 4.1 Chemical and Physical Properties of BTEX Compounds ............................ 31

Table 4.2 Headspace Operating Conditions for BTEX Analysis ................................. 35

Table 4.3 GC Operating .......................................................................................... 35

Table 4.4 GC Detection Times for BTEX Compounds and TFT ................................. 36

Table 4.5 Method Detection Limits for BTEX Compounds......................................... 36

Table 4.6 Calibration Curve Slopes Obtained from Matrices of Ultrapure Water and

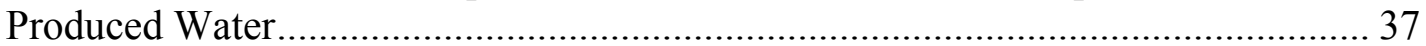

Table 4.7 Standard Curve Solution Concentrations...................................................... 38

Table 4.8 Metals Analysis Methods Used by DHL Analytical .................................... 40

Table 4.9 Ion Analysis Methods Used by DHL Analytical ......................................... 41

Table 4.10 Results from Analyses of MCA Petroleum Corp. Samples .......................... 41

Table 4.11 Octanol/Water Partition Coefficients and Aqueous Solubilities of BTEX

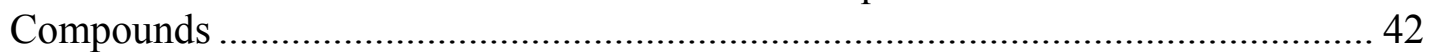

Table 4.12 BTEX Losses Observed in Multi-Solute Sorption Study in Ultrapure Water45

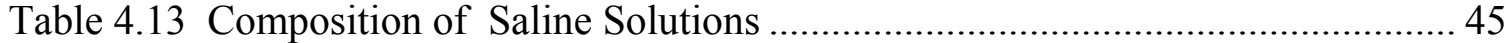

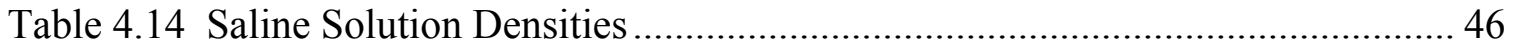

Table 4.15 Benzene Compound Losses in Blanks for Single-Solute Study in Saline

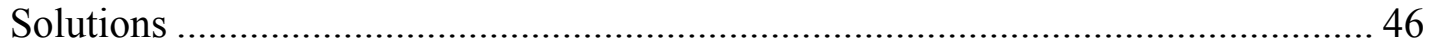

Table 4.16 BTEX Compound Losses in Blanks for Multi-Solute Study in Saline

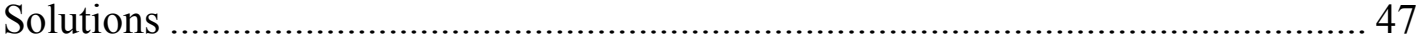

Table 4.17 BTEX Compound Losses in Batch Temperature Tests .............................. 49

Table 4.18 Prospective Pilot Scale Column Dimensions.............................................. 53

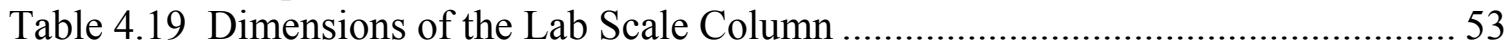

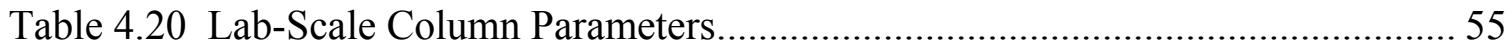

Table 5.1 BTEX Concentrations in Phillips Petroleum Water Samples......................... 61

Table 5.2 TPH, Anions and Cations in Phillips Petroleum Water Samples ................... 62

Table 5.3 Results from Analyses of MCA Petroleum Corp. Samples ............................. 63

Table 5.4 Initial Metals Analysis for Wamsutter Site Samples ...................................... 64

Table 5.5 Initial BTEX Concentrations and Total Dissolved Solids in Wamsutter Site

Samples

Table 5.6 Comparison of Produced Water Characteristics from the Wamsutter Site to

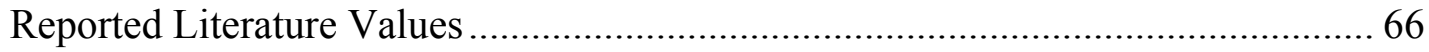

Table 5.7 Benzene Sorption Capacities for Sorption to SMZ in Ultrapure Water .......... 68

Table 5.8 Toluene Sorption Capacities for Sorption to SMZ in Ultrapure Water........... 68

Table 5.9 Benzene Distribution Coefficients Predicted Using Published Correlations... 72

Table 5.10 Toluene Distribution Coefficients Predicted Using Published Correlations . 72

Table 5.11 Multi-Solute Isotherm Distribution Coefficients for BTEX in Ultrapure Water

Table 5.12 BTEX Removal Efficiencies for SMZ in Multi-Solute Sorption Study ....... 76 
Table 5.13 Results from Hypothesis Testing for Single-Solute and Multi-Solute Sorption Studies in Ultrapure Water.

Table 5.14 Distribution Coefficients for Benzene Isotherms in Ultrapure and Saline Water.

Table 5.15 Results for Hypothesis Testing of Isotherms Generated in Single-Solute (Benzene) Studies in Ultrapure Water and Salt Solutions

Table 5.16 Distribution Coefficients for BTEX Sorption Isotherms in Ultrapure and Saline Background Water

Table 5.17 Distribution Coefficients Calculated for Individual Data Points in 200,000 ppm Salt Solution...

Table 5.18 Statistical Comparison Between Multi-Solute Studies Conducted in Ultrapure Water and Saline Solutions 85

Table 5.19 Comparison of Observed and Predicted Distribution Coefficients for Benzene

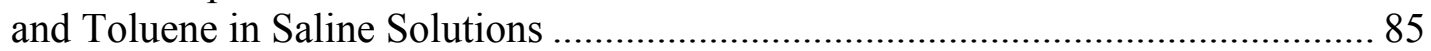

Table 5.20 Regression Parameters for $\log \mathrm{K}_{\mathrm{d} \text {,salt }}-[\mathrm{salt}]_{\mathrm{M}}$ Empirical Relationships ....... 88

Table 5.21 Linear Isotherm Parameters for BTEX Multi-Solute Sorption to SMZ in ultrapure Water at Different Temperatures......................................................... 91

Table 5.22 Sorption Enthalpies $\left(\Delta H_{s}^{\text {net }}\right.$ ) for Sorption of BTEX Compounds onto SMZ in Ultrapure Water 93

Table 5.23 Sorption Enthalpies for Sorption of BTEX Compounds onto Sediment (Dewulf et al.1999)

Table 5.24 Results from Previous Studies Examining the Influence of Temperature on Sorption Equilibrium

Table 5.25 Values of Coefficients a, b, c and d for Calculation of Aqueous Activity Coefficients (Dewulf et al. 1999)

Table 5.26 Theoretical Aqueous Activities and Aqueous Enthalpy Values for BTEX Sorption.

Table 5.27 Calculated $\Delta H_{o c}$ Data with 95\% Confidence Limits $(\mathrm{kJ} / \mathrm{mol})$ for Sorption of BTEX onto SMZ

Table 5.28 BTEX Concentrations in Produced Water from the Wamsutter, WY Site.. 100

Table 5.29 Comparison of $\mathrm{K}_{\mathrm{d}}$ values from Batch Isotherm Studies using Ultrapure and Produced Water Background using Hypothesis Testing

Table 5.30 Comparison of $\mathrm{K}_{\mathrm{d}}$ Values for Different Sizes of SMZ .............................. 101

Table 5.31 Parameters Applied in CXTFIT2 for Predicting BTEX Breakthrough Curves in Ultrapure Water

Table 5.32 Parameters Used in CXTFIT2 to Calibrate $\mathrm{K}_{d}$ Values in Saline Water Column Study

Table 5.33 Calculated Retardation Factors and Distribution Coefficients Determined using CXTFIT2 for BTEX Column Studies in Saline Water ....

Table 5.34 Comparison of BTEX $K_{d}$ Values for Ultrapure Water and 100,000 ppm Saline Water.

Table 5.35 Parameters Used in CXTFIT2 Calculating Retardation Factor $\left(\mathrm{K}_{\mathrm{d}}\right.$ Values) in Produced Water in Column Study ....

Table 5.36 Calculated Retardation Factors and Distribution Coefficients, for CXTFIT2 for Produced Water Column Studies. 
Table 5.37 Amount of BTEX Sorbed in Laboratory Columns and Comparison of $\mathrm{K}_{\mathrm{d}}$

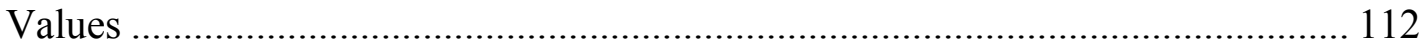

Table 5.38 Average and range of BTEX component concentrations in WY Produced

Water

Table 5.39 Industrial Produced Water Discharge Flow Rates....................................... 117

Table 5.40 Capital and Operating Costs of Industrial SMZ Column ............................. 118

Table 5.41 Total Cost of Industrial SMZ System ........................................................ 119

Table 5.42 Summary of Treatment Costs of Other Technologies (API, 1995) ............. 120

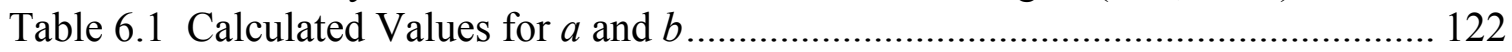

Table 6.2 $\mathrm{K}_{\mathrm{d}}$ Values from Ultrapure, Saline, and Produced Water Column Studies.... 123 


\section{Introduction}

\subsection{Problem Statement}

The United States oil and gas industry generates more than three billion tons of saline wastewater every year (API, 1987). This is by some estimates the single largest waste stream in the U.S., aside from non-hazardous industrial wastes (Allen and Rosselot, 1994). This so-called produced water contains many pollutants, including dispersed and dissolved hydrocarbons, salts, and metals. In addition to prevalent oil and grease, the presence of hazardous aromatic compounds such as benzene, toluene, ethylbenzene, and xylenes (BTEX) increases the toxicity of produced water (Fucik, 1992). Quality tends to be field-specific, and varies within and between reservoirs and types of fields such as oil, gas, and coal-bed methane.

Although most produced water generated by onshore oil and gas operations is disposed of through deep-well reinjection, a substantial percentage of it is discharged to the environment after minimal treatment to remove dispersed oil and suspended solids. Offshore and coastal facilities normally release their effluent to the ocean, and many small producers cannot afford the high price of deep-well reinjection. These small producers must release their effluent through surface discharge. Due to concerns regarding the harmful constituents in produced water, members of the industry feel that regulation of all types of produced water disposal will soon become more stringent (Lawrence et al., 1995).

In addition, many of the areas used by the onshore oil and gas industry are arid, and in these regions, water is a valuable commodity. The ability to reuse produced water for beneficial purposes such as irrigation, livestock watering, and road maintenance would substantially benefit communities in water-scarce regions. Hence, produced water treatment that can yield an effluent that is environmentally innocuous or of sufficient quality to permit reuse would benefit producers, community members, and the environment.

Current treatment methods do not focus on the removal of BTEX compounds. Rather, the traditional oil/water separation tanks and hydrocyclones serve to recover oil that can be refined and marketed. Research has been conducted to evaluate various other methods to remove hazardous compounds in produced water, but much of this research has focused on expensive technologies that are not economically viable for small producers. Lawrence and others (1995) concluded that further research was needed to improve removal efficiencies for oil and grease and dissolved organic compounds.

Cost is a major consideration in the evaluation of treatment processes, especially for small scale producers. A stripper well that produces two barrels of oil per day at a price of $\$ 12 / \mathrm{bbl}$ yields a profit in the cents to low dollar range. If $20 \mathrm{bbls} /$ day of produced water result from this operation, then any treatment requirement must be low cost (cents/day, or a few cents/bbl). Because of larger volumes, total costs increase greatly if off-shore produced water cannot be directly discharged, or if the treatment process requires the well to be shut-in. The development of cost effective processes is therefore essential to the development of any treatment process for produced water.

Treatment through sorption onto materials such as surfactant-modified zeolite (SMZ) may be both effective and relatively inexpensive. Zeolites are naturally occurring 
aluminosilicate minerals that have large capacities for cation exchange. By utilizing this property, natural zeolites can be modified by cationic surfactants, rendering them capable of sorbing anions, cations, and non-polar organic compounds such as BTEX. One study has shown that SMZ can reduce BTEX levels in contaminated water (Janks and Cadena, 1992). While the sorption capacity of SMZ for BTEX is low relative to other adsorbents, it is likely that the SMZ is readily regenerated based on proposed sorption mechanisms. Thus, feasibility analyis of an SMZ treatment process should include a study the potential for regeneration. In order to evaluate the cost-effectiveness of an SMZ treatment process, design criteria for an SMZ system for produced water must be established, and these design criteria should include a cost-effective method for regeneration.

\subsection{Objectives and Approach}

The overall goal of this research was to develop a cost-effective and practical method of treating co-produced waters from oil-field sources using a treatment scheme that includes surfactant-modified zeolite. Potential impediments to system performance and potential methods of system regeneration were also addressed. Existing data on SMZ use as a treatment method for contaminated ground water and an experimental program were used to support the development process. The experimental program included three components: laboratory scale batch experiments, laboratory scale column experiments, and a pilot test. The objectives of this work are as follows:

Objective 1: Verify sorptive properties of SMZ for BTEX in laboratory studies;

Objective 2: Design a practical, inexpensive, modular system for SMZ use in the field;

Objective 3: Verify the system at a field site;

Objective 4: Test regeneration methods for spent SMZ;

Objective 5: Develop a cost analysis for the process.

The first task required to accomplish these objectives was to conduct a review of literature pertaining to produced water composition and treatment. The literature review included:

- a description of the sources, characteristics and variability of produced waters with respect to salinity and BTEX concentrations to aid the site selection and composition of synthetic waters to be used in the laboratory studies;

- a discussion of the current and proposed regulations for BTEX in produced water to set the effluent objectives for the proposed treatment scheme;

- a description of various treatment alternatives to assess which processes should be considered during the cost analysis; and, 
- a review of literature describing the characteristics of surfactant modified zeolite.

This literature review is presented in Chapter 2, Background.

Based on the literature review, it was determined that a number of parameters would impact sorption of BTEX compounds from produced water including the presence of multiple BTEX components, salinity, temperature and other hydrophobic or moderately hydrophobic compounds present in the produced water background matrix. For example, produced water contains salt concentrations that can vary from $100 \mathrm{ppm}-300,000 \mathrm{ppm}$. This high salinity may enhance the sorbability of BTEX on SMZ due to a "salting out" effect. The "salting out" effect is a commonly known phenomenon that reduces the solubility of organic compounds in water (Schwarzenbach et al., 1993). As salt concentrations increase, water molecules become bound to the electrolyte ions which reduces the amount of water molecules available to dissolve organic molecules. Hence, these compounds are forced into a non-aqueous phase. Though the salting out effect usually acts to decrease the solubility of non-polar organic compounds, it has also been found to result in the increase of aqueous solubility for a few weakly polar compounds such as phenol (Hashimoto et al., 1984).

As a result, laboratory scale experiments were designed to study the impact of each of these parameters on BTEX sorption as part of phase I of the experimental plan. The details of the research plan and experimental methods are present ed in Chapter 3 and the experimental results are presented in Chapter 4. Batch experiments were conducted to evaluate multicomponent sorption phenomena in ultrapure water, saline water, and actual produced water, and to quantify the impact of salinity and temperature on the equilibrium sorption parameters. Selected conditions were also examined in laboratory scale column studies to confirm the sorption equilibrium parameters determined from the batch experiments, and to aid in the development of design criteria for the field scale column. The design of the laboratory and field columns was based on the RSSCT approach described by Hand et al. (1984). This method assumes that both internal and external diffusion may affect the rates of sorption. The goal of the method is to simulate sorption behavior in long-term pilot studies operation using a smaller scale setup that maintains dynamic similitude between the performance of the large scale and small scale adsorption columns (Sontheimer et al. 1988).

The literature review suggested that cost effective regeneration should be possible using an air stripping process. Laboratory columns studies were conducted to test this method of regeneration as part of Objective 4 of the project. The methods and results for these experiments are also presented in Chapters 3 and 4, respectively.

The results from the laboratory studies associated with Objective 1, were used to develop the SMZ adsorption system outlined in Objective 2. Produced water characterization of several sites provided criteria for selection of the Wyoming Site for conducting field studies associated with Objective 3 and 4. A pilot scale adsorption/regeneration system was constructed based on the design criteria. The performance of the system was then tested at the field site. The results of the studies were then used to conduct a cost-analysis of the SMZ process. The analysis, presented in Chapter 4, included a comparison of the costs of the SMZ process to other potential treatment approaches. 


\section{Executive Summary}

Co-produced water from the oil and gas industry accounts for a significant waste stream in the United States. It is by some estimates the largest single waste stream in the country, aside from nonhazardous industrial wastes. Characteristics of produced water include high total dissolved solids content, dissolved organic constituents such as benzene and toluene, an oil and grease component, and chemicals added during the oilproduction process. While most produced water is disposed via reinjection, some facilities are required to remove organic constituents before the water is discharged. Current treatment options are successful in reducing oil and fewaw; however, they cannot always meet the levels of current or proposed regulations for discharged water. Therefore, an efficient, cost-effective treatment technology is needed for removal of dissolved constituents such as benzene, toluene, ethylbenzene and xylenes (BTEX).

Treatment through sorption onto materials such as surfactant-modified zeolite (SMZ) may be both effective and relatively inexpensive. Zeolites are naturally occurring aluminosilicate minerals that have large capacities for cation exchange. By utilizing this property, natural zeolites can be modified by cationic surfactants such as hexadecyltrimethylammonium (HDTMA). HDTMA is a tetrasubstituted ammonium cation with a permanently charged pentavalent nitrogen and a long, straight alkyl chain $\left(\mathrm{C}_{16}\right)$. The long hydrocarbon chain imparts a strong degree of hydrophobicity to the surfactant tail while the positively charged ammonium head remains hydrophilic. Counterions such as bromide or chloride serve to neutralize the cationic effect of the head group a rendering them capable of sorbing anions. Thus, thSMZ has some adsorption capacity for cations, anions, and non-polar organic compounds such as BTEX.

The overall goal of this research was to develop a cost-effective and practical method of treating co-produced waters from oil-field sources using a treatment scheme that includes surfactant-modified zeolite. Potential impediments to system performance and potential methods of system regeneration were also addressed. Existing data on SMZ use as a treatment method for contaminated ground water and an experimental program were used to support the development process. The experimental program included three components: laboratory scale batch experiments, laboratory scale column experiments, and a pilot test.

Batch sorption experiments were performed to characterize sorption of BTEX to SMZ as a function of salinity, temperature, and in the presence of produced water. The goals of the laboratory scale column tests were to evaluate process kinetics, verify the batch results, assess the feasibility of the process in a continuous flow system, and evaluate the potential for regeneration of the SMZ using an air sparging system. Several possible sites/sources of produced water were evaluated including a small producer in East Texas near Smithville, a gas well array near Houston, Texas, an offshore oil well, and a treatment facility owned by BC Technologies in Wamsutter, Wyoming. The facility owned by BC Technologies was chosen as the site for field study in this project because the salinity, BTEX concentrations, source quantity, and reproducibility of source volumes and chemistry were all appropriate for field tests.

Single-solute and multi-solute sorption tests showed that the partitioning of BTEX compounds remained linear through concentrations ranging over five orders of magnitude. The distribution coefficients for the BTEX compounds increased with increasing 
compound hydrophobicity, and as proven through hypothesis testing, the distribution coefficients for benzene and toluene were not significantly changed by the addition of the remaining BTEX compounds. Furthermore, the distribution coefficients for benzene and toluene were underestimated by typical published correlations relating organic carbon normalized partition coefficients to either aqueous solubility or octanol- water partition coefficients. As a result, independent correlations between the distribution coefficient and either octanol-water partition coefficient or aqueous solubility were developed using data generated in this study. BTEX sorption isotherms on SMZ in saline solutions remained linear; however, statistically significant increases in the distribution coefficients for all of the BTEX were observed when the salt concentration in solution was increased to $100,000 \mathrm{ppm}$ or greater. Empirical relationships were developed to correlate the increase in the distribution coefficient as a function of the salt concentration, but attempts to predict distribution coefficients with the Setchenow equation or regressions based on first-principles were unsuccessful. The BTEX distribution coefficients increased with increasing temperature. The data was used to estimate enthalpy values and an analysis of the enthalpy data was used to confirm that the process was endothermic and consistent with a partitioning mechanism for sorption.

Batch sorption isotherms were also developed in a produced water background using produced water obtained from the Wamsutter site owned by BC Technologies and operated by Crystal Solutions, LLC. The produced water used in the batch experiments contained 11,400 ppm total dissolved solids. In all cases, the produced water BTEX distribution coefficients were higher than those obtained in ultrapure water; however, the differences were only statistically significant for the benzene and $\mathrm{m}-\& \mathrm{p}$ - xylene.

Laboratory scale column experiments confirmed the sorption capacities and the effect of salinity and background produced water obtained in the batch studies. Laboratory scale regeneration tests showed that air sparging was effective in stripping all of the benzene and toluene from the column, but not all of the ethylbenzene and the xylenes were removed under the conditions employed. The breakthroughs of benzene and toluene for the regenerated SMZ were similar to their breakthroughs with virgin SMZ.

The field test conducted at the BC Technologies site in Wamsutter, WY successfully verified the laboratory findings. The SMZ treatment system removed BTEX using virgin $\mathrm{SMZ}$ and regenerated SMZ. Benzene breakthough in the field column occurred after a greater number of pore volumes than observed in the laboratory columns, suggesting that the background produced water increased the sorption capacity of the SMZ for benzene.

Regeneration of a 14-inch column showed results similar to regeneration of the lab column. Benzene was the first compound to be removed from the spent SMZ, and was the only compound that fully stripped from the column. Comparison of breakthrough profiles from the regenerated SMZ to the virgin SMZ suggested that the regenerated SMZ had a greater capacity for benzene. This result was consistent with the results of the laboratory columns.

When compared to other existing treatment technologies, the cost of the SMZ system is very competitive. Furthermore, the SMZ system is relatively compact, does not require the storage of potentially hazardous chemicals, and could be readily adapted to an automated system. The analysis also demonstrated that the cost of the system would depend on the need for off-gas treatment and the replacement interval for the SMZ. 


\section{Background}

This literature review describes the characteristics of produced water, identifies potential processes for treating produced water, describes the components used to manufacture surfactant modified zeolite, and reviews previous literature relevant to its use for produced water. The review also provides information necessary for determining the key parameters required for evaluating SMZ sorption of BTEX from produced water.

\subsection{Produced Water}

\subsubsection{Sources of Produced Water}

Oil and gas exploration and production processes require large volumes of water. The three industries that combine to form the oil and gas industry are oil, coalbed methane, and conventional non-associated gas producers. The aqueous effluent from these operations is the largest volume stream in the oil and gas operation and exploration processes (Janks and Cadena, 1992). For every barrel of oil that is generated, ten barrels of produced water result (API, 1987). Every 1000 cubic feet of coalbed methane and conventional non-associated gas results in 0.31 and 0.023 barrels of produced water, respectively (Lawrence et al., 1995).

Produced water is generated throughout the oil and gas production process. Water that is naturally present in oil and gas reservoirs, referred to as formation water, is often pumped out with the crude oil and gas. In addition, water is pumped back into the reservoir to maintain reservoir pressure and force oil and gas into production wells. Smaller oily streams are also generated from oil storage facilities, and process and drainage water (Jacobs et al., 1992). This produced water is normally recovered at the production wellhead. However, the effluent stream can also be recovered via pipeline drips and/or separators, processing/conditioning plants, and underground storage facilities (Fillo et al., 1992). These sources annually generate more than three billion tons of produced water (API, 1987).

The constituents in produced water vary with reservoir and type of production, but usually include dissolved salts and metals, soluble and insoluble hydrocarbons, treating chemicals, radionuclides and dissolved gases (Caudle et al. 1995). The BTEX compounds are the major volatile components found in produced water, but the concentration of BTEX varies substantially among water samples (Fillo et al., 1992). Polynuclear aromatic hydrocarbon concentrations in produced water are generally far below their toxic levels. Dissolved salt concentrations in produced water vary from about $100 \mathrm{ppm}$ to $300,000 \mathrm{ppm}$ (Fillo et al., 1992). For example, total dissolved solids (TDS) concentrations range from 40,000 ppm to over 100,000 ppm. Oil and grease are often in the form of very small droplets as a mixture of oxygenated compounds and small amounts of hydrocarbons. Semi-volatile compounds exist mostly as $\mathrm{C}_{10}-\mathrm{C}_{30}$ straightchain alkanes, but phenols, carboxylic acids, and naphthalene are all present in smaller concentrations (Fillo et al., 1992). Metals, such as barium, strontium, arsenic, cadmium, lead, nickel and mercury etc. have been found in produced water samples. Treating chemicals added into the process, include scale inhibitors, corrosion inhibitors, biocides, 
emulsion breakers etc. The presence and concentration of these chemicals vary depending on the specific requirement of the process. Not only are some of the volatile organics and hydrogen sulfide believed to be toxic to aquatic organisms, the high salinity associated with many produced waters is thought to be another source of aquatic toxicity.

The temperature of produced water varies with several geographical, geological and separation process factors. Some water is discharged barely near ambient temperatures while others are discharged at $200^{\circ} \mathrm{F}$ for offshore facilities (Stephenson et al. 1992).

\subsubsection{Produced Water Characterization}

The constituents found in produced water vary with geological setting and type of production, but usually include dissolved salts and metals, soluble and insoluble hydrocarbons, and hydrogen sulfides (Lawrence et al., 1995). In general, offshore oil production generates effluent that is higher in total dissolved solids (TDS) but lower in BTEX concentrations than onshore gas production. Onshore oil production usually results in a water with BTEX and TDS concentrations between those of offshore oil and onshore gas production (Lawrence et al., 1995; Smith et al., 1996; Fillo et al., 1992). The BTEX compounds are the most prevalent volatile compounds found in produced water, but levels of BTEX contamination vary substantially among water samples (Fillo et al., 1992). Fillo et al. found that BTEX compounds were detected in $75-80 \%$ of production samples and in all storage samples. Total dissolved solids (TDS) concentrations vary even more than BTEX concentrations. These salt and metal concentrations can range from lower than 100 parts per million (ppm) to greater than 300,000 ppm (Fillo et al., 1992). The USEPA Maximum Contaminant Levels (MCLs) for BTEX in drinking water and representative concentration ranges of BTEX and TDS are presented in Table 3.1.

Table 3.1 Representative BTEX and TDS Concentrations for Produced Water

\begin{tabular}{|c|c|c|}
\hline Measured Constituents & $\begin{array}{c}\text { Concentration Range } \\
(\mu \mathbf{g} / \mathbf{L} \text { unless otherwise } \\
\text { noted })\end{array}$ & $\begin{array}{c}\text { Maximum } \\
\text { Contaminant Levels } \\
(\mu \mathbf{g} / \mathbf{L})\end{array}$ \\
\hline Benzene & $70-4400$ & 5 \\
\hline Toluene & $90-5800$ & 1000 \\
\hline Ethylbenzene $^{\text {m-Xylene }} \mathbf{a}^{\mathbf{a}}$ & $29-110$ & 700 \\
\hline o-Xylene $^{\mathbf{a}}$ & $70-460$ & 10000 \\
\hline p-Xylene $^{\mathbf{a}}$ & $12-110$ & 10000 \\
\hline Total Dissolved Solids (TDS) & $35-290$ & Variable \\
\hline
\end{tabular}

${ }^{\mathbf{a}}$ Xylene concentrations are normally reported and regulated as combined xylene. Combined xylene concentrations can range up to $5000 \mu \mathrm{g} / \mathrm{L}$. 
References: Smith et al., 1996; Lawrence et al., 1995; Fillo et al., 1992

In addition to mineral salts and volatile organic compounds, oil and grease, semivolatile compounds, and metals are also present in produced water. Oil and grease are generally present in small droplets that escape the oil/water separation unit. Semivolatile compounds exist mostly as $\mathrm{C}_{10}-\mathrm{C}_{30}$ straight-chain alkanes, but phenols, carboxylic acids, and naphthalene are all present in smaller concentrations (Fillo et al., 1992). Trace and heavy metals such as barium, strontium, arsenic, cadmium, lead, and mercury have been found in produced water samples, but the heavy metals have been detected at lower levels than other metals.

In certain geological formations, produced water also contains substantial amounts of hydrogen sulfide which can contribute to aquatic toxicity (Fucik, 1992). Mount et al., (1992) determined that salinity also plays an important role in aquatic toxicity. These findings are consistent with other research suggesting that volatile organics, hydrogen sulfide, and salinity in varying combinations are the causes of toxicity (Schiff et al., 1992; Sauer et al., 1992). As a result, it is generally agreed that produced water is harmful to marine-life.

Thus, in addition to the known and potential carcinogenic and neurotoxic properties of BTEX compounds, other compounds in produced water are also of concern. As such, various regulations regarding produced water disposal exist.

\subsubsection{Regulation of Produced Water Disposal}

Produced water is normally disposed of via three options: deep-well injection, surface discharge, and recycle/reuse. Regulation of water that is injected into saline aquifers is conducted through the Underground Injection Control program of the Safe Drinking Water Act (SDWA). This water is exempt from Subtitle C of the Resource Conservation and Recovery Act (RCRA) and can be injected into non-drinking water aquifers through Class II wells (RCRA: Section 3001 (b) (2) (A)). Despite the exemption from Subtitle C, Subtitle D of RCRA continues to apply, and handling and disposal of produced water must still be conducted in compliance with these regulations. In addition, states can also have restrictions on deep-well injection and applicable state regulations must be followed.

Discharge to onshore, coastal, and offshore waters is primarily governed through the Clean Water Act and issuance of National Pollutant Discharge Elimination System (NPDES) permits (Fillo et al., 1992). Only those onshore producers who generate a maximum of 10 barrels of oil or associated gas per day, or those who generate effluent of sufficiently high quality for beneficial reuse can be granted NPDES permits for onshore surface discharge (Lawrence et al., 1995). In addition to limiting the volume of effluent wasted, these permits also state maximum allowable oil and grease concentrations, metal concentrations, toxicity, and a variety of other parameters. Although most coastal and offshore waters are classified as federal territories, some waters off the states of Florida and Texas remain within state boundaries. In these states, as well as several others, the state environmental agencies are responsible for issuing NPDES permits and overseeing compliance with other federal and state regulations. 
State regulations are also the primary method of control over recycling and reuse of produced water. Many western states experience arid conditions which limit the amount of water available for irrigation, livestock watering, and wetting of unpaved dirt roads. Some waters generated through oil and gas production are of sufficient quality for these uses and are therefore utilized. Application of produced water for these purposes is usually governed by state agencies on a case-by-case basis (Fillo et al., 1992). Treatment of the produced water that does not currently meet standards for beneficial reuse would allow this wastewater to become a commodity for both producers and residents of waterscarce areas. Lawrence et al. (1995) state that future regulations for produced water would require additional treatment for the removal of organic compounds and minerals. Thus, removal of BTEX would be an important step in treatment of produced water.

\subsection{Potential Treatment Options}

\subsubsection{Current Treatment Methods}

Current methods for treatment of produced water have focused on removal of oil and grease and suspended solids. Those producers who are required to treat their effluent mostly rely on oil/water separation, hydrocyclones, and gas flotation (Santos and Wiesner, 1997). These common treatment methods share the characteristic that they allow viable oil to be extracted. Thus, they prove economically beneficial to producers, and so the industry continues to use and refine them. For example, Casaday (1993) conducted a study on how to improve gas flotation methods for oil recovery and suspended solids removal. However, these methods do not remove dissolved hydrocarbons, metals, or salts (Bilstad and Espedal, 1996). As previously stated, regulations for produced water disposal may become stricter in the future and these constituents may have to be removed to meet these standards (Santos and Wiesner, 1997). In addition, for reuse of produced water in arid areas, treatment methods must improve water quality to levels acceptable for reuse. Because current treatment appears to be ineffective for hydrocarbons, metals and dissolved salts, several studies have been conducted to test other removal methods.

\section{Produced Water Treatment through Filtration}

Physical methods of salt and oil/grease removal have been investigated by several researchers. Tao et al. (1993) utilized the San Ardo water treatment pilot plant in California to convert oil field produced water into an effluent that satisfied California's drinking water standards. The pilot plant included chemical clarification, softening, filtration, and reverse osmosis (RO). Extensive fouling of the RO unit was encountered so this problem had to be solved before further treatment could occur. The authors stated that after the plant was optimized, water containing 7,000 $\mathrm{mg} / \mathrm{L}$ total dissolved solids, $250 \mathrm{mg} / \mathrm{L}$ silica, and $170 \mathrm{mg} / \mathrm{L}$ soluble oil was successfully handled by the treatment system. Although the study included information about BTEX removal, the method for that removal was not explained and volatilization could have occurred throughout the treatment process. Additionally, the use of RO can be very expensive. Capital costs 
were estimated to be $\$ 7-9$ million for a 50,000 barrels/day (b/d) plant and operating expenses were stated to be up to $\$ 0.08 / \mathrm{bbl}$.

A less expensive treatment option that has been considered is membrane filtration. Bilstad and Espedal (1996) conducted a pilot scale study aboard an offshore drilling platform. The authors stated that as the amount of produced water in the North Sea increases, European effluent standards for the disposal of the water are also expected to become more stringent. Hence, they chose to study membrane filtration for the removal of dispersed and dissolved hydrocarbons and metals. Through their study, it was found that while microfiltration (MF) did not perform to standards, ultrafiltration (UF) generated effluent that would meet more stringent standards for total hydrocarbons, suspended solids, and dissolved constituents. Reduction of benzene, toluene, and xylenes reached 54\% while reduction of total hydrocarbons was 95\%. Heavy metals, including copper and zinc, were also reduced by $95 \%$. The authors further declared that no irreversible fouling was experienced during the study and included in their conclusion the necessary design criteria for large-scale UF plants. Although costs are reported in 1996 British pounds rather than in U.S. dollars, the cost for a plant that would treat 50,000 $\mathrm{m}^{3} /$ day remained at least $\$ 2$ million dollars less than the RO unit described in the previous study.

In contrast to the study conducted by Bilstad and Espedal (1996), Santos and Wiesner (1997) stated that ultrafiltration membranes do not typically remove dissolved materials such as salts and small organic compounds. The results from their research showed that with the exception of iron, inorganic species were not removed and only larger hydrocarbons, such as dispersed oil, were rejected by the UF membrane. The authors suggested that pronounced iron removal was the result of oxidation and subsequent precipitation. Indeed, fouling due to iron precipitation became a problem during the study. However, oil and grease were successfully removed from the four different produced waters tested and effluent levels for these constituents were well below foreseen U.S. standards. Chemical cleaning of the membranes had mixed results for the various waters tested. In certain circumstances, the authors stated that fouling worsened after chemical cleaning. Variability of the results of different water sample led the authors to conclude that the economic feasibility of this treatment method depends on the characteristics of the specific water to be treated. As a result, the blanket use of UF technology as a Best Available Technology (BAT) standard is unadvisable at this time.

\subsubsection{Innovative Treatment Methods}

\subsubsection{Bubble Separation of Hydrocarbons}

Thoma et al. (1999) tested the microbubble-based separation of dissolved aliphatic and aromatic hydrocarbons from synthetic produced water into a floating immiscible layer on top of a water column. By changing the gas flow rate of the microbubbles, different removal efficiencies for test organic compounds were attained. With a gas flow rate of $100 \mathrm{~mL} / \mathrm{min}$, octane and decane were reduced $95 \%$ and $75 \%$ in 25 and 30 minutes, respectively. However, even after 360 minutes at a gas flow rate of $60 \mathrm{~mL} / \mathrm{min}$, only $40 \%$ of the dissolved ethylbenzene and toluene was removed. Raising the gas flow rate to $200 \mathrm{~mL} / \mathrm{min}$ increased the removal of the aromatic hydrocarbons to $70 \%$. Although 
benzene was reported to be a test compound, no further results for this compound were included in the paper. The removal of other dissolved compounds, such as salts, metals, or other hydrocarbons, was not tested in this study and costs for the process were not reported.

\subsubsection{Oxidation of Organic Compounds}

Bessa et al. (2001) researched photocatalytic treatment and oxidation with hydrogen peroxide of four different produced waters. The authors explained that the unique nature of semiconductors allows them to be powerful oxidants in the presence of high-energy photons. Using a titanium oxide semiconductor, the authors studied how phenols would undergo chemical oxidation in the presence of a high-pressure mercury lamp. Prior to the oxidation, the produced waters had to undergo clarification to remove particulate matter. During the subsequent photocatalysis, air was continuously bubbled into a stirred water column. Although the authors stated that no volatilization of low-molecular weight organics, such as BTEX, was observed, they offered no experimental data to corroborate that statement. Bubbles were reported to remove organic compounds from solution in the previous study so it seems unlikely that no organic compounds partitioned into the air phase while the water column was bubbled with air.

Nevertheless, the authors further reported results for the oxidation of phenol through photocatalysis and through contact with hydrogen peroxide. These results were presented as total reduction in peaks obtained through gas chromatography/mass spectroscopy (GC/MS). The peaks for compounds that initially eluted late were shown to decrease substantially with time of photocatalysis. However, the size of peaks for compounds with smaller retention times increased because, presumably, the larger compounds were transformed into these smaller compounds through oxidation. These results also showed that one brand of semiconductor performed substantially better and did not degrade whereas the other brand corroded. Lastly, the authors stated that the use of hydrogen peroxide is inadvisable because of the increased corrosion on the semiconductor plates. This treatment technique, though innovative, would likely prove uneconomical for the small oil and gas producer because of the expense associated with semiconductors.

\subsubsection{Phytoremediation of Produced Water}

Researchers at Argonne National Laboratory studied the use of halophilic plants to reduce produced water volume, enhance contaminant degradation, and immobilize pollutants in the root/rhizosphere zone (Negri and Hinchman, 1997). The optimal plants were chosen after extensive greenhouse testing, and results from an engineered plant ecosystem showed a $75 \%$ reduction of saline wastewater in 8 days. The salt concentrations tested ranged up to $6 \%$, which the authors stated is twice the salinity of seawater. However the study did not specifically address the removal of compounds such as BTEX and metals. Because the effectiveness of this method would decrease in seasons other than the growing season, the authors suggested that phytoremediation be used in conjunction with another method. Nevertheless, for producers who are located in remote regions, this treatment method could prove to be low cost and low maintenance. 


\subsubsection{Sorption of Produced Water by Commercially Available Sorbents}

Sorption studies have focused mainly on the removal of BTEX compounds. Both activated carbon and ion exchange resins have been investigated. Powdered and granular activated carbon have been used for sorption in water treatment for many decades. Industrial scale production of activated carbon began in the 1920s when it was used primarily for the removal of chemicals that caused odors and bad taste in drinking water. Activated carbon (AC) was later found to remove non-polar organic pollutants from water and has been used for this purpose in many remediation sites and water treatment plants (Sontheimer et al., 1988).

Activated carbon is produced from raw carbon sources such as peat, coconut shells, wood, and bituminous coal. After an initial pyrolysis step, the raw material is chemically activated and sieved into different sizes. The activation process produces a highly porous material containing surface areas typically ranging from 500 to $1400 \mathrm{~m}^{2} / \mathrm{g}$. Because the surface of activated carbon is primarily hydrophobic, it is an excellent sorbent for organic compounds. (Sontheimer et al., 1988).

Powdered activated carbon (PAC) consists of particles less than $0.05 \mathrm{~mm}$ in diameter. This material is primarily added as a suspension in rapid mix and flocculation basins to remove odor and bad-taste causing compounds from drinking water. After a contact time of 10-15 minutes, the PAC is removed through flocculation and filtration and then regenerated. Because of the small size of this material, PAC is not normally used as filter media. In addition to large head losses due to back pressure, PAC also promotes excessive bacterial growth which leads to additional head losses (Sontheimer et al., 1988).

Granular activated carbon (GAC) ranges in particle size from 0.3 to $3 \mathrm{~mm}$ and is the primary sorbent used in most remediation projects because of its excellent sorption properties (Sontheimer et al., 1988). However, activated carbon has some drawbacks when used for sorption of organic chemicals. Sorption of most organic carbons onto activated carbon is typically described using a non-linear isotherm model (e.g. Freundlich isotherm) and the sorption process is often controlled by surface and/or pore diffusion processes. Competitive sorption often limits the sorption capacity for mixtures of organic compounds because only a finite number of adsorption sites exist on the surface. If one compound has much greater affinity for the $\mathrm{AC}$, it can effectively take up the majority of available sites in an AC column. This allows the remaining compounds to stay in solution and can even cause higher effluent concentrations of some pollutants than the influent concentrations depending on the relative rates of diffusion. This latter phenomenon occurs when the rates of sorption are faster for the compound that has a lower affinity for the surface. In these cases, the compound with higher affinity for the $\mathrm{AC}$ exchanges with the lower affinity compound that has adsorbed more rapidly. In this manner, the effluent concentration for that first compound can be higher than the initial influent concentration (Sontheimer et al., 1988).

Another drawback to using activated carbon for treatment of water with multiple types of contaminants is its inability to effectively remove metals and other polar constituents from solution. Many wastewaters contain trace amounts of heavy metals and hydrophilic 
pollutants in addition to organic compounds. Most activated carbons cannot be used for the removal of all of these constituents because the hydrophobicity of the surface prevents the sorption of polar compounds.

Though the chemical properties stated above limit the attractiveness of AC as an allpurpose sorbent, the most significant deterrent for using AC is economic. Activated carbon is expensive to produce and to regenerate. The purchasing price for granular activated carbon can range from $\$ 1.50$ - $\$ 2.50$ per pound. Regeneration costs for activated carbon are also quite high because of the large amount of energy required. Based on these high costs and because of its limited potential in wastewaters containing constituents other than organics, activated carbon may not be the most suitable sorbent for small scale oil producers.

Gallup et al. (1996) used commercially manufactured carbonaceous sorbents, Ambersorb, to reduce BTEX concentrations in oil-field produced water. These compounds are created from the partial pyrolysis of macroporous polymer beads. The pyrolysis process causes the materials to lose their ionic functional groups and retain nonpolar surfaces (Weber and van Vliet, 1981). The resulting compounds exhibit hydrophobic properties that allow non-polar organic compounds to be effectively removed from water. Ambersorb ${ }^{\circledR} 572$ and 563 (Rohm and Haas Company; Spring House, PA) carbonaceous sorbents are formed through the partial pyrolysis of macroporous sulfonated styrene-divinylbenzene ion exchange resin (Parker, 1992). They tend to be hard black spherical beads with average diameters between $0.085-0.3 \mathrm{~mm}$ (Rohm and Hass, 1992-1999; Isacoff et al., 1992).

The research conducted by Gallup et al. used column studies to compare the Ambersorb $® 572$ to Hydrodarco GAC (American Norit Co., Inc.; Atlanta, GA) and organically-modified clays EC-100 and EC-199 (Biomin Inc.; Huntington Woods, MI). Each $5 \mathrm{~cm}$ glass column contained $50 \mathrm{~cm}^{3}$ of the sorbents being tested. Aqueous solutions containing $50-150 \mathrm{mg} / \mathrm{L}$ of dissolved BTEX compounds were allowed to flow at a rate of $1.1 \mathrm{~mL}$ per minute per $\mathrm{cm}^{3}$ of sorbent. After solving extensive clogging

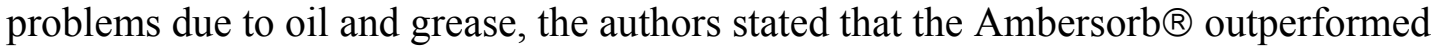
both the GAC and the modified clays tested and was less expensive than the GAC. After treatment of 1200 bed volumes, Ambersorb ${ }^{\circledR} 572$ was reported to remove $93 \%$ of benzene and toluene while Hydrodarco GAC provided only a 23\% removal. Additionally, the authors stated that the modified clays used in the study removed between $21-23 \%$ of benzene and toluene in the produced water. Although neither the commercial sorbents nor the GAC removed the emulsified oil, modified clays reduced the emulsified oil from $25 \mathrm{mg} / \mathrm{L}$ to $12 \mathrm{mg} / \mathrm{L}$.

Isotherms and isotherm parameters were not included in the study. However, it was possible to estimate the sorption density through the information obtained from The California MTBE Research Partnership (1999) and the information presented in the Gallup et al. study about the column, influent BTEX concentrations, and percent removal of benzene and toluene. The estimated sorption density for Ambersorb $® 572$ at the end of the study was between $125-376 \mathrm{mg} / \mathrm{g}$ for an influent concentration of $25-130 \mathrm{mg} / \mathrm{L}$ BTEX.

Solvent regeneration of the carbonaceous sorbents was reported by Gallup et al.(1992) to be effective, but GAC could not be efficiently regenerated due to substantial oil fouling. Further demonstrations resulted in BTEX breakthrough as more strongly sorbing 
species replaced BTEX compounds on the Ambersorb ${ }^{\circledR} 572$. However, because the analytical HPLC techniques and the sorbent itself were proprietary, little methodological information was presented to fully evaluate these results.

Various methods of oil removal were tested in the Gallup et al. study because of the extensive fouling problems encountered in the field. Bench scale tests showed that modified clays could reduce the oil concentration by a factor of two but fouling continued to occur. Thus, a coalescer was tested and found to be very site- and water-dependent. However, a demonstration of compounds classified as emulsion breakers showed that Magnifloc 494C (Cytec Industries; West Patterson, NJ) was very successful at causing oil to float. The oil was then easily skimmed off and the remaining water was treated sufficiently by Ambersorb ${ }^{\circledR} 572$, even after regeneration. The authors concluded that with the use of an effective oil and grease removal system, Ambersorb ${ }^{\circledR}$ carbonaceous sorbent was a better BTEX remover than either GAC or modified clays.

One substantial disadvantage of using a carbonaceous sorbent rather than modified clays or zeolite is the inability to remove hydrophilic compounds such as salts and metals. This study did not delve into this topic. In addition, although the authors stated that the expense of the commercial sorbent compared favorably to the cost of using GAC, no specific information was given about the capital costs or operating expenses. It was suggested that the regeneration of GAC would result in an annual increased cost 4 to 7 times that of Ambersorb ${ }^{\circledR} 572$.

\subsubsection{Surfactant Modified Zeolite}

Janks and Cadena (1992) investigated BTEX and barium sorption capacities of zeolites modified with several different surfactants. The water used for this study was produced water from an oil field and contained $1 \%$ insoluble long chain hydrocarbons, $860 \mathrm{mg} / \mathrm{L}$ soluble hydrocarbons of which $70 \mathrm{mg} / \mathrm{L}$ consisted of BTEX compounds, and $10,300 \mathrm{mg} / \mathrm{L}$ total dissolved solids. Nine different surfactants and two types of zeolite, chabazite and clinoptilolite, were used in this study. The authors reported the CEC values for the two zeolites to be $72 \mathrm{meq} / 100 \mathrm{~g}$ for chabazite and $80 \mathrm{meq} / 100 \mathrm{~g}$ for clinoptilolite. The authors noted that the actual makeup of the zeolites included not only the zeolites themselves, but also compounds such as cristobalite, smectite, quartz, calcite, and dolomite. The nine surfactants included diethylenetriamine (DETA), ethylenediamine (EDA), monoethanolamine (MEA), piperazine (PIP), tetramethylammonium chloride (TMA), triethylamine (TEA), tetraethylenepentamine (TEPA), triethylenetetramine (TETA), and HDTMA-Cl. In contrast to the studies on BTX sorption (ethylbenzene not included) conducted by Bowman et al. (1993), the zeolites in the study performed by Janks and Cadena were treated only to $100 \%$ of their reported CEC values rather than $200 \%$.

The batch tests were performed on dried modified zeolite. Initial spiking of the SMZ with produced water was followed by four hours of tumbling on a roller over at $25^{\circ} \mathrm{C}$. The water was then analyzed by purge and trap gas chromatography. There was no mention of any centrifugation after the tumbling or what types of vials were used in the study. Benzene and toluene removal from laboratory solutions was tested and reported for HDTMA along with TMA and TEA, but the actual batch studies with produced water were conducted only with TMA, EDA, PIP, TETA, TEPA, and MEA. No explanation 
was given regarding the exclusion of three surfactants, including HDTMA, from the batch tests. This missing information and the unique nature of zeolites from specific locations makes it difficult to compare results from this and other studies.

The authors cited several general observations regarding the results from their batch tests. For the ethyleneamine group, those surfactants with higher molecular weights tended to be less efficient at BTEX removal than lower molecular weight surfactants. Total BTEX removal ranged from 9.4\% (MEA) to 85.2\% (EDA) but the surfactants showed preference for specific compounds. Xylenes were removed most effectively by EDA while PIP seemed to exclude them. Even though TMA showed affinity for benzene $\left(\mathrm{K}_{\mathrm{D}}>0.9 \mathrm{~L} / \mathrm{g}\right.$ for chabazite and $\mathrm{K}_{\mathrm{D}}>0.7 \mathrm{~L} / \mathrm{g}$ for clinoptilolite), it was almost as ineffective at toluene removal as natural zeolite. The hydroxyl group on the MEA served to generally exclude BTEX sorption. Interestingly, in this study, it was found that maximum distribution coefficients for benzene removal on TMA-modified chabazite and clinoptilolite occurred between $40-60 \%$ of the CEC. This is in contrast to results presented by Li et al. (2000) who found the maximum distribution coefficient $\left(\mathrm{K}_{\mathrm{d}}\right)$ for HDTMA-modified zeolite at the CEC. However, comparisons between these studies may not be valid because of differences in surfactant, zeolite type, and zeolite size.

The authors also report the contents of their zeolite samples as analyzed through XRD. Smectite fractions ranged from 10-50\% while cristobalite formed 7-24\% and clinoptilolite $20-60 \%$ of the zeolites studied. Though the high variability of zeolite content in samples from different sources was noted, the sources of the zeolites used in this study were not discussed. Nevertheless, it was suggested that smectite fractions play an important role in BTEX removal. The authors stated that BTEX sorption may have actually occurred on the smectite and that the removal efficiency increased with smectite percentage. These assertions were supported by a correlation between BTEX removal and d-spacing of the smectite basal reflection. To explain the preference for specific BTEX compounds, it was hypothesized that the orientation of specific BTEX compounds may have allowed them to or excluded them from sorbing to smectite. The size and configuration of the surfactant tails also played a part in this theory.

Lastly, the authors reported that barium, which was used as a representative metal ion, was not substantially removed by five of the six surfactants tested. The sole exception was PIP, which reduced the initial barium concentration from $28 \mathrm{mg} / \mathrm{L}$ to $17.3 \mathrm{mg} / \mathrm{L}$. Although this specific metal was not removed by the modified zeolites, Bowman et al. (1997) demonstrated that metals such as lead are sorbed by zeolite while others like strontium lose their affinity for the compound once it is modified. Because only one metal was used in this study, it is difficult to make a general statement about the affinity of heavy metals for SMZ.

Janks and Cadena concluded by stating that modified zeolites would be effective at BTEX removal in the field, especially because the presence of other organic and inorganic constituents did not seem to affect the removal capacity of the SMZ. It was implied that increased smectite percentage and the use of surfactants with small molecular sizes would result in the greatest sorption capacity for BTEX compounds. They also went on to suggest future research topics, including the determination of salt effects on BTEX removal and investigations on regeneration options. 


\subsubsection{Zeolite Properties}

Natural zeolites are hydrated aluminosilicate minerals with cage-like structures. They have very high internal and external surfaces areas and high internal and external cation exchange capacities (CEC). According to Haggerty and Bowman (1994) forty-one naturally occurring zeolites have been found and several others have been synthesized, of which the most popular natural zeolite is clinoptilolite as shown in Figure 3.1. Its dry unit cell formula is $\left(\mathrm{Ca}, \mathrm{Na}_{2}, \mathrm{~K}_{2}\right)_{3}\left[\mathrm{Al}_{6} \mathrm{Si}_{30} \mathrm{O}_{72}\right] \cdot 24 \mathrm{H}_{2} \mathrm{O}$. The largest cavity dimension within clinoptilolite was found by Newsom (1986) to be 4.4 x 7.2 Angstroms. The BET external surface area for zeolite from the St. Cloud mine in Winston, New Mexico was determined by Sullivan et al. (1997) to be $15.7 \mathrm{~m}^{2} / \mathrm{g}$. The total cation exchange capacity (CEC) for clinoptilolite obtained from St. Cloud Mine, New Mexico is $230 \mathrm{meq} / \mathrm{kg}$ ( $\mathrm{Li}$, et al. Natural zeolites have low organic carbon contents $(<0.5 \%)$ and do not favor sorption of organic compounds. However, natural zeolites have been found to effectively remove several types of metals, such as lead and strontium, from aqueous solutions (Bowman et al., 1993).

Zeolites are similar to smectite clays in their surface chemistry properties, but these materials do not exhibit the shrink/swell behavior of clays in water. The measured cation exchange capacities of natural zeolite have been found to be as much as $50 \%$ greater than those of clays (Janks and Cadena, 1992). In addition, zeolite particles usually occur in millimeter or greater particle sizes. This larger particle size allows zeolites to be well suited for use as permeable barriers.

Surfaces of both clays and natural zeolites are negatively charged, making them hydrophilic. Positively charged counterions neutralize the zeolite's negative charge. Large cationic surfactant molecules can also neutralize the surface charge and they have greater affinity for the zeolitic surface. 


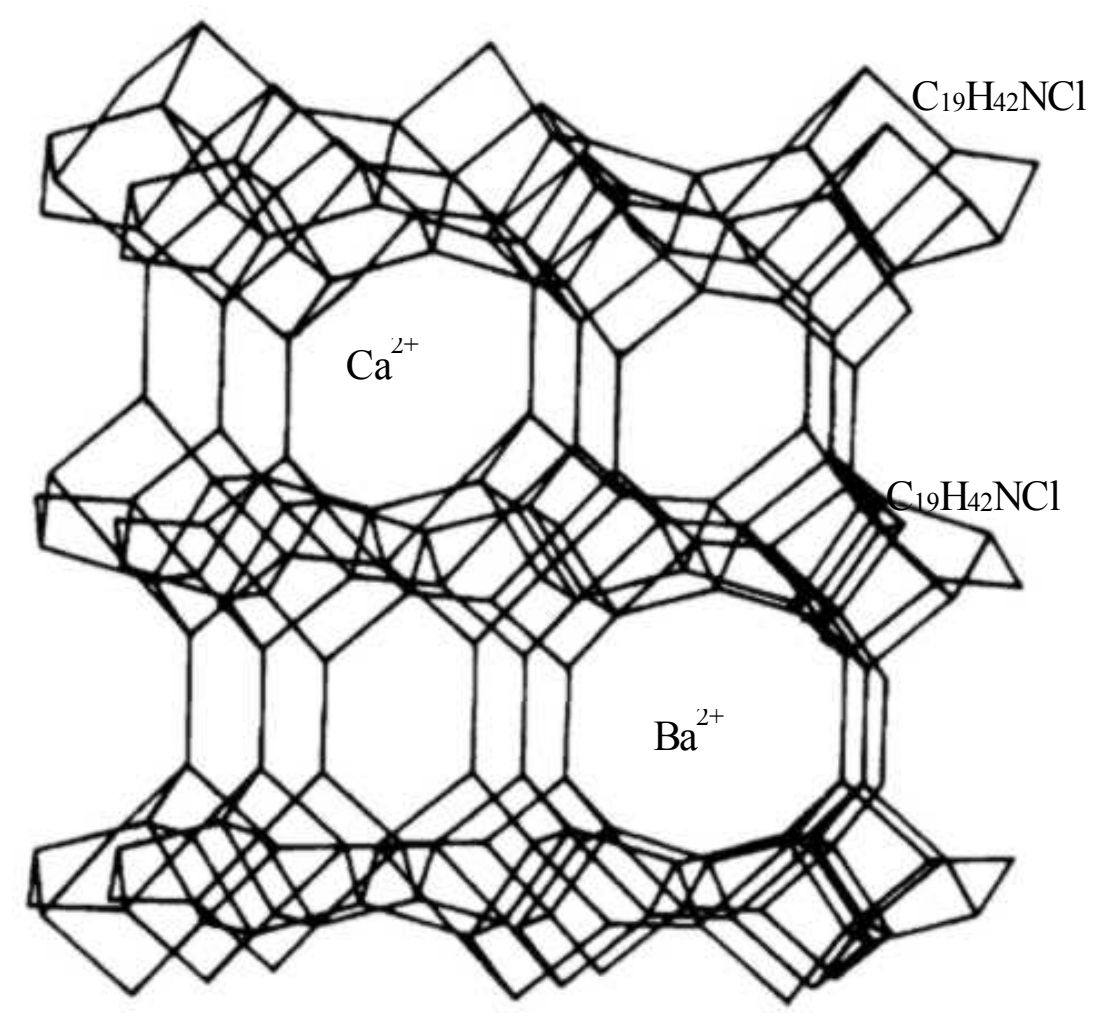

Figure 3-1 Crystal Structure for Clinoptilolite (adapted from Manley and Holmes, 1989, Minerals with Natural Advantage, New Scientist, March 25, 1989, pp. 39-43)

\subsubsection{HDTMA}

Surfactants are surface active agents that exhibit both hydrophobic and hydrophilic properties. The hydrophobic portions are commonly called tails and consist of hydrocarbon alkyl chains or aromatic rings. The opposing head groups can be charged or neutral, but tend to exhibit hydrophilic properties. These surfactants can be anionic, cationic, or non-ionic, depending on the charge of the head group. When in aqueous solutions, surfactant monomers form spherical micelles in which the head groups extend into the aqueous phase while the tail groups remain close to one another inside the micelles. This phenomenon occurs once the concentration of surfactant is high enough to exceed the critical micelle concentration (CMC). Many different surfactants exist and the phenomena described above apply to most of them, but only the surfactant most relevant to this research is described below.

Hexadecyltrimethylammonium (HDTMA) is a tetrasubstituted ammonium cation with a permanently charged pentavalent nitrogen and a long, straight alkyl chain $\left(\mathrm{C}_{16}\right)$ (Haggerty and Bowman, 1994). The long hydrocarbon chain imparts a strong degree of hydrophobicity to the surfactant tail while the positively charged ammonium head remains hydrophilic. Counterions such as bromide or chloride serve to neutralize the cationic effect of the head group. 
This surfactant is commonly used in products such as hair conditioner, mouthwash, and fabric softener so it is assumed that the chemical is not hazardous (Li et al., 1998). Furthermore, HDTMA is easily accessible and has been found to have excellent chemical properties for sorption-related water treatment.

\subsubsection{SMZ}

Saturation of natural zeolite with a surfactant such as HDTMA yields a surfactantmodified zeolite. As mentioned above, the cationic surfactant head exchanges with the naturally occurring cations on the surface of the zeolite. Due to the large size of HDTMA monomers, only external pore spaces are subject to this cation exchange. The surfactant is unable to enter the small internal pores and therefore, leaves the internal surface chemistry of the zeolite unchanged and potentially available for cation exchange (Barrer et al., 1967; Li and Bowman, 1997).

Sorption of HDTMA has been described by the non-linear Langmuir isotherm (Figure 3.2) which assumes that monolayer adsorption occurs to a finite number of homogeneous sites. The equation for the Langmuir isotherm is shown below:

$$
q_{e}=\frac{Q_{\max } b C_{e}}{1+b C_{e}}
$$

where $\mathrm{Q}_{\max }$ is the maximum sorption capacity $(\mathrm{mmol} / \mathrm{kg}), \mathrm{b}$ is the sorption intensity $(\mathrm{L} / \mathrm{mmol})$, and $\mathrm{C}_{\mathrm{e}}$ is the aqueous phase equilibrium concentration $(\mathrm{mmol} / \mathrm{L})$.

The maximum sorption capacity can be obtained from a plot of the equilibrium sorbed phase concentration versus the equilibrium aqueous phase concentration of a solute as shown in Figure 3.2. This maximum sorption capacity is often used as an estimate of the exchange capacity (EC) and indicates that the maximum sorption capacity for HDTMABr- and HDTMA-Cl- are 208 and $151 \mathrm{mmol} / \mathrm{kg}$, respectively. During the sorption process, the head group of the surfactant remains sorbed to the surface of the zeolite while the tail group floats in solution. To balance the positive charge of the head groups, counterions such as chloride and bromide form electrostatic bonds with the head groups. Due to the larger hydrated radius of chloride, Li and Bowman state that this counterion is less able to deeply penetrate the Stern layer and neutralize the head group's positive charge than the smaller hydrated bromide ion. Thus, the repulsion among head groups prevents surfactant sorption and reduces the exchange capacity for HDTMA-Cl. As a point of comparison, using a modified method developed by Ming and Dixon (1987), the external exchange capacity of zeolite has been found by Li and Bowman (1997) to be between $90-110 \mathrm{meq} / \mathrm{kg}$, suggesting that the surfactant is forming a bilayer on the surface of the zeolite. 


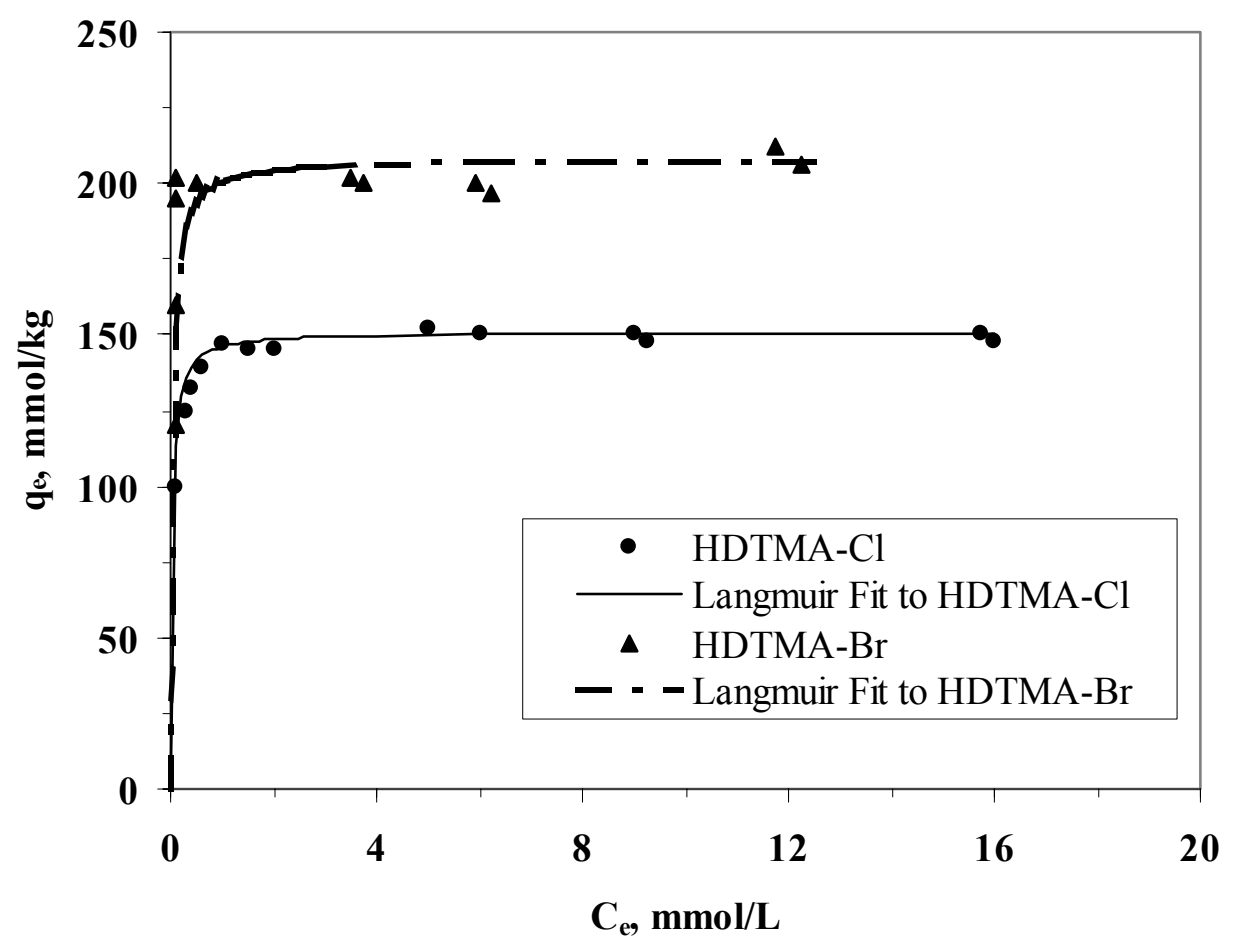

Figure 3.2 HDTMA Sorption to Zeolite

While the head groups sorb onto the zeolite surface, the hydrophobicity of the tail groups forces tail-tail interactions to occur and hemimicelles to form in order to minimize association with water molecules. In the past, it was believed that while the concentration of HDTMA remained below the critical micelle concentration (CMC), monolayer coverage would continue and surfactant monomers would attach to the surface as hemimicelles. As the concentration surpassed the CMC, monolayer coverage of the zeolite would be completed and patches of a second layer or admicelles would begin to develop above the bottom layer (Haggerty and Bowman, 1994). However, a more recent study conducted by Sullivan et al. in 1997 showed with Tapping Mode ${ }^{\mathrm{TM}}$ atomic force microscopy and high-resolution thermogravimetric analysis that the buildup of the HDTMA bilayer begins prior to completion of monolayer coverage. Chen et al. (1994) suggest that once the CMC is surpassed, previously formed micelles sorb onto negatively charged surfaces to create an admicelle or bilayer. These results were supported by Li and Bowman (1998) who determined that organic contaminants are sorbed at low HDTMA concentrations. If complete monolayer coverage were necessary prior to the formation of a patchy bilayer, these organic contaminants would not be strongly sorbed by the SMZ.

The formation of bilayers or hemimicelles creates a hydrophobic region inside the bilayer with positively charged outer head groups extending out into solution. Thus, the original negative charge of the natural zeolite is reversed by surfactant modification. Through ion exchange with these positively charged head groups, anionic contaminants can be removed from aqueous solutions. Several studies have shown that oxyanions such as arsenate, chromate, and selenate are very effectively removed from water by SMZ but not by untreated zeolite (Li and Bowman, 1997; Bowman et al., 1997; Haggerty and 
Bowman, 1994). It has also been shown that better sorption of oxyanions occurs when the counterions are weakly bonded (Li and Bowman, 1997). This intuitive trend was shown to increase in strength for hydrogen sulfate, chloride, and bromide, in that order. Although the sorption isotherms for these oxyanions all resembled Langmuir isotherms, the authors in each study were quick to point out that the sorption of the anions does not meet the assumed criteria for the Langmuir isotherm. Thus, the sorption can be described by the Langmuir parameters $\mathrm{K}_{\mathrm{L}}$ and $\mathrm{q}_{\max }$, but these parameters do not have true chemical significance.

The natural ability of zeolite to remove metallic cations from solution is somewhat altered by surfactant modification. The sorption of metals such as lead that originally sorbed to the internal pores of zeolite has been shown to remain unchanged (Haggerty and Bowman, 1994; Bowman et al., 1997). Thus, the presence of HDTMA seems to have little effect on the sorption of metals onto internal pore sites within zeolite. However, those cations that were removed by cation exchange with the external surface of the natural zeolite cannot be removed from solution by treated zeolite (Bowman et al., 1997). This inability to remove cations such as strontium is due to the strong sorption of the surfactant to the surface and to the repulsion between the metallic cations and the surfactant head groups.

\subsubsection{Sorption Mechanisms and Predictive Models}

The mechanism for non-polar organic sorption onto SMZ has been described as partitioning into the hydrophobic pseudophase formed by the tail groups of the HDTMA bilayer (Li and Bowman, 1998; Bowman et al., 1993; Bowman et al., 1997). Hydrophobic compounds have extremely large activity coefficients in water. A great deal of energy is required to break the hydrogen bonds linking water molecules to create cavities suitable for hydrophobic compounds (Schwarzenbach et al., 1993). Additional energy is required to reconfigure water molecules into ice-like formations around nonpolar organics. However, much less energy is required for non-polar organics to dissolve into a hydrophobic phase. Thus, thermodynamics drive this partitioning process and cause organic compounds such as benzene to leave the aqueous phase. The magnitude of the thermodynamic driving force is based on the water solubility of the various organic compounds. Because benzene has a higher water solubility than the other BTEX compounds, it is less likely to leave the aqueous phase (Schwarzenbach et al., 1993). The relationship between water solubility and driving force to leave the aqueous phase also yields a corresponding relationship between the molecular weight of organic compounds and sorption. Increasing numbers of carbons on organic compounds increases the hydrophobicity and decreases the water solubility. Hence, xylenes are more hydrophobic than toluene, which is more hydrophobic than benzene (Schwarzenbach et al., 1993).

At equilibrium, non-polar organic compounds distribute themselves between the hydrocarbon and water through a linear isotherm in which the aqueous phase concentration, $\mathrm{C}_{\mathrm{e}}$, is directly related to the sorbed phase concentration, $\mathrm{q}_{\mathrm{e}}$, by a single parameter defined as the distribution coefficient, $\mathrm{K}_{\mathrm{d}}$ as shown:

$$
q_{e}=K_{D} C_{e}
$$


As a result, the distribution coefficient for sorption of hydrophobic compounds to organic matter is expected to increase with increasing solute hydrophobicity.

A study conducted by Bowman et al. (1993) demonstrated that removal of benzene, toluene, and para-xylene increased substantially with surface alteration of natural zeolite. In fact, the sorption of benzene increased 20 -fold with SMZ as opposed to natural zeolite. The sorption isotherms for all of these three compounds were linear throughout the concentration ranges tested $(0,10,50,100,150$ and $250 \mathrm{mg} / \mathrm{L}$ for benzene and toluene and $0,10,50,100,150$, and $198 \mathrm{mg} / \mathrm{L}$ for $\mathrm{p}$-xylene). The distribution coefficient values determined in the study conducted by Neel and Bowman (1991) are shown in Table 3.2.

Table 3.2 Distribution Coefficients Determined by Neel and Bowman (1991)

\begin{tabular}{|c|c|}
\hline Chemicals & Distribution Coefficient $\left(\mathbf{K}_{\mathbf{d}}\right), \mathbf{L} / \mathbf{k g}$ \\
\hline Benzene & 8.59 \\
Benzene with Toluene & 8.44 \\
Benzene with para-Xylene & 9.40 \\
Toluene & 19.2 \\
Toluene with Benzene & 19.1 \\
Para-Xylene & 70.4 \\
Para-Xylene with Benzene & 56.6 \\
\hline
\end{tabular}

During this same study, the effects of co-solutes were tested to see how the SMZ would respond to multiple organic contaminants. Single solutes were initially tested, followed by pairs of benzene/toluene, and benzene/p-xylene. It was determined that removal of these compounds did not significantly change when present in pairs. These results were consistent with earlier findings from Neel and Bowman (1991). The isotherm linearity combined with the lack of competitive effects support the proposed sorption mechanism involving absorption into the surfactant bilayer.

For soils, the magnitude of the distribution coefficient is related to the amount of organic matter present. For many neutral hydrophobic organics, sorption is directly proportional to the quantity of organic matter content in the solid (Chiou et al., 1979; Karickhoff, 1981). Thus, the distribution coefficients can be normalized to the fractional organic matter content which generates organic matter partitioning coefficients, $\mathrm{K}_{\mathrm{om} \text { (or }}$ organic carbon, $\mathrm{K}_{\mathrm{oc}}$ ) and these normalized coefficients are considered as a unique property of the organic chemical being sorbed $\mathrm{K}_{\mathrm{oc}} / \mathrm{K}_{\mathrm{om}}$, (Schwarzenbach et al. 1993).

$$
\begin{aligned}
& K_{d}=K_{o c} f_{o c} \\
& K_{d}=K_{o m} f_{o m}
\end{aligned}
$$

where, 
$\mathrm{K}_{\mathrm{oc}}$ : the organic carbon normalized sorption coefficient,

$\mathrm{K}_{\mathrm{d}}$ : the linear sorption coefficients specific to a particular sorbent and chemical combination,

$\mathrm{K}_{\mathrm{om}}$ : natural organic matter-water partition coefficient with a unit of $\mathrm{L} / \mathrm{kg}$ om for soil.

$f_{o c}$ : the organic carbon content of that sorbent $\mathrm{g}$ oc/g dry soil

$f_{o m}$ : the fractional organic matter content on a soil, which is a constant for a particular soil;

For soil, $\mathrm{K}_{\mathrm{om}}=1.724 \mathrm{~K}_{\mathrm{oc}}$ (Boethling and Mackay 2000); however, for SMZ the relationship between $\mathrm{K}_{\mathrm{om}}$ and $\mathrm{K}_{\mathrm{oc}}$ is

$$
\mathrm{K}_{\mathrm{om}}=1.248 \mathrm{~K}_{\mathrm{oc}}
$$

Differences in $K_{\text {om }}$ from chemical to chemical primarily arise from corresponding differences in $\gamma_{w}$, and

$$
K_{o m}=\frac{\gamma_{w} * \bar{V}_{w}}{\gamma_{o m} * \bar{V}_{o m} * \rho_{o m}}
$$

where

$\gamma_{o m}$ : activity coefficient reflecting the incompatibility of the sorbate associated

with the natural organic matter as compared to in solution of its own liquid;

$\gamma_{w}$ : activity coefficient of solute in water, independent of aqueous concentration

for neutral nonpolar compounds;

$\bar{V}_{w}$ : molar volumes of the water (L water $\mathrm{mol}^{-1}$ water);

$\bar{V}_{o m}$ : molar volumes of natural organic matter $\left(\mathrm{L} \mathrm{mol}^{-1} \mathrm{om}\right)$;

$\rho_{\text {om }}:$ the organic matter density $\left(\mathrm{kg} \mathrm{om} \mathrm{L} \mathrm{L}^{-1} \mathrm{om}\right)$

Schwarzenbach et al. 1993 also support the contention that temperature changes only affect $\gamma_{w}$, not much of $\gamma_{o m}$.

In applying these relationships, the assumption is that sorption process is happened exclusively to the organic component of the SMZ, all organic carbon has same sorption capacity per unit mass. In this manner, Li and Bowman (1998) showed that Equation 2.3 only holds true when HDTMA loading is less than $100 \%$ of the external cation exchange capacity. It has also been found that Equation 3.3 is valid primarily when $\mathrm{f}_{\mathrm{oc}}>0.001$ (McCarty et al., 1981). For soils, it is possible to relate aqueous solubility (S) and octanol-water partitioning coefficients $\left(\mathrm{K}_{\mathrm{ow}}\right)$ to partitioning into organic carbon $\left(\mathrm{K}_{\mathrm{oc}}\right)$. In fact, several investigations have found empirical relationships that relate $\mathrm{K}_{\mathrm{oc}}$ in soils of differing fractional organic matter contents $\left(\mathrm{f}_{\mathrm{om}}\right)$ to $\mathrm{K}_{\mathrm{ow}}$ and aqueous solubility $(\mathrm{S})$.

These linear free-energy equations all take log linear forms:

$$
\begin{aligned}
& \log \left(K_{o c}\right)=a^{*} \log \left(K_{o w}\right)+b \\
& \log \left(K_{o c}\right)=c^{*} \log (S)+d
\end{aligned}
$$


where $a, b, c$, and $d$ are regression parameters. These relationships are presented in Table 3.3 along with their applicable organic compounds, organic carbon contents, and corresponding correlation coefficients $\left(\mathrm{R}^{2}\right)$. The values for $\mathrm{K}_{\mathrm{oc}}$ and $\mathrm{K}_{\mathrm{om}}$ were expressed as $\mathrm{L} / \mathrm{kg}$ organic carbon and $\mathrm{L} / \mathrm{kg}$ organic matter, respectively. The octanol-water partition coefficient was expressed as $\mathrm{L}$ water/L octanol and in most of the regressions, $\mathrm{S}$ was expressed in mol/L. However, in the regressions developed by Abdul et al. (1987), the solubility was expressed in $\mathrm{mg} / \mathrm{L}$.

Table 3.3 Published Correlations Relating $K_{0 c}, K_{0 m}, K_{0 w}$, and $S$

\begin{tabular}{|c|c|c|c|c|}
\hline Source & Regression & $\begin{array}{l}\text { Applicable } \\
\text { Compounds }\end{array}$ & $\begin{array}{c}\text { Applicable } \\
\text { f }_{o c} \%\end{array}$ & $\mathbf{R}^{2}$ \\
\hline $\begin{array}{l}\text { Schwarzenbach } \\
\text { et al., } 1993\end{array}$ & $\log \mathrm{K}_{\mathrm{om}}=-0.93 * \log \mathrm{S}-0.17$ & $\begin{array}{c}\text { Aromatic } \\
\text { Hydrocarbons }\end{array}$ & Unreported & 0.92 \\
\hline $\begin{array}{l}\text { Schwarzenbach } \\
\text { et al., } 1993\end{array}$ & $\log \mathrm{K}_{\mathrm{om}}=1.01 * \log \mathrm{K}_{\mathrm{ow}}-0.72$ & $\begin{array}{c}\text { Aromatic } \\
\text { Hydrocarbons }\end{array}$ & Unreported & 0.99 \\
\hline $\begin{array}{c}\text { Karickhoff et } \\
\text { al., } 1979\end{array}$ & $\log \mathrm{K}_{\mathrm{oc}}=1.00 \log \mathrm{K}_{\mathrm{ow}}-0.21$ & Benzene & $0.13-3.29$ & 1.00 \\
\hline $\begin{array}{l}\text { Karickhoff, } \\
1981\end{array}$ & $\log \mathrm{K}_{\mathrm{oc}}=0.989 \log \mathrm{K}_{\mathrm{ow}}-0.346$ & Benzene & $0.11-2.38$ & 0.997 \\
\hline $\begin{array}{c}\text { Schwarzenbach } \\
\text { and Westall, } \\
1981 \\
\end{array}$ & $\log \mathrm{K}_{\mathrm{oc}}=0.72 \log \mathrm{K}_{\mathrm{ow}}+0.49$ & $\begin{array}{l}\text { Toluene, } \\
\text { Xylenes }\end{array}$ & $1-33$ & 0.95 \\
\hline $\begin{array}{c}\text { Chiou et al., } \\
1983\end{array}$ & $\log \mathrm{K}_{\mathrm{om}}=-0.729 \log \mathrm{S}+0.001$ & $\begin{array}{c}\text { Benzene, } \\
\text { Ethylbenzene }\end{array}$ & $\mathrm{f}_{\mathrm{om}}=1.9$ & 0.996 \\
\hline $\begin{array}{c}\text { Chiou et al., } \\
1983\end{array}$ & 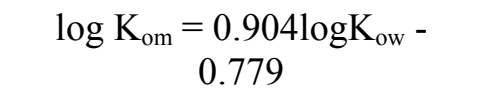 & $\begin{array}{c}\text { Benzene, } \\
\text { Ethylbenzene }\end{array}$ & $\mathrm{f}_{\mathrm{om}}=1.9$ & 0.989 \\
\hline $\begin{array}{l}\text { Abdul et al., } \\
1987\end{array}$ & $\log \mathrm{K}_{\mathrm{oc}}=1.04 \log \mathrm{K}_{\mathrm{ow}}-0.84$ & $\begin{array}{l}\text { Benzene, } \\
\text { Toluene, } \\
\text { Xylenes } \\
\end{array}$ & $0.4-2$ & 0.98 \\
\hline $\begin{array}{l}\text { Abdul et al., } \\
\qquad 1987\end{array}$ & $\log K_{o c}=-0.74 \log S+4.0$ & $\begin{array}{l}\text { Benzene, } \\
\text { Toluene, } \\
\text { Xylenes }\end{array}$ & $0.4-2$ & 0.99 \\
\hline $\begin{array}{l}\text { Vowles and } \\
\text { Mantoura, } \\
1987\end{array}$ & $\log \mathrm{K}_{\mathrm{oc}}=1.20 \log \mathrm{K}_{\mathrm{ow}}-1.13$ & $\begin{array}{c}\text { Benzene, } \\
\text { Ethylbenzene, } \\
\text { o- \& p- } \\
\text { Xylenes }\end{array}$ & 4.02 & 0.998 \\
\hline $\begin{array}{l}\text { Pussemier et } \\
\text { al., } 1990\end{array}$ & $\begin{array}{c}\log \mathrm{K}_{\mathrm{oc}}=-0.531 \\
+1.009 \log \mathrm{K}_{\mathrm{ow}}\end{array}$ & BTEX & Unreported & 0.92 \\
\hline
\end{tabular}

All of these relationships were developed for sorption to natural soils, so their applicability to SMZ is unknown. If these published correlations can be used to predict the distribution coefficients for BTEX sorption to SMZ, this process can be easily modeled and the predictions can be used in future studies.

In their study, Li and Bowman (1998) tested the sorption of perchloroethylene (PCE) by SMZ and found that PCE sorption was dependent on both bound surfactant monomer 
configuration and fractional organic carbon. The authors primarily studied the sorption of PCE as a function of surfactant loading and results showed that sorption occurred even for zeolite treated with small concentrations of HDTMA. Through manipulation of the initial and final concentrations of surfactant in solution, they found that PCE was most efficiently removed for surfactant concentrations at or below the external EC $\left(\mathrm{f}_{\mathrm{oc}} \approx 0.02\right)$. This optimal efficiency may be accounted for by the finding that the point of zero charge (ZPC) was reached at a surfactant-loading of $80-90 \mathrm{mmol} / \mathrm{kg}$, which is in agreement with the external EC of $90-110 \mathrm{meq} / \mathrm{kg}$ (Li and Bowman, 1998). The ZPC is also the point at which the surface exhibits the maximum hydrophobicity. Thus, theoretically, hydrophobic compounds such as PCE would have a greater attraction for the SMZ near the ZPC. As the surfactant concentration increased beyond the external EC up to the maximum amount of $200 \mathrm{mmol}$ HDTMA $/ \mathrm{kg}$ zeolite $\left(0.02>\mathrm{f}_{\mathrm{oc}}>0.04\right)$, no further increase in distribution coefficient was reported. The authors state that this lack of increase in $\mathrm{K}_{\mathrm{d}}$ values suggests the importance of both fractional organic carbon content and surfactant configuration to sorption onto SMZ. As a result, the above correlations may not be applicable to $\mathrm{SMZ}$

Recently, Li et al. (2000) researched the sorption of ionizable organic solutes by SMZ. The solutes tested included benzene and its ionizable counterparts phenol and aniline. Testing involved determining the effects of $\mathrm{pH}$ and surfactant loading on the sorption of $\mathrm{pH}$-dependent compounds. Benzene was included in the study for comparative purposes. At neutral $\mathrm{pH}$, all three compounds included in the study showed increasing distributions coefficients with increasing surfactant concentrations until monolayer coverage was achieved at $100 \mathrm{mmol} / \mathrm{kg}$. Beyond this surfactant concentration, no increases in distribution coefficient were reported and the distribution coefficient for aniline actually decreased because of the electrostatic repulsion between the positively-charged head groups of the surfactant and the positively charged amine group of aniline. Results also showed that sorption of phenol increased as $\mathrm{pH}$ surpassed 7 whereas aniline demonstrated less affinity for the $\mathrm{SMZ}$ at low $\mathrm{pH}$ values. These results were consistent with the known acid-base characteristics of phenol and aniline whose $\mathrm{pK}_{\mathrm{a}}$ values are 9.95 and 4.62, respectively.

As described above, SMZ has been shown to remove a wide variety of contaminants from aqueous systems. In fact, research shows that waters polluted simultaneously with several types of compounds can be effectively treated with SMZ. Bowman et al. (1993) found that water contaminated with benzene, toluene, p-xylene, lead, chromate, selenate, and sulfate could be treated with SMZ. While lead was effectively removed both prior to and after treatment of zeolite, all the other compounds were only removed after the material was modified with HDTMA. No evidence of competition among benzene, toluene, and p-xylene were found in this study. The competitive effects of multiple oxyanions in solution were not studied because only single inorganic compound solutions were exposed to SMZ. Nevertheless, the authors suggest that the use of this compound for in situ reactive barriers can result in relatively inexpensive remediation techniques for many sites. However, prior to using the material, its long term stability and the effects of various chemical conditions on its sorptive properties should be known.

$\underline{\text { Ionic Strength Effects on Sorption of Organics }}$ 
Though studies specifically focusing on ionic strength effects on the sorption of organic compounds on SMZ have not been reported, general behavior of hydrophobic compounds in the presence of aqueous salts has been observed. The "salting out" effect is a well-known phenomenon in which water molecules bind to charged entities and prevent uncharged entities from developing necessary cavities in which to dissolve (Schwarzenbach et al., 1993). The polar nature of water molecules causes them to have greater affinity for charged compounds, and once such electrolytes are in solution, water molecules almost immediately hydrate them. These tightly bound hydration shells reduce the amount of water available for dissolution of non-polar organic compounds, and these compounds cannot break the hydration shells to increase the number of available water molecules. The hydrogen bonding and van der Waals forces that connect hydrophobic compounds with water molecules are much weaker than the electrostatic bonds water molecules form with electrolytes. Hence, the water solubility of non-polar compounds decreases in the presence of salts and these organic compounds preferentially dissolve into another phase.

Setchenow (1889) developed an empirical relationship between aqueous solubility and salt concentration:

$$
\log \left[\frac{C_{w}^{\text {sat }}}{C_{w, \text { salt }}}\right]=K^{s}[\text { salt }]_{t}
$$

where:

$$
\begin{aligned}
& \mathrm{C}_{\mathrm{w}}^{\mathrm{sat}}=\text { solubility of compound in pure water (mass compound/volume of } \\
& \text { solution) } \\
& \mathrm{C}_{\mathrm{w}, \text { salt }}^{\mathrm{sat}}=\text { solubility of compound in saline water (mass of compound/volume of } \\
& \text { solution) } \\
& \mathrm{K}^{\mathrm{s}} \quad=\text { salting constant (volume of solution/moles of salt) } \\
& {[\text { salt }]_{t}=\text { total molar salt concentration (moles of salt/volume of solution) }}
\end{aligned}
$$

Values for salting constants have been reported for a few organic compounds and for different salts. When used for compounds such as benzene and naphthalene, Equation 5 is valid over a wide range of salt concentrations (Schwarzenbach et al., 1993). For nonpolar organic compounds, the effects of several types of salts are additive and the salting constant can be expressed as:

$$
K^{s}=\sum_{i} K_{i}^{s} x_{i}
$$

where:

$$
\begin{aligned}
& \mathrm{K}_{\mathrm{i}}^{\mathrm{s}}=\text { salting constant of salt } \mathrm{i} \\
& \mathrm{x}_{\mathrm{i}}=\text { mole fraction of salt } \mathrm{i}
\end{aligned}
$$

In seawater, which consists of many types of salts, aqueous solubilities for several organic compounds decreased $10-50 \%$ as compared to pure water due to the presence of $0.5 \mathrm{M}$ salts (Schwarzenbach et al., 1993). On the other hand, the presence of electrolytes decreases the salting out effect for polar organic compounds because the presence of a polar group decreases the hydrophobic surface area of the compound. The polar group 
can also contribute to thermodynamically favorable interactions with the ions in solution (Schwarzenbach et al., 1993). Though not much data for this phenomenon exist, the few that are available seem to support the assertion that the salting out effect is decreased (Hashimoto et al., 1984).

Based on this knowledge, it is presumed that decreasing the aqueous solubility of a non-polar organic compound will increase the sorption of that compound onto a sorbent such as SMZ. This presumption can be tested by determining the distribution coefficients for several non-polar organic compounds. As larger magnitudes for distribution coefficients are found with increasing ionic strength, the compounds should be gaining affinity for the sorbent. However, to date, these tests have yet to be conducted for SMZ.

\section{Temperature Effects on Sorption of Organics}

Temperature has been known an important factor in affecting sorption process and the temperature of produced water varies from field to field. Previous studies of sorption to soils have reported increases, decreases or negligible effects of increasing temperature. Ten and co-workers (1996) reviewed most of the data on the temperature dependence of the sorption of organic compounds on soil, sediment and phenyl coated silica. However most of the data is based on pesticides, chlorinated benzenes and a number of polycyclic aromatic hydrocarbons. Piatt et al. (1996) reported that equilibrium distribution coefficients for naphthalene, phenanthrene, and pyrene to low organic carbon $\left(\mathrm{f}_{\mathrm{oc}}=\right.$ $0.00019 \pm 0.00008)$ aquifer sediments increases 1.1-1.6 times for a decrease in temperature from $26^{\circ} \mathrm{C}$ to $4^{\circ} \mathrm{C}$, while solubility decreased by 2-3 times with over this temperature range. The increase in $\mathrm{K}_{\mathrm{d}}$ with decreasing temperature was predicted assuming that the aqueous phase activity coefficient was the driving force for sorption of the PAHs. Dewulf et al. (1999) conducted a study on sorption of 12 VOCs to a Belgian riverine sediment $\left(f_{o c}=0.041\right)$ as a function of temperature $\left(2-25^{\circ} \mathrm{C}\right)$ by means of a modified equilibrium partitioning in a closed system (EPICS) technique. Chloroform, 1,1-dichloroethylene, tetrachloethylene, trichloroethylene, tetrachloroethylene, tetrachloromethane, benzene, toluene, ethylbenzene, o- and p-xylene were studied. It was found that the distribution coefficient $\mathrm{K}_{\mathrm{d}}$ increased with increasing temperature for BTEX sorbed onto the sediment. The results are shown in Table 3.4.

Table 3.4 Effect of Temperature on Sediment/Water Linear Partitioning Coefficients

\begin{tabular}{llllllll}
\hline Compounds & $\mathrm{T}=2.3^{1}$ & $\mathrm{~T}=3.8$ & $\mathrm{~T}=6.2$ & $\mathrm{~T}=8.0$ & $\mathrm{~T}=13.5$ & $\mathrm{~T}=18.6$ & $\mathrm{~T}=25.0$ \\
\hline Benzene & $2.8 \pm 0.07$ & $3.0 \pm 0.04$ & $3.05 \pm 0.11$ & $3.1 \pm 0.03$ & $3.3 \pm 0.01$ & $3.1 \pm 0.07$ & $3.3 \pm 0.09$ \\
Toluene & $7.04 \pm 0.2$ & $8.5 \pm 0.36$ & $8.9 \pm 0.17$ & $8.9 \pm 0.26$ & $10.3 \pm 0.1$ & $8.5 \pm 0.35$ & $9.1 \pm 0.4$ \\
Ethylbenzene & $12.6 \pm 0.3$ & $21.9 \pm 1.0$ & $18.2 \pm 0.9$ & $22.1 \pm 2.9$ & $24.4 \pm 2.3$ & $21.9 \pm 1.4$ & $22.8 \pm 1.7$ \\
p-Xylene & $12.7 \pm 0.4$ & $23.1 \pm 0.5$ & $18.3 \pm 1.4$ & $23.5 \pm 3.9$ & $25.3 \pm 2.9$ & $24 \pm 1.3$ & $24.7 \pm 2.2$ \\
o-Xylene & $10.4 \pm 0.3$ & $20.8 \pm 0.5$ & $15.5 \pm 1.3$ & $19.8 \pm 4.3$ & $21.9 \pm 3.6$ & $20.4 \pm 1.3$ & $19.8 \pm 2.6$ \\
\hline
\end{tabular}

Reference: Dewulf et al. 1999

${ }^{1}$ Temperature in degrees centigrade

Based on these results, it is expected that the distribution coefficients for BTEX sorbed onto SMZ will increase with increasing temperature over typical field temperatures. 


\subsubsection{Long Term Stability of SMZ}

Li et al. (1998) performed a study on the stability of surfactant-modified zeolite under several chemical and biological conditions, including varying ionic strength, $\mathrm{pH}$, and microbial activity. The findings from this study showed that SMZ is very stable in conditions involving high ionic strength $\left(1 \mathrm{M} \mathrm{CaCl}_{2}\right)$, low $\mathrm{pH}$, and high $\mathrm{pH}$. Even after washing with 100 pore volumes, more than $90 \%$ of the HDTMA remained bound to the surface under these conditions. However, results also showed that HDTMA was subject to substantial desorption under conditions of low ionic strength and in high concentrations $(1.0 \mathrm{mM})$ of cesium. Up to $50 \%$ of the surfactant washed off in the presence of $1.0 \mathrm{mM}$ cesium while $20 \%$ desorbed in solutions of low ionic strength. The authors suggest that desorption in the presence of such high concentrations of cesium should not present a substantial problem as these concentrations are not commonly found even in highly contaminated systems. Li et al. also explain desorption in solutions of low ionic strength by stating that the electric double layer expands under such conditions and the interactions between the surfactant head groups and counterions are then weakened. This causes a destabilization of the admicelle and allows HDTMA monomers to desorb from the bilayer. These low ionic strength studies were conducted with Type I water which is not normally found at contaminated sites. Natural water systems and wastewaters generally include mineral salts, so SMZ should be stable when used at most sites. Additionally, the surfactant concentration required for monolayer coverage of the zeolite remained sorbed in all circumstances. As stated above, monolayer coverage has been found to be sufficient to efficiently remove organic contaminants from solution. Thus, even with desorption of some of the monomers forming the bilayer, SMZ can remain a viable sorbent for non-polar organics.

While several surfactants have been found to be biocidal, some bacteria can still degrade them (Gilbert and Al-taae, 1985). Thus, in order to use SMZ in natural systems, it is important that it resist microbial degradation. Pseudomonas sp. extracted from activated sludge has been found to metabolize aqueous HDTMA-Cl completely in $70 \mathrm{~h}$ (van Ginkel et al., 1992). However, no studies on biodegradation of sorbed HDTMA had been completed prior to the research conducted by Li et al. (1998). These authors found that even after 12-17 weeks of incubation under aerobic and anaerobic conditions, more than $98 \%$ of the HDTMA remained sorbed to the zeolite. The counterion did not seem to have a substantial impact on biodegradation and both HDTMA-Br and HDTMA-Cl remained stable throughout the study. In addition, sorbed HDTMA did not inhibit microbial growth although aqueous HDTMA solutions were found to do so. Thus, although SMZ was not prone to degradation by microorganisms, neither was it biocidal to activated sludge bacteria. With these results, the authors state that the use of SMZ should not harm organisms found in the natural environment and can even be used to enhance biodegradation of pollutants. 


\subsubsection{Regeneration of SMZ}

Sorbents for use in water treatment processes must be cost effective and therefore, the ability to reuse a sorbent is highly desired. All sorbents become saturated and must be regenerated prior to further use. A recent study conducted by Li and Bowman (2001) focused on this issue for SMZ saturated with chromate and PCE. Extraction of chromate was attempted using a carbonate solution, chemical reduction of chromate was tested with sodium dithionite, and PCE was removed through air sparging. Regeneration of chromate-saturated SMZ through extraction by carbonate proved successful when the $\mathrm{pH}$ decreased to 5 (110\% regeneration efficiency), but the material only resulted in $75 \%$ and $63 \%$ regeneration efficiencies at $\mathrm{pH} 8$ and 11, respectively. In addition, further tests showed that hydraulic conductivity was severely hampered as carbon dioxide filled the pore spaces of the SMZ. This gas formed as a result of carbonate reacting with protons at low $\mathrm{pH}$ values. Thus, due to the impracticality of this regeneration method, the reduction of chromate was attempted. In these tests, it was found that $85 \%$ of the residual chromate was reduced in situ, but breakthrough was detected earlier with the regenerated SMZ than with the virgin material. The authors suggest that a decrease in chromate sorption affinity or changes in the hydraulic properties of the system may have caused an increase in hydrodynamic dispersion and earlier breakthrough.

The tests conducted on PCE-saturated SMZ demonstrated that both the carbonate solution and air sparging fully regenerated the sorbent. Thus, it was shown that SMZ can be chemically regenerated, although decreased hydraulic conductivity or earlier breakthrough may occur when saturated with chromate. The authors also suggested that these regeneration methods can be utilized for both ex situ and in situ sorbent systems once the systems are modified with appropriate recirculation apparatus.

\subsection{Literature Review Summary}

Produced water contains many constituents that are considered harmful to humans and the environment. Regulations for the disposal of this wastewater may become increasingly stringent in the future and treatment methods will have to include removal of benzene, toluene, ethylbenzene, and xylenes (BTEX) among other components. In addition, deep-well reinjection is not economically feasible for many small producers, and reuse of produced water can benefit both producers and communities in arid areas. Thus, a low-cost method for produced water treatment that can remove BTEX compounds will benefit the oil and gas industry as well as the environment.

Traditional produced water treatment methods such as oil/water separation and hydrocyclones do not remove dissolved constituents from produced water. More sophisticated techniques like reverse osmosis, ultrafiltration, and photocatalytic oxidation are expensive and would probably not be viable for small producers. Although it requires large amounts of area, phytoremediation is low-cost and effective at volume reduction, but BTEX removal efficiency has not been reported. Sorption to GAC and commercial carbonaceous sorbents has been demonstrated to remove non-polar organics, but these 
sorbents tend to be cost- and maintenance-intensive and do not remove heavy metals from solution. Surfactant-modified zeolite has been shown to be a versatile sorbent that can remove anions, cations, and non-polar organic compounds from water.

The use of surfactant-modified zeolite for produced water treatment in one study demonstrated its effectiveness at reducing the concentration of BTEX compounds in oilfield water. However, results from this study did not include batch tests conducted with the commonly found surfactant, HDTMA and a predictive model relating the hydrophobicity of a compound to the linear partitioning coefficient were not developed. Additionally, ionic strength and temperature effects were not explored although the authors did cite investigation of ionic strength effects as a field deserving future study. Indeed, the salting out effect is known to substantially decrease the aqueous solubility of hydrophobic compounds, and because produced water is classified as a brine,the presence of salts can act to increase partitioning of non-polar organics to non-aqueous phases.

Produced water temperatures at field scale sites also vary among sites and temporally at a particular site. It is assumed that higher temperatures will increase the sorption of BTEX onto SMZ because the aqueous activity coefficient of BTEX increases with temperatures above $20^{\circ} \mathrm{C}$; however, the magnitude of the change in the sorption capacity as measured by a linear partitioning coefficient $\left(\mathrm{K}_{\mathrm{d}}\right)$ is not expected to be very significant. 


\section{Experimental Plan and Methodology}

\subsection{Approach}

The experimental program included three components: laboratory scale batch experiments, laboratory scale column experiments, and a field test. A brief description of the experiments conducted for each of these components is described below.

\subsubsection{Batch Studies}

Batch sorption experiments were performed to characterize sorption of BTEX to SMZ as a function of salinity, temperature, and in the presence of produced water. This relationship could then be used for predicting the sorption capacity of SMZ under different field-scale conditions. The goal of the batch study conducted in the presence of produced water was to compare the distribution coefficients of BTEX sorbed onto SMZ in ultrapure water, saline water and produced water.

\subsubsection{Column Studies}

The goals of the laboratory scale column tests were to evaluate process kinetics, verify the batch results, and assess the feasibility of the process in a continuous flow system. Various approaches can be used to evaluate kinetics in column reactions, including the rapid small-scale column test (RSSCT) developed by Crittenden and co-workers. This method assumes that both internal and external diffusion may affect the rates of sorption. The principle of this method is to simulate sorption behavior in pilot and field scale systems using a smaller scale setup that maintains perfect similarity between the performance of the large scale and small scale adsorbers (Sontheimer et al. 1988). The RSSCT approach uses a set of scaling parameters to reduce the size and flowrates in field scale columns to laboratory scale columns. The adsorbent particle size, hydraulic loading and EBCT of the RSSCT are determined by using scaling equations described by Hand et al. (1984). Thus, RSSCT columns should mimic the breakthrough curves of the full-scale columns as long as the assumptions inherent in the scaling equations are valid.

Regeneration studies were also conducted in laboratory scale columns as well as the pilot scale field test columns. The spent SMZ was regenerated by air-sparging using compressed air tank and a flowmeter to control flowrate through the column. Samples were taken periodically by withdrawing gas through a sampling port at the effluent end of the column. The air-sparging experiment was continued until the BTEX mass coming off of the column was negligible. The regenerated SMZ was again saturated with the aqueous BTEX solution. The input BTEX concentration and flow rate were the same as for the original saturation.

\subsubsection{Field Studies}

Several possible sites/sources of produced water were evaluated including a small producer in East Texas near Smithville, a gas well array near Houston, Texas, an offshore 
oil well, and a treatment facility of BC Technologies in Wamsutter, Wyoming. The facility of BC Technologies was chosen as the site for field study in this project. The site is operated by Crystal Solutions, LLC., and is located in an oil producing region just outside of Wamsutter, WY. The facility is set up to receive produced water from the region by tanker trucks. Two columns were used in the field to test the capability of SMZ treatment of BTEX in this facility. The columns were provided by a local Culligan distributor in Austin, TX, and were readily adapted to the needs of this study by substituting the ion exchange resin with SMZ.

\subsection{Materials}

\subsubsection{BTEX compounds}

Benzene, ortho-xylene, and para-xylene were obtained from J. T. Baker (Phillipsburg, NJ). Toluene was obtained from EM Science (Gibbstown, NJ), ethylbenzene from Mallinckrodt Chemical Inc. (Paris, KY), and meta-xylene from Aldrich (Milwaukee, WI). All of these chemicals were $99 \%$ purity. Their chemical formulas, molecular weight and water solubilities $\left(25^{\circ} \mathrm{C}, 1 \mathrm{~atm}\right)$ are reported in Table 4.1.

Table 4.1 Chemical and Physical Properties of BTEX Compounds

\begin{tabular}{|l|l|l|l|l|l|l|}
\hline & Benzene & Toluene & m-Xylene & o-Xylene & p-Xylene & Ethylbenzene \\
\hline $\begin{array}{l}\text { Chemical } \\
\text { formula }\end{array}$ & $\mathrm{C}_{6} \mathrm{H}_{6}$ & $\mathrm{C}_{7} \mathrm{H}_{8}$ & $\mathrm{C}_{8} \mathrm{H}_{10}$ & $\mathrm{C}_{8} \mathrm{H}_{10}$ & $\mathrm{C}_{8} \mathrm{H}_{10}$ & $\mathrm{C}_{8} \mathrm{H}_{10}$ \\
\hline $\begin{array}{l}\text { Molecular } \\
\text { Weight (g/mol) }\end{array}$ & 78 & 92 & 106 & 106 & 106 & 106 \\
\hline $\begin{array}{l}\text { Log Water } \\
\text { Solubility at } \\
25^{\circ} \mathrm{C}(\mathrm{mol} / \mathrm{L})\end{array}$ & -1.64 & -2.25 & & -2.76 & -2.77 & -2.80 \\
\hline
\end{tabular}

Reference: Schwarzenbach et al. 1993

\subsection{2 $\alpha, \alpha, \alpha$-Trifluorotoluene (TFT)}

An internal standard was used during gas chromatography analyses of BTEX compounds. The internal standard was $\alpha, \alpha, \alpha$-trifluorotoluene (TFT) purchased from Restek Corption at an initial concentration of $2500 \mu \mathrm{g} / \mathrm{mL}$. The solution was initially diluted to $25 \mathrm{mg} / \mathrm{L}$ in methanol and stored at $-18^{\circ} \mathrm{C}$.

\subsubsection{Electrolytes for Saline Water Preparation}

A number of the experiments conducted in this research used synthetically prepared background water. The dissolved solids were added to the synthetic water using reagent grade calcium chloride $\left(\mathrm{CaCl}_{2}\right)$, magnesium sulfate $\left(\mathrm{MgSO}_{4}\right)$, sodium chloride $(\mathrm{NaCl})$, and potassium chloride $(\mathrm{KCl})$. The sodium chloride and calcium chloride were obtained from EM Science (Gibbstown, NJ), magnesium sulfate was obtained from J. T. Baker 
(Phillipsburg, NJ), and the potassium chloride was obtained from Fisher Scientific (Fairlawn, NJ). All of these chemicals were dried at $105^{\circ} \mathrm{C}$ for 24 hours prior to use.

\subsubsection{Natural Zeolite}

The zeolite used in this study was a clinoptilolite from the St. Cloud mine in Winston, New Mexico. Clinoptilolite has an approximate chemical formula of ( $\mathrm{Ca}, \mathrm{Na}$, $\mathrm{K})_{6} \mathrm{Al}_{6} \mathrm{Si}_{30} \mathrm{O}_{72} \cdot 24 \mathrm{H}_{2} \mathrm{O}$ and the dimensions of the open channels in are $0.89 \times 0.35 \mathrm{~nm}^{2}$ for the 10 -member ring and $0.44 \times 0.30 \mathrm{~nm}^{2}$ for the 8 -member ring. These dimensions are large enough for diffusion of a small cation but too small for a surfactant the size of hexadecyltrimethylammonium(HDTMA) head groups. An XRD analysis conducted by Sullivan et al. (1997), found it to be comprised of 74\% clinoptilolite, $5 \%$ smectite, $10 \%$ quartz cristobalite, 10\% feldspar, and 1\% illite. Potassium and calcium were determined to be the major exchangeable cations and the external cation exchange capacity was calculated to be between 90-110 meq/ $\mathrm{kg}$ (Li and Bowman, 1997). The internal, or zeolitic, cation exchange capacity was $800 \mathrm{meq} / \mathrm{kg}$. Sullivan et al. (1997) also found that the BET external surface area for the material was $15.7 \mathrm{~m}^{2} / \mathrm{g}$.

The zeolite was ground and screened to two different grain sizes: $14 \mathrm{x} 40$ mesh (1.4 to $0.4 \mathrm{~mm})$ for the field columns and $18 \times 100$ mesh $(0.18$ to $0.15 \mathrm{~mm})$ for the laboratory columns. Batch experiments were conducted with both particles sizes depending on the experiments.

\subsubsection{Hexadecyltrimethylammonium Surfactant}

Hexadecyltrimethylammonium chloride (HDTMA, or cetyltrimethylammonium chloride, CTAC) obtained from Aldrich (Milwaukee, WI) was selected for use in this research for surfactant modification based on previous research by P.I. Bowman and coworkers. HDTMA has a molecular weight of $320 \mathrm{~g} / \mathrm{mole}$, a critical micelle concentration of $0.9 \mathrm{mM}$, and is a bulk production surfactant used in shampoo, mouthwash, and other products.

\subsubsection{Hexadecyltrimethylammonium Surfactant Modification of Zeolite}

HDTMA sorption to zeolite creates an organic coating over the surface of the zeolite, which allows partitioning of the organic molecules into the organic coating. The procedure to coat the SMZ with the surfactant involves mixing the surfactant and zeolite for several hours followed by several stages of washing with ultrapure water.

Specifically, a solution containing $3000 \mathrm{~mL}$ of $0.1 \mathrm{M}$ HDTMA-Cl solution was prepared and mixed with $1000 \mathrm{~g}$ of zeolite. The mixture was placed into ten $500 \mathrm{~mL}$ polyethylene centrifuge bottles and equilibrated on a shaker at $150 \mathrm{rpm}$ and $25^{\circ} \mathrm{C}$ for 8 hour, which was sufficient to achieve sorption equilibrium (Bowman et al., 1997). Experiments conducted at New Mexico Tech (Bowman et al., 1997) have shown that HDTMA does not sorb to plastic labware including polyethylene.

After equilibrium, the mixture was centrifuged to yield a clear supernatant solution (7250 $\mathrm{G}$ for $50 \mathrm{~min}$ ) and the supernatant was removed and saved for later HDTMA analysis. The HDTMA-zeolite was washed with two $180 \mathrm{~mL}$ portions of ultrapure water (water treated using a Milli-Q system, ultrapure Corp., Bedford, MA). For each wash, 
the bottles were shaken at $150 \mathrm{rpm}$ for $15 \mathrm{~min}$ and centrifuged at $7250 \mathrm{~g}$ for $50 \mathrm{~min}$. The samples were air-dried following the final washing.

Supernatant analysis showed that the HDTMA loading rate was $180 \mathrm{mmol} / \mathrm{kg}$ for $14 \times 40 \mathrm{SMZ}$ compared to $157 \mathrm{mmol} / \mathrm{kg}$ for the $80 \times 100 \mathrm{SMZ}$. The amount of HDTMA sorbed was calculated from the difference between the initial and final concentrations. After drying, the SMZ was sieved again to remove fines.

The organic carbon content, which is primarily responsible for sorption of non-polar organic compounds to soils (Chiou 1989), was increased by HDTMA modification. The $14 \times 40$-mesh size SMZ had an organic carbon content of 0.041 and the $80 \times 100$ mesh size had an organic carbon content of 0.036 .

\subsubsection{Produced Water}

\subsubsection{Sources}

Many company representatives were hesitant to participate in this research. Four possible sites/sources of produced water were evaluated. The first was a small producer in East Texas near Smithville. The water from the tested sources was quite fresh and is in current use for agricultural purposes (irrigation and stock watering). BTEX concentrations were too low for experimental use, however. The second source was from a gas well array near Houston, Texas. This water was moderately saline with useful concentrations of BTEX. The third was a source of water from an offshore oil well, again, moderately to highly saline with appropriate BTEX concentrations. The available volumes of water were not sufficient for field testing (volumes quite variable and chemistry variable). The final, selected source was from the treatment facility of BC Technologies in Wamsutter, Wyoming. BC Technologies provides produced water treatment and disposal options for small oil and gas producers in Wyoming. As previously stated, produced water differs with location and type of operation. Thus, the sample obtained from this facility contained a mixture of many different effluents and should be generally representative of produced water generated by the onshore gas industry in the Northern Rocky Mountains. The produced water at the site tended to be high in BTEX concentrations and of moderate salinity $(10,000 \mathrm{ppm}-30,000 \mathrm{ppm})$.

\subsubsection{Sample Collection}

Samples for analysis of BTEX and semi-volatile compounds were collected in $40 \mathrm{~mL}$ volatile organics analysis (VOA) vials with screw cap and PTFE/silicone septa. The samples for each site were placed in plastic bags to prevent cross-contamination and then stored in the dark in an ice chest. All of these vials and their caps were rinsed three times with the produced water before taking samples. Care was taken not to introduce air bubbles into the vials when screwing the caps onto the vials.

Collection of produced water for use in laboratory experiments required larger volume containers. Zero-Headspace Extraction (ZHE) vessels are commonly used for the Toxicity Characteristic Leaching Procedure (TCLP) endorsed by the EPA for testing the leaching ability of hazardous wastes. However, these containers also provide a headspace-free environment in which to store samples of water that contain volatile 
compounds. Using the spigot on the holding tank, four stainless steel ZHE vessels (Ultrapure, Inc.) were rinsed three times with produced water prior to being completely filled ( $250 \mathrm{~mL})$ and pressurized to 20 psi by an air compressor.

\subsubsection{Characterization of Field Samples}

All three water samples that were acquired were analyzed to determine their initial characterization. The Phillips Petroleum samples were analyzed at UT for BTEX and by an outside laboratory (DHL Analytical, Round Rock, Texas) for total petroleum hydrocarbons (TPH), anions, and cations. The MCA Petroleum samples were analyzed only by DHL Analytical for TPH, BTEX, semi-volatile organics, ammonia, anions, and cations. The Wamsutter site samples were provided by John Harju and were analyzed for BTEX and TDS at UT and DHL Analytical and for metals by DHL Analytical.

\subsection{Analytical Methods}

\subsubsection{Analysis for BTEX}

Laboratory and field samples and BTEX standards were analyzed at either the University of Texas or New Mexico Tech through headspace analysis and gas chromatography. Preliminary experiments using gas chromatography/mass spectroscopy showed that all of the BTEX compounds could be uniquely identified and quantified in the presence of the produced waters used in this research with the exception of ethylbenzene. Ethylbenzene eluted close to or at the same time as a chemical that was most likely 2-methyl octane and that o-xylene was also found to elute near nonane. However, both of these non-BTEX chemicals showed small peaks and the remaining BTEX compounds were not found to co-elute with other chemicals. In addition, selected field samples were also analyzed by DHL Analytical Laboratories to provide verification of our results.

The GC/Headspace method used for BTEX analysis was capable of analyzing BTEX concentrations to the ppb range. Samples and standards were placed in headspace vials were crimped shut with aluminum crimp caps fitted with PTFE/black butyl rubber septa (Agilent Technologies, HP9301-0976). After all of the samples and standards were prepared, an internal standard was injected through the septa into the aqueous solutions. The internal standard, $\alpha, \alpha, \alpha$-trifluorotoluene (TFT), eluted from the GC between the benzene and toluene peaks. Because the TFT (Restek) was purchased at a concentration of $2,500 \mu \mathrm{g} / \mathrm{mL}$, it was diluted to $25 \mathrm{mg} / \mathrm{L}$ in methanol prior to use. A constant volume of $200 \mu \mathrm{L}$ was then injected into the headspace vials to yield an internal standard concentration of $1000 \mu \mathrm{g} / \mathrm{L}$. The standards and samples were then placed in a Tekmar 7000 Headspace Autosampler (HSA). The headspace autosampler was heated to increase partitioning of BTEX compounds into the headspace above the aqueous solution. The HSA working conditions are listed in Table 4.2. A $1 \mathrm{~mL}$ sample of that headspace was then transferred into a Hewlett-Packard (HP) 5890 gas chromatograph (GC) equipped with a 30 m Restek capillary column (RTX-624; ID0.53 mm; DF3.0) and flame ionization detector (FID) detector. Compressed air and hydrogen were burned in the FID with nitrogen as an auxiliary gas. Helium was used as an inert carrier gas at a flowrate of 
$36 \mathrm{~mL} / \mathrm{min}$. The GC operating conditions and ramping program in this study are listed in Table 4.3 .

Table 4.2 Headspace Operating Conditions for BTEX Analysis

\begin{tabular}{|c|c|c|}
\hline $\begin{array}{c}\text { Zone } \\
\text { Temperatures }\end{array}$ & & ${ }^{\circ} \mathbf{C}$ \\
\hline \multirow{5}{*}{ Event Times } & Water bath & 80 \\
\cline { 2 - 3 } & Loop & 170 \\
\cline { 2 - 3 } & Transfer Line & 170 \\
\hline \multirow{5}{*}{} & Vial Equilibration & Minu \\
& Mixing & 15 \\
\cline { 2 - 3 } & Pressurization & 1 \\
\cline { 2 - 3 } & Pressure & 0.25 \\
& Equilibration & 1 \\
\cline { 2 - 3 } & Loop filling & 0.25 \\
\cline { 2 - 3 } & $\begin{array}{c}\text { Loop } \\
\text { Equilibration }\end{array}$ \\
\cline { 2 - 3 } & Loop Injection & 1 \\
\hline \multirow{2}{*}{ Flowrate } & & 1 \\
\hline & mL/min & \\
\hline
\end{tabular}

Table 4.3 GC Operating Conditions for BTEX Analysis

\begin{tabular}{|c|l|l|}
\hline $\begin{array}{c}\text { Ramping } \\
\text { Program }\end{array}$ & & \\
\hline & Initial Oven Temp & $40^{\circ} \mathrm{C}$ \\
& Initial Time & $1 \mathrm{~min}$ \\
& Rate & $20^{\circ} \mathrm{C} \mathrm{m^{-1 }}$ \\
& Final Oven Temp & $85^{\circ} \mathrm{C}$ \\
& Final Time & $0 \mathrm{~min}$ \\
& Rate A & $0.5^{\circ} \mathrm{C} \mathrm{min}$ min $^{-1}$ \\
& Final Oven Temp & $90^{\circ} \mathrm{C}$ \\
& A & $1 \mathrm{~min}^{-}$ \\
\hline Other & Final Time A & \\
\hline Settings & & $250^{\circ} \mathrm{C}$ \\
& Injector Temp & $275^{\circ} \mathrm{C}$ \\
& FID Detector & $11 \mathrm{psi}$ \\
& Temp & 0.1 \\
\hline
\end{tabular}


Data from the gas chromatograph were analyzed with EZChrom Chromatography Data System (Scientific Software, Inc., San Ramon, CA; (510) 244-6622), version 6.5 software. An internal standard (TFT) was used to define the area ratios of the amount of each BTEX compound detected to the amount of TFT detected were used to prepare calibration curves. The elution times for the BTEX compounds and TFT are shown in Table 4.4.

Table 4.4 GC Detection Times for BTEX Compounds and TFT

\begin{tabular}{|c|c|}
\hline Compound & $\begin{array}{c}\text { Peak Detection Times } \\
(\mathbf{\pm 0 . 0 1})\end{array}$ \\
\hline & minutes \\
\hline Benzene & 2.84 \\
$\alpha, \alpha, \alpha-$ Trifluorotoluene & 3.40 \\
Toluene & 4.11 \\
Ethylbenzene & 5.90 \\
p- \& m-Xylenes & 6.11 \\
o-Xylene & 6.84 \\
\hline
\end{tabular}

The method detection limit (MDL) was calculated according to Method 1030E of Standard Methods for the Examination of Water and Wastewater (1989). For this process, seven samples containing $9 \mu \mathrm{g} / \mathrm{L}$ of BTEX were analyzed. The standard deviation of these results was calculated and multiplied by the Student's one-tailed tvalue for $99 \%$ confidence and six degrees of freedom $(t=3.14)$. The final results from this process are presented in Table 4.5.

Table 4.5 Method Detection Limits for BTEX Compounds

\begin{tabular}{|l|c|c|c|c|c|}
\hline & Benzene & Toluene & Ethylbenzene & m- \& p-Xylenes & o-Xylene \\
\hline MDL $(\mu \mathbf{g} / \mathbf{L})$ & 1.0 & 0.94 & 1.2 & 1.1 & 1.1 \\
\hline
\end{tabular}

Several steps were taken to assure the quality of the data collected. Standard curves, which served to calibrate the instruments, were run prior to every analysis. The instruments used in the investigations were not turned off between analysis of standard solutions and batch samples because prior experience showed that data become slightly skewed if the machines are not left on throughout an analytical run. These standard curves were for the most part run with triplicates to ensure statistical significance. If the correlation coefficient $\left(\mathrm{R}^{2}\right)$ for the standard curves was below 0.995 , these tests were redone until sufficient $\mathrm{R}^{2}$ values were obtained.

The single-solute studies were conducted in triplicate to allow the calculation of standard deviation. Replicates for the multi-solute studies were constrained by the maximum number of headspace vials allowed on the autosampler. However, duplicates were used to compare results among samples. 
Checks were included within the sample runs to ascertain whether the standard curve remained valid for the samples. If the results for these checks did not agree within $5 \%$ of the known concentration, the analysis was rejected and the entire batch test was rerun. These checks were prepared identically to the solutions for the standard curve.

One concern that arose during the course of the project involved the impact of the background produced water matrix on the headspace method. To evaluate the impact of the produced water background, an experiment was conducted for which standard curves were prepared for both ultrapure water and produced water to determine whether the presence of produced water had an impact on BTEX analyses. In a column test, the effluent from the column changes over the course of the experiment. These two matrices, ultrapure water and produced water represent the extremes in variability. If there is little difference between BTEX concentrations obtained from these two matrices, then it is unlikely that the presence of produced water in the samples would affect the BTEX analyses for all of the column effluent samples. As shown in Table 4.6, there is a slight increase in the calibration curve slope in the produced water matrix. However, the percent increase in the slope is well within the analysis error of the gas chromatography method. In the column experiment with produced water, calibration curves were prepared using a produced water background. Because the variability between calibration curves was so small, no corrections were made when using this calibration curves for laboratory and field samples; however, analysis of the produced water from the Wyoming field site were evaluated using a standard addition technique to account for the produced water matrix.

Table 4.6 Calibration Curve Slopes Obtained from Matrices of Ultrapure Water and Produced Water

\begin{tabular}{|l|c|c|}
\hline Compound & $\begin{array}{l}\text { Calibration Curve Slope } \\
\text { from Ultrapure Water }\end{array}$ & $\begin{array}{l}\text { Calibration Curve Slope } \\
\text { from Produced Water }\end{array}$ \\
\hline Benzene & 783.79 & 793.87 \\
\hline Toluene & 763.65 & 772.79 \\
\hline Ethyl benzene & 739.27 & 746.81 \\
\hline m-\&p-Xylene & 373.98 & 378.15 \\
\hline o-Xylene & 805.59 & 816.5 \\
\hline
\end{tabular}

\subsubsection{Preparation of Standards for BTEX Analysis}

It was found that working with methanol solutions reduced BTEX losses due to volatilization during transfer processes. Thus, stock solutions of high concentrations of BTEX in methanol were used for both standard curve preparation and batch tests. To avoid co-solvency effects, the amount of methanol in aqueous solutions was kept below $1 \%$ by volume (Pinal et al., 1990). Stock solutions of $10 \mathrm{~g} / \mathrm{L}, 1 \mathrm{~g} / \mathrm{L}, 0.2 \mathrm{~g} / \mathrm{L}$, and 0.03 $\mathrm{g} / \mathrm{L}$ in methanol were made for all of the BTEX compounds combined and for benzene and toluene, individually. These individual stock solutions were used to test the effects of multiple solutes in solution. 
Stock solutions were prepared in serial dilutions. However, the initial solution was prepared by first calculating the correct volume of neat BTEX compounds required to generate a $10 \mathrm{~g} / \mathrm{L}$ solution in methanol. This volume was found through the following formula:

$$
C=\frac{\rho * 10^{3} * X}{10^{3} * V^{*} P}
$$

where:

$\mathrm{C}=$ desired concentration $(\mathrm{g} / \mathrm{L})$

$\mathrm{R}=$ density of pure BTEX compound $(\mathrm{g} / \mathrm{mL})$

$10^{3}$ in numerator $=$ conversion from $\mathrm{mL}$ to $\mathrm{L}$

$\mathrm{X}=$ volume of BTEX compound required to reach desired concentration $(\mu \mathrm{L})$

$10^{3}$ in denominator $=$ conversion from $\mu \mathrm{L}$ to $\mathrm{mL}$

$\mathrm{V}=$ volume of methanol for dilution $(\mathrm{mL})$

$\mathrm{P}=$ purity of BTEX compounds in decimal form

Further dilutions were prepared with volumetric pipettes to generate the three remaining concentrations. Because the solutions were made in methanol, it was assumed that negligible volatilization of BTEX compounds would occur during the transfer phase. Pasteur pipettes were used to transfer each of the four solutions to $2 \mathrm{~mL} \mathrm{GC}$ vials that were immediately crimped shut, labeled, and stored in $\mathrm{a}-18^{\circ} \mathrm{C}$ freezer. According to the manufacturers of the septa (Agilent Technologies, Wilmington, DE; HP5182-0837), the vials should have remained leak-free for 4 months, but during this study, vials older than 2 months were discarded.

Standard curve solutions were in general generated in triplicate for a range of concentrations $(0-10 \mathrm{mg} / \mathrm{L})$. After many curves were produced, it became clear that the GC became saturated after approximately $1,500 \mu \mathrm{g} / \mathrm{L}$ of a single BTEX compound. Hence, the standard curves prepared after reaching this conclusion included only the concentrations shown in Table 4.7.

Table 4.7 Standard Curve Solution Concentrations

\begin{tabular}{|c|}
\hline $\begin{array}{c}\text { Desired Standard } \\
\text { Solution Concentration }\end{array}$ \\
\hline$\mu \mathbf{g} / \mathbf{L}$ \\
\hline 0 \\
9 \\
15 \\
30 \\
60 \\
120 \\
200 \\
500 \\
800 \\
1000 \\
1500 \\
\hline
\end{tabular}


These aqueous solutions were prepared in $22 \mathrm{~mL}$ headspace vials (Agilent Technologies; HP5182-0837) by initially using a $5 \mathrm{~mL}$ volumetric pipette to fill each vial with $5 \mathrm{~mL}$ of water. The vials were then loosely capped to minimize evaporation until BTEX stock solutions were injected into them. To determine the volume required for injection, the following formula was used:

where:

$$
V_{1} C_{1}=V_{2} C_{2}
$$

$\mathrm{V}_{1}=$ volume of stock solution required $(\mu \mathrm{L})$

$\mathrm{C}_{1}=$ concentration of stock solution $(\mathrm{g} / \mathrm{L})$

$\mathrm{V}_{2}=$ volume of standard solution $(\mathrm{mL})$

$\mathrm{C}_{2}=$ desired concentration $(\mu \mathrm{g} / \mathrm{L})$

In order to account for the complex chemistry of the samples obtained from the Wamsutter site by Crystal Solutions, LLC., the standard curves used for their analysis were generated with diluted sample waters using a standard addition technique (Skoog and West, 1998). The standard curve solutions were prepared with $5 \mathrm{~mL}$ ultrapure water followed by injecting $50 \mu \mathrm{L}$ of produced water through the septa in consideration of the complex chemistry. The produced water was actually diluted by a factor of 100 . The vials were then sealed with crimp caps fitted with PTFE/black butyl rubber septa. The varying volumes of BTEX stock solutions required to generate a range of standard concentrations were then injected with gastight syringes through the septa. Following these injections, the internal standard was also added to the vials through the septa. It was assumed that the absolute value of the intercepts of the linear standard addition calibration curves for the BTEX compounds was the BTEX concentration in the produced water sample. Figure 4.1 shows a representative linear curve for the benzene concentration analysis of the produced water obtained from the Wamsutter site by Crystal Solutions, LLC. As shown in the standard curve, the vertical axis reflects the initial benzene concentration that is represented by the negative of the y-intercept. Because the initial produced water was diluted 100 -fold, the value for the initial benzene concentration was found by multiplying the magnitude of the intercept by 100 . 


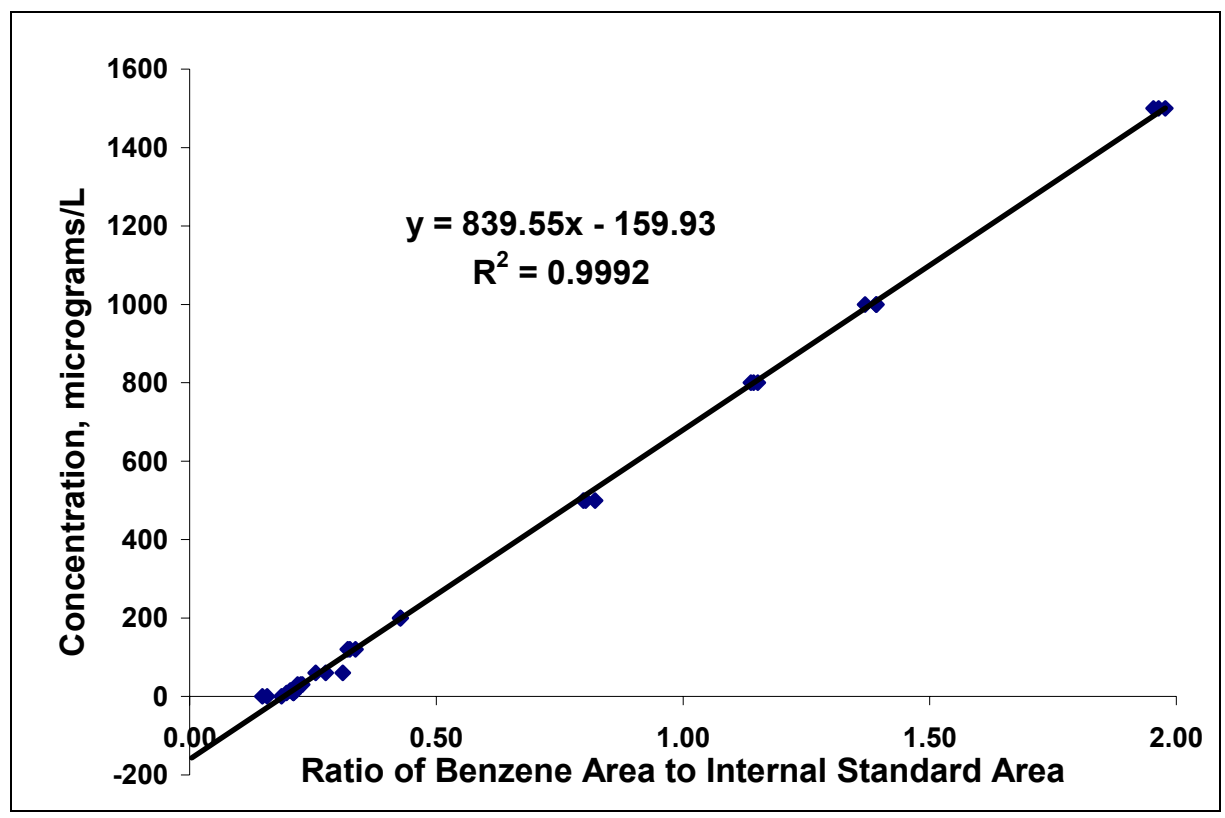

Figure 4.1 Standard Curve for Benzene in Wamsutter Site Holding Pond Produced Water

\subsubsection{Analysis for Metals and Semi-Volatiles}

DHL Analytical laboratories were used to analyze all produced water samples for metals, total petroleum hydrocarbons, and semi-volatiles. The samples provided by Crystal Solutions LLC, underwent testing for cations, anions and arsenic, barium, lead, and cadmium as well as semi-volatile compounds. For the other produced water limited metal analyses were conducted. The analytical techniques used and reporting limits for the methods are presented in Tables 4.8 to 4.10. Method TX1005 is a state-approved analytical technique in Texas while the remaining methods listed are all endorsed by the EPA.

Table 4.8 Metals Analysis Methods Used by DHL Analytical

\begin{tabular}{|c|c|c|c|}
\hline Analysis & Method & Units & Reporting Limit \\
\hline Metals: ICP-MS & SW6020 & & \\
Arsenic & & $\mu \mathrm{g} / \mathrm{L}$ & 10.0 \\
Barium & & $\mu \mathrm{g} / \mathrm{L}$ & 100 \\
Cadmium & & $\mu \mathrm{g} / \mathrm{L}$ & 1.00 \\
Lead & & $\mu \mathrm{g} / \mathrm{L}$ & 3.00 \\
\hline
\end{tabular}


Table 4.9 Ion Analysis Methods Used by DHL Analytical

\begin{tabular}{|c|c|c|c|}
\hline Analysis & Method & Units & Reporting Limit \\
\hline Anions & SW9056 & & \\
Chloride & & & \\
Nitrate-N & & $\mathrm{mg} / \mathrm{L}$ & 200 \\
Sulfate & & $\mathrm{mg} / \mathrm{L}$ & 0.500 \\
\hline Metals & SW6020 & & 3.00 \\
Calcium & & $\mu \mathrm{g} / \mathrm{L}$ & 5000 \\
Magnesium & & $\mu \mathrm{g} / \mathrm{L}$ & 1000 \\
Potassium & & $\mu \mathrm{g} / \mathrm{L}$ & 1000 \\
Sodium & & $\mu \mathrm{g} / \mathrm{L}$ & 50000 \\
\hline Alkalinity & $\mathrm{E} 310.1$ & $\mathrm{mg} / \mathrm{L}$ & 10 \\
\hline
\end{tabular}

Table 4.10 Results from Analyses of MCA Petroleum Corp. Samples

\begin{tabular}{|l|c|c|c|}
\hline \multicolumn{1}{|c|}{ Analysis } & Method & Units & $\begin{array}{c}\text { Reporting } \\
\text { Limit }\end{array}$ \\
\hline TPH & TX1005 & $\mathrm{mg} / \mathrm{L}$ & 5.0 \\
\hline TOC & $\mathrm{E} 415.1$ & $\mu \mathrm{g} / \mathrm{L}$ & 400 \\
\hline PAHS & $\mathrm{SW} 827$ & \multicolumn{2}{|c|}{} \\
2,4-Dimethylphenol & & $\mu \mathrm{g} / \mathrm{L}$ & 80 \\
2-Methylnaphthalene & & $\mu \mathrm{g} / \mathrm{L}$ & 80 \\
2-Methylphenol & $\mu \mathrm{g} / \mathrm{L}$ & 80 \\
4-Methylphenol & $\mu \mathrm{g} / \mathrm{L}$ & 80 \\
Dibenzofuran & $\mu \mathrm{g} / \mathrm{L}$ & 4 \\
Fluorene & $\mu \mathrm{g} / \mathrm{L}$ & 4 \\
Naphthalene & $\mu \mathrm{g} / \mathrm{L}$ & 8.25 \\
Phenanthrene & $\mu \mathrm{g} / \mathrm{L}$ & 4 \\
Pyrene & $\mu \mathrm{g} / \mathrm{L}$ & 4 \\
Phenol & $\mu \mathrm{g} / \mathrm{L}$ & 80 \\
\hline
\end{tabular}




\subsection{Batch Adsorption Studies}

Once the produced water samples had been characterized, batch tests were conducted to study the adsorption of BTEX compounds onto SMZ. These batch tests had several foci:

- compare adsorption of single BTEX compounds versus multiple BTEX compounds in ultrapure water

- study the effects of ionic strength on single- and multi-solute BTEX adsorption in ultrapure water

- study the differences in adsorption caused by the complex chemistry of produced water

Hence, several different types of batch test methods were developed.

\subsubsection{Single- and Multi-Solute Batch Experiments}

Single and multi-solute batch isotherm experiments were conducted over a range of initial BTEX concentrations. Because the aqueous solubilities of benzene and toluene are higher than all of the other compounds and the octanol-water partitioning coefficients $\left(\mathrm{K}_{\mathrm{ow}}\right)$ are lower (Table 4.11), it was felt that these two compounds would be the least absorbable and future design of treatment columns would have to be based on these solutes. Hence, the competitive effects of the other BTEX compounds on the sorption of benzene and toluene were of primary interest in the multi-solute experiments.

Table 4.11 Octanol/Water Partition Coefficients and Aqueous Solubilities of BTEX Compounds

\begin{tabular}{|c|c|c|}
\hline Compound & $\begin{array}{c}\log \mathbf{K}_{\mathbf{0 w}} \text { at } \mathbf{2 0}^{\circ} \mathbf{C} \\
(\mathbf{L} \text { octanol/L water) }\end{array}$ & $\begin{array}{c}-\log \mathbf{S} \text { at } \mathbf{2 0}^{\circ} \mathbf{C} \\
(\mathbf{m o l} / \mathbf{L})\end{array}$ \\
\hline $\begin{array}{c}\text { Benzene } \\
\text { Toluene }\end{array}$ & 2.13 & 1.66 \\
Ethylbenzene & 3.15 & 2.25 \\
m-Xylene & 3.20 & 2.84 \\
p-Xylene & 3.15 & 2.73 \\
o-Xylene & 3.12 & 2.73 \\
\hline
\end{tabular}

Reference - Schwarzenbach et al. (1993) 
To obtain data throughout several orders of magnitude, the following initial BTEX concentrations were used in the single-solute studies: $0,0.005,0.01,0.1,1,10,40$, and 75 $\mathrm{mg} / \mathrm{L}$. Each single-solute batch study was conducted in either duplicate or triplicate, depending on the test. The remaining batch tests were limited by the number of vials allowed on the headspace autosampler, so duplicates could not be used for some tests. Blanks (vials excluding SMZ but including BTEX) were used to determine the effects of SMZ.

The initial step of these batch tests was to saturate the SMZ with ultrapure water to replicate the physical scenario of a potential treatment column. Ultrapure water is produced by the Milli-Q UV Plus water purification system with reverse osmosis and ultraviolet radiation disinfection. A resin mixture polisher in the Milli-Q system also removed trace organics and inorganics. Preliminary tests showed that centrifuge tubes (Corex, Corning) with PTFE lined screw caps allowed substantial losses to occur. Thus, the same $22 \mathrm{~mL}$ headspace vials used in the preparation of standard curves were used throughout these tests so as to minimize volatilization. All vials were first weighed with their crimp caps and septa loosely capping them. Once the vials were separated into those that would contain SMZ (samples) and those that would not (blanks), the appropriate vials were filled with $2.5 \mathrm{~g}$ of SMZ. Prior to crimping the vials, approximately $20 \mathrm{~mL}$ of ultrapure water were added to each vial. All of the vials were then placed in a $20^{\circ} \mathrm{C}$ room for 24 hours of tumbling at $11 \mathrm{rpm}$.

After 24 hours of mixing, the vials were removed from the tumbler and uncrimped. Each vial was then completely filled with ultrapure water to eliminate headspace in the system, loosely capped, and weighed. After measuring the water temperature, the density and mass of water were used to calculate the volume of water in each vial. Then the correct volumes of stock solution required to obtain the initial concentrations listed above were calculated. These volumes were injected with gastight syringes near the bottom of each vial to minimize opportunity for the BTEX compounds to volatilize and escape the system. Each vial was sealed immediately after injection and once all of the vials were sealed, they were again placed in the $20^{\circ} \mathrm{C}$ room for 24 hours of tumbling at $11 \mathrm{rpm}$. Past studies showed that this period of time would be adequate for equilibration (Neel and Bowman, 1991).

Following tumbling, all vials were centrifuged at $4000 \mathrm{rpm}$ for 30 minutes with a Beckman Model J2-21 centrifuge fitted with a JA-20 rotor at $20^{\circ} \mathrm{C}$. Rubber sleeve adapters (Corning 8446-A0) were required to minimize breakage of the small $22 \mathrm{~mL}$ headspace vials. Nevertheless, a few vials did break during spinning.

Sample extraction was conducted once the vials had been centrifuged. This step was most susceptible to losses due to volatilization because some of the vials had to be unsealed. Those vials that initially contained BTEX concentrations greater than $1.5 \mathrm{mg} / \mathrm{L}$ were diluted to prevent saturation of the GC column. The extent of dilution depended on the initial concentration, but involved either a factor of 10 or a factor of 100 . Diluted samples were prepared by initially adding the appropriate water volume to clean $22 \mathrm{~mL}$ headspace vials, which held a total of $5 \mathrm{~mL}$ of fluid. Then, the proper volume of sample supernatant was extracted and injected into the dilution water. These vials were immediately sealed and stored until all other samples had been transferred to clean vials for analysis. 
Those samples that did not require dilution were directly transferred to clean headspace vials. However, because of the back pressure generated in these vials, it was not possible to extract $5 \mathrm{~mL}$ of sample without venting. Hence, part of the crimp caps on these vials was removed, leaving a small space between the septa and vial lip exposed. A $10 \mathrm{~mL}$ glass barrel syringe was quickly forced into this space and $5 \mathrm{~mL}$ of the fluid in the middle of the vial were extracted. This volume was immediately transferred to clean headspace vials which were then sealed. Contamination with either BTEX or SMZ was an issue during this process. Thus, each syringe was rinsed seven times with ultrapure water prior to reuse. A glass barrel syringe was used in this transfer because large volume gastight syringes required too much time to fill. Throughout the time that the gastight syringe was extracting fluid, volatilization was occurring through the opening created previously. Glass barrel syringes were used to prevent this occurrence.

After all of the samples had been transferred to clean headspace vials for analysis, the internal standard was injected through the septa into each vial. Care was taken not to allow the needle to touch any liquid which could cause contamination of other vials. The vials were then immediately placed on the HSA carousel and analyzed. All of the HSA and GC settings remained the same as for the standard curves that were run immediately prior to the batch test analyses.

The only difference between batch tests conducted with single or multiple solutes was the type of stock solution used for BTEX injection. Stocks containing only one compound were used for the single-solute studies, whereas stocks containing all of the BTEX compounds were injected into vials for multi-solute tests.

\section{Characterization of Losses from Batch Experiments}

The initial concentrations for the batch tests included $0,0.005,0.01,0.1,1.0,10,100$, and $250 \mathrm{mg} / \mathrm{L} \mathrm{BTEX}$. However, results from the blanks used in the study (vials including BTEX but not SMZ) showed that losses between $20-86 \%$ occurred in the vials containing solutions of the last two concentrations listed above. The presence of SMZ changed the volatility characteristics of the compounds so it was not possible to correlate losses from blanks with those in the vials containing SMZ. Hence, the data for the 100 and $250 \mathrm{mg} / \mathrm{L} \mathrm{BTEX}$ vials were not used in the final analysis.

It is likely that most of the losses that occurred for these high BTEX concentrations were during the initial BTEX injection into the headspace vials prior to tumbling. The vials were filled completely with water prior to injection so as to minimize headspace. The volumes of stock solution required to attain the high concentrations were large enough to cause the loss of some solution. Although injections were made into the middle of the vials rather than the top, the loss of solution could have also caused the loss of BTEX compounds. This theory is supported by the lack of substantial losses for the lower concentrations which did not require large volumes of stock solution compared to the $100 \mathrm{mg} / \mathrm{L}$ and $250 \mathrm{mg} / \mathrm{L}$ BTEX samples. Table 4.12 presents the losses that occurred in the blanks for each of the initial BTEX concentrations used in the multi-solute sorption study. 
Table 4.12 BTEX Percent Losses Observed in Multi-Solute Sorption Study in Ultrapure Water

\begin{tabular}{|c|c|c|c|c|c|}
\hline $\begin{array}{c}\text { Initial } \\
\text { Concentration, } \\
\text { mg/L }\end{array}$ & Benzene & Toluene & Ethylbenzene & $\begin{array}{c}\text { m- \& p- } \\
\text { Xylenes }\end{array}$ & $\begin{array}{c}\mathbf{0 -} \\
\text { Xylene }\end{array}$ \\
\hline $\mathbf{0 . 0 0 5}$ & 4 & 7 & 14 & 8 & 13 \\
$\mathbf{0 . 0 1}$ & 7 & 8 & 10 & 7 & 11 \\
$\mathbf{0 . 1}$ & 3 & 4 & 3.2 & 2.7 & 3.6 \\
$\mathbf{1}$ & 18 & 10 & 6 & 6 & 8 \\
$\mathbf{1 0}$ & 7 & 10 & 10 & 10 & 10 \\
$\mathbf{1 0 0}$ & 20 & 41 & 67 & 68 & 65 \\
$\mathbf{2 5 0}$ & 36 & 66 & 86 & 86 & 85 \\
\hline
\end{tabular}

\subsubsection{Ionic Strength Effects Batch Experiments}

The water used in batch tests conducted with solutions of differing salinities included not only ultrapure water, but also moderate and high salinity solutions. As previously stated, produced water salinity can range from $100 \mathrm{ppm}-300,000 \mathrm{ppm}$ with moderate waters falling between 10,000 and $30,000 \mathrm{ppm}$. Solutions containing 30,000 ppm salts and 300,000 ppm were attempted for a single-solute study, but the latter solution exceeded the salt solubility at a $20^{\circ} \mathrm{C}$. Thus, this water was diluted to $231,000 \mathrm{ppm}$. Later multi-solute tests involved the preparation of $100,000 \mathrm{ppm}$ and 200,000 ppm solutions rather than the 231,000 ppm solution.

The salts used in the generation of saline solutions included $\mathrm{NaCl}, \mathrm{CaCl}_{2}, \mathrm{MgSO}_{4}$, and $\mathrm{KCl}$. The specific salts and the percentages of each salt dissolved in solution were determined on the basis of common occurrence in produced waters. The percentages for each salt in solution are reported in Table 4.13.

Table 4.13 Composition of Saline Solutions

\begin{tabular}{|c|c|}
\hline Salt & Percentage in Solution \\
\hline $\mathrm{NaCl}$ & 94 \\
$\mathrm{CaCl}_{2}$ & 5 \\
$\mathrm{MgSO}_{\mathbf{4}}$ & 0.5 \\
$\mathrm{KCl}$ & 0.5 \\
\hline
\end{tabular}

Solutions were prepared with salts that had been dried for 24 hours in an $105^{\circ} \mathrm{C}$ oven. Drying was used to prevent the miscalculation of salt masses due to hydration. Each salt was weighed out and added to $500 \mathrm{~mL}$ of ultrapure water to generate the appropriate salinity. Because such large amounts of salts were added to water, the density of that water was recalculated for use in batch tests. This calculation was conducted through gravimetric analysis of a $50 \mathrm{~mL}$ volumetric flask filled with saline solution. The densities of the $30,000 \mathrm{ppm}, 100,000 \mathrm{ppm}, 200,000 \mathrm{ppm}$, and 231,000 ppm solutions are reported in Table 4.14 .

Once the salt solutions were prepared, they were substituted for ultrapure water during the batch studies. Batch tests were conducted with ultrapure water and multiple saline 
solutions. The vials containing ultrapure water were treated in the same manner as described in the previous section. The vials used for the saline solutions were infused with the appropriate salt solution rather than ultrapure water throughout the procedure. Hence, SMZ saturation as well as dilution occurred with saline solutions.

Table 4.14 Saline Solution Densities
\begin{tabular}{|c|c|}
\hline Solution Salinity & Density \\
\hline ppm & g/mL \\
\hline 30,000 & 1.022 \\
100,000 & 1.084 \\
200,000 & 1.168 \\
231,000 & 1.173 \\
\hline
\end{tabular}

The single-solute study was conducted in saline solutions with benzene concentrations of $0,0.01,0.1,1,10,40$, and $75 \mathrm{mg} / \mathrm{L}$. The losses generated in the blanks used in this study were within acceptable levels for both 30,000 ppm and 231,000 ppm salt solutions. These percent losses are reported in Table 4.15. In contrast to the single-solute study, the blanks used in the multi-solute study exhibited substantial losses for higher BTEX concentrations and salinities. The initial concentrations used in this study were $0,0.015$, 1,10 , and $75 \mathrm{mg} / \mathrm{L}$. Large losses occurred in the blanks for all of the BTEX compounds when the initial BTEX concentration was $75 \mathrm{mg} / \mathrm{L}$. Thus, the samples that contained this same initial BTEX concentration could not be used to generate sorption isotherms. In addition, as salinity increased to $200,000 \mathrm{ppm}$, the losses for all of the BTEX compounds became unacceptable when initial BTEX concentrations were $10 \mathrm{mg} / \mathrm{L}$ or greater. Hence, data generated for BTEX sorption at initial BTEX concentrations of $10 \mathrm{mg} / \mathrm{L}$ or greater could not be used to generate isotherms for the $200,000 \mathrm{ppm}$ salt solution. The percent lost of each BTEX compound in the three salt solutions used in this study are reported in Table 4.16. Because of the losses in the $200,000 \mathrm{ppm}$ salt solution, only the data gathered for the $0,0.015$, and $1 \mathrm{mg} / \mathrm{L}$ initial BTEX concentrations are presented in Chapter 5. These data were not used to generate a sorption isotherm at this salinity. Rather, the distribution coefficients for individual data points were calculated and reported. If these distribution coefficients were similar, they would theoretically describe a single sorption isotherm.

Table 4.15 Benzene Compound Losses in Blanks for Single-Solute Study in Saline Solutions

\begin{tabular}{|c|c|c|}
\hline Initial Concentration (mg/L) & $\begin{array}{c}\text { 30,000 ppm Solution } \\
\text { (\% lost) }\end{array}$ & $\begin{array}{c}\mathbf{2 3 1 , 0 0 0} \text { ppm Solution } \\
\text { (\% lost) }\end{array}$ \\
\hline $\mathbf{0 . 0 1}$ & 6 & 13 \\
$\mathbf{0 . 1}$ & 12 & 13 \\
$\mathbf{1}$ & 2 & 3 \\
$\mathbf{1 0}$ & 5 & 5 \\
$\mathbf{4 0}$ & 3 & 4 \\
$\mathbf{7 5}$ & 2 & 5 \\
\hline
\end{tabular}


Table 4.16 BTEX Compound Losses in Blanks for Multi-Solute Study in Saline Solutions

\begin{tabular}{|c|c|c|c|c|}
\hline Compound & $\begin{array}{c}\text { Initial } \\
\text { Concentration } \\
(\mathbf{m g} / \mathrm{L})\end{array}$ & $\begin{array}{c}30,000 \\
\text { ppm } \\
\text { Solution } \\
\text { (\% lost) } \\
\end{array}$ & $\begin{array}{c}100,000 \\
\text { ppm } \\
\text { Solution } \\
\text { (\% lost) }\end{array}$ & $\begin{array}{c}200,000 \\
\text { ppm } \\
\text { Solution } \\
\text { (\% lost) }\end{array}$ \\
\hline \multirow[t]{4}{*}{ Benzene } & 0.015 & -10 & -10 & -8 \\
\hline & 1 & -2 & -1 & -1 \\
\hline & 10 & -5 & -3 & 14 \\
\hline & 75 & 6 & 22 & 52 \\
\hline \multirow[t]{4}{*}{ Toluene } & 0.015 & -5 & -15 & -10 \\
\hline & 1 & -2 & 0 & 3 \\
\hline & 10 & -3 & -1 & 39 \\
\hline & 75 & 30 & 59 & 85 \\
\hline \multirow[t]{4}{*}{ Ethylbenzene } & 0.015 & 1 & 2 & 14 \\
\hline & 1 & -2 & 1 & 9 \\
\hline & 10 & -1 & 3 & 69 \\
\hline & 75 & 63 & 86 & 97 \\
\hline \multirow[t]{4}{*}{$\begin{array}{l}\text { m- \& p- } \\
\text { Xylenes }\end{array}$} & 0.015 & -1 & 0 & 14 \\
\hline & 1 & -1 & 2 & 13 \\
\hline & 10 & 0 & 5 & 72 \\
\hline & 75 & 64 & 86 & 97 \\
\hline \multirow[t]{4}{*}{ o-Xylene } & 0.015 & 2 & 0 & 8 \\
\hline & 1 & -3 & -1 & 5 \\
\hline & 10 & -4 & 1 & 65 \\
\hline & 75 & 59 & 83 & 96 \\
\hline
\end{tabular}

\subsubsection{Temperature Effect Batch Studies}

Batch isotherms were conducted in $22 \mathrm{~mL}$ headspace vials with crimp caps, and the initial concentrations for the batch isotherm test ranged from 100 to $40,000 \mu \mathrm{g} / \mathrm{L} \mathrm{BTEX}$. The temperature study was prepared in ultrapure water. Teflon-faced butyl rubber septa, vials and caps were weighed prior to use. To each isotherm vial, $2.5 \mathrm{~g} \mathrm{SMZ}$ was added. Blank samples that did not contain SMZ for each concentration were used to quantify the extent of volatilization of BTEX compounds during the experimental process. For each concentration, triplicate samples were prepared. All vials were filled with ultrapure water almost full and crimped shut. All vials were then placed in $4{ }^{\circ} \mathrm{C}, 10^{\circ} \mathrm{C}, 15^{\circ} \mathrm{C}, 20^{\circ} \mathrm{C}, 25$ ${ }^{\circ} \mathrm{C}, 30^{\circ} \mathrm{C}$, or $36^{\circ} \mathrm{C}$ constant temperature rooms for 24 hours and mixed at $11 \mathrm{rpm}$ for the purpose of water saturating the SMZ. The ultrapure water to be used to fill the remaining headspace was stored in the corresponding temperature controlled room for one day. After 24 hours, all vials were removed from the tumbler, uncrimped and completely filled with ultrapure water leaving no headspace, and loosely capped. The vials were then reweighed, so that the mass of water added could be obtained from the 
difference between the final and initial weights and the weight of SMZ. The densities of water at $4{ }^{\circ} \mathrm{C}, 10^{\circ} \mathrm{C}, 15^{\circ} \mathrm{C}, 20^{\circ} \mathrm{C}, 25^{\circ} \mathrm{C}, 30^{\circ} \mathrm{C}$, and $36^{\circ} \mathrm{C}$ were measured to calculate the volume of water in each vial, respectively. Then the required volumes of stock solutions were calculated and injected using gas-tight syringes near the bottom of each vial (minimizing volatilization) to obtain the desired initial concentration of $\operatorname{BTEX}(0,100$, $10000,10000,40000 \mu \mathrm{g} / \mathrm{L}$ ) in each vial. Each vial was sealed immediately after injection to avoid loss of BTEX compounds from solution. All of the vials were then placed in a tumbler $(11 \mathrm{rpm})$ in the corresponding temperature controlled rooms for another 24 hours. Previous studies showed that 24 hours was sufficient time for sorption equilibrium to occur. In fact, for toluene one hour was shown to be sufficient. After tumbling, all vials were centrifuged at $4000 \mathrm{rpm}$ for 30 minutes in a centrifuge equipped with a JA-20 rotor (Beckman Model J2-21). Rubber sleeve adaptors (Corning 8446-A0) were used to avoid breakage of the $22 \mathrm{~mL}$ vials during centrifugation. Even so some vials did break during the centrifuge process.

Five $\mathrm{mL}$ of supernatant containing initial BTEX concentrations of $0,100,1000,10000$ $\mu \mathrm{g} / \mathrm{L}$ to $22 \mathrm{~mL}$ were used for the sample analysis. Due to the backpressure within the vials, it was not possible to extract $5 \mathrm{~mL}$ of supernatant without venting. As a result, the vials were partially opened with only a small space between the septa and vial lip exposed to the atmosphere. For the vials containing the highest initial BTEX concentration $(40,000 \mu \mathrm{g} / \mathrm{L}), 50 \mu \mathrm{L}$ of supernatant was extracted from each vial and added to a $22 \mathrm{~mL}$ headspace vial containing $5 \mathrm{~mL}$ of ultrapure water, yielding a dilution factor of 100. The vials were crimped immediately. Contamination with either SMZ or BTEX could occur in the transferring process, thus, each syringe was rinsed seven times with ultrapure water prior to extraction of the next vial. After all of the samples had been transferred to headspace vials, a $200 \mu \mathrm{L}$ internal standard $(25 \mathrm{mg} / \mathrm{L})$ was injected through the septa into each vial before analysis. Then the vials were immediately placed on the HSA for analysis. Calibration curves were run prior to each batch test and the HSA and $\mathrm{GC}$ were not shut down while waiting for the batch vials to be ready. Results from the blanks used in the study (vials including BTEX but not SMZ) showed that losses did occur but were within acceptable ranges as shown in Table 4.17. Sorption to SMZ affected the amount of BTEX volatilized from solution so it was not possible to correlate losses from blanks with those vials containing SMZ. 
Table 4.17 BTEX Compound Losses in Batch Temperature Tests

\begin{tabular}{|c|c|c|c|c|c|c|c|}
\hline Compound & $\begin{array}{l}\text { Initial } \\
\text { Concentration } \\
(\mu \mathrm{g} / \mathrm{L})\end{array}$ & $\begin{array}{l}\text { Batch } \\
\text { Test } \\
\text { at } \\
4^{\circ} \mathrm{C} \\
(\%) \\
\end{array}$ & $\begin{array}{l}\text { Batch } \\
\text { Test } \\
\text { at } \\
10^{\circ} \mathrm{C} \\
(\%)\end{array}$ & $\begin{array}{l}\text { Batch } \\
\text { Test } \\
\text { at } \\
15^{\circ} \mathrm{C} \\
(\%)\end{array}$ & $\begin{array}{l}\text { Batch } \\
\text { Test } \\
\text { at } \\
20^{\circ} \mathrm{C} \\
(\%)\end{array}$ & $\begin{array}{l}\text { Batch } \\
\text { Test } \\
\text { at } \\
25^{\circ} \mathrm{C} \\
(\%)\end{array}$ & $\begin{array}{l}\text { Batch } \\
\text { Test } \\
\text { at } \\
36^{\circ} \mathrm{C} \\
(\%)\end{array}$ \\
\hline \multirow[t]{4}{*}{ Benzene } & 100 & 1 & -1 & -2 & 2 & 3 & 4 \\
\hline & 1000 & 1 & 1 & 4 & 1 & 2 & -1 \\
\hline & 10000 & -4 & -7 & -11 & 0 & -7 & -7 \\
\hline & 40000 & 1 & 1 & 0 & 7 & 7 & -2 \\
\hline \multirow[t]{4}{*}{ Toluene } & 100 & 1 & -1 & -2 & 1 & 4 & 5 \\
\hline & 1000 & 0 & 1 & 4 & 0 & 2 & 0 \\
\hline & 10000 & -4 & -8 & -5 & 1 & -8 & -7 \\
\hline & 40000 & 2 & 3 & 1 & 2 & 2 & 0 \\
\hline \multirow[t]{4}{*}{ Ethylbenzene } & 100 & 1 & -1 & -2 & 2 & 5 & 6 \\
\hline & 1000 & 0 & 1 & 5 & 0 & 2 & 0 \\
\hline & 10000 & -4 & -8 & 0 & 3 & -9 & -6 \\
\hline & 40000 & 4 & 5 & 6 & 2 & 0 & 3 \\
\hline \multirow[t]{4}{*}{ m,p-Xylene } & 100 & 1 & -1 & -2 & 2 & 5 & 6 \\
\hline & 1000 & -1 & 1 & 5 & 1 & 2 & 1 \\
\hline & 10000 & -4 & -7 & 0 & 3 & -8 & -5 \\
\hline & 40000 & 4 & 5 & 7 & 8 & 13 & 3 \\
\hline \multirow[t]{4}{*}{ o-Xylene } & 100 & 0 & -1 & -2 & 2 & 4 & 5 \\
\hline & 1000 & 0 & 0 & 4 & 1 & 2 & 0 \\
\hline & 10000 & -4 & -7 & -2 & 3 & -8 & -6 \\
\hline & 40000 & 3 & 4 & -5 & 1 & 1 & 2 \\
\hline
\end{tabular}

\subsubsection{Batch Studies with Produced Water}

Rather than testing the removal of BTEX compounds already in produced water, researchers used the produced water as a matrix. The complex chemistry of this wastewater was assumed to change the adsorption behavior of BTEX onto SMZ. Therefore, additional amounts of BTEX stock solutions were injected into the produced water to magnify the effects of produced water chemistry. A single batch study was conducted with produced water that was spiked with BTEX concentrations of $0,0.01$, $0.1,1$, and $10 \mathrm{mg} / \mathrm{L}$. One blank and two samples were included for each of these concentrations. In order to keep the adsorption time for both the initial and injected BTEX the same, saturation of the SMZ with produced water was not attempted. Rather, previously weighed blank vials containing no SMZ and sample vials containing $2.5 \mathrm{~g}$ of SMZ were completely filled with produced water and loosely capped immediately prior to weighing. Transfer of the produced water from the VOA vials to the headspace vials was conducted with a $30 \mathrm{~mL}$ glass-barrel syringe that was rinsed seven times with ultrapure water between subsequent transfers. The VOA vials were vented during water extraction through the insertion of a needle into the septa. This needle was removed after each extraction process. 
Evaluation of the produced water density and the total mass of the sample in the vials allowed the calculation of the volume of water in each vial. These volumes were calculated through a spreadsheet immediately after each vial was weighed. The spreadsheet was set up to allow the calculation of the volume of BTEX stock solution required to obtain the desired additional BTEX concentration in each vial. The calculated volume of stock solution was then transferred into the headspace vials by removing the cap and injecting the solution into the middle of the vial. Each vial was crimp sealed immediately after injection. Every vial was prepared in this manner, and tumbling and centrifugation for these vials were conducted in the same way as described for the other types of batch tests.

Analysis for this batch test posed a few problems because of the unknown initial BTEX concentration already in the produced water prior to spiking due to losses during sample preparation. It is probable that most of these losses occurred during weighing and injection of BTEX because the vials had to be left unsealed until injection was completed. This assertion is supported by the presence of greater BTEX concentrations in the produced water blanks not injected with additional BTEX than in the blanks injected with small volumes of additional BTEX. The blanks that did not require additional BTEX were immediately sealed after filling, but the vials requiring injections had to remain uncovered for a time during injection.

Due to these losses, an assumption for baseline BTEX concentrations had to be made to proceed with data analysis and development of isotherms. The assumption agreed upon was that the blanks for each additional BTEX concentration actually represented the baseline concentration for that set of vials. For example, it was assumed that the set of vials that had an additional $1 \mathrm{mg} / \mathrm{L} \mathrm{BTEX}$ injected into them contained a baseline BTEX concentration from the produced water equal to the concentrations found in the vial that had no SMZ but was also injected with the additional compounds. This assumption did not allow the determination of losses for the blanks, but prior batch tests showed that the methods used had minimized these losses in the past. Hence, it was also assumed that any losses that occurred after the injection were negligible because the same methods were used for sample tumbling, centrifugation, and transfer into headspace vials for analysis.

\subsubsection{Statistical Analyses for Batch Experiments}

Hypothesis testing was used to determine whether various isotherms were statistically parallel. By proving the parallelism of these isotherms, it can be said they are statistically equivalent because all of these isotherms were forced to pass through the origin $\left(\mathrm{q}_{\mathrm{e}}=0\right.$ and $\mathrm{C}_{\mathrm{e}}=0$ ) during analysis. The hypothesis testing consisted of proving or disproving a null hypothesis by testing all other possible hypotheses. The null hypothesis for all comparisons was that the isotherms being compared were parallel. By proving that the slopes of the isotherms were not greater than, less than, or unequal to each other, the null hypothesis was proven. A full explanation of the method can be found in Kleinbaum et al. (1988), but a synopsis is provided below.

The null hypothesis $\left(\mathrm{H}_{\mathrm{o}}\right)$ is symbolized as:

$$
H_{o}: \beta_{1 A}=\beta_{1 B}
$$


where $\beta_{1 \mathrm{~A}}$ is the slope of isotherm $A$ and $\beta_{1 \mathrm{~B}}$ is the slope of isotherm $B$. The alternative hypotheses that can be tested to disprove the null hypothesis $\left(\mathrm{H}_{\mathrm{A}}\right)$ are:

$$
H_{A}:\left\{\begin{array}{l}
\left.\beta_{1 A}>\beta_{1 B} \text { (one sided }\right) \\
\left.\beta_{1 A}<\beta_{1 B} \text { (one sided }\right) \\
\left.\beta_{1 A} \neq \beta_{1 B} \text { (two sided }\right)
\end{array}\right.
$$

The test statistic (T) used to test each of these alternative hypotheses is defined as:

$$
T=\frac{\beta_{1 A}-\beta_{1 B}}{S_{\beta_{1 A}-\beta_{1 B}}}
$$

where $S_{\beta I A-\beta 1 B}$ is an approximation of the standard deviation of the estimated difference between the slopes for isotherms A and B. This estimated standard deviation is the square root of the sample variance which is defined as:

$$
S_{\beta_{1 A}-\beta_{1 B}}^{2}=S_{P, Y \mid X}^{2}\left[\frac{1}{\left(n_{A}-1\right) S_{X_{A}}^{2}}+\frac{1}{\left(n_{B}-1\right) S_{X_{B}}^{2}}\right]
$$

where:

$S_{P, Y \mid X}^{2}=$ a pooled estimate of $\sigma^{2}$ based on residual mean-square errors for the slopes of isotherms A and B

$n_{i} \quad=$ number of samples used to generate isotherms $\mathrm{i}$

$S_{X_{A}}^{2}=$ variance of $\mathrm{x}$-values used to generate isotherm A

$S_{X_{B}}^{2}=$ variance of $\mathrm{X}$-values used to generate isotherm B

The value for $S_{P, Y \mid X}^{2}$ can be found through:

$$
S_{P, Y \mid X}^{2}=\frac{\left(n_{A}-2\right) S_{Y \mid X_{A}}^{2}+\left(n_{B}-2\right) S_{Y \mid X_{B}}^{2}}{n_{A}+n_{B}-4}
$$

where $S_{Y \mid X_{A}}^{2}$ and $S_{Y \mid X_{B}}^{2}$ are the residual mean-square errors for isotherms A and B. Once all of these values are calculated, the test statistic (T) can be compared with Student's $t$ with $n_{A}+n_{B}-4$ degrees of freedom and a significance level of $\alpha$. Whether the one sided Student's $t$ value or the two sided value is used depends on the hypothesis being tested. The critical regions for the alternative hypotheses are:

$$
\left\{\begin{array}{c}
T \geq t_{n_{A}+n_{B}-4,1-\alpha} \text { for } \mathrm{H}_{\mathrm{A}}: \beta_{1 A}>\beta_{1 B} \text { (one sided) } \\
T \leq-t_{n_{A}+n_{B}-4,1-\alpha} \text { for } \mathrm{H}_{\mathrm{A}}: \beta_{1 A}<\beta_{1 B} \text { (one sided) } \\
|T|>t_{n_{A}+n_{B}-4,1-\alpha} \text { for } \mathrm{H}_{\mathrm{A}}: \beta_{1 A} \neq \beta_{1 B} \text { (two sided) }
\end{array}\right.
$$


If any of these hypotheses is proven, the null hypothesis is invalid and the slopes for the isotherms are not statistically equal. If none of the alternative hypotheses is proven, the null hypothesis remains valid and the isotherms are found to be parallel.

These hypotheses were tested for isotherms generated in the single-solute and multisolute studies conducted in ultrapure water to determine whether competitive effects significantly changed the distribution coefficients of benzene and toluene. The singleand multi-solute isotherms generated in the salinity studies were also compared to ensure that the presence of salts did not allow competitive effects between BTEX compounds to become significant. The isotherms generated in the multi-solute studies conducted in both ultrapure water and salt solutions were compared to demonstrate the effects of salinity on BTEX sorption. Lastly, the BTEX sorption isotherms found for produced water were compared to both the ultrapure and salt solution studies to determine whether these isotherms were changed by the chemistry of the produced water.

The confidence level at which these hypothesis tests were performed was determined through a comparison of replicate isotherms generated for benzene in ultrapure water. These isotherms represent the variation that can occur when replication of isotherms is attempted. The largest confidence level at which the null hypothesis was valid for these isotherms was $99.95 \%$. Hence, all other comparisons were conducted with this confidence level.

\subsection{Column Adsorption Studies}

In order to design an RSSCT, several field-scale design parameters must be specified. Therefore, a number of assumptions were made regarding the operation of the pilot scale testing to be conducted for the field tests. First, the volume of water to be treated each day was assumed to be 3,000 liters (approximately $20 \mathrm{bbl} /$ day). A hydraulic loading rate of $2 \mathrm{gpm} / \mathrm{ft}^{2}$ was assumed for the pilot scale column. A porosity of 0.6 and bulk density of $1 \mathrm{~g} / \mathrm{cm}^{3}$ was assumed based on previous studies by Bowman et. al (2001). One day of service time was estimated. The adsorption capacity of $14 \times 40 \mathrm{SMZ}$ for benzene was estimated to be $8.24 \mu \mathrm{g} / \mathrm{g}$. Benzene was used for the design basis, because it was the least hydrophobic BTEX compound and the compound of greatest health concern at low concentrations.

The service time, flow rate and influent concentration $\left(\mathrm{a} \mathrm{C}_{\text {in }}\right.$ of $835 \mu \mathrm{g} / \mathrm{L}$ was assumed) determined the mass of contaminant (benzene) passing through the column during that period. The mass of SMZ required to treat the contaminant was obtained by dividing the mass of contaminant passing through the column by the adsorption capacity for benzene. The column volume was obtained by dividing the mass of SMZ required by the bulk density of packed SMZ. The diameter of the column was derived from the column sectional area, which was obtained by dividing the flow rate $\mathrm{Q}$ by the hydraulic loading rate. The length of the column was obtained by dividing the volume of the column by the column cross sectional area. The pilot-scale column dimensions were determined assuming that the produced water could contain significant salinity. Thus, an adsorption capacity of $32.96 \mathrm{ug}$ of benzene/g of SMZ was used for the initial design. The assumed dimensions of the prospective pilot scale column and the lab scale column parameters are reported in Tables 4.18 and 4.19 respectively. It was expected that $14 \times 40$ 
mesh size of SMZ would be used in the pilot scale column test. The particle diameter corresponding to $14 \times 40$ mesh size is $2.4-1.4 \mathrm{~mm}$ with an average diameter of $1.9 \mathrm{~mm}$. Scaling using this particle size and the RSSCT design equations yields a particle size for the laboratory scale columns corresponding to 80x100 mesh size.

Table 4.18 Prospective Pilot Scale Column Dimensions

\begin{tabular}{|l|l|l|l|l|l|l|l|l|}
\hline $\begin{array}{l}\text { Flowrate } \\
(\mathrm{L} / \text { day })\end{array}$ & $\begin{array}{l}\mathrm{q}_{\mathrm{e}} \\
(\mu \mathrm{g} / \mathrm{g})\end{array}$ & $\begin{array}{l}\text { Bulk } \\
\text { Density } \\
\left(\mathrm{g} / \mathrm{cm}^{3}\right)\end{array}$ & $\begin{array}{l}\text { Service } \\
\text { life } \\
(\text { days })\end{array}$ & $\begin{array}{l}\text { Benzene } \\
\text { adsorbed } \\
(\mathrm{mg})\end{array}$ & $\begin{array}{l}\text { Column } \\
\text { Volume } \\
(\mathrm{L})\end{array}$ & $\begin{array}{l}\text { Column } \\
\text { Diameter } \\
(\mathrm{cm})\end{array}$ & $\begin{array}{l}\text { lolumn } \\
\text { Length } \\
(\mathrm{cm})\end{array}$ & $\begin{array}{l}\text { Hydraulic } \\
\text { loading } \\
\left(\mathrm{gpm} / \mathrm{ft}^{2}\right)\end{array}$ \\
\hline 3000 & 32.96 & 1 & 1 & 2505 & 76 & 18 & 297 & 2 \\
\hline
\end{tabular}

Table 4.19 Dimensions of the Lab Scale Column

\begin{tabular}{|l|l|}
\hline Internal Diameter (ID) & $0.80 \mathrm{~cm}$ \\
\hline Length & $27 \mathrm{~cm}$ \\
\hline Volume & $50.3 \mathrm{~cm} 3$ \\
\hline Cross-Sectional Area & $2.01 \mathrm{~cm} 2$ \\
\hline Volumetric Flux & $22.5 \mathrm{~mL} / \mathrm{min}$ \\
\hline Porosity Estimate & 0.6 \\
\hline Hydraulic loading rate & $10.98 \mathrm{gmp} / \mathrm{ft} 2$ \\
\hline Flowrate & $22.5 \mathrm{~mL} / \mathrm{min}$ \\
\hline
\end{tabular}

Lab-scale column studies were conducted to verify the batch adsorption capacities determined previously and to evaluate how accurately we can predict BTEX breakthrough in the SMZ columns. This data was used for the design of the pilot-scale column-testing phase of this project. The approach was to collect and analyze data from laboratory scale columns packed with SMZ. In each experiment, a Tedlar bag was filled with the influent water containing BTEX. Flow was initiated through the column and influent and effluent samples were collected as a function of time. The influent concentration was chosen based on analysis of field produced water samples. The influent concentrations of BTEX were sampled less frequently than the effluent concentrations because preliminary results suggested that the influent concentration was constant over the course of the experiment. Effluent BTEX concentration data was used to develop breakthrough curves for each compound. In some cases, these data were compared to predictions derived from batch experiments, and in other cases the data was used to determine sorption capacities for the BTEX compounds.

\section{$\underline{\text { Breakthrough Profile Analysis }}$}

The CXTFIT Code for Estimating Transport Parameters from Laboratory or Field Tracer Experiments Version 2.0 (US Salinity Laboratory, Toride et al, 1995) was used to calibrate and predict breakthrough profiles from the experiments. Specifically, CXTFIT2 was used to solve the direct problem of using transport parameters and batch isotherm parameters to predict contaminant (BTEX) breakthrough curves, and to solve the inverse problem to estimate distribution coefficients based on column effluent data. For the direct problem, CXTFIT2 predicts solute concentrations at a given location (column 
outlet) as a function of time. For the inverse problem, CXTFIT2 uses a nonlinear leastsquares algorithm to optimize unknown parameters by best fitting the observed data points with predicted ones.

The assumptions inherent in the model used in CXTFIT2 were a constant flux or velocity, homogeneous packing of sorbent in the columns (with homogeneous properties of the medium, including porosity), and saturated conditions. No production or decay of contaminant was assumed. The boundary condition at the column inlet was assumed to be a constant concentration input of BTEX. Inputs included boundary and initial values conditions, column length (since data was collected at the column outlet), and average linear velocity (which is dependent on porosity). The initial condition for the column inlet is $\mathrm{C}(0, \mathrm{~T})=\mathrm{C}_{0}(\mathrm{~T})$. The top (column outlet) boundary condition is a flux-averaged concentration $(\mathrm{MODC}=2)$. The modeling approach used in the initial studies assumed local linear local equilibrium sorption using a retardation factor as shown in

where,

$$
\mathrm{R}=1+\left(\rho_{\mathrm{b}} * \mathrm{~K}_{\mathrm{d}} / \theta\right)
$$

$\mathrm{R}$ is the retardation factor, which quantifies retardation of reactive solute compared to a non-reactive one,

$\theta$ is the porosity or volumetric moisture content,

$\rho_{\mathrm{b}}$ is the bulk density $\left(\mathrm{g} / \mathrm{cm}^{3}\right)$, and

$\mathrm{K}_{\mathrm{d}}$ is the linear sorption distribution coefficient,

Hydrodynamic dispersion was not measured in the initial experiments; however, it was estimated by (EPA, 1986):

$$
\mathrm{D}=0.1 \mathrm{X}_{\max } \mathrm{V}
$$

where $\mathrm{v}$ is the linear velocity through the column, $\mathrm{D}$ is the hydrodynamic dispersion coefficient, and $\mathrm{X}_{\max }$ is the column length.

In the direct problem, the projected time and flux averaged concentration were derived for all BTEX species based on the $\mathrm{K}_{\mathrm{d}}$ values from batch studies. Thus, the model results are truly predictive in this case. In the inverse problem, the retardation factor, and hence $\mathrm{K}_{\mathrm{d}}$ values, were derived for all BTEX species based on the collected breakthrough data from the column study. In this case, the breakthrough data served to calibrate the model.

\subsubsection{Single- and Multi-Solute Column Experiments}

A schematic of the column set up is shown in Figure 4.2. The entire column apparatus (including end fitting, ferrule, screens, and three-way valves) was weighed while empty. The column was then packed with SMZ ( $80 \times 100$ mesh) by adding small amounts of SMZ to the column which was attached onto a shaking rack with unbalanced motors. This step was repeated until the column was completely filled with SMZ. At least four hours was needed to ensure good packing. Both ends of the column were sealed with the end fittings and ferrules and the column was weighed again to determine the amount of dry SMZ within the column. The weights were used to calculate a dry bulk density 
which is equal to the mass of SMZ per filled volume of the column. Empty and filled column, endfitting weights and other important parameters are provided in Table 4.20.

The column was secured vertically using a ring stand with the inlet at the bottom and the outlet at the top (Figure 4.2). Stainless steel tubing (1/8") was secured to both ends of the column via 3-way Swagelok stainless steel valves. The influent tubing was attached to a high-pressure pump to ensure a constant flow rate through the column. The SMZfilled column was saturated with ultrapure water (that had been vacuum-filtered to remove any air bubbles) at a flow rate of $2 \mathrm{~mL} \mathrm{~min}^{-1}$ for approximately $24 \mathrm{hr}$. Once the column was saturated, it was sealed by closing the 3-way valves, and the column was weighed once more to determine the column pore volume.

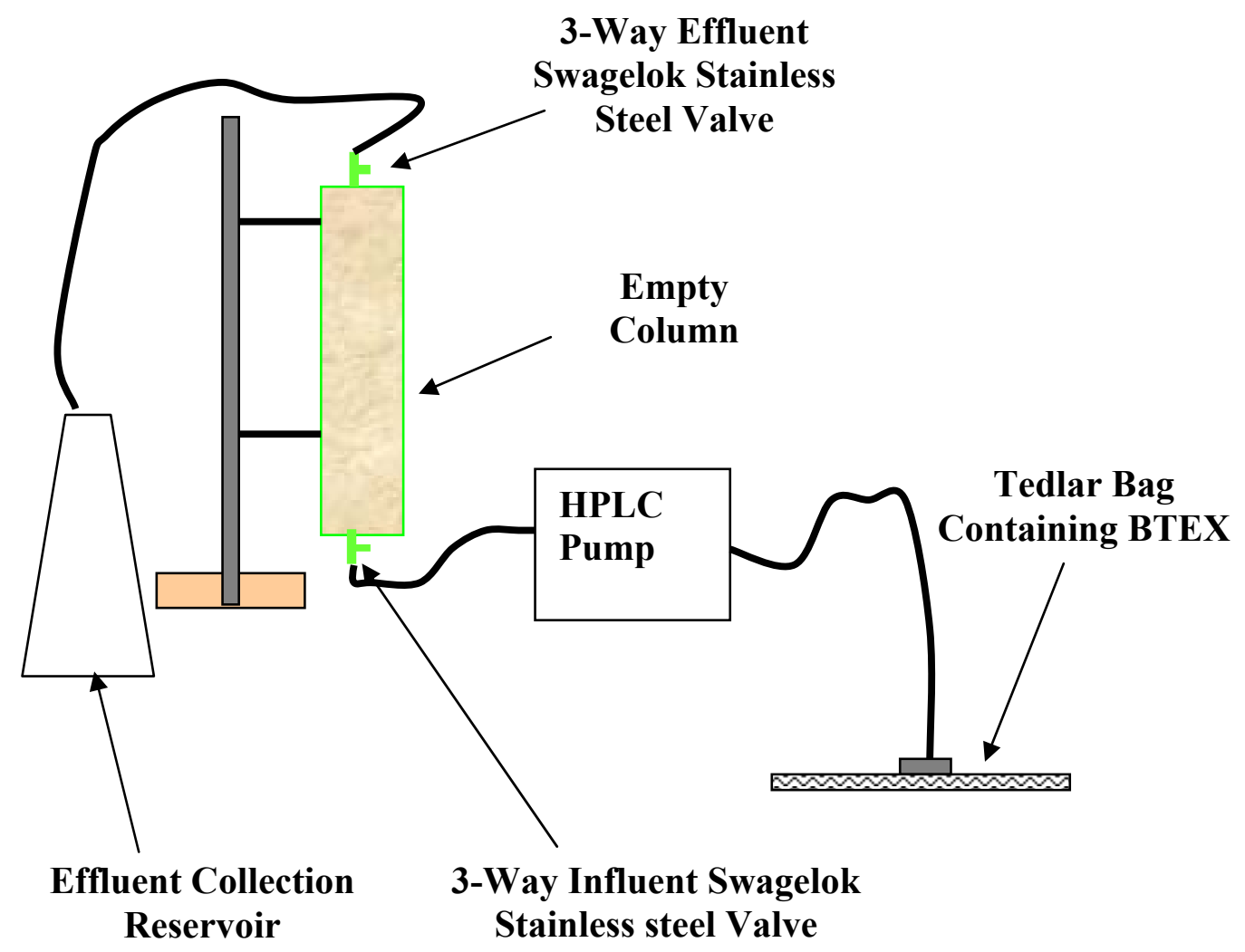

Figure 4.2 Diagram of Laboratory Column Adsorption System

Table 4.20 Lab-Scale Column Parameters

\begin{tabular}{|l|l|l|l|l|l|l|}
\hline $\begin{array}{l}\text { Column } \\
\text { No. }\end{array}$ & $\begin{array}{l}\text { Empty } \\
\text { Mass }(\mathrm{g})\end{array}$ & $\begin{array}{l}\text { Filled } \\
\text { Mass }(\mathrm{g})\end{array}$ & $\begin{array}{l}\text { Endfitting } \\
\text { Mass }(\mathrm{g})\end{array}$ & $\begin{array}{l}\text { Water } \\
(\mathrm{g})\end{array}$ & $\begin{array}{l}\text { Bulk } \\
\text { Density } \\
\left(\mathrm{g} / \mathrm{cm}^{3}\right)\end{array}$ & Porosity \\
\hline $1^{*}$ & 59.64 & 73.09 & 30.25 & 6.96 & 0.99 & 0.52 \\
\hline $2 * *$ & 59.64 & 73.22 & 30.25 & 6.85 & 1.0 & 0.56 \\
\hline $3 * * *$ & 59.64 & 73.52 & 30.25 & 6.80 & 1.067 & 0.50 \\
\hline
\end{tabular}

*Column 1 was conducted with ultrapure water background.

** Column 2 was conducted with 100,000 saline water

**Column 3 was conducted with produced water from the Wamsutter site. 
The influent BTEX solution was prepared in a collapsible 5-L Tedlar ${ }^{\circledR}$ Gas Sampling Bag (SKC, item no. 231-08A) with a barbed on/off valve. First, the volume of solution was estimated and injected into the Tedlar bag. Approximately 2 liters of solution was injected into the bag through the on/off valve using a jumbo gas-tight glass syringe. Any air bubbles in the bag were extracted through the on/off valve after filling up the reservoir with ultrapure water. Then $200 \mu \mathrm{L}$ of BTEX stock solution $\left(10 \mathrm{~g} \mathrm{~L}^{-1}\right)$ were transferred into the bag through the on/off valve using a gas-tight glass syringe yielding a $1000 \mu \mathrm{g} / \mathrm{L}$ concentration of BTEX. The solution was well mixed using manual agitation.

The on/off valve was then connected to the HPLC pump using $1 / 8$ " stainless steel tubing. Another piece of stainless steel tubing(1/8") connected the pump to the three-way valve at the bottom of the column. Teflon tubing was attached to the three-way valve at the top of the column with the other end staying in a 2-L glass flask as an effluent collection container.

The BTEX solution was introduced into the column at a flow rate of $22 \mathrm{ml} \mathrm{min}^{-1}$. Effluent samples $(5 \mathrm{~mL})$ were taken every 2 to 3 minutes by attaching 10 -ml gas-tight glass syringes (Hamilton), which was replaced by a $5-\mathrm{mL}$ non gas-tight glass syringe to the outlet of the three-way valve at the end of the column. Samples were collected until the SMZ column was exhausted. Influent samples $(5 \mathrm{~mL})$ were taken every 10 or 15 minutes to ensure that the influent concentration was constant during each run. The samples were immediately transferred to glass headspace free vials and sealed with aluminum crimp caps (fitted with Teflon-faced Butyl rubber septa). They were then analyzed using gas chromatography after all samples were collected

\subsubsection{Column Study in Saline Water Background}

The salts (and the percentage of each salt) used in the preparation of the 100,000 ppm TDS salt solution used in this research were the same as those used in the batch experiments. All salts were dried for 24 hours in a $105^{\circ} \mathrm{C}$ oven to remove any moisture before use. Each salt was weighed accordingly and added to ultrapure water to prepare the $100,000 \mathrm{ppm}$ saline water. The target concentration for the saline water column test was approximately $1000 \mu \mathrm{g} / \mathrm{L}$. The same procedure was followed as described in 4.4.1 for the column operation.

\subsubsection{Column Study in Produced Water Background}

The influent reservoir was filled with produced water from a ZHE filled with produced water obtained from the Wamsutter, WY site by Crystal Solutions, LLC and stored at $4 \mathrm{C}$ in our laboratory. The samples were allowed to equilibrate in the influent reservoir for one day to allow the temperature to be as close to $20^{\circ} \mathrm{C}$ before running the column. The column operation followed the procedure described in Sections 4.4.1. 


\subsubsection{Regeneration Tests}

The regeneration tests were conducted at New Mexico Tech using the same approach used in the experiments at the University of Austin for the adsorption phase. A glass column 270-mm long with a 4-mm radius was selected for the laboratory tests and was packed with SMZ (80x100 mesh). The column was purged with $\mathrm{CO}_{2}$ for $24 \mathrm{hr}$ in order to flush out any air remaining in the column, followed by saturation with purified water (reverse osmosis).

The influent BTEX solution (with a concentration of $16 \mathrm{mg} \mathrm{L}^{-1}$ for each of the six compounds) was prepared in a collapsible 10-L (12" x 19”) Tedlar® Gas Sampling Bag (Alltech) with a barbed on/off valve. The BTEX solution was introduced into the saturated column at a flow rate of $1.19 \mathrm{~cm} \mathrm{~min}^{-1}$. Influent and effluent samples were taken to monitor the BTEX concentrations flowing into and out of the column. Flow was terminated when the BTEX effluent concentrations were equal to the influent concentrations; the column was then sealed prior to regeneration.

The spent SMZ was regenerated by air-sparging as shown in the schematic in Figure 4.3. A 65-mm, single-float flowmeter (Cole Parmer) and compressed gas tank (air) were attached to the influent end of the column for the regeneration step. The compressed air tank was set to 20 psi and the flowmeter was used to control flowrate through the column. Flowrate was set at $2.3 \mathrm{~mL} \mathrm{~min}^{-1}$. Using a $1.0-\mathrm{mL}$ glass gas-tight syringe, samples periodically were taken by withdrawing gas through a sampling port at the effluent end of the column. The air-sparging experiment was continued until the BTEX mass coming off of the column was negligible.

The regenerated $\mathrm{SMZ}$ was again saturated with the aqueous BTEX solution. The input BTEX concentration and flow rate were the same as for the original saturation. However, for this experiment the SMZ-filled column was not purged with $\mathrm{CO}_{2}$ or saturated with pure water prior to introducing the BTEX solution.

Aqueous BTEX concentrations from the laboratory columns were measured using a Hewlett-Packard (HP) Model 7694 headspace sampler attached to a HP Model 5890A gas chromatograph (GC) with a $30 \mathrm{~m}$ 0.53-mm ID Megabore ${ }^{\circledR}$ high resolution column (J\&W, model GS-Q) and flame ionization detector (FID) with helium as the carrier gas. The GC was calibrated during each run with five BTEX standards of varying concentrations over the linear response range. $\mathrm{p}$-Xylene and $\mathrm{m}$-xylene were not resolved by this method and were treated as a single compound. 


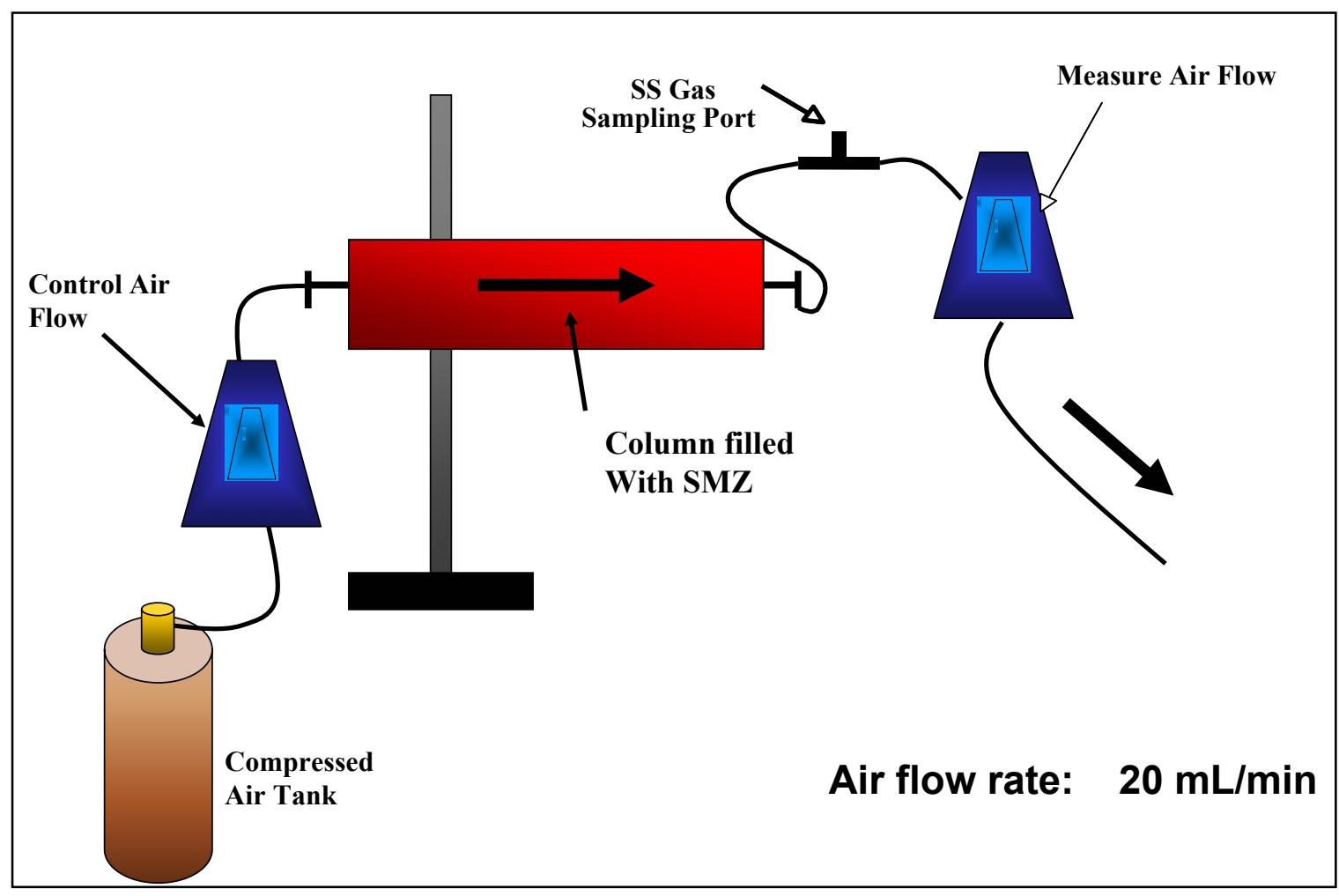

Figure 4.3 Diagram of Laboratory Column Regeneration System

\subsection{Field Tests}

\subsubsection{Site Selection}

As stated above, four possible sites/sources of produced water were evaluated. Based on the characterization studies and the availability of the site, the treatment facility of BC Technologies in Wamsutter, Wyoming was selected. The salinity, BTEX concentrations, source quantity, and reproducibility of source volumes and chemistry were all appropriate for field tests.

\subsubsection{System Design}

The columns selected for use in the field trials were provided by a local Culligan distributor in Austin, TX. Originally designed for use in ion exchange systems, the columns were readily adapted to the needs of this study by substituting the ion exchange resin with SMZ. The columns were constructed from fiberglass and PVC and were designed to operate with the influent stream dispersing at the top of the resin and flowing down to the bottom. Inside the column, the influent port contained a coarse filter to prevent large debris from fouling the column. At the bottom of the column, a perforated collector plate funneled the water up a 1" PVC pipe through the middle of the column to the effluent port.

Two of these columns were used in the field. The first column was 14 " in diameter and 48 " in height, while the second had a diameter of 12 " and was 44 " in height. The 
available volumes of these columns were approximately $3.6 \mathrm{ft}^{3}$ and $2.4 \mathrm{ft}^{3}$ respectively. The 14" column was completely filled with $192.0 \mathrm{lbs}$. of $14 \times 40$ mesh SMZ, while the 12" column contained approximately 4 " of headspace and held $132.25 \mathrm{lbs}$ of 14x40 SMZ.

\subsubsection{Field Experiments}

The site chosen for the field study is operated by Crystal Solutions, LLC., and is located in an oil producing region just outside of Wamsutter, WY. The facility is set up to receive produced water from the region by tanker truck. The water is unloaded from the trucks into an oil/water separation tank. Overflow from this tank flows into a second separation tank. Both tanks are identical, and measure approximately 20 ' in height and 10 ' in diameter. Oil is sent into an oil condensate tank for later processing. As the second separation tank fills with water, it flows into a lined separation pond. From the separation pond, water is pumped through a series of lined evaporation ponds.

The field columns were connected to the second separation tank at a 4" valve located about 2' from the bottom. This connection point provided approximately 15' of head, driving water flow through the SMZ system. Just downstream of the tank valve was a strainer to prevent large debris from entering the system. The 4" line was reduced to a 1" PVC pipe that ran to a flow meter, sample port, and influent port of the column. The effluent pipe from the column consisted entirely of 1" PVC, contained a sample port for effluent sample collection, and led into the lined separation pond. Regeneration was attempted in the field using a portable air compressor provided by the field operators. The same setup was used, except the influent water connection was replaced with an air connection, and an air flow meter was used. The effluent line remained in place until the column was drained. The effluent pipe was then replaced with tygon tubing so air samples could be collected easily.

Influent and effluent water samples were collected from the sample ports periodically. A portable photoionization detector (PID) was used to estimate total concentrations of volatiles in water and air during produced water treatment and SMZ regeneration. Air samples were collected during regeneration by placing the tygon tubing of the effluent air into the bottom of the vial and filling until all the original air in the vial had been displaced. The vial was then quickly closed and sealed as the tygon tubing was being removed.

The 14" column was the first column connected and run from the separation tank (Figure 4.4). This column was operated for about 46 hours with a few minutes downtime to repair a minor leak. During the operation, the flow rate averaged $25 \mathrm{gph}$ but was dropping throughout the course of the run to $17.5 \mathrm{gph}$. It is believed this drop in flow rate was caused by clogging of the SMZ pores inside the column by particles in the water. BTEX concentrations were constant throughout the trial at levels similar to those of the previous analysis.

The 12" column was put into service next and was in operation for approximately 45 hours, with 1 hour of stoppage for repairs. The average flow rate during this run was 19 gph. However, once again there was a drop in flow rate as the trial progressed, reaching as low as $12.5 \mathrm{gph}$. A large increase in BTEX influent concentrations occurred during the last 36 hours of operation, when BTEX concentrations jumped to the highest concentrations observed during the testing. Toward the end of the run with the 12 " 
column, most BTEX concentrations had fallen from these peaks, but were still high. It is believed that these elevated measurements were caused by the discharge of one or more trucks carrying produced water with these high BTEX levels into the separation tanks.

Regeneration was intended to occur for approximately 12 hours, or until the PID gave insignificant readings from the effluent air. However, due to compressor failure, regeneration had to take place sporadically with active regeneration taking place for about 8.5 hours at air flow rates between 3.0 and $3.5 \mathrm{scfm}$.

Although the regeneration was not complete, the 14-inch column was run a second time for nearly 48 hours, with an average flow rate of $20 \mathrm{gph}$. Once again, flow rate dropped with time, reaching as low as $16.5 \mathrm{gph}$. The BTEX concentrations were consistent during this operation, at levels slightly higher than the 14-inch column trial with virgin SMZ. The concentrations averaged: benzene- $20 \mathrm{mg} / \mathrm{L}$, toluene- $40 \mathrm{mg} / \mathrm{L}$, ethylbenzene- $30 \mathrm{mg} / \mathrm{L}, \mathrm{m}-\&$ p-xylene- $30 \mathrm{mg} / \mathrm{L}$, and o-xylene-5 mg/L.

Aqueous BTEX concentrations from the field columns were measured using a Tekmar 7000 headspace sampler attached to an HP 5890 GC equipped with a $30 \mathrm{~m} 0.53-\mathrm{mm}$ ID Restek capillary column (RTX-624) and FID. Nitrogen was an auxiliary gas, and helium was the carrier gas.
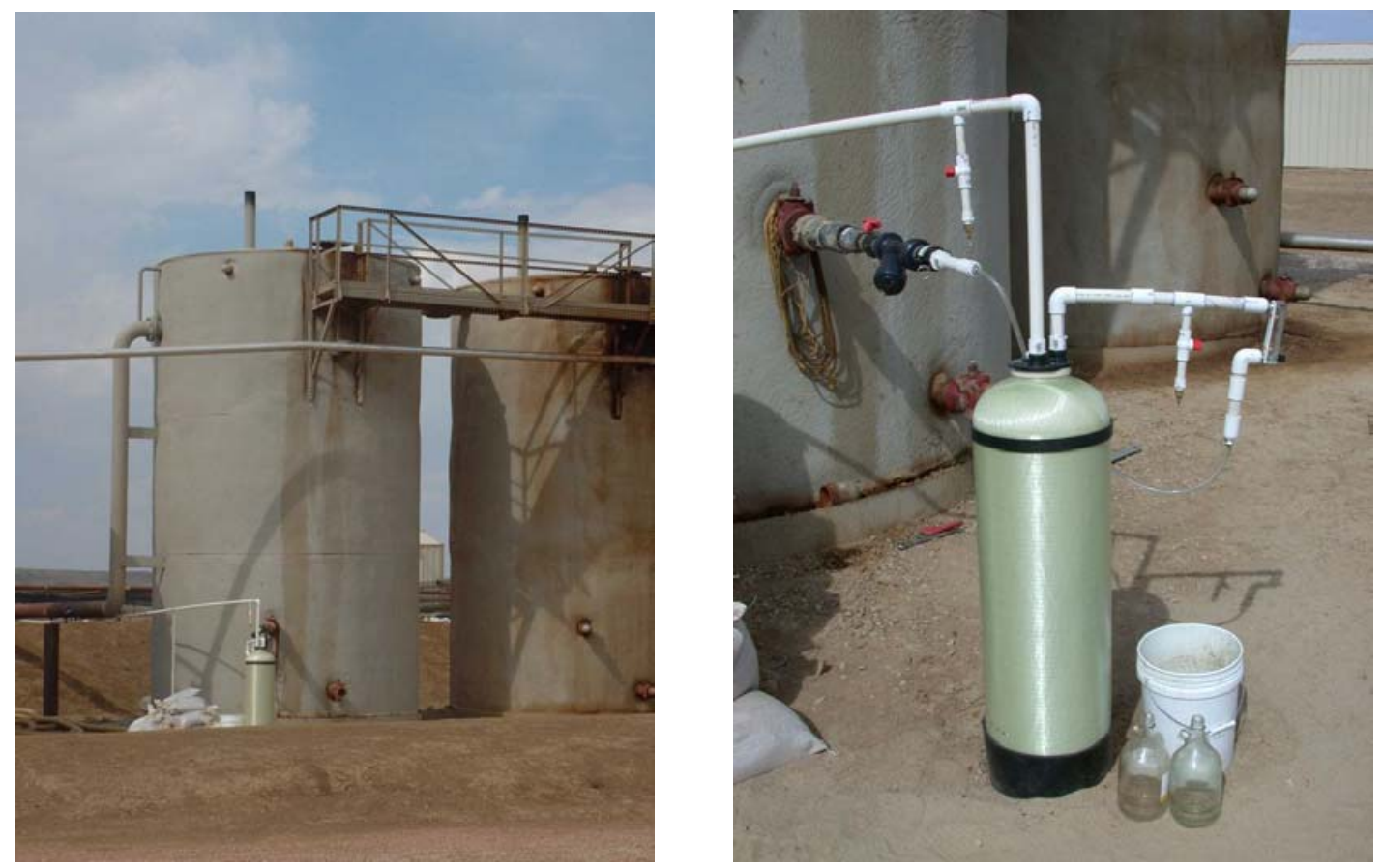

Figure 4.4 Testing of a prototype SMZ-based water treatment column at a water treatment facility near Wamsutter, WY.: (a) a SMZ column connected to waste water storage tanks at the treatment site; (b) an enlarged view of the SMZ column with sampling valves. 


\section{Results}

\subsection{Produced Water Characterization}

Produced waters from three different oil fields were characterized during the initial phase of this project. The first water was obtained from an offshore platform operated by Phillips Petroleum in the Gulf of Mexico. This sample was observed to be quite salty and had a distinct odor. In contrast, the second water sample, obtained from onshore oilproducing fields operated by MCA Petroleum Corporation in Flatonia, Texas, was neither salty nor odorous. The third water was from the treatment facility of BC Technologies in Wamsutter, Wyoming. BC Technologies provides produced water treatment and disposal options for small oil and gas producers in Wyoming.

\subsubsection{Phillips Petroleum Offshore Sample}

The analysis conducted at the University of Texas at Austin for this sample consisted of identifying the amount of BTEX dissolved in the produced water. With respect to BTEX concentrations (Table 5.1), the Phillips Petroleum water had the desired characteristics, but samples are not easily acquired because the samples must be obtained directly from the offshore platform in the Gulf of Mexico.

DHL Analytical laboratories in Round Rock, Texas, conducted further analyses of the concentrations of Total Petroleum Hydrocarbons (TPH), cations, and anions. The DHL results shown in Table 5.2 suggest that the water is moderately to highly saline. The TPH testing proved inconclusive for any hydrocarbons present below the detection limit of 5 $\mathrm{mg} / \mathrm{L}$. No petroleum hydrocarbons present at concentrations above this detection limit were detected.

Table 5.1 BTEX Concentrations in Phillips Petroleum Water Samples

\begin{tabular}{|c|c|c|}
\hline Compound & Average & Standard Deviation \\
\hline & $\boldsymbol{\mu g} / \mathbf{L}$ & $\boldsymbol{\mu g} / \mathbf{L}$ \\
\hline Benzene & 835 & 43 \\
Toluene & 227 & 15 \\
Ethylbenzene & 19 & 1 \\
p- \& m-Xylenes & 42 & 1 \\
o-Xylene & 48 & 1 \\
\hline
\end{tabular}


Table 5.2 TPH, Anions and Cations in Phillips Petroleum Water Samples

\begin{tabular}{|c|c|c|c|c|}
\hline Analyses & Method & Result & Units & $\begin{array}{c}\text { Reporting } \\
\text { Limit }\end{array}$ \\
\hline TPH & TX1005 & $\mathrm{ND}$ & $\mathrm{mg} / \mathrm{L}$ & 5.0 \\
\hline Anions & SW9056 & & & \\
Chloride & & 58700 & $\mathrm{mg} / \mathrm{L}$ & 200 \\
Nitrate-N & & $\mathrm{ND}$ & $\mathrm{mg} / \mathrm{L}$ & 0.500 \\
Sulfate & & $\mathrm{ND}$ & $\mathrm{mg} / \mathrm{L}$ & 3.00 \\
\hline Metals & SW6020 & & & \\
Calcium & & 1690000 & $\mu \mathrm{g} / \mathrm{L}$ & 5000 \\
Magnesium & & 263000 & $\mu \mathrm{g} / \mathrm{L}$ & 1000 \\
Potassium & & 151000 & $\mu \mathrm{g} / \mathrm{L}$ & 1000 \\
Sodium & & 33200000 & $\mu \mathrm{g} / \mathrm{L}$ & 50000 \\
\hline
\end{tabular}

Note: ND - not detected

\subsubsection{MCA Petroleum Corporation Onshore Samples}

Samples were taken both upstream and downstream of the detention ponds at the MCA Burleson oil field. The upstream samples were taken directly from an outfall from the tank used to separate oil and water. The downstream samples were taken from the discharge outfall from the last detention pond. This discharge was being applied directly to the land around it, in effect creating an artificial wetland. DHL Analytical laboratories analyzed these samples for a number of parameters

The parameters that were tested for by DHL included the following: TPH, semivolatile organics, anions, aqueous ammonia, metals, and BTEX. The results from these analyses and the methods used by DHL are included in Table 5.3. The semivolatile organics analysis included 67 different chemicals. However, none of these compounds were detected above the detection limits so all of the 67 unique chemicals are not included in Table 4.3.

As seen in the Table 5.3, the MCA Petroleum water samples have very low concentrations of salt and non-detectable amounts of BTEX both upstream and downstream of the detention ponds. Although the low salt concentrations may be a natural tendency for the water in the Flatonia, Texas area, the lack of BTEX compounds may be linked with the site's water discharge processes. As shown in Figure 5.1, the water from the separation tank is directly discharged into a pond via an open pipe. This allows substantial volatilization to occur both in the pipe and during the time when the water flow is exposed the atmosphere. Thus, as these characteristics would not have allowed us to determine the efficacy of the proposed treatment process and was not selected for further study. 
Table 5.3 Results from Analyses of MCA Petroleum Corp. Samples

\begin{tabular}{|c|c|c|c|c|c|}
\hline $\begin{array}{c}\text { Sample } \\
\text { Location }\end{array}$ & Analyses & Method & Result & Units & $\begin{array}{c}\text { Reporting } \\
\text { Limit }\end{array}$ \\
\hline \multirow{19}{*}{$\begin{array}{c}\text { Up } \\
\text { Stream }\end{array}$} & TPH & TX1005 & & & \\
\hline & $\mathrm{C}_{6}-\mathrm{C}_{10}$ & & ND & $\mathrm{mg} / \mathrm{L}$ & 4.72 \\
\hline & $\mathrm{C}_{10}-\mathrm{C}_{28}$ & & 7.45 & $\mathrm{mg} / \mathrm{L}$ & 4.72 \\
\hline & Semivol. Organics & SW8270C & ND & $\mu \mathrm{g} / \mathrm{L}$ & Varies \\
\hline & Anions & SW9056 & & & \\
\hline & Chloride & & 20.9 & $\mathrm{mg} / \mathrm{L}$ & 1 \\
\hline & Nitrate-N & & ND & $\mathrm{mg} / \mathrm{L}$ & 0.500 \\
\hline & Sulfate & & 11.1 & $\mathrm{mg} / \mathrm{L}$ & 3.00 \\
\hline & Ammonia (as N) & M4500- & 0.716 & $\mathrm{mg} / \mathrm{L}$ & 0.250 \\
\hline & Metals & SW6020 & & & \\
\hline & Calcium & & 2090 & $\mu \mathrm{g} / \mathrm{L}$ & 100 \\
\hline & Magnesium & & 547 & $\mu \mathrm{g} / \mathrm{L}$ & 100 \\
\hline & Potassium & & 1940 & $\mu \mathrm{g} / \mathrm{L}$ & 100 \\
\hline & Sodium & & 211000 & $\mu \mathrm{g} / \mathrm{L}$ & 5000 \\
\hline & Aq. BTEX & SW8021B & & & \\
\hline & Benzene & & ND & $\mu \mathrm{g} / \mathrm{L}$ & 5.0 \\
\hline & Toluene & & ND & $\mu \mathrm{g} / \mathrm{L}$ & 5.0 \\
\hline & Ethylbenzene & & ND & $\mu \mathrm{g} / \mathrm{L}$ & 5.0 \\
\hline & Xylenes, Total & & ND & $\mu \mathrm{g} / \mathrm{L}$ & 5.0 \\
\hline \multirow{19}{*}{$\begin{array}{l}\text { Down } \\
\text { Stream }\end{array}$} & TPH & TX1005 & & & \\
\hline & $\mathrm{C}_{6}-\mathrm{C}_{10}$ & & ND & $\mathrm{mg} / \mathrm{L}$ & 5.81 \\
\hline & $\mathrm{C}_{10}-\mathrm{C}_{28}$ & & $\mathrm{ND}$ & $\mathrm{mg} / \mathrm{L}$ & 5.81 \\
\hline & Semivol. Organics & SW8270C & $\mathrm{ND}$ & $\mu \mathrm{g} / \mathrm{L}$ & Varies \\
\hline & Anions & SW9056 & & & \\
\hline & Chloride & & 20.1 & $\mathrm{mg} / \mathrm{L}$ & 1 \\
\hline & Nitrate-N & & $\mathrm{ND}$ & $\mathrm{mg} / \mathrm{L}$ & 0.500 \\
\hline & Sulfate & & 10.1 & $\mathrm{mg} / \mathrm{L}$ & 3.00 \\
\hline & Ammonia (as N) & M4500- & ND & $\mathrm{mg} / \mathrm{L}$ & 0.250 \\
\hline & Metals & SW6020 & & & \\
\hline & Calcium & & 2120 & $\mu \mathrm{g} / \mathrm{L}$ & 100 \\
\hline & Magnesium & & 538 & $\mu \mathrm{g} / \mathrm{L}$ & 100 \\
\hline & Potassium & & 1810 & $\mu \mathrm{g} / \mathrm{L}$ & 100 \\
\hline & Sodium & & 189000 & $\mu \mathrm{g} / \mathrm{L}$ & 5000 \\
\hline & Aq. BTEX & SW8021B & & & \\
\hline & Benzene & & $\mathrm{ND}$ & $\mu \mathrm{g} / \mathrm{L}$ & 5.0 \\
\hline & Toluene & & $\mathrm{ND}$ & $\mu \mathrm{g} / \mathrm{L}$ & 5.0 \\
\hline & Ethylbenzene & & ND & $\mu \mathrm{g} / \mathrm{L}$ & 5.0 \\
\hline & Xylenes, Total & & ND & $\mu \mathrm{g} / \mathrm{L}$ & 5.0 \\
\hline
\end{tabular}

Note: ND - not detected 


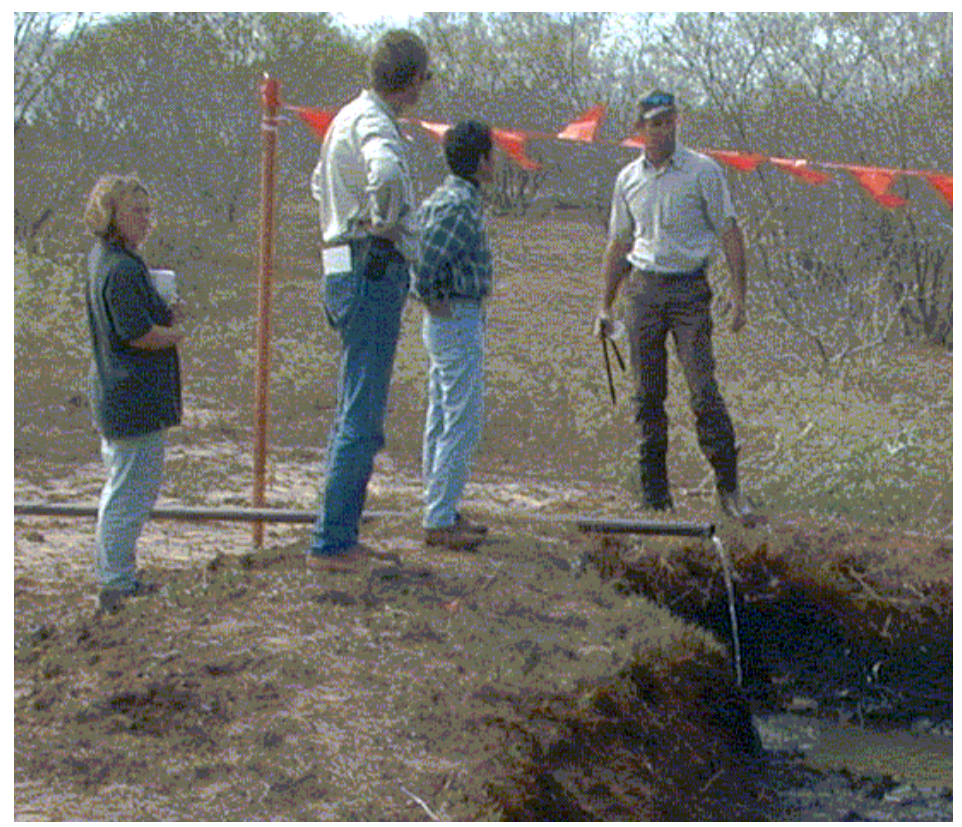

Figure 5.1 Produced Water Outfall for MCA Petroleum Corp.

\subsubsection{Produced Water from BC Technologies Wamsutter Treatment Facility}

The site, located in an oil producing region just outside of Wamsutter, WY is operated by Crystal Solutions, LLC. It receives produced water from the region by tanker truck. The water is unloaded from the trucks into an oil/water separation tank. Overflow from this tank flows into a second separation (or holding) tank. Both tanks are identical, and measure approximately 20' in height and 10' in diameter. The results from the initial analysis of samples from this facility were limited to selected metals, BTEX and TDS. Results for both the oil/water separation tank and holding tank, and the TDS results for the holding tank are reported in Table 5.4 The water from the oil/water separation tank was not tested for TDS because this water would not be used for subsequent batch tests.

Table 5.4 Initial Metals Analysis for Wamsutter Site Samples

\begin{tabular}{|c|c|c|c|c|}
\hline Analyses & Method & Result & Units & Reporting Limit \\
\hline Metals: ICP-MS & SW6020 & & & \\
Arsenic & & 24.4 & $\mu \mathrm{g} / \mathrm{L}$ & 10.0 \\
Barium & & 8650 & $\mu \mathrm{g} / \mathrm{L}$ & 100 \\
Cadmium & & None Detected & $\mu \mathrm{g} / \mathrm{L}$ & 1.00 \\
Lead & & 6.58 & $\mu \mathrm{g} / \mathrm{L}$ & 3.00 \\
\hline
\end{tabular}


Table 5.5 Initial BTEX Concentrations and Total Dissolved Solids in Wamsutter Site Samples

\begin{tabular}{|l|c|c|}
\hline \multicolumn{1}{|c|}{ Compound } & Oil/Water Separation Tank & Holding Tank \\
\hline Benzene $(\mu \mathbf{g} / \mathbf{L})$ & 13.0 & 2.6 \\
Toluene $(\mu \mathbf{g} / \mathbf{L})$ & 30.6 & 6.1 \\
Ethylbenzene $(\mu \mathbf{g} / \mathbf{L})$ & 1.4 & 0.2 \\
m- \& p-Xylenes $(\mu \mathbf{g} / \mathbf{L})$ & 7.1 & 1.9 \\
o-Xylene $(\mu \mathbf{g} / \mathbf{L})$ & 3.8 & 0.7 \\
TDS $(\mathbf{m g} / \mathbf{L})$ & - & 11,280 \\
\hline
\end{tabular}

Based on the results of the analyses from the three water sources and the potential for conducting a field study at the site, this site was selected for further study. The salinity, BTEX concentrations, source quantity, and reproducibility of source volumes and chemistry were all appropriate for field tests. Furthermore, the site personnel were eager to participate in our study.

As a result, two subsequent analyses of the water were conducted at the time of the field test (July, 2002) and approximately one year later. These results are presented in Table 5.6 which also provides a comparison of the values to reported literature ranges. The differences in contaminant levels in these produced waters confirms the reported variability of water quality for this type of waste stream (Smith et al., 1996; Lawrence et al., 1995; Fillo et al., 1992). It also suggests that the selected site has low to moderate levels of salinity, high BTEX concentrations, and low to moderate phenol levels. 
Table 5.6 Comparison of Produced Water Characteristics from the Wamsutter Site to Reported Literature Values

\begin{tabular}{|c|c|c|c|c|c|}
\hline Analysis & Parameter & units & Literature $^{1}$ & Summer 2002 & Summer 2003 \\
\hline \multirow[t]{4}{*}{ Total Petrol. Hydrocarbons } & C6-C12 & $\mathrm{mg} / \mathrm{L}$ & - & 128.5 & 43.5 \\
\hline & $\mathrm{C} 12-\mathrm{C} 28$ & $\mathrm{mg} / \mathrm{L}$ & - & 7.3 & ND \\
\hline & $\mathrm{C} 28-\mathrm{C} 35$ & $\mathrm{mg} / \mathrm{L}$ & - & ND & ND \\
\hline & total & $\mathrm{mg} / \mathrm{L}$ & $2-565$ & 135.8 & 43.5 \\
\hline Total Disolved Soilds & & $\mathrm{mg} / \mathrm{L}$ & - & 11400 & 10230 \\
\hline Total Organic Carbon & & $\mathrm{mg} / \mathrm{L}$ & $0-1500$ & 470 & 2983 \\
\hline \multirow[t]{4}{*}{ Anions } & Bromide & $\mathrm{mg} / \mathrm{L}$ & - & ND & 22 \\
\hline & Chloride & $\mathrm{mg} / \mathrm{L}$ & $80-200000$ & 4510 & 4400 \\
\hline & Flouride & $\mathrm{mg} / \mathrm{L}$ & - & 10 & 57 \\
\hline & Sulfate & $\mathrm{mg} / \mathrm{L}$ & $2-1650$ & 56.6 & 13 \\
\hline \multirow[t]{4}{*}{ Cations } & Calcium & $\mathrm{mg} / \mathrm{L}$ & $13-25800$ & 38.1 & 30 \\
\hline & Magnesium & $\mathrm{mg} / \mathrm{L}$ & $8-6000$ & 9.47 & 6.4 \\
\hline & Potassium & $\mathrm{mg} / \mathrm{L}$ & $24-4300$ & 1530 & 44 \\
\hline & Sodium & $\mathrm{mg} / \mathrm{L}$ & $132-97000$ & 4050 & 4100 \\
\hline \multirow[t]{4}{*}{ Alkalinity (CaCO3) } & Bicarbonate & $\mathrm{mg} / \mathrm{L}$ & $77-3990$ & 2860 & 3120 \\
\hline & Carbonate & $\mathrm{mg} / \mathrm{L}$ & - & ND & 60 \\
\hline & Hydroxide & $\mathrm{mg} / \mathrm{L}$ & - & ND & ND \\
\hline & Total & $\mathrm{mg} / \mathrm{L}$ & - & 2860 & 3180 \\
\hline \multirow[t]{8}{*}{ Metals } & Mercury & $\mathrm{ug} / \mathrm{L}$ & $1-2$ & ND & $\overline{---}$ \\
\hline & Arsenic & $\mathrm{ug} / \mathrm{L}$ & $5-300$ & ND & --- \\
\hline & Barium & $\mathrm{ug} / \mathrm{L}$ & $1300-650000$ & 9920 & --- \\
\hline & Cadmium & $\mathrm{ug} / \mathrm{L}$ & $5-200$ & ND & --- \\
\hline & Chromium & $\mathrm{ug} / \mathrm{L}$ & $20-1100$ & ND & --- \\
\hline & Lead & $\mathrm{ug} / \mathrm{L}$ & $2-8800$ & ND & --- \\
\hline & Selenium & $\mathrm{ug} / \mathrm{L}$ & $<0.001$ & 25.2 & --- \\
\hline & Silver & $\mathrm{ug} / \mathrm{L}$ & $1-150$ & ND & --- \\
\hline \multirow[t]{9}{*}{ Semivolatiles } & 2,4-Dimethylphenol & $\mathrm{ug} / \mathrm{L}$ & 1 & 816 & 802 \\
\hline & 2-Methylnaphthalen & $\mathrm{ug} / \mathrm{L}$ & 1 & 160 & 717 \\
\hline & 2-Methylphenol & $\mathrm{ug} / \mathrm{L}$ & 1 & 1350 & 1440 \\
\hline & 4-Methylphenol & $\mathrm{ug} / \mathrm{L}$ & 1 & 1000 & 672 \\
\hline & Dibenzofuran & $\mathrm{ug} / \mathrm{L}$ & - & 4.4 & ND \\
\hline & Fluorene & $\mathrm{ug} / \mathrm{L}$ & - & 4.6 & ND \\
\hline & Naphthalene & $\mathrm{ug} / \mathrm{L}$ & - & 164 & 419.2 \\
\hline & Phenanthrene & $\mathrm{ug} / \mathrm{L}$ & - & 3.8 & ND \\
\hline & Phenol & $\mathrm{ug} / \mathrm{L}$ & $9-23000^{2}$ & 764 & 2383 \\
\hline \multirow[t]{5}{*}{ BTEX } & Benzene & $\mathrm{ug} / \mathrm{L}$ & $77-44000$ & 21300 & 15800 \\
\hline & Tolulene & $\mathrm{ug} / \mathrm{L}$ & $90-5800$ & 33200 & 36700 \\
\hline & Ethylbenzene & $\mathrm{ug} / \mathrm{L}$ & $29-110$ & 22800 & 1400 \\
\hline & m\&p-Xylene & $\mathrm{ug} / \mathrm{L}$ & $47-400$ & 9800 & 6400 \\
\hline & o-Xylene & $\mathrm{ug} / \mathrm{L}$ & $70-460$ & 4900 & 3400 \\
\hline
\end{tabular}

${ }^{1}$ Literarure data fromTibbetts et al. (1992)

${ }^{2}$ Phenol data given as sum of all phenols

Note: ND - Not Detected 


\subsection{Batch Adsorption Studies}

There were three primary objectives of the batch sorption studies. The first was to evaluate the sorption behavior of BTEX compounds on SMZ in ultrapure water. The second goal involved the study of BTEX removal efficiency by SMZ in the presence of various salt concentrations. Lastly, the effects of produced water chemistry on BTEX sorption were investigated through the determination of distribution coefficients in this matrix. Hypothesis testing was used to determine whether isotherms developed under these different solution conditions were statistically identical. The distribution coefficients determined from the single-solute batch tests were compared to values predicted by various types of correlations published in literature. If these correlations compare favorably to observed data, then they could be used in future studies to predict sorption of BTEX in other produced waters.

\subsubsection{Single-Solute Batch Isotherms}

Many adsorbents in natural and engineered systems exhibit lower removal efficiencies in complex systems due to competitive sorption. Prior to building an SMZ treatment system for streams contaminated with BTEX, data quantifying these competitive effects need to be gathered. Hence, the first objective of this research was met through tests conducted with both specific BTEX compounds and combinations of all six chemicals. These tests demonstrated how sorption to SMZ was affected as more chemicals were added to solution. Effects were quantified through the determination of distribution coefficients in both single-solute and multi-solute cases. The distribution coefficients determined from the isotherms were statistically compared to determine whether differences in adsorption capacity were evident in the presence of additional sorbates. Thus, the first task was to quantify sorption in single-solute systems for toluene and benzene, the two least hydrophobic compounds.

Single-solute sorption studies included initial concentrations of $0,0.005,0.01,0.1,1$, 10,40 , and $75 \mathrm{mg} / \mathrm{L}$. Results from the single-solute studies conducted with benzene and toluene are presented in Figures 5.2 and 5.3. Figure 5.2(b) and Figure 5.3 (b) include the $95 \%$ confidence limits on the results obtained in this study. Distribution coefficients $\left(\mathrm{K}_{\mathrm{d}}\right)$ were calculated for all of the isotherms using the LINEST linear regression tool built into Microsoft Excel 2000. Each isotherm was based on the model:

$$
q_{e}=K_{d} C_{e}
$$

where $\mathrm{q}_{\mathrm{e}}$ is the sorption density, $\mathrm{K}_{\mathrm{d}}$ is the distribution coefficient, and $\mathrm{C}_{\mathrm{e}}$ is the equilibrium concentration. As shown in these isotherms, sorption was linear throughout a wide range of concentrations, and the $95 \%$ confidence limits on $K_{d}$ were calculated. A comparison of distribution coefficients demonstrates that toluene has a greater affinityt for SMZ than benzene. This result is supported both by benzene's aqueous solubility which is higher than that of toluene and the $\mathrm{K}_{\mathrm{ow}}$ which is lower. 
The linear model fit the data for both benzene and toluene well, as demonstrated by the coefficients of determination $\left(\mathrm{R}^{2}\right)$. This strong linear trend was apparent throughout the wide range of BTEX concentrations tested. Triplicates were used throughout the single-solute studies so that statistical analyses could be conducted on the results. Tables 5.7 and 5.8 present the averages and standard deviations for the sorption density and equilibrium concentrations measured for the benzene and toluene single-solute studies, respectively.

Table 5.7 Benzene Sorption Capacities for Sorption to SMZ in Ultrapure Water

\begin{tabular}{|c|cc|cc|}
\hline Initial Concentration $(\mu \mathrm{g} / \mathrm{L})$ & \multicolumn{2}{|c|}{ Final Concentration $(\mu \mathrm{g} / \mathrm{L})$} & \multicolumn{2}{c|}{ Sorption Density $(\mu \mathrm{g} / \mathrm{g})$} \\
\hline & Average & Std. Dev. & Average & Std. Dev. \\
\hline $\mathbf{0}$ & 0 & 0 & 0 & 0 \\
$\mathbf{5}$ & 2.2 & 0.093 & 0.023 & 0.00079 \\
$\mathbf{1 0}$ & 4.5 & 0.17 & 0.045 & 0.0013 \\
$\mathbf{1 0 0}$ & 48.4 & 2.0 & 0.41 & 0.014 \\
$\mathbf{1 0 0 0}$ & 515 & 16 & 4.0 & 0.10 \\
$\mathbf{1 0 0 0 0}$ & 5427 & 858 & 38 & 6.3 \\
$\mathbf{4 0 0 0 0}$ & 18162 & 883 & 176 & 4.8 \\
$\mathbf{7 5 0 0 0}$ & 34153 & 745 & 324 & 5.3 \\
\hline
\end{tabular}

Table 5.8 Toluene Sorption Capacities for Sorption to SMZ in Ultrapure Water

\begin{tabular}{|c|cc|cc|}
\hline Initial Concentration $(\mu \mathrm{g} / \mathrm{L})$ & \multicolumn{2}{|c|}{ Final Concentration $(\mu \mathrm{g} / \mathrm{L})$} & \multicolumn{2}{c|}{ Sorption Density $(\mu \mathrm{g} / \mathrm{g})$} \\
\hline & Aver age & Std. Dev. & Average & Std. Dev. \\
\hline $\mathbf{0}$ & 0 & 0 & 0 & 0 \\
$\mathbf{5}$ & 1.1 & 0.054 & 0.032 & 0.00047 \\
$\mathbf{1 0}$ & 2.2 & 0.07 & 0.063 & 0.0019 \\
$\mathbf{1 0 0}$ & 22 & 0.8 & 0.62 & 0.005 \\
$\mathbf{1 0 0 0}$ & 229 & 5 & 6.4 & 0.03 \\
$\mathbf{1 0 0 0 0}$ & 2234 & 26 & 62 & 1.3 \\
$\mathbf{4 0 0 0 0}$ & 8975 & 246 & 249 & 2.2 \\
$\mathbf{7 5 0 0 0}$ & 15922 & 260 & 471 & 2.3 \\
\hline
\end{tabular}



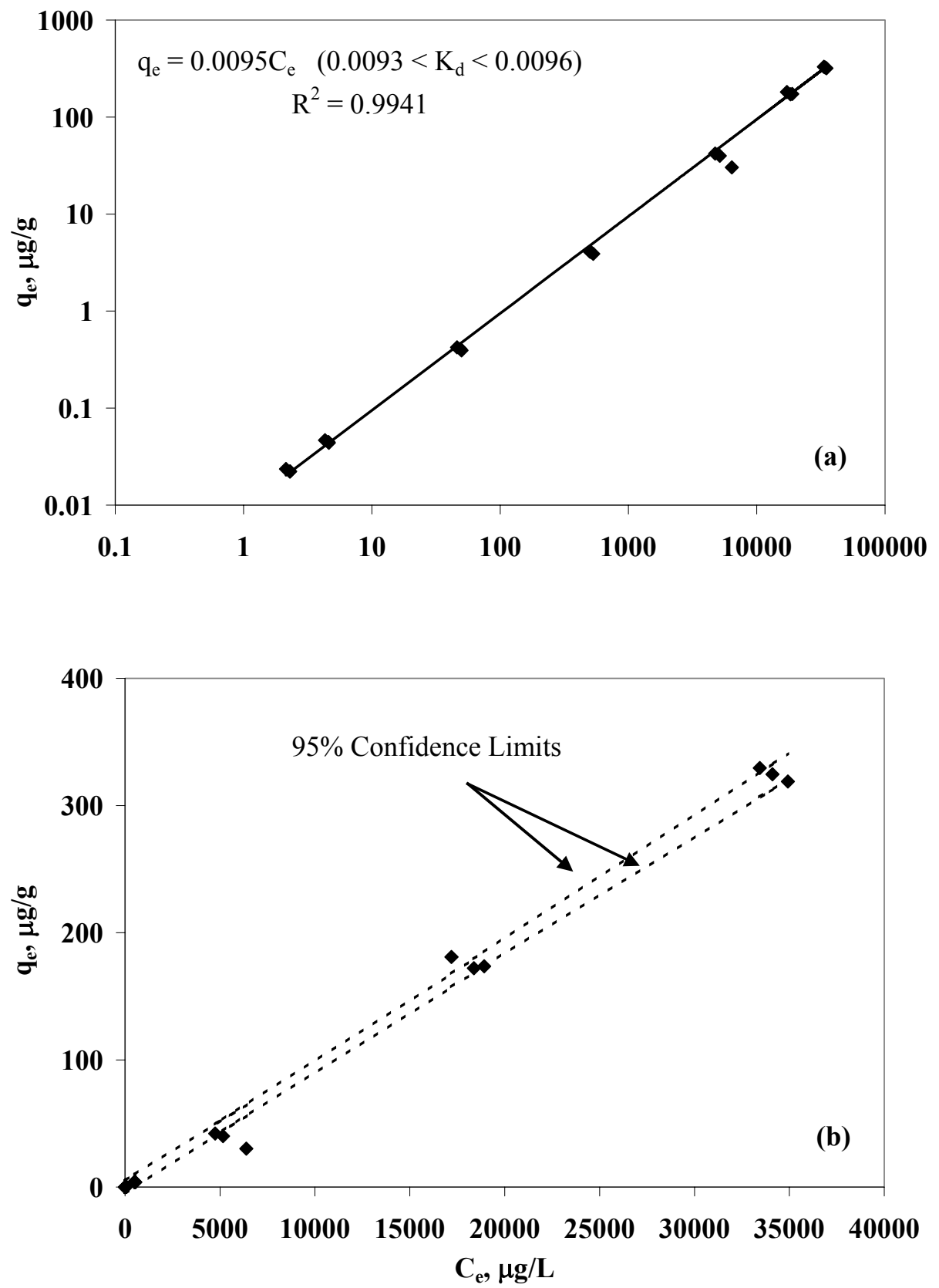

Figure 5.2 Single-Solute Sorption Isotherm for Benzene on SMZ in Ultrapure Water (a) Logarithmic $\left(q_{e}=K_{d} C_{e}\right.$ with $95 \%$ Confidence Limits for $K_{d}$ (L/g SMZ) in Parentheses); (b) Linear (95\% Confidence Limits for Data Shown by Dashed Lines) 

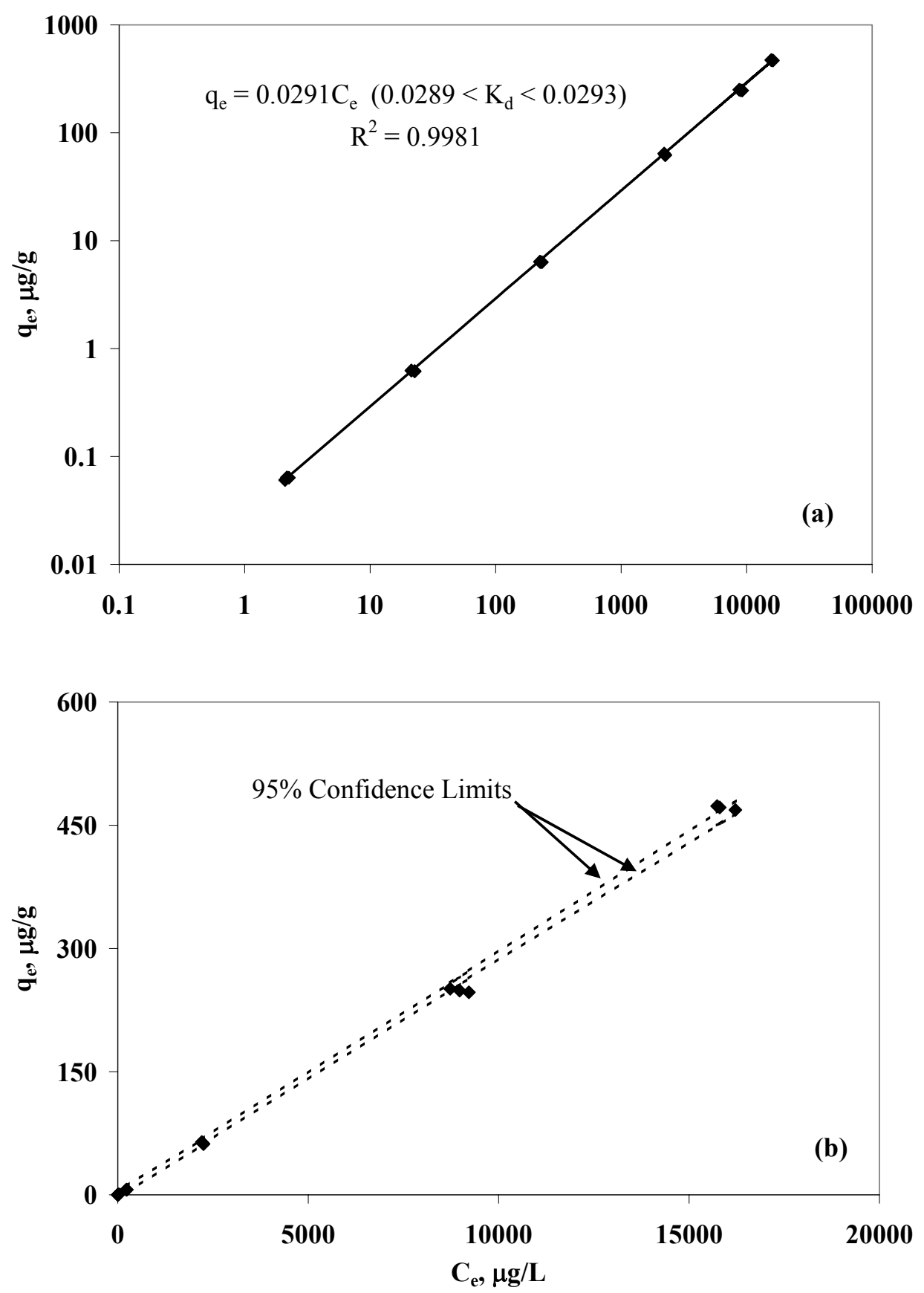

Figure 5.3 Single-Solute Sorption Isotherm for Toluene on SMZ in Ultrapure Water (a) Logarithmic $\left(q_{e}=K_{d} C_{e}\right.$ with $95 \%$ Confidence Limits for $K_{d}$ (L/g SMZ) in Parentheses); (b) Linear (95\% Confidence Limits for Data Shown by Dashed Lines) 
The percent of each compound removed was calculated for benzene and toluene. The average removal of benzene was $52 \%$ while that of toluene was $78 \%$. As expected for a linear isotherm, the removal for each compound was relatively constant and increased removal at lower concentrations was not observed. These removals were consistent with the values of the distribution coefficients in that the numerical value for benzene was smaller than for toluene. This was expected because toluene has a lower aqueous solubility than benzene, and therefore, a greater preference for the hydrophobic phase present in SMZ.

\section{Comparison of Single-Solute Results with Published Correlations}

As stated in Chapter 2, numerous correlations relating either the octanol-water partitioning coefficient $\left(\mathrm{K}_{\text {ow }}\right)$ or aqueous solubility $(\mathrm{S})$ to the partitioning coefficient onto organic carbon $\left(\mathrm{K}_{\mathrm{oc}}\right)$ have been reported in literature. Schwarzenbach et al. (1993) also stated that a relationship between the distribution coefficient and the organic matter partitioning coefficient $\left(\mathrm{K}_{\mathrm{om}}\right)$ exists. This relationship is

$$
K_{d}=K_{o m} f_{o m}
$$

where $f_{o m}$ is the fractional organic matter content on a soil The SMZ used in this study had an $\mathrm{f}_{\text {om }}$ of 0.051 as calculated by the HDTMA loading of $180 \mathrm{mmol} / \mathrm{kg}$.

With this equation and values for $\mathrm{K}_{\mathrm{ow}}$ and $\mathrm{S}$ found in literature, it was possible to compare the observed distribution coefficients to those that would be predicted by the published correlations. These correlations were conducted with specific soils and for certain compounds. While most of the correlations involved benzene, only six included toluene. Hence, distribution coefficients for benzene and toluene were calculated with only the correlations that were developed with the appropriate chemicals. The results for these comparisons for benzene and toluene are presented in Tables 5.9 and 5.10, respectively.

The distribution coefficients found in this study for benzene and toluene were 9.5 $\mathrm{L} / \mathrm{kg}$ and $29.1 \mathrm{~L} / \mathrm{kg}$, respectively. A comparison between these values and those predicted by the published correlations shows that the correlations dramatically underestimated the $\mathrm{K}_{\mathrm{d}}$ values for both benzene and toluene. Thus, the use of these correlations would not be accurate for the prediction of benzene and toluene sorption on SMZ. As mentioned earlier, the published correlations were found through studies conducted on soils with various organic carbon contents. These results suggest that HDTMA is a much better sorbent than soil organic matter for moderately hydrophobic contaminants.

Because none of the published correlations proved to accurately predict observed distribution coefficient values, regressions were conducted between the $\mathrm{K}_{d}$ values found in this study and the $\mathrm{K}_{\mathrm{ow}}$ and $\mathrm{S}$ values found in literature for the BTEX compounds. 
Table 5.9 Benzene Distribution Coefficients Predicted Using Published Correlations

\begin{tabular}{|c|c|c|}
\hline Source & Correlation & $\begin{array}{c}\text { Calculated } \\
\mathbf{K}_{\mathrm{d}}(\mathrm{L} / \mathrm{kg})\end{array}$ \\
\hline Schwarzenbach et al. (1993) & $\log \mathrm{K}_{\mathrm{om}}=-0.93 \log \mathrm{S}-0.17$ & 0.97 \\
\hline Schwarzenbach et al. (1993) & $\log \mathrm{K}_{\mathrm{om}}=1.01 \log \mathrm{K}_{\mathrm{ow}}-0.72$ & 1.11 \\
\hline Karickhoff et al. (1979) & $\log \mathrm{K}_{\mathrm{oc}}=1.00 \log \mathrm{K}_{\mathrm{ow}^{-}}-0.21$ & 1.98 \\
\hline Karickhoff (1981) & $\log \mathrm{K}_{\mathrm{oc}}=0.989 \log \mathrm{K}_{\mathrm{ow}}-0.346$ & 1.37 \\
\hline Chiou et al. (1983) & $\log \mathrm{K}_{\mathrm{om}}=-0.729 \log \mathrm{S}+0.001$ & 0.67 \\
\hline Chiou et al. (1983) & $\log \mathrm{K}_{\mathrm{om}}=0.904 \log \mathrm{K}_{\mathrm{ow}}-0.779$ & 0.57 \\
\hline Abdul et al. (1987) & $\log \mathrm{K}_{\mathrm{oc}}=1.04 \log \mathrm{K}_{\mathrm{ow}}-0.84$ & 0.56 \\
\hline Abdul et al. (1987) & $\log \mathrm{K}_{\mathrm{oc}}=-0.74 \log \mathrm{S}+4.0$ & 0.97 \\
\hline Vowles and Mantoura (1987) & $\log \mathrm{K}_{\mathrm{oc}}=1.20 \log \mathrm{K}_{\mathrm{ow}}-1.13$ & 0.63 \\
\hline Pussemier et al. (1990) & $\log \mathrm{K}_{\mathrm{oc}}=1.009 \log \mathrm{K}_{\mathrm{ow}}-0.531$ & 0.99 \\
\hline Results of This Study & - & 9.5 \\
\hline
\end{tabular}

Table 5.10 Toluene Distribution Coefficients Predicted Using Published Correlations

\begin{tabular}{|c|c|c|}
\hline Source & Correlation & $\begin{array}{l}\text { Calculated } \\
K_{d}(L / k g)\end{array}$ \\
\hline Schwarzenbach et al. (1993) & $\log \mathrm{K}_{\mathrm{om}}=-0.93 \log \mathrm{S}-0.17$ & 3.43 \\
\hline Schwarzenbach et al. (1993) & $\log \mathrm{K}_{\mathrm{om}}=1.01 \log \mathrm{K}_{\mathrm{ow}}-0.72$ & 4.07 \\
\hline Schwarzenbach and Westall (1981) & $\log \mathrm{K}_{\mathrm{oc}}=0.72 \log \mathrm{K}_{\mathrm{ow}}+0.49$ & 6.35 \\
\hline Abdul et al. (1987) & $\log \mathrm{K}_{\mathrm{oc}}=1.04 \log \mathrm{K}_{\mathrm{ow}}-0.84$ & 2.16 \\
\hline Abdul et al. (1987) & $\log \mathrm{K}_{\mathrm{oc}}=-0.74 \log \mathrm{S}+4.0$ & 2.34 \\
\hline Pussemier et al. (1990) & $\log \mathrm{K}_{\mathrm{oc}}=1.009 \log \mathrm{K}_{\mathrm{ow}}-0.531$ & 3.63 \\
\hline Results of This Study & - & 29.1 \\
\hline
\end{tabular}


These regressions are shown in Figures 5.4 and 5.5 along with several of the published correlations that were developed for combined BTEX compounds. The predicted values for $\mathrm{K}_{\mathrm{om}}$ and $\mathrm{K}_{\mathrm{oc}}$ from these correlations were converted to predicted $\mathrm{K}_{\mathrm{d}}$ values with the relationships $\mathrm{K}_{\mathrm{d}}=\mathrm{K}_{\mathrm{om}} \mathrm{f}_{\mathrm{om}}$ and $\mathrm{K}_{\mathrm{d}}=\mathrm{K}_{\mathrm{oc}} \mathrm{f}_{\mathrm{oc}}$ where $\mathrm{f}_{\mathrm{om}}=0.051$ and $\mathrm{f}_{\mathrm{oc}}=0.041$ for SMZ.

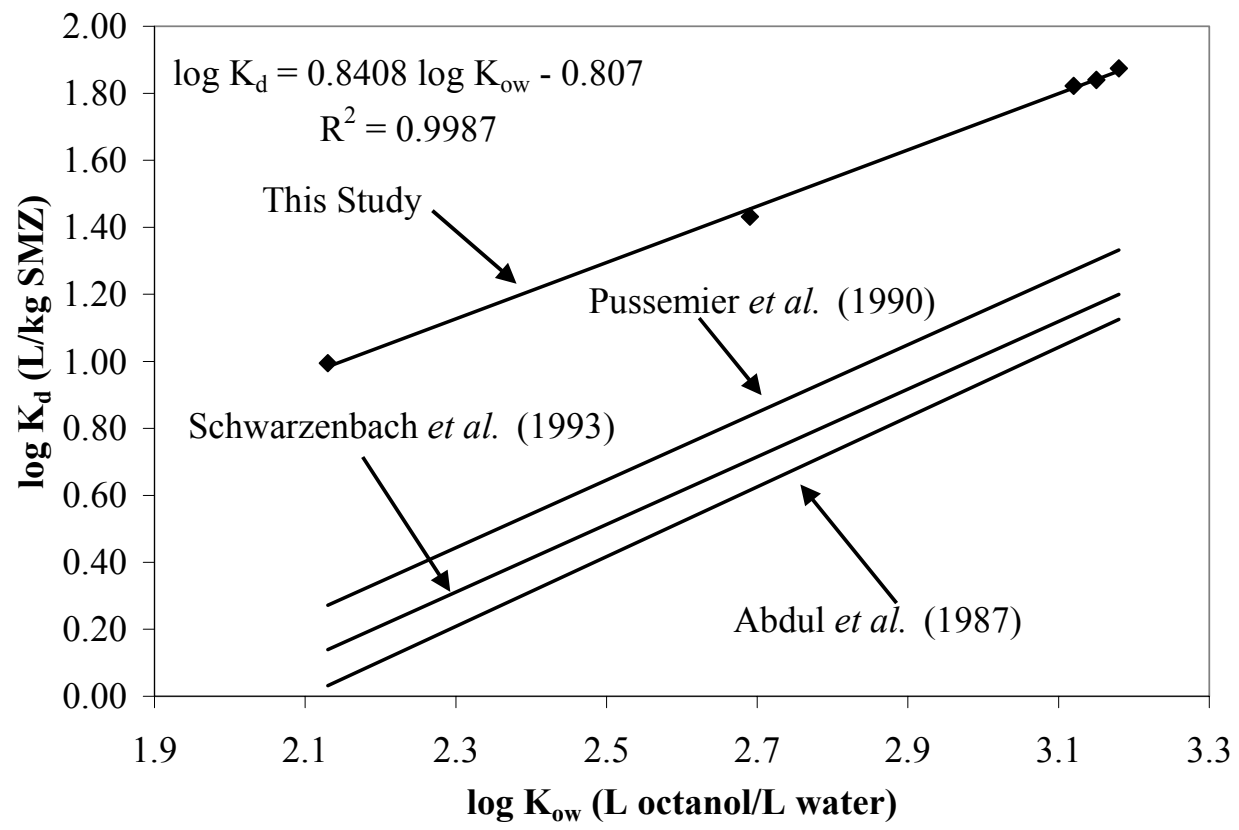

Figure 5.4 Relationships Between $K_{d}$ and $K_{o w}$

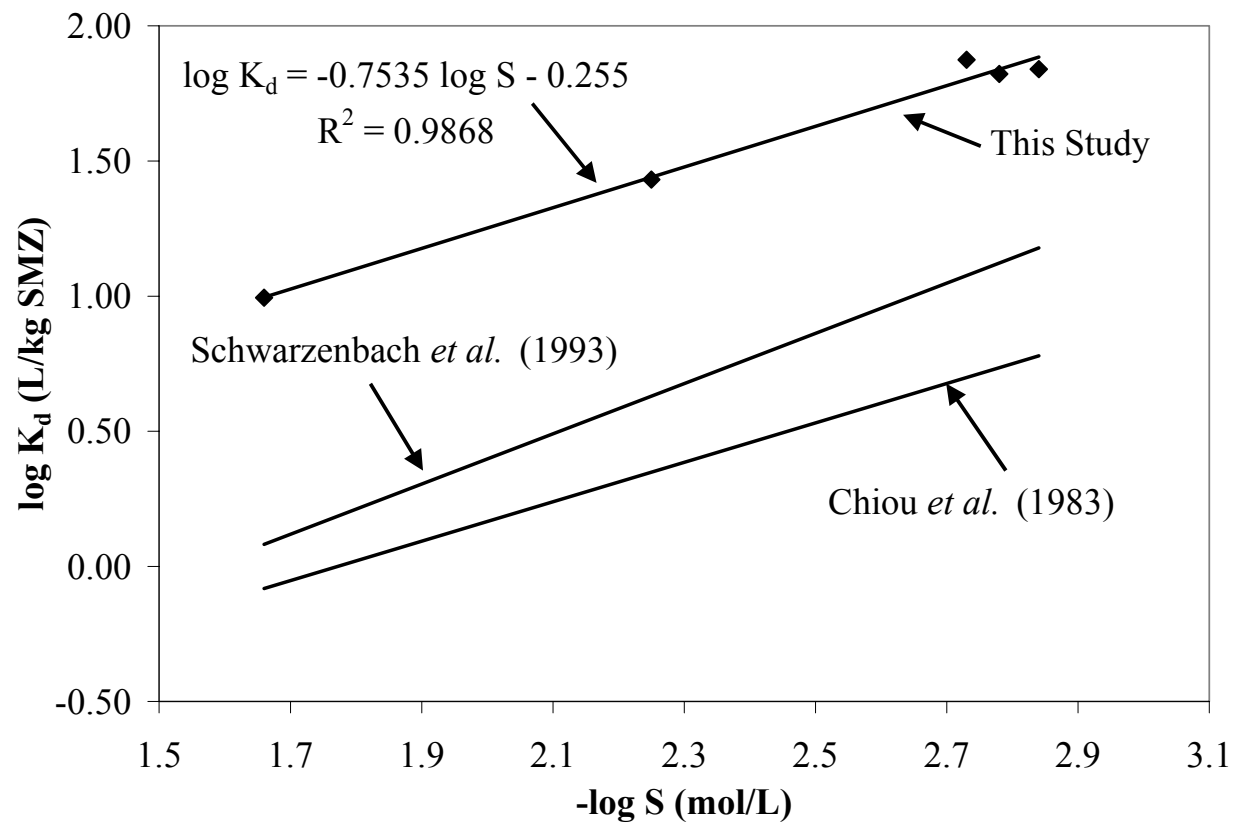

Figure 5.5 Relationships Between $K_{d}$ and $S$ 
As shown in both Figures 5.4 and 5.5, the regressions developed from this study result in much higher $K_{d}$ values than previously published correlations developed for soil organic matter. In addition, the correlation developed with $\mathrm{K}_{\mathrm{ow}}$ provides a better fit to the data than the correlation developed with solubility.

\subsubsection{Multi-Solute Batch Isotherms}

If competitive effects were to impact the sorption of BTEX compounds by SMZ, the distribution coefficients for benzene and toluene would significantly differ from those found in single-solute studies. The Ideal Adsorbed Solution Theory (IAST) indicates that sorption for compounds that have linear single-solute sorption isotherms will not change in the presence of multiple solutes (Weber and DiGiano, 1996). Multi-solute sorption studies in ultrapure water were conducted to determine whether this theory holds for SMZ.

Figure 5.6 shows the sorption isotherm data for all of the BTEX compounds in the multi-solute study. Linear regressions and distribution coefficients are not included in Figure 5.6 to minimize clutter. Rather, the coefficients of determination $\left(\mathrm{R}^{2}\right)$, distribution coefficients, and $95 \%$ confidence limits on $\mathrm{K}_{\mathrm{d}}$ are reported in Table 5.7. As shown in Figure 5.6, the data for ethylbenzene and the xylenes lie very close to one another. The similarity of the data may be explained because the solubilities of ethylbenzene and all of the xylenes are relatively close in value. Thus, each exhibits approximately the same affinity for SMZ. The $\mathrm{R}^{2}$ values for each isotherm show the goodness of fit for all of the data gathered during this test. The $\mathrm{K}_{\mathrm{d}}$ values presented in Table 5.11 represent the slope of each isotherm when the y-intercept for the model

$$
q_{e}=K_{d} C_{e}+y_{\text {intercept }}
$$

was forced to equal zero. However, determination of the $95 \%$ confidence limits for the data used to develop the isotherms showed that none of the y-intercept values were statistically different from zero, even when they were not forced to this value. This is represented in Figure 5.7 for a benzene isotherm plotted on a linear scale with 95\% confidence limits on the y-intercept. Hence, as widely accepted, Equation 5.1 describes the linear sorption of these non-polar organic compounds quite well. Though data are not presented here, similar results were found for all remaining isotherms.

Table 5.11 Multi-Solute Isotherm Distribution Coefficients for BTEX in Ultrapure Water

\begin{tabular}{|l|l|l|l|}
\hline Compound & $\mathbf{R}^{\mathbf{2}}$ & $\begin{array}{l}\mathbf{K}_{\mathbf{d}}(\mathbf{L} / \mathbf{g} \\
\mathbf{S M Z})\end{array}$ & $\begin{array}{l}\mathbf{9 5 \%} \text { Confidence Limits on } \\
\mathbf{K}_{\mathbf{d}}\end{array}$ \\
\hline $\begin{array}{l}\text { Benzene } \\
\text { Toluene }\end{array}$ & 0.9993 & 0.00982 & $0.00968,0.00101$ \\
$\begin{array}{l}\text { Ethylbenzene } \\
\text { m- \& p- }\end{array}$ & 1.000 & 0.0270 & $0.02699,0.0271$ \\
$\begin{array}{l}\text { Xylenes } \\
\text { o-Xylene }\end{array}$ & 0.9999 & 0.0692 & $0.0687,0.0692$ \\
\hline
\end{tabular}




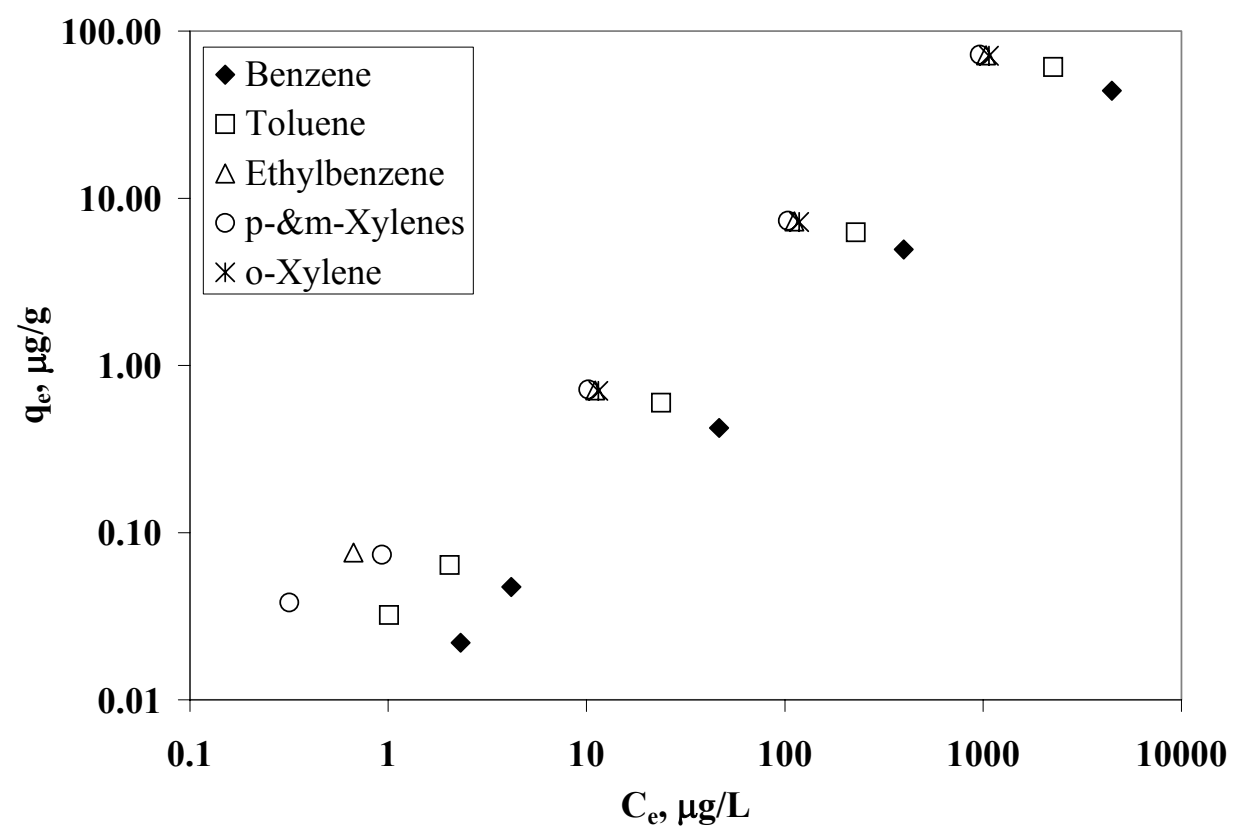

Figure 5.6 Multi-Solute Sorption Isotherms for BTEX on SMZ in ultrapure Water

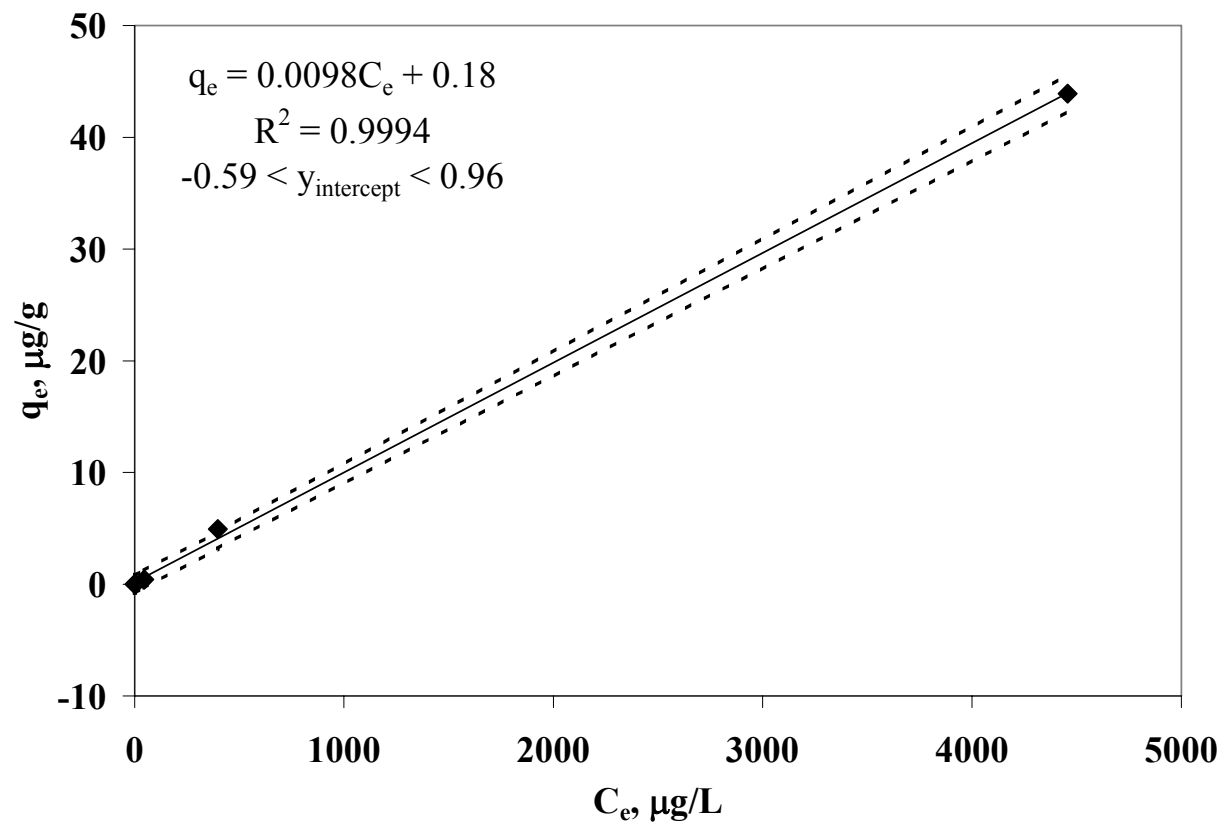

Figure 5.7 Benzene Sorption Isotherm in Presence of Other BTEX Compounds with 95\% Confidence Limits on Data (shown in dashed lines) and y-Intercept 
The average removal efficiencies for all of the BTEX compounds in a combined system are presented in Table 5.12. Again, the percent removed for each compound remained relatively constant as expected for a linear isotherm. The removal of ethylbenzene and the xylenes was substantially greater than that of benzene or toluene. This result supports the use of benzene and toluene as design compounds for treatment systems because they will most likely be the compounds that will require the largest volume of SMZ to meet design criteria. In addition to showing the least affinity for SMZ, benzene and toluene are also typically found in higher concentrations in produced water than other BTEX compounds.

Table 5.12 BTEX Removal Efficiencies for SMZ in Multi-Solute Sorption Study

\begin{tabular}{|l|l|}
\hline Compound & $\begin{array}{l}\text { Removal Efficiency } \\
(\%)\end{array}$ \\
\hline Benzene & 56 \\
Toluene & 78 \\
Ethylbenzene & 92 \\
m- \& p- & 91 \\
$\begin{array}{l}\text { Xylenes } \\
\text { o-Xylene }\end{array}$ & 93 \\
\hline
\end{tabular}

$\underline{\text { Statistical Comparisons of Single-Solute and Multi-Solute Sorption Isotherms }}$

As stated in Chapter 4, statistical comparison of the isotherms between single-solute and multi-solute studies was examined through the use of hypothesis testing. Separate regression fits were conducted to compare benzene and toluene single-solute isotherms with their corresponding multi-solute isotherms. The null hypothesis for these tests was that the slopes (distribution coefficients) for each isotherm were equal. By proving that the slope for the single-solute isotherm was not greater than, less than, or unequal to the slope for the multi-solute isotherm, the null hypothesis could be confirmed. Were a slope found to be significantly different from another, the null hypothesis was rejected and these slopes were determined to be unequal.

Table 5.13 includes the results from these statistical tests. With a $99.95 \%$ confidence level, the single-solute and multi-solute isotherms for both benzene and toluene were found to be statistically equal. No competitive effects could be distinguished in the multi-solute sorption test. This is in contrast to results found by other researchers who cited significant multi-solute effects in aqueous systems (Stuart et al., 1991). Stuart et al. studied the effects of competition between benzene, toluene, and the xylenes (BTX). Toluene and the xylenes were shown to experience less sorption in the presence of the other BTX compounds while benzene sorption increased in the presence of these compounds. However, the Stuart et al. study was conducted with a natural sandy loam soil. The discrepancy in the results found in the present research and those found by Stuart et al. may be due to the differences in chemical and physical characteristics between SMZ and natural soils.

Because competitive effects were not apparent during this study, the published correlations that were used to compare the observed and predicted $\mathrm{K}_{\mathrm{d}}$ values for benzene 
and toluene in the single-solute studies would still result in erroneous sorption predictions for solutions containing multiple solutes. However, the regressions with the data collected in this research show good correlation between $\mathrm{K}_{\mathrm{ow}}$ and $\mathrm{K}_{\mathrm{d}}$ as well as between $\mathrm{S}$ and $K_{d}$. Again, these regressions are shown above in Figures 5.4 and 5.5.

Table 5.13 Results from Hypothesis Testing for Single-Solute and Multi-Solute Sorption Studies in Ultrapure Water

\begin{tabular}{|l|l|l|l|l|}
\hline Compound & $\begin{array}{l}\mathbf{K}_{\mathbf{d}} \text { from } \\
\text { Single- } \\
\text { Solute } \\
(\mathbf{L} / \mathbf{k g})\end{array}$ & $\begin{array}{l}\mathbf{K}_{\mathbf{d}} \text { from } \\
\text { Multi- } \\
\text { Solute } \\
(\mathbf{L} / \mathbf{k g})\end{array}$ & $\begin{array}{l}\text { T- } \\
\text { Value }\end{array}$ & $\begin{array}{l}\text { Validity of Null Hypothesis for Equal } \\
\text { Slopes between Single and Multi-solute } \\
\text { Isotherms }\end{array}$ \\
\hline Benzene & 9.5 & 9.82 & -0.19 & Valid \\
Toluene & 29.1 & 27.0 & 0.64 & Valid \\
\hline
\end{tabular}

Conclusions for Single-Solute and Multi-Solute Sorption Studies in ultrapure Water

Benzene and toluene sorption to SMZ can be described with linear isotherms in both single-solute and multi-solute systems. A multi-solute study demonstrated that the remaining BTEX compounds also follow strong linear trends throughout a large range of concentrations and sorption densities. Statistical regressions showed that the presence of ethylbenzene and the xylenes does not significantly change the distribution coefficients for benzene or toluene. In addition, the magnitude of distribution coefficients are inversely related to the aqueous solubilities of the BTEX compounds as shown in Figure 5.5. The most soluble chemicals, benzene and toluene, show the least removal by SMZ. Therefore, the removal of these compounds should be used as design criteria for systems that incorporate SMZ for the treatment of BTEX-contaminated waste streams.

Predicted distribution coefficients found through published correlations should not be used to describe the sorption of BTEX compounds to SMZ. These relationships dramatically underestimate the distribution coefficients found in this research. A possible reason for this may be that SMZ has sufficiently different chemical properties from soil to preclude the use of published correlations for sorption to this material. However, the regressions that were developed in this research show good correlation between the octanol-water partition coefficient and distribution coefficient as well as between aqueous solubility and distribution coefficient. Hence, these regressions may describe the sorption to SMZ better than previously published correlations developed for natural soil and sediment.

\subsubsection{Batch Studies in High Salinity Background Water}

Produced water can range in salinity from 100 ppm - 300,000 ppm (Fillo et al., 1992), and many researchers have shown that increasing ionic strength tends to decrease the aqueous solubility of non-polar organic compounds (Schwarzenbach et al., 1993). Both of these facts support the hypothesis of this research that increased solution salinity will enhance the removal of BTEX compounds from produced water through sorption onto SMZ. This hypothesis was tested through sorption studies conducted with BTEX compounds in solutions of varying salinities for both single-solute benzene experiments 
and multi-solute BTEX experiments. The solutions were made with different amounts of $\mathrm{NaCl}, \mathrm{CaCl}_{2}, \mathrm{KCl}$, and $\mathrm{MgSO}_{4}$ dissolved in ultrapure water. Results from the singlesolute and multi-solute studies were compared through hypothesis testing.

As mentioned in Chapter 3, Setchenow developed an equation in 1889, relating changes in aqueous solubility to the total salt concentration present in solution (Setchenow, 1889). This equation is presented below:

$$
\log \left[\frac{C_{w}^{s a t}}{C_{w, \text { salt }}}\right]=K^{s}[\text { salt }]_{t}
$$

where the numerator and denominator in the logarithm represent the solubility of a compound in pure water and a saline solution, respectively, $\mathrm{K}_{\mathrm{s}}$ is the salting coefficient, and $[\mathrm{salt}]_{\mathrm{t}}$ is the total molar salt concentration present in solution. Through the use of this correlation and the following correlation from Schwarzenbach et al. (1993), distribution coefficients for different salt concentrations were predicted using $\mathrm{K}_{d}=\mathrm{K}_{\mathrm{om}} \mathrm{f}_{\mathrm{om}}$.

$$
\log K_{o m}=-0.93 \log S-0.17
$$

In Equation 5.5, $\mathrm{K}_{\mathrm{om}}$ represents the partitioning coefficient onto organic matter and $\mathrm{S}$ is the aqueous solubility of a certain compound. This relationship does not take salt effects into account until Equation 5.4 is substituted into it, as explained below.

If the predicted distribution coefficients were to match those that were observed in the sorption studies, future design work for BTEX removal could be conducted with only the knowledge of salt concentration in the waste stream rather than through lab-scale batch tests.

\subsubsection{Benzene Sorption onto SMZ in the Presence of Different Salt Concentrations}

The sorption isotherms for benzene in ultrapure water and saline water with salt concentrations of 30,000 ppm, and 231,000 ppm are shown in Figure 5.8. The correlation coefficients, distribution coefficients, and 95\% confidence limits on $\mathrm{K}_{\mathrm{d}}$ are presented in Table 5.14. The data for benzene sorption in ultrapure water in Figure 5.8 encompass all of the data gathered for benzene in a single-solute system. However, in Table 5.14 the distribution coefficients and corresponding parameters are differentiated between the data gathered in the previous single-solute experiments with ultrapure water and the data gathered in control samples analyzed during the saline solution experimental phase. This differentiation was necessary because the isotherm developed for ultrapure water during the salinity studies was different from the previously developed isotherm (although, not statistically). Indeed, hypothesis testing used to determine the statistical difference between these two isotherms using a confidence level of $99.95 \%$ based on preliminary experiments indicated that the two isotherms were equivalent as shown in Table 5.15. 


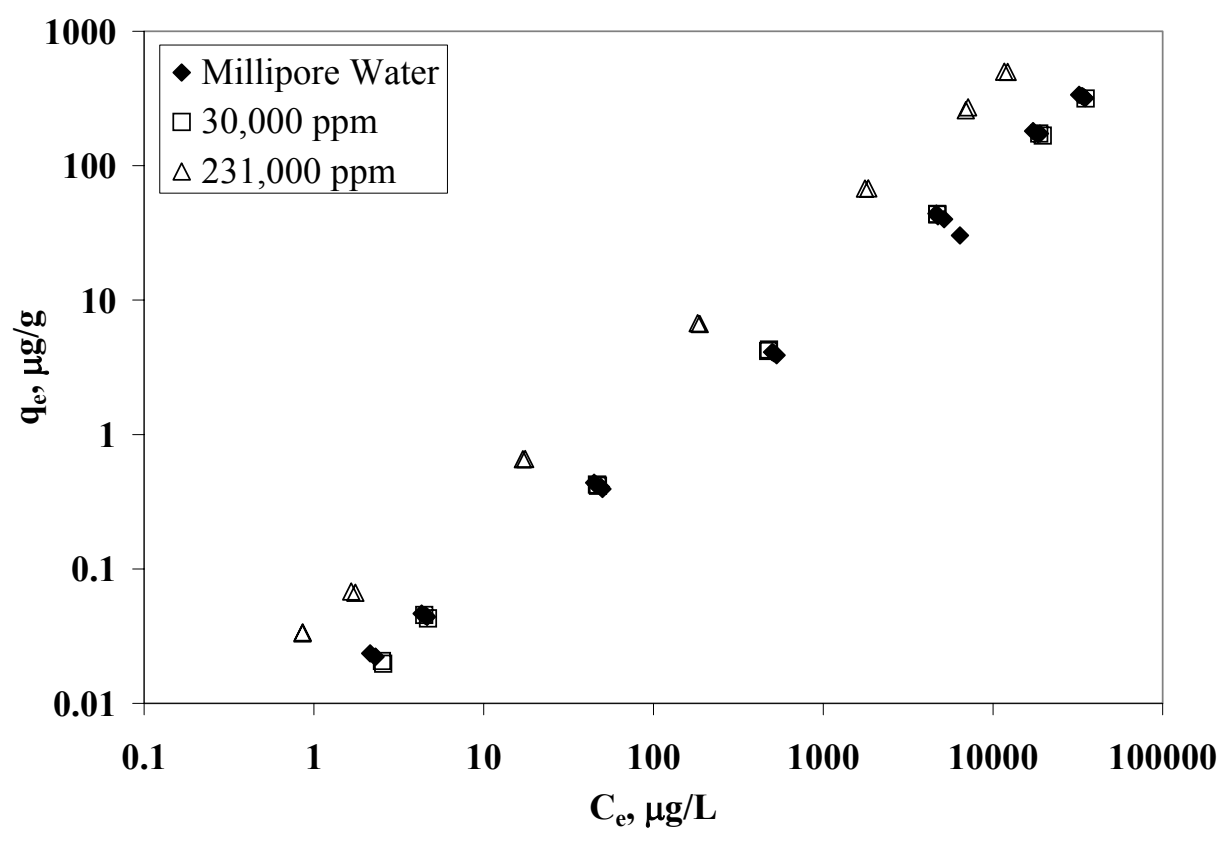

Figure 5.8 Benzene Sorption Isotherms at Differing Solution Salinities

Table 5.14 Distribution Coefficients for Benzene Isotherms in Ultrapure and Saline Water

\begin{tabular}{|l|l|l|l|}
\hline Salinity (ppm) & $\mathbf{R}^{\mathbf{2}}$ & $\begin{array}{c}\mathbf{K}_{\mathbf{d}} \\
\text { (L/g SMZ) }\end{array}$ & \multicolumn{1}{|c|}{$\begin{array}{c}\mathbf{9 5 \%} \text { Confidence } \\
\text { Limits on } \mathbf{K}_{\mathbf{d}}\end{array}$} \\
\hline $\begin{array}{l}\text { ultrapure (previously) } \\
\text { ultrapure (saline } \\
\text { study) }\end{array}$ & 0.9941 & 0.00947 & $0.00934,0.00960$ \\
$\mathbf{3 0 , 0 0 0}$ & 0.9997 & 0.0105 & $0.0103,0.0107$ \\
$\mathbf{2 3 1 , 0 0 0}$ & 0.9991 & 0.00895 & $0.00887,0.00903$ \\
\hline
\end{tabular}

Comparisons between the isotherm generated in a 30,000 ppm salt solution suggested that the distribution coefficient in the saline solution was slightly lower than the value determined from experiments in ultrapure water; however, only one of the ultrapure $\mathrm{K}_{\mathrm{d}}$ values was statistically different than the $30,000 \mathrm{ppm} \mathrm{K}_{\mathrm{d}}$ value. In contrast, hypothesis testing showed that the isotherm generated for benzene in a $231,000 \mathrm{ppm}$ salt solution had a significantly greater slope than the two ultrapure isotherms and the $30,000 \mathrm{ppm}$ salt solution isotherm. 
Table 5.15 Results for Hypothesis Testing of Isotherms Generated in Single-Solute (Benzene) Studies in Ultrapure Water and Salt Solutions

\begin{tabular}{|l|l|l|}
\hline Isotherms Being Compared & T-Value & $\begin{array}{l}\text { Validity of Null } \\
\text { Hypothesis for Equal } \\
\text { Slopes between } \\
\text { Ultrapure and Saline } \\
\text { Water Isotherms }\end{array}$ \\
\hline ultrapure (previous), ultrapure & -2.93 & Valid \\
\hline ultrapure (previous), 30,000 ppm & 2.36 & Valid \\
\hline ultrapure, 30,000 ppm & 11.67 & Invalid \\
\hline ultrapure (previously), 231,000 ppm & -53.3 & Invalid \\
\hline ultrapure, 231,000 ppm & -40.1 & Invalid \\
\hline 30,000 ppm, 231,000 ppm & -63.0 & Invalid \\
\hline
\end{tabular}

\subsubsection{Multi-Solute BTEX Sorption onto SMZ in Salt Solutions}

As in the studies conducted in ultrapure water, the effects of multiple organic solutes on sorption were investigated through multi-solute batch tests. Because all of the BTEX compounds and three different salt solutions were tested, a great deal of data were generated. Representative data are presented in this chapter, but most are included in Appendix B. The test results for benzene and toluene are shown in Figures 5.9 and 5.10. The basic patterns found in the data for these two chemicals were representative of the remaining BTEX compounds. This batch test was conducted with duplicates rather than triplicates because of the space constraint for the headspace autosampler. However, as seen in Figures 5.9 and 5.10, data from replicates were close to one another for both benzene and toluene. Similar results were also observed for the remaining BTEX compounds.

Although graphical results for ethylbenzene and the xylenes are not shown here, the correlation coefficients, distribution coefficients, and $95 \%$ confidence limits on $\mathrm{K}_{\mathrm{d}}$ values for all of the BTEX compounds in 30,000 ppm and 100,000 ppm salt solutions are included in Table 5.16. Graphs of the isotherms for the remaining BTEX compounds in these same salt solutions and the data used to generate those isotherms are included in Appendix B. Because of the losses mentioned in Chapter 4, the data gathered for the 200,000 ppm salt solution are presented only as points in Figures 5.9 and 5.10 as well as in Appendix B. However, Table 5.17 includes the distribution coefficients calculated for each duplicate at this salt concentration. 


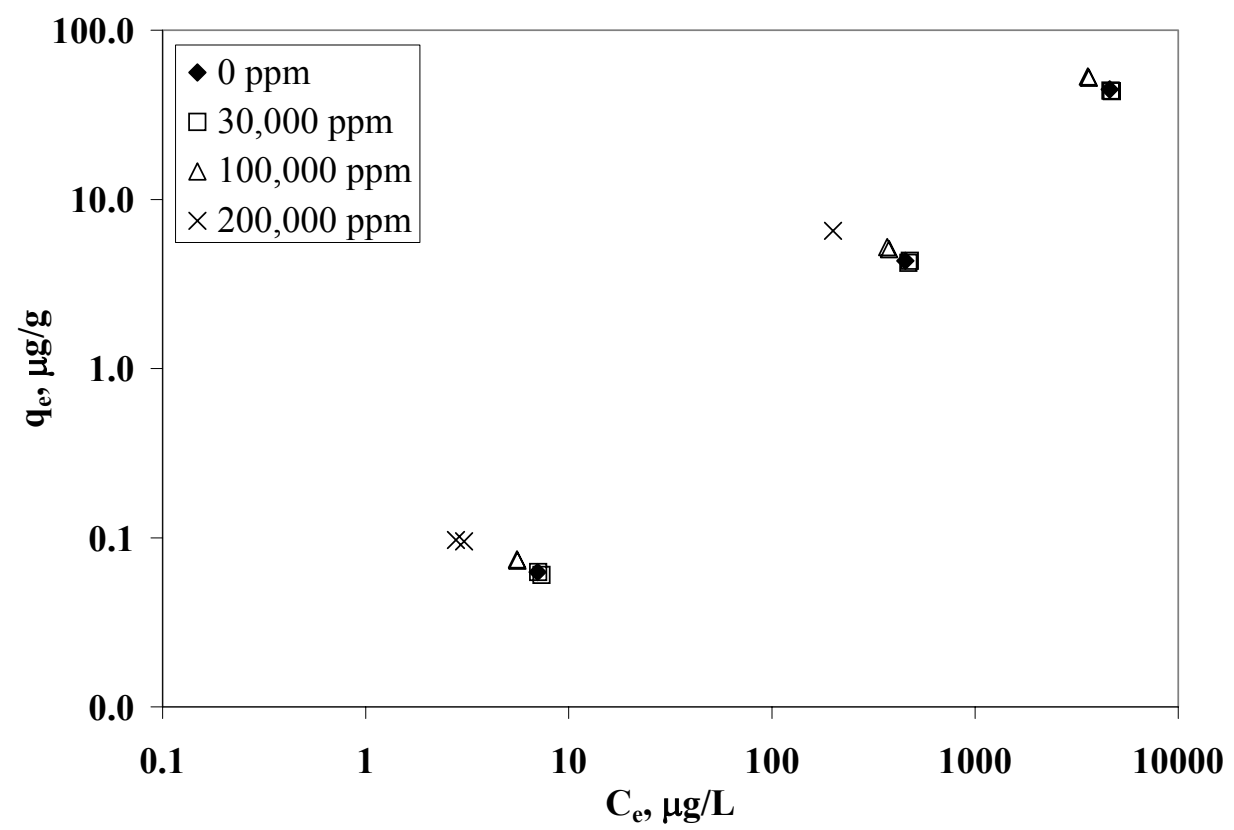

Figure 5.9 Benzene Sorption Isotherms at Differing Solution Salinities and in the Presence of the Remaining BTEX Compounds

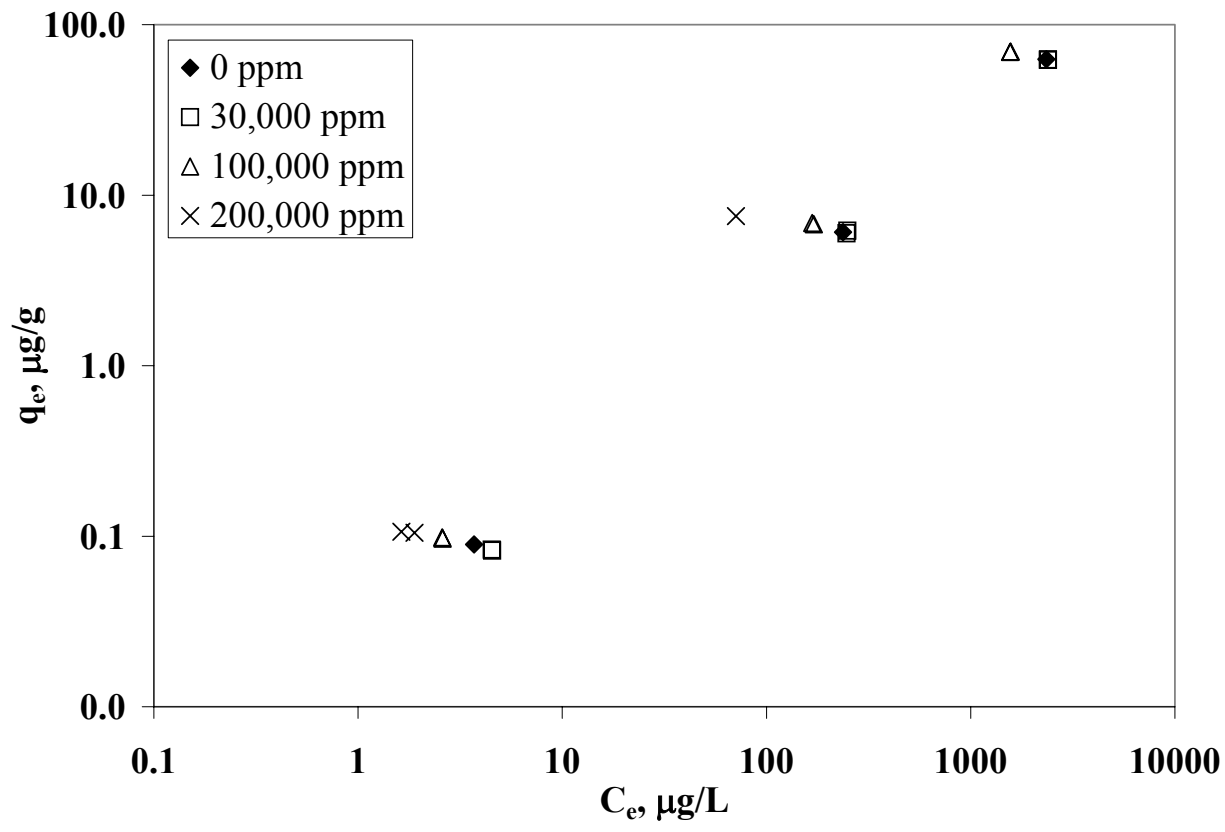

Figure 5.10 Toluene Sorption Isotherms at Differing Solution Salinities and in the Presence of the Remaining BTEX Compounds 
Table 5.16 Distribution Coefficients for BTEX Sorption Isotherms in Ultrapure and Saline Background Water

\begin{tabular}{|l|l|l|l|l|}
\hline Compound & Salinity (ppm) & $\mathbf{R}^{2}$ & $\mathbf{K}_{\mathbf{d}}(\mathbf{L} / \mathbf{g ~ S M Z )}$ & $\begin{array}{l}\text { 95\% Confidence } \\
\text { Limits on } \mathbf{K}_{\mathbf{d}}\end{array}$ \\
\hline Benzene & ultrapure & 1.000 & 0.00970 & $0.00968,0.00972$ \\
\hline & 30,000 & 0.9997 & 0.00934 & $0.00929,0.00939$ \\
\hline & 100,000 & 0.9997 & 0.0146 & $0.0145,0.0147$ \\
\hline Toluene & ultrapure & 0.9998 & 0.0267 & $0.0266,0.0268$ \\
\hline Ethylbenzene & 30,000 & 0.9998 & 0.0261 & $0.02607,0.02613$ \\
\hline & 100,000 & 0.9997 & 0.0444 & $0.0442,0.0446$ \\
\hline & ultrapure & 0.9998 & 0.0659 & $0.0655,0.0663$ \\
\hline m- \& p-Xylenes & 30,000 & 0.9996 & 0.0676 & $0.06759,0.06761$ \\
\hline & ultrapure & 0.9998 & 0.0735 & $0.0731,0.0739$ \\
\hline & 30,000 & 0.9997 & 0.0762 & $0.07619,0.07621$ \\
\hline o-Xylene & 100,000 & 0.9997 & 0.143 & $0.1420,0.1434$ \\
\hline & ultrapure & 0.9998 & 0.0642 & $0.0638,0.0646$ \\
\hline & 30,000 & 0.9995 & 0.0658 & $0.06578,0.06582$ \\
\hline & 100,000 & 0.9997 & 0.119 & $0.1180,0.1190$ \\
\hline
\end{tabular}

Table 5.17 Distribution Coefficients Calculated for Individual Data Points in 200,000 ppm Salt Solution

\begin{tabular}{|l|l|l|l|l|l|}
\hline $\begin{array}{l}\text { Initial BTEX } \\
\text { Concentration } \\
(\mathbf{m g} / \mathbf{L})\end{array}$ & Benzene & Toluene & Ethylbenzene & $\begin{array}{l}\mathbf{m}-\mathbf{\&} \text { p- } \\
\text { Xylenes }\end{array}$ & $\begin{array}{l}\text { o- } \\
\text { Xylene }\end{array}$ \\
\hline $\mathbf{0 . 0 1 5}$ & 0.0349 & 0.0653 & ND & ND & ND \\
\hline $\mathbf{0 . 0 1 5}$ & 0.0312 & 0.0554 & ND & ND & ND \\
\hline $\mathbf{1}$ & 0.0326 & 0.107 & 0.331 & 0.385 & 0.318 \\
\hline
\end{tabular}

Note: ND - not detected 
Because of the affinities of ethylbenzene and the xylenes for SMZ, the final concentrations of these compounds were below detection limits for the gas chromatograph. As a result, distribution coefficients could not be calculated for these compounds at the initial concentration of $0.015 \mathrm{mg} / \mathrm{L}$. In addition, the duplicate values for the sample containing an initial BTEX concentration of $1 \mathrm{mg} / \mathrm{L}$ could not be presented in Table 5.17 because one of the duplicates broke during centrifugation. However, the values that were obtained for the distribution coefficients do yield some interesting information. The values for benzene are relatively close and can probably be used to generate an isotherm. Distribution coefficients for toluene did not correspond well between the lower and higher initial concentrations. Hence, these values probably do not accurately describe an isotherm at 200,000 ppm salinity. The magnitude of the values for ethylbenzene and the xylenes is substantially greater than $\mathrm{K}_{\mathrm{d}}$ values for benzene or toluene. This is in keeping with the trend apparent throughout the other batch tests. These compounds have greater affinity for the hydrophobic phase and therefore, they are removed more effectively by SMZ. In addition, all of the values presented in Table 5.17 are greater than the distribution coefficients in solutions of lower salinity. Hence, a general conclusion that can be made about these data is that the $200,000 \mathrm{ppm}$ salt solution creates an environment that allows the BTEX compounds to more easily leave the aqueous phase for the more hydrophobic phase in SMZ.

Figure 5.11 shows the increase in distribution coefficient with increasing salinity. Again, no statistically significant increase was found between the $\mathrm{K}_{\mathrm{d}}$ values in ultrapure water and 30,000 ppm, but large increases were found for the 100,000 ppm salt concentration. This trend is more apparent for the least soluble of the BTEX compounds than for benzene or toluene, but Table 5.16 shows that the $\mathrm{K}_{\mathrm{d}}$ values for these compounds also show increases at the higher salinities.

Statistical analysis also verified the hypothesis that the presence of multiple organic solutes did not significantly alter the sorption of benzene at 30,000 ppm. The null hypothesis was that the distribution coefficients found in the saline single-solute benzene and multi-solute benzene were equal at similar salinities. This null hypothesis was tested by determining whether the distribution coefficients were statistically greater than, less than, or unequal to each other. By proving that none of these scenarios hold for the isotherms being compared, it can be said that the null hypothesis is valid and that the distribution coefficients for each isotherm are statistically equal.

Comparisons were also made between the distribution coefficients found in the previous ultrapure water multi-solute study and those determined at the various salinities and in ultrapure water used in the controls for the present multi-solute study. Table 5.18 summarizes the results from these hypothesis tests. The results for the Millipore water compared to the Millipore water during the saline study show the ability to replicate multi-solute isotherms in Millipore water. As shown in Table 5.18, the isotherms for all of the BTEX compounds were found to be statistically the same in both tests involving only Millipore water. The major conclusion to be drawn from these results is that the distribution coefficient increased for the higher salt concentration of $100,000 \mathrm{ppm}$. This result is supported by the data collected at 200,000 ppm and the single-solute benzene data collected at 231,000 ppm. 


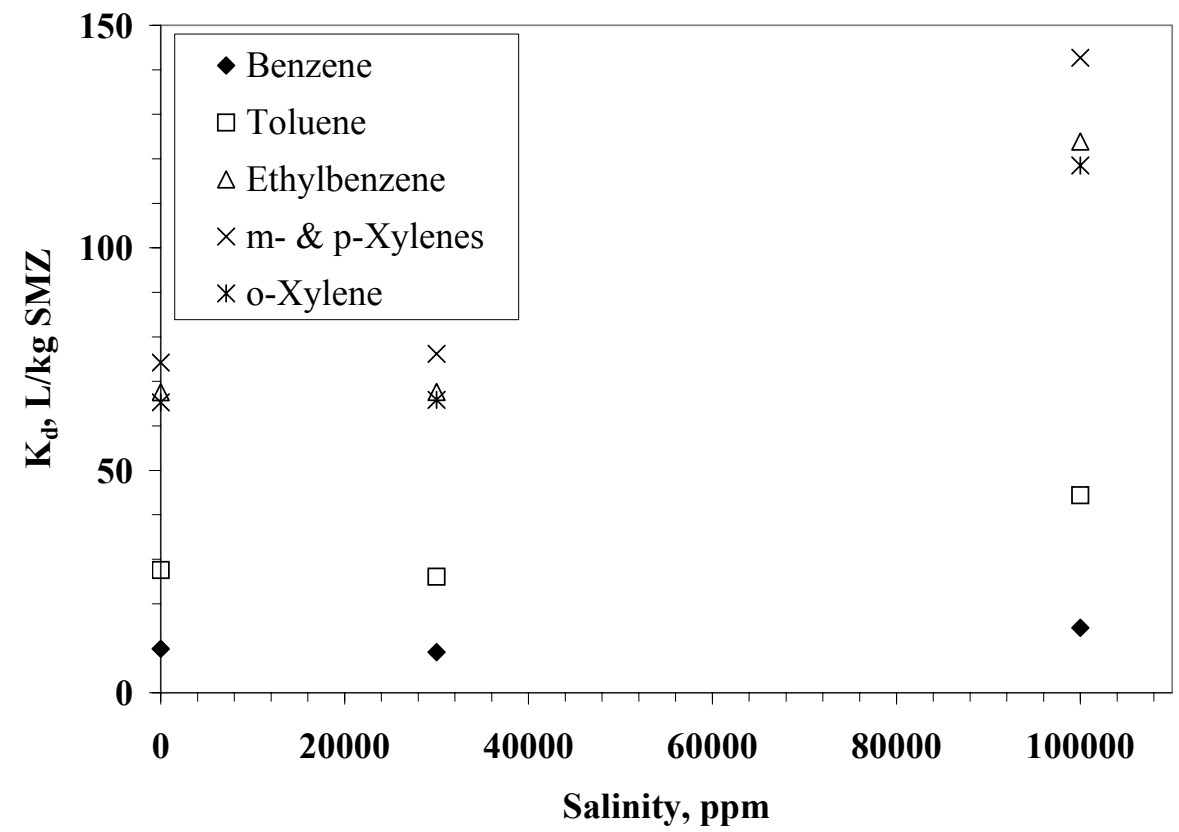

Figure 5.11 Distribution Coefficient as a Function of Salinity for BTEX Compounds Sorbed to SMZ

\subsubsection{Predictive and Empirical Descriptions of BTEX Sorption in Saline Water}

The ability to predict how sorption will change in the presence of various salinities would prove valuable for industries that generate saline waste streams that vary in salinity with time or temperature. Hence, Equations 5.4 and 5.5 were used to determine whether observed distribution coefficients could be accurately predicted for benzene and toluene. Other BTEX compounds were not addressed in this analysis because salting coefficients were found only for $\mathrm{NaCl}$ solutions containing benzene $\left(\mathrm{K}^{\mathrm{s}}=0.196\right)$ and toluene $\left(\mathrm{K}^{\mathrm{s}}=0.240\right)$ (Schwarzenbach et al., 1993; Peng and Wan, 1998).

Combining Equations 4.4 and 4.5 yields the following equation (Schwarzenbach et al., 1993):

$$
\log K_{\text {om,salt }}=\log K_{\text {om }}+a K^{s}[\text { salt }]
$$

where $\mathrm{K}_{\mathrm{om} \text {,salt }}$ is the partitioning coefficient for organic matter in the presence of salt, $a$ is 0.93 for aromatic hydrocarbons, and the other variables were previously defined (Schwarzenbach et al., 1993). Values for $\mathrm{K}_{\mathrm{om}}$ were calculated with Equation 5.2 where $\mathrm{K}_{\mathrm{d}}$ values were averages of the values found for the batch studies conducted in ultrapure water and $\mathrm{f}_{\text {om }}$ was 0.051 for $\mathrm{SMZ}$. Because $\mathrm{NaCl}$ was the primary salt used to generate saline solutions, salting coefficients for the other salts were not used in the analysis (Schwarzenbach et al., 1993). The molar $\mathrm{NaCl}$ concentrations were determined for each of the single-solute and multi-solute saline solutions, and Equation 5.6 was used to determine $\mathrm{K}_{\mathrm{om} \text {,salt. }}$ This value was then converted back into $\mathrm{K}_{\mathrm{d} \text {,salt }}$ with Equation 5.2. Results from this analysis for benzene and toluene are presented in Table 5.19. 
Table 5.18 Statistical Comparison Between Multi-Solute Studies Conducted in Ultrapure Water and Saline Solutions

\begin{tabular}{|c|c|c|c|l|}
\hline Compound & $\begin{array}{c}\text { Salinity } \\
\text { (ppm) }\end{array}$ & T-Value & $\begin{array}{c}\text { Result for } \\
\text { Null } \\
\text { Hypothesis }\end{array}$ & $\begin{array}{c}\text { Description of } \\
\text { Result }\end{array}$ \\
\hline Benzene & Ultrapure & 0.897 & Valid & $\mathrm{K}_{\mathrm{d} \text { Millipore }}=\mathrm{K}_{\mathrm{d} \text { Salt }}$ \\
\hline & 30,000 & 5.24 & Invalid & $\mathrm{K}_{\mathrm{d} \text { Millipore }}>\mathrm{K}_{\mathrm{d} \text { Salt }}$ \\
\hline Toluene & 100,000 & -28.0 & Invalid & $\mathrm{K}_{\mathrm{d} \text { Millipore }}<\mathrm{K}_{\mathrm{d} \text { Salt }}$ \\
\hline & Ultrapure & 3.51 & Valid & $\mathrm{K}_{\mathrm{d} \text { Millipore }}=\mathrm{K}_{\mathrm{d} \text { Salt }}$ \\
\hline & 30,000 & 7.80 & Invalid & $\mathrm{K}_{\mathrm{d} \text { Millipore }}>\mathrm{K}_{\mathrm{d} \text { Salt }}$ \\
\hline Ethylbenzene & Ultrapure & 6.90 & Valid & $\mathrm{K}_{\mathrm{d} \text { Millipore }}=\mathrm{K}_{\mathrm{d} \text { Salt }}$ \\
\hline & 30,000 & 2.42 & Valid & $\mathrm{K}_{\mathrm{d} \text { Millipore }}=\mathrm{K}_{\mathrm{d} \text { Salt }}$ \\
\hline & 100,000 & -61.6 & Invalid & $\mathrm{K}_{\mathrm{d} \text { Millipore }}<\mathrm{K}_{\mathrm{d} \text { Salt }}$ \\
\hline & Ultrapure & 2.79 & Valid & $\mathrm{K}_{\mathrm{d} \text { Millipore }}=\mathrm{K}_{\mathrm{d} \text { Salt }}$ \\
\hline m- \& p- & 1000 & -70.2 & Invalid & $\mathrm{K}_{\mathrm{d} \text { Millipore }}<\mathrm{K}_{\mathrm{d} \text { Salt }}$ \\
\hline Xylenes & 30,000 & -2.00 & Valid & $\mathrm{K}_{\mathrm{d} \text { Millipore }}=\mathrm{K}_{\mathrm{d} \text { Salt }}$ \\
\hline & 100,000 & .71 .7 & Invalid & $\mathrm{K}_{\mathrm{d} \text { Millipore }}<\mathrm{K}_{\mathrm{d} \text { Salt }}$ \\
\hline & Ultrapure & 4.00 & Valid & $\mathrm{K}_{\mathrm{d} \text { Millipore }}=\mathrm{K}_{\mathrm{d} \text { Salt }}$ \\
\hline & 30,000 & 0.887 & Valid & $\mathrm{K}_{\mathrm{d} \text { Millipore }}=\mathrm{K}_{\mathrm{d} \text { Salt }}$ \\
\hline & 100,000 & -22.6 & Invalid & $\mathrm{K}_{\mathrm{d} \text { Millipore }}<\mathrm{K}_{\mathrm{d} \text { Salt }}$ \\
\hline
\end{tabular}

Table 5.19 Comparison of Observed and Predicted Distribution Coefficients for Benzene and Toluene in Saline Solutions

\begin{tabular}{|c|cc|cc|}
\hline Salinity & \multicolumn{2}{|c|}{ Benzene } & \multicolumn{2}{c|}{ Toluene } \\
\hline (ppm) & $\begin{array}{c}\text { Predicted } \mathbf{K}_{\mathbf{d}} \\
\text { (L/kg) }\end{array}$ & $\begin{array}{c}\text { Observed } \mathbf{K}_{\mathbf{d}} \\
\text { (L/kg) }\end{array}$ & $\begin{array}{c}\text { Predicted } \mathbf{K}_{\mathbf{d}} \\
\text { (L/kg) }\end{array}$ & $\begin{array}{c}\text { Observed } \mathbf{K}_{\mathbf{d}} \\
(\mathbf{L} / \mathbf{k g})\end{array}$ \\
\hline $\mathbf{3 0 , 0 0 0}$ & 11.75 & $9.92^{\mathrm{a}}$ & 36.2 & 26.1 \\
$\mathbf{1 0 0 , 0 0 0}$ & 21.4 & 14.6 & 75.4 & 44.4 \\
$\mathbf{2 3 1 , 0 0 0}$ & 102 & 40.7 & - & - \\
\hline
\end{tabular}

${ }^{\mathrm{a}}$ Value was averaged between single-solute and multi-solute tests at 30,000 ppm. 
Because the observed and predicted $\mathrm{K}_{\mathrm{d}}$ values did not agree for this comparison, another comparison was performed between the observed values for $\mathrm{K}_{\mathrm{d}}$ and values that are predicted by:

$$
\log K_{d, \text { salt }}=\log K_{d, \text { Millipore }}+0.7535 K^{s}[\text { salt }]_{\text {total }}
$$

where $K_{d \text {,salt }}$ is the predicted value for the distribution coefficient in saline solutions and $K_{d, \text { Millipore }}$ is the observed distribution coefficient in Millipore water. This equation was generated by combining Equation 5.4 and the regression relating $\mathrm{K}_{\mathrm{d}}$ to $\mathrm{S}$ found in this study. Results for this comparison are shown in Figures 5.12 and 5.13. Figure 5.12 includes predicted and observed values for the distribution coefficient for benzene while Figure 5.13 includes these values for toluene.

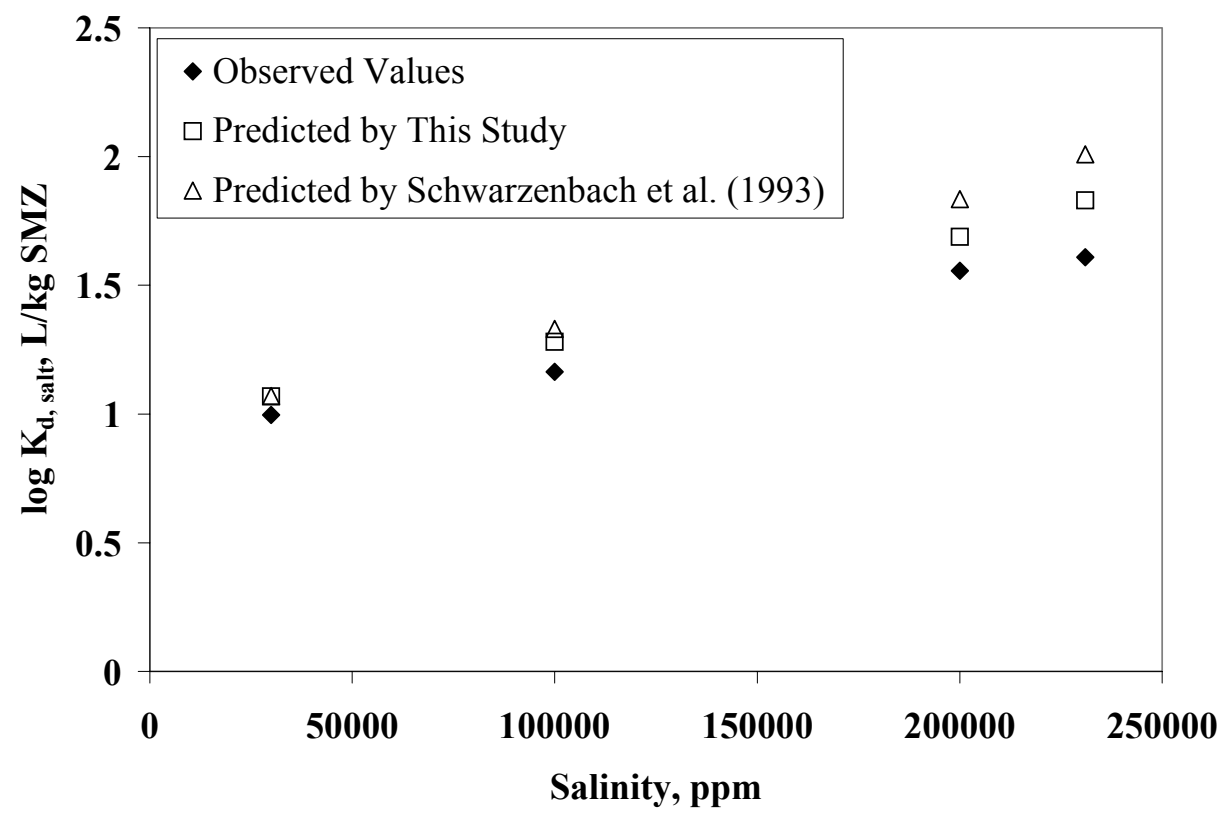

Figure 5.12 Observed and Predicted Distribution Coefficient Values for Benzene in Multi-Solute Saline Solutions

The values observed for benzene distribution coefficients in the 200,000 ppm salt solution were averaged and are included in Figure 5.12. Although the toluene distribution coefficient values at this salinity were not similar for various BTEX concentrations, the value found for $1 \mathrm{mg} / \mathrm{L}$ BTEX was used strictly for comparative purposes in Figure 5.13.

As shown in Figures 5.12 and 5.13, Equation 5.7 did not accurately predict the observed $\mathrm{K}_{\mathrm{d}}$ values. However, values predicted by Equation 5.7 were closer to observed distribution coefficients than those predicted by Equation 5.6. Hence, if rough estimates of distribution coefficients are required, Equation 5.7 may predict these values to within an order of magnitude. Nevertheless, accurate predictions of $K_{d}$ cannot be made with Equation 5.7. 


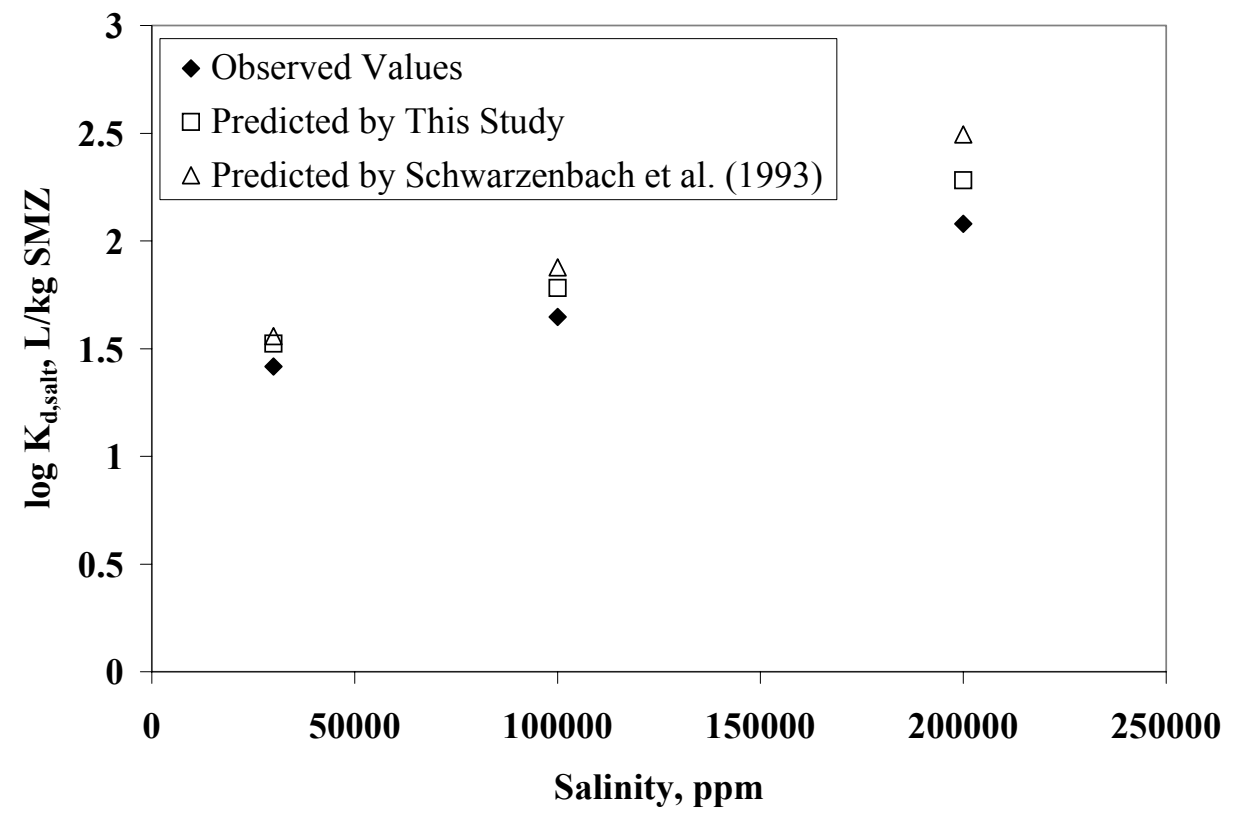

Figure 5.13 Observed and Predicted Distribution Coefficient Values for Toluene in Multi-Solute Saline Solutions

Also demonstrated in Figures 5.13 and 5.14 is that as salinity increases, the differences between predicted and observed values also increase for both the correlation developed during this study and the correlation developed by Schwarzenbach et al. (1993).

As a final step empirical relationships were developed to describe the variations in observed $\mathrm{K}_{\mathrm{d}}$ values and salt concentrations for all of the BTEX compounds. These regressions all took the basic form:

$$
\log K_{d, \text { salt }, \text { observed }}=a[\text { salt }]_{M}+b
$$

where $K_{d, \text { salt,observed }}$ represents observed distribution coefficients, [salt $]_{M}$ is the total molar salt concentration, $a$ is the empirically determined salting coefficient $\left(\mathrm{K}^{\mathrm{s}}\right)$ multiplied by the magnitude of the slope of the $\log \mathrm{K}_{\mathrm{d}}-\log \mathrm{S}$ regression (Figure 5.4), and $b$ is the logarithm of the distribution coefficient in pure water. The data used for these regressions are shown in Figure 5.14 and the calculated values for $\mathrm{R}^{2}, a, b$, and $\mathrm{K}^{\mathrm{s}}$ are included in Table 5.20. 


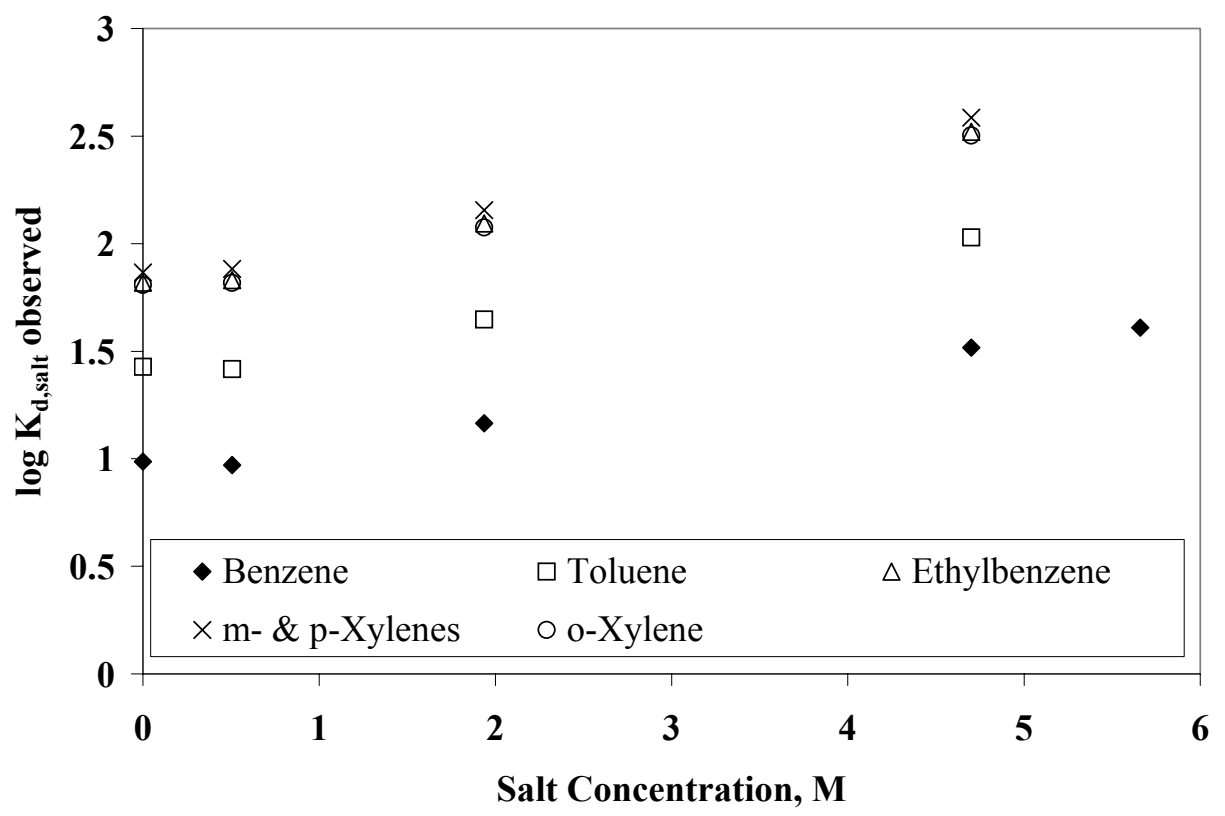

Figure 5.14 Data Used in $\log \mathbf{K}_{\mathrm{d}, \text { salt }}-[\mathrm{salt}]_{M}$ Regressions

Table 5.20 Regression Parameters for $\log K_{\mathrm{d}, \text { salt }}-[\text { salt }]_{M}$ Empirical Relationships

\begin{tabular}{|c|c|c|c|c|}
\hline Compound & $\mathbf{R}^{\mathbf{2}}$ & $\boldsymbol{a}\left(\mathbf{M}^{-\mathbf{1}}\right)$ & $\boldsymbol{b}$ & $\mathbf{K}^{\mathbf{s}}\left(\mathbf{M}^{\mathbf{- 1}}\right)$ \\
\hline Benzene & 0.9907 & 0.118 & 0.948 & 0.156 \\
\hline Toluene & 0.9874 & 0.135 & 1.39 & 0.179 \\
\hline Ethylbenzene & 0.9928 & 0.155 & 1.79 & 0.206 \\
\hline m- \& p-Xylenes & 0.9935 & 0.159 & 1.83 & 0.211 \\
\hline o-Xylene & 0.9928 & 0.154 & 1.78 & 0.204 \\
\hline
\end{tabular}

The goodness of fit of these regressions is represented by the $\mathrm{R}^{2}$ values in Table 5.17. These values are sufficient to estimate distribution coefficients for BTEX sorption onto SMZ in solutions of various salinities. Hence, the regressions can be used to quickly estimate the salt concentration required to reduce initial BTEX concentrations in solution to allowable effluent concentrations. Analysis of the salting coefficients calculated through these regressions shows that the values for benzene and toluene compare relatively well to values found in literature, 0.196 and 0.240 , respectively (Schwarzenbach et al., 1993; Peng and Wan, 1998). 


\subsubsection{Conclusions for Sorption of BTEX in Saline Solutions}

As in the batch tests for the single-solute and multi-solute tests conducted in ultrapure water, there were no significant competitive sorption effects between the BTEX compounds in the saline solutions. Increases in $\mathrm{Kd}$ values for the BTEX compounds with increasing salinity were apparent for $100,000 \mathrm{ppm}$ and higher salt concentrations, but could not be statistically proven for salt solutions of $30,000 \mathrm{ppm}$. Distribution coefficients for the compounds that initially had the lowest aqueous solubilities showed the most obvious increases, but sorption of benzene and toluene was also substantially enhanced by the presence of high concentrations of salt.

The prediction of $K_{d}$ values through Equations 5.2 to 5.7 showed that these predictions were significantly greater than observed values. As a result, empirically based regressions having the same form as the prediction equations were developed. Regressions performed using observed distribution coefficients and known salt concentrations for the BTEX compounds in saline solutions yielded correlations which could be used for estimating distribution coefficients during SMZ treatment system design.

\subsubsection{Effect of Temperature on BTEX Sorption to SMZ}

Temperature has been recognized as an important factor to define the sorption characteristics of different solutes and sorbents. Schwarzenbach et al. (1993) stated that the temperature effect on the change of organic phase activity coefficients was negligible for NOM in soil, and the aqueous phase activity coefficients would be the sole factor affecting sorption enthalpy for hydrophobic and moderately hydrophobic solutes. He also stated that below $15^{\circ} \mathrm{C}$ the solubility of benzene decreases with increasing temperature and above $20^{\circ} \mathrm{C}$ the solubility of benzene increases with increasing temperature. Bohon and Claussen (1951) also found that benzene, toluene, ethylbenzene and $\mathrm{m}, \mathrm{p}$-xylene exhibited a solubility minimum near $18^{\circ} \mathrm{C}$. As a result, it was initially assumed that the distribution coefficients for BTEX sorption onto SMZ would reach a maximum around $15-20^{\circ} \mathrm{C}$. However, Dewulf et al. (1999) observed increasing sorption capacity with increasing temperature $\left(2-25^{\circ} \mathrm{C}\right)$ in their study on sorption of BTEX to a Belgian riverine sediment. Due to the difference between SMZ and sediment and the limited temperature range considered by Dewulf and co-workers, examination of the impact of temperature was warranted in this study. The temperature range of $4-36^{\circ} \mathrm{C}$ was chosen in order to encompass the minimum solubility temperatures for BTEX and the environmental temperature range found in many field scale applications.

The initial concentration of BTEX used in the batch isotherm studies included 0, 100, 1000,10000 , and $40000 \mu \mathrm{g} / \mathrm{L}$. Sorption was evaluated on $14 \times 40$ mesh size SMZ. Distribution coefficients $\left(\mathrm{K}_{\mathrm{d}}\right)$ were calculated for all of the isotherms using the LINEST linear regression function in Microsoft Excel. The linear isotherm model presented in equation 5.1 was employed. As shown in Figure 5.15 for toluene, sorption was linear through a wide range of concentrations. This result held true for all of the BTEX compounds at all temperatures. Based on the values of the distribution coefficients (shown in Table 5.21), a much greater affinity of ethylbenzene and xylenes for SMZ was observed compared to toluene and benzene for all temperatures tested. These results are 
consistent with the results of the experiments conducted for the ionic strength and multisolute studies.
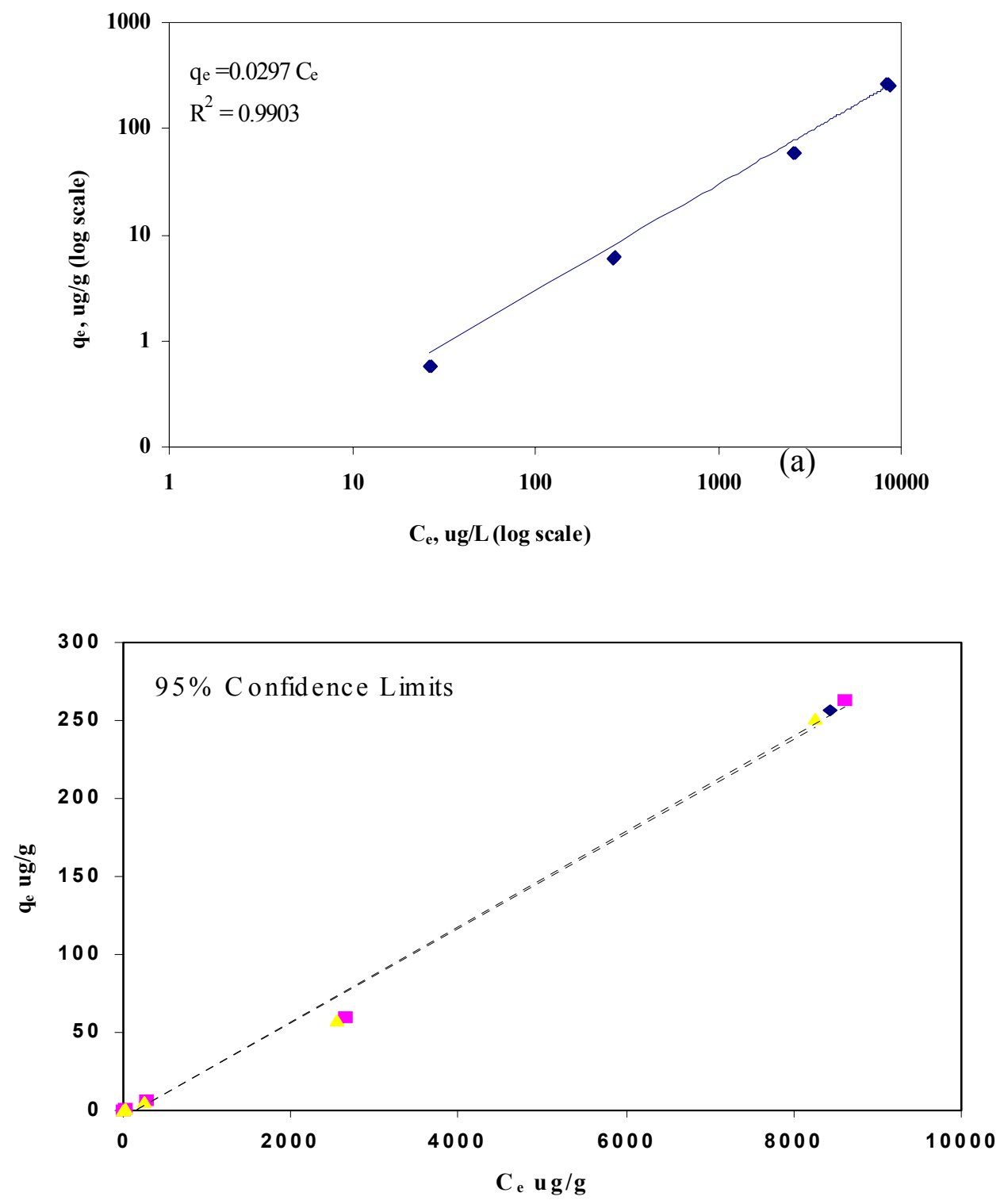

(b)

Figure 5.15 Sorption Isotherm for Toluene on SMZ in Ultrapure Water at 20oC-

(a) Linear scale showing data and regression equation (b) Logarithmic scale showing data and $95 \%$ confidence limits on the regression line. 
Table 5.21 Linear Isotherm Parameters for BTEX Multi-Solute Sorption to SMZ in ultrapure Water at Different Temperatures

\begin{tabular}{|c|c|c|c|}
\hline Compound & Temp. (K) & $\mathbf{R}^{2}$ & Kd (L/g SMZ) \\
\hline \multirow[t]{6}{*}{ Benzene } & 277.15 & 0.9899 & 0.0085 \\
\hline & 283.15 & 0.9899 & 0.0094 \\
\hline & 288.15 & 0.9924 & 0.0094 \\
\hline & 293.15 & 0.9886 & 0.0109 \\
\hline & 298.15 & 0.9931 & 0.0117 \\
\hline & 309.15 & 0.995 & 0.012 \\
\hline \multirow[t]{6}{*}{ Toluene } & 277.15 & 0.9883 & 0.0219 \\
\hline & 283.15 & 0.9892 & 0.025 \\
\hline & 288.15 & 0.9909 & 0.0263 \\
\hline & 293.15 & 0.9903 & 0.0297 \\
\hline & 298.15 & 0.9941 & 0.0319 \\
\hline & 309.15 & 0.996 & 0.0329 \\
\hline \multirow[t]{6}{*}{ Ethylbenzene } & 277.15 & 0.9829 & 0.0534 \\
\hline & 283.15 & 0.9851 & 0.0628 \\
\hline & 288.15 & 0.988 & 0.0671 \\
\hline & 293.15 & 0.9896 & 0.0742 \\
\hline & 298.15 & 0.9933 & 0.0794 \\
\hline & 309.15 & 0.9946 & 0.0842 \\
\hline \multirow{6}{*}{ m,p-Xylene } & 277.15 & 0.9846 & 0.0601 \\
\hline & 283.15 & 0.9869 & 0.0699 \\
\hline & 288.15 & 0.9881 & 0.0755 \\
\hline & 293.15 & 0.9895 & 0.0829 \\
\hline & 298.15 & 0.9934 & 0.0886 \\
\hline & 309.15 & 0.9957 & 0.0915 \\
\hline \multirow[t]{6}{*}{ o-Xylene } & 277.15 & 0.9838 & 0.0549 \\
\hline & 283.15 & 0.9856 & 0.0634 \\
\hline & 288.15 & 0.9883 & 0.0665 \\
\hline & 293.15 & 0.9887 & 0.0736 \\
\hline & 298.15 & 0.9932 & 0.0786 \\
\hline & 309.15 & 0.9951 & 0.0813 \\
\hline
\end{tabular}

Note: The SMZ mesh size used in all experiments was $14 \times 40$ 


\subsubsection{Comparison of Sorption Enthalpy Change with Published Data}

One of the goals of this project was to provide a means to predict sorption capacity as a function of temperature. The effect of temperature on equilibrium constants is generally described using the van't Hoff equation:

$$
\frac{d \ln K_{d}}{d T}=\frac{\Delta H_{s}^{\text {net }}}{R * T^{2}} \quad \text { (Vemulapalli, 1993) }
$$

where $\Delta H_{s}^{\text {net }}$ represents the net sorption enthalpy $(\mathrm{J} / \mathrm{mol}), \mathrm{T}$ is the temperature in $\left({ }^{\circ} \mathrm{K}\right)$. and $\mathrm{R}$ is the ideal gas constant $\left(8.314 \mathrm{~J} / \mathrm{mol}^{-} \mathrm{K}\right)$. The higher the sorption enthalpy $\left(\Delta H_{s}^{\text {net }}\right)$, the greater effect of temperature on sorption capacity.

Based on the assumption that the change of enthalpy is constant over the considered temperature range, equation 5.9 can be integrated to yield a linear relationship between $\ln K_{d}$ and $1 / \mathrm{T}$,

$$
\ln K_{d}=-\frac{\Delta H_{s}^{n e t}}{R * T}+\text { const }
$$

Data presented in Table 5.21 were used to determine the value of $\Delta H_{s}^{\text {net }}$ for SMZ sorption of each of the BTEX compounds. In order to calculate the sorption enthalpies for BTEX sorption to SMZ, $\operatorname{lnK}_{d}$ values were plotted vs. 1/T (van't Hoff plots) and the data was linearly regressed. These plots are presented in Figures 5.16 and 5.17. From Figures 5.16 and Figure 5.17 it can be seen that $\mathrm{K}_{\mathrm{d}}$ increases with increasing temperature for each BTEX compound sorbed onto SMZ within the temperature range of $4-36^{\circ} \mathrm{C}$. This finding is consistent with results for BTEX sorption onto sediment by Dewulf et al. (1999). Sorption enthalpies were obtained from the slopes of the regression equations using Equation 5.10. The enthalpy values are presented in Table 5.22 along with the 95\% confidence limits for the enthalpy and correlation coefficients for the data. As shown in Table 5.22, all of the values of enthalpy are positive and relatively similar. A positive value of enthalpy suggests that it requires energy to extract BTEX from the aqueous phase and dissolve it into the organic carbon associated with the surfactant sorbed to the zeolite.

Dewulf et al. (1999) obtained very similar sorption enthalpies for benzene, toluene, ethylbenzene, and o- \& p-xylene (m-xylene was not studied) sorbed onto a riverine sediment as shown in Table 5.23. However the 95\% confidence limits for their enthalpies were much larger and the correlation coefficients were much weaker.

It is generally expected that the value of the sorption enthalpy will change with both the solute and sorbent. As shown in Table 5.24, previous studies examining sorption of aromatic hydrocarbons support this expectation. The sorption enthalpy changes with different sorbates for a specific sorbent. Note that in most of these studies, the enthalpy values for these contaminants were negative indicating that sorption will increase with decreasing temperature. 


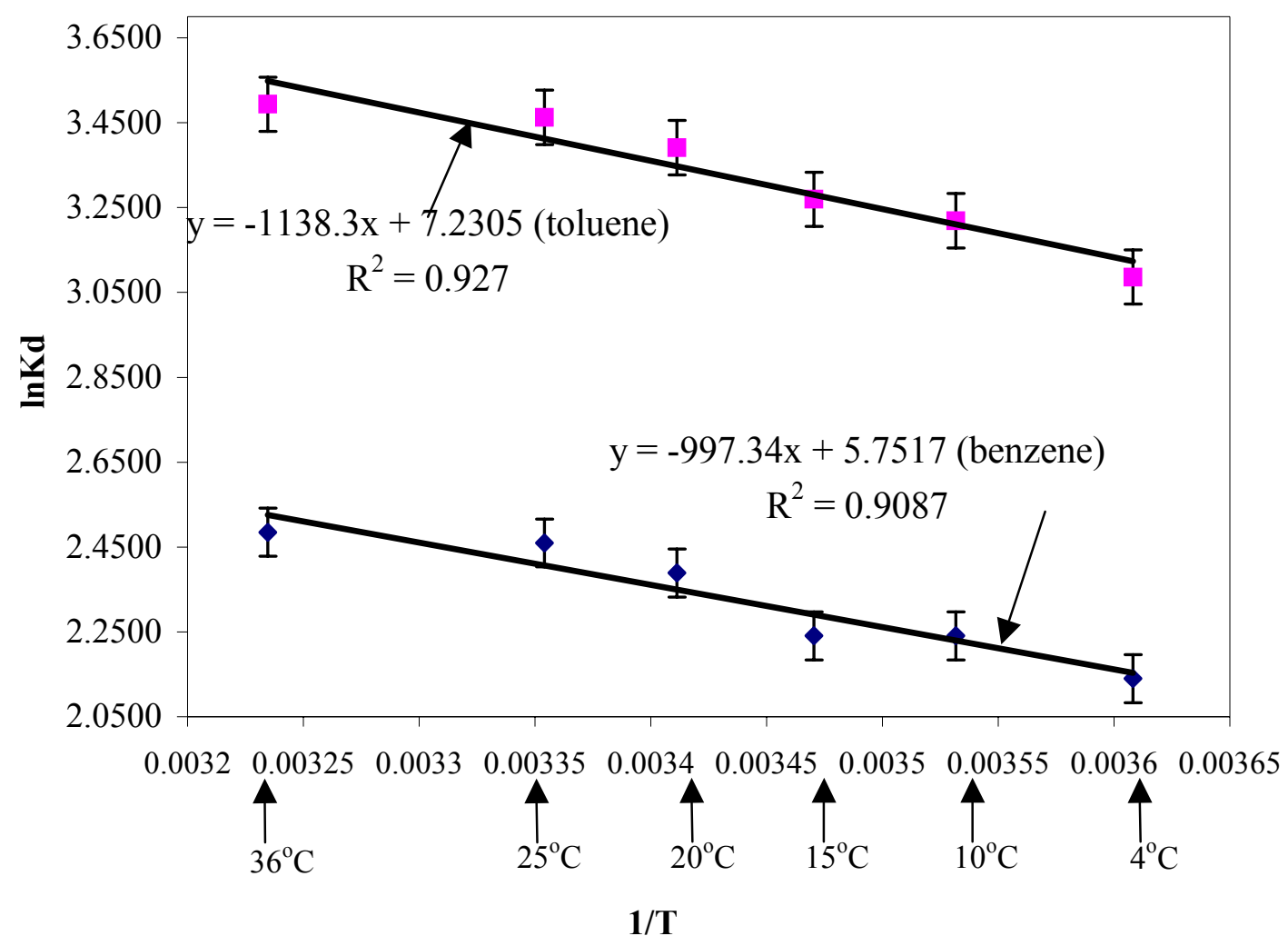

Figure 5.16 Van't Hoff Plots of SMZ Equilibrium Partitioning for Benzene and Toluene. Solid lines are regression lines. Bars indicate standard error bars.

Table 5.22 Sorption Enthalpies ( $\Delta H_{s}^{\text {net }}$ ) for Sorption of BTEX Compounds onto SMZ in Ultrapure Water

\begin{tabular}{|l|l|l|}
\hline Compounds & $\Delta H_{s}^{\text {net }} \mathbf{( k J / m o l )}$ & $\mathbf{R}^{\mathbf{2}}$ \\
\hline Benzene & $8.26(8.15,8.37)$ & 0.9087 \\
Toluene & $9.46(9.33,9.59)$ & 0.927 \\
Ethylbenzene & $10.17(10.04,10.3)$ & 0.9404 \\
m\&p-Xylene & $8.9(8.77,9.03)$ & 0.9153 \\
o-Xylene & $9.53(9.41,9.65)$ & 0.9248 \\
\hline
\end{tabular}




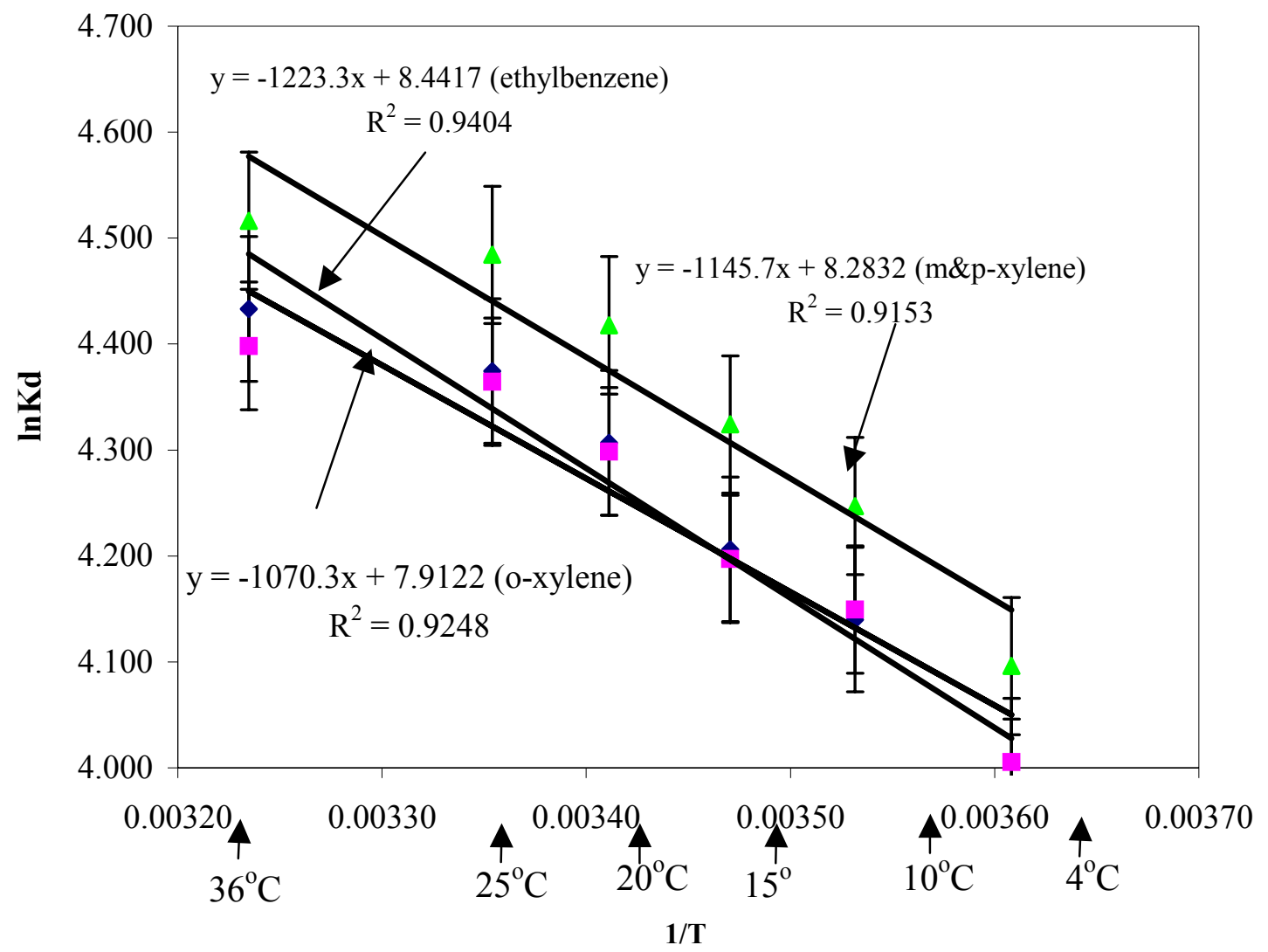

Figure 5.17 Van't Hoff Plots of SMZ Equilibrium Partitioning for Ethylbenzene, m, p-Xylene, and o-Xylene. Solid Lines are Regression Lines. Bars Indicate Standard Errors.

Table 5.23 Sorption Enthalpies for Sorption of BTEX Compounds onto Sediment (Dewulf et al.1999)

\begin{tabular}{|l|l|l|}
\hline Compounds & $\Delta H_{s}^{\text {net }}(\mathbf{k J} / \mathbf{m o l})$ & $\mathbf{R}^{2}$ \\
\hline Benzene & $3.5(0.0,6.9)$ & 0.75 \\
Toluene & $4.4(-4.9,13.7)$ & 0.48 \\
Ethylbenzene & $10.8(-6.4,27.9)$ & 0.59 \\
p-Xylene & $12.8(-5.4,31)$ & 0.63 \\
o-Xylene & $11.5(-9.2,32.2)$ & 0.54 \\
\hline
\end{tabular}


Table 5.24 Results from Previous Studies Examining the Influence of Temperature on Sorption Equilibrium

\begin{tabular}{|c|c|c|c|c|}
\hline Compound & $\Delta H_{s}^{n e t}(\mathbf{k J} / \mathbf{m o l})$ & $\begin{array}{l}\text { Temperatu } \\
\text { re range } \\
\left({ }^{\circ} \mathrm{C}\right)\end{array}$ & Type of adsorbent ${ }^{1}$ & $\underset{2}{\text { Ref. }}$ \\
\hline Naphthalene & $-6.2 \pm 3.1$ & $6.5-37$ & Silt loam, $1 \%$ oc & 1 \\
\hline Fluoranthene & -18.3 & $16-45$ & Sediment, $5.1 \%$ oc & 2 \\
\hline Benzo[b]fluoranthene & -36.24 & $16-45$ & Sediment, $5.1 \%$ oc & 2 \\
\hline Benzo[k]fluoranthene & -25.6 & $16-45$ & Sediment, $5.1 \%$ oc & 2 \\
\hline Benzo[a]pyrene & -31.28 & $16-45$ & Sediment $5.1 \%$ oc & 2 \\
\hline Benzo[ghi]perylene & -40.6 & $16-45$ & Sediment $5.1 \%$ oc & 2 \\
\hline 1,4-dichlorobenzene & -12 to -16 & $3-48$ & Phenyl-modified silica, $1.6 \%$ oc & 3 \\
\hline 1,2,4-trichlorbenzene & -13 to 17 & $3-483.5-20$ & Phenyl-modified silica, $1.6 \%$ oc & 3 \\
\hline
\end{tabular}

${ }^{1} \mathrm{oc}=\%$ organic carbon; $\mathrm{om}=\%$ organic matter $(=1.7 \mathrm{oc})$

${ }^{2}$ References: 1 = Wauchope et al. (1983); 2 = F. Lüers and Th. E. M. ten Hulscher (1996); $3=$ Szecsody and Bales (1991)

\subsubsection{Hypothesized Mechanism of Sorption}

Not only can knowledge of the enthalpy be used to predict sorption distribution coefficients, but the impact of temperature on sorption capacity can also give insight into the sorption mechanism. The mechanism of BTEX sorption onto SMZ has been attributed to a partitioning of the organic contaminant into the organic "layer" on the solid surface (Chiou, 1989). The organic contaminant is more soluble in the organic surfactant layer than it is in the aqueous phase. Chiou et al. (1979) asserted that sorption enthalpy may be used to differentiate between adsorption processes and a partitioning mechanism. Adsorption refers to condensation of solutes (referred to as adsorbates) on surfaces or interior pores of a solid (adsorbent) by physical or chemical bonding forces. Partitioning refers to the organic chemical permeating into an organic medium by forces common to solution (e. g., by van der Waals forces). Chiou (1979) states that adsorption is generally exothermic in nature, while partitioning is thought to be only weakly exothermic or even endothermic. This supposition suggests that sorption enthalpies of organic solutes to soil organic matter (SOM) may be positive as shown in this study. Borisover et al. (1998) argued that when sorption enthalpies of organic solutes to SOM are more positive than the corresponding dissolution enthalpies from water, the sorption process can be considered as partitioning of those solutes into SOM.

To examine these contentions, it is necessary to understand the factors contributing to the net sorption enthalpy. The net enthalpy change for sorption $\left(\Delta H_{s}^{\text {net }}\right)$ of a compound to the organic matter in SMZ or any other soil organic matter is the result of two processes (Dewulf et al. 1999). According to Dewulf, the first step in the sorption process is to extract the solute (BTEX) from the aqueous phase. This is a reversible process and the reverse of this extraction process is commonly referred to as the excess enthalpy of solution $\left(\Delta H_{a q}\right)$. The second step in the sorption process is the dissolution of BTEX into organic matter associated with the $\operatorname{SMZ}\left(\Delta H_{o c}\right)$. So $\Delta H_{s}^{\text {net }}$ can be expressed as: 


$$
\Delta H_{s}^{n e t}=\Delta H_{o c}-\Delta H_{a q}
$$

where,

$\Delta H_{o c}$ : the change of enthalpy associated with dissolution of the solute into the organic phase $(\mathrm{J} / \mathrm{mol})$, and,

$\Delta H_{a q}$ : the change of enthalpy associated with dissolution of the solute into the aqueous phase $(\mathrm{J} / \mathrm{mol})$.

Distribution coefficients $\left(\mathrm{K}_{\mathrm{d}}\right.$ 's) determined from sorption experiments conducted at different temperatures can be used to determine the value of $\Delta H_{s}^{\text {net }}$ for a particular sorbate/sorbent system. As stated before, the net sorption enthalpy $\Delta H_{s}^{\text {net }}$ is a combination of $\Delta H_{o c}$ and $\Delta H_{a q}$.

The temperature dependence of both components may influence the net sorption enthalpy. $\Delta H_{a q}$ can be calculated from

$$
\ln \gamma_{w}=\frac{\Delta H_{a q}}{R * T}+\text { const. }
$$

where $\gamma_{w}$ is the (dimensionless) aqueous activity coefficient of the solute and can be calculated from,

$$
\begin{aligned}
& \gamma_{w}=\frac{H^{\prime \prime}}{P_{i}} \quad(\text { Stumm and Morgan, 1981) } \\
& H^{\prime \prime}=\frac{H * R * T}{18 * 10^{-6}} * \exp \left(\frac{a}{T}+b\right) \\
& P_{i}=\exp \left(\frac{c}{T}+d\right)
\end{aligned}
$$

and where,

$\mathrm{H}$ is the dimensionless Henry's law coefficient, $H^{\prime \prime}$ is the Henry's law coefficient $(\mathrm{Pa} / \mathrm{mole})$, $P_{i}$ is the saturated vapor pressure $(\mathrm{Pa})$,

a, b are coefficients for calculation of Henry's law constant H', and $\mathrm{c}, \mathrm{d}$ are coefficients for calculation of vapor pressure.

The coefficients a, b, c and d are solute specific and have been determined by Dewulf et al. (1999) for BTEX as shown in Table 5.25. The activity coefficients $\gamma_{w}$ were calculated using equation $5.13,5.14$ and 5.15 for temperatures of $4^{\circ} \mathrm{C}, 10^{\circ} \mathrm{C}, 15^{\circ} \mathrm{C}, 20$ ${ }^{\circ} \mathrm{C}, 25{ }^{\circ} \mathrm{C}$, and $36{ }^{\circ} \mathrm{C}$ as shown in Table 5.26. The calculated values of $\gamma_{w}$ were used to 
estimate aqueous enthalpy values $\left(\Delta H_{a q}\right.$ ) for each of the BTEX compounds using linear regression of a plot of $\ln \gamma_{w}$ vs. 1/T and equation 5.12. These enthalpy values are also presented in Table 5.26 along with the correlation coefficient obtained from the regression analysis. The regressions provide good correlations even though the coefficients $\mathrm{a}$ and $\mathrm{b}$ were only determined for a temperature range of $2-25^{\circ} \mathrm{C}$ by Dewulf et al. (1995). The enthalpies $\Delta H_{a q}$ are positive values for all BTEX compounds. According to Dewulf et al. 1999, the enthalpies $\left(\Delta H_{a q}\right)$ account for the temperature dependence of both the aqueous solubility and vapor pressure.

Table 5.25 Values of Coefficients a, b, $c$ and d for Calculation of Aqueous Activity Coefficients (Dewulf et al. 1999)

\begin{tabular}{|l|l|l|l|l|}
\hline Compounds & a & b & c & d \\
\hline Benzene & -3640 & 10.577 & -4693 & 25.017 \\
Toluene & -4064 & 12.150 & -4567 & 23.495 \\
Ethylbenzene & -4567 & 14.001 & -4902 & 23.564 \\
p-Xylene & -4479 & 13.597 & -4939 & 23.596 \\
o-Xylene & -4232 & 12.400 & -5032 & 23.645 \\
\hline
\end{tabular}

Table 5.26 Theoretical Aqueous Activities and Aqueous Enthalpy Values for BTEX Sorption

\begin{tabular}{|c|c|c|c|c|c|}
\hline & Benzene & Toluene & Ethylbenzene & p-Xylene & o-Xylene \\
\hline \hline$\gamma_{\mathrm{w}}$ at $277.15^{\circ} \mathrm{K}$ & 3063 & 9298 & 30133 & 30589 & 30026 \\
\hline$\gamma_{\mathrm{w}}$ at $283.15^{\circ} \mathrm{K}$ & 2887 & 9141 & 30007 & 30171 & 28837 \\
\hline$\gamma_{\mathrm{w}}$ at $288.15^{\circ} \mathrm{K}$ & 2754 & 9020 & 29916 & 29850 & 27942 \\
\hline$\gamma_{\mathrm{w}}$ at $293.15^{\circ} \mathrm{K}$ & 2633 & 8907 & 29838 & 29953 & 27112 \\
\hline$\gamma_{\mathrm{w}}$ at $298.15^{\circ} \mathrm{K}$ & 2521 & 8802 & 29770 & 29276 & 26341 \\
\hline$\gamma_{\mathrm{w}}$ at $309.15^{\circ} \mathrm{K}$ & 2305 & 8595 & 29659 & 28735 & 24826 \\
\hline $\begin{array}{c}\mathrm{Calculated} \\
\Delta \mathrm{Haq}(\mathrm{kJ} / \mathrm{mol})\end{array}$ & $6.32 \pm 0.08$ & $1.75 \pm 0.22$ & $0.35 \pm 0.005$ & $1.39 \pm 0.017$ & $4.22 \pm 0.054$ \\
\hline $\mathrm{R}^{2}$ & 1 & 0.9994 & 0.9853 & 0.9999 & 0.999 \\
\hline
\end{tabular}

From the values of $\Delta H_{a q}$ and $\Delta H_{s}^{\text {net }}$, the enthalpy of dissolution of the compounds into the SMZ (organic carbon) $\Delta H_{o c}$ can be calculated using equation 5.11. In addition, 95\% confidence intervals for $\Delta H_{o c}$ can be calculated via the standard deviations through the following relationship described by Dewulf et al. (1999), 


$$
\left[\operatorname{SD}\left(\Delta H_{o c}\right)\right]^{2}=\left[\operatorname{SD}\left(\Delta H_{a q}\right)\right]^{2}+\left[\operatorname{SD}\left(\Delta H_{s}^{n e t}\right)\right]^{2}
$$

where $\mathrm{SD}\left(\Delta H_{o c}\right), \mathrm{SD}\left(\Delta H_{a q}\right)$, and $\mathrm{SD}\left(\Delta H_{s}^{\text {net }}\right)$ are the relative standard deviations of $\Delta H_{o c}, \Delta H_{a q}$, and $\Delta H_{s}^{\text {net }}$ respectively. $\Delta H_{o c}$ values obtained using equation 5.11 are presented in Table 5.27 with their $95 \%$ confidence limits. $\Delta H_{o c}$ values were positive for all BTEX compounds, which means it requires energy to dissolve BTEX into the organic carbon fraction of SMZ. The dissolution of BTEX into the organic matter of the solid phase (SMZ) requires more energy than extraction of BTEX out of aqueous phase ( $\left.\left|\Delta H_{o c}\right|>\left|-\Delta H_{a q}\right|\right)$. The sorption process for all BTEX partitioning into SMZ is endothermic so that sorption is favored at higher temperature. Indeed, the results showed that the highest distribution coefficients were achieved at the temperature of $36^{\circ} \mathrm{C}$ within the range of $4-36^{\circ} \mathrm{C}$. These results would suggest that a partitioning mechanism controls the sorption process.

Table 5.27 Calculated $\Delta H_{o c}$ Data with $95 \%$ Confidence Limits $(\mathrm{kJ} / \mathrm{mol})$ for Sorption of BTEX onto SMZ

\begin{tabular}{|l|l|}
\hline Compounds & $\left.\Delta H_{o c} \mathbf{( k J / m o l}\right)$ \\
\hline Benzene & $14.58(14.44,14.72)$ \\
Toluene & $11.21(11.09,11.34)$ \\
Ethylbenzene & $10.52(10.39,10.66)$ \\
p-Xylene & $10.29(10.16,10.42)$ \\
o-Xylene & $13.74(13.61,13.87)$ \\
\hline
\end{tabular}

Chiou et al. (1979) concluded that the temperature dependence of $\mathrm{K}_{\mathrm{d}}$ is related to the change in enthalpy of the dissolution of the solute in water, $\Delta H_{a q}$, which is correlated to the temperature dependence of the solubility. Schwarzenbach et al.(1993) also argued that the enthalpy of dissolution ( $\left.\Delta H_{o c}\right)$ into natural organic matter (NOM) in soil should be quite small, and can be neglected. As shown in Table 5.27, values of $\Delta H_{o c}$ are not zero and there is a temperature impact on dissolution of BTEX into the organic phase. This contradicts Schwarzenbach and co-workers' (1993) hypothesis that there is no temperature impact on dissolution of BTEX into the organic phase. Furthermore, according to their hypothesis, the trend of the effects of temperature on $\mathrm{K}_{\mathrm{d}}$ would follow the inverse of solubility trends. These trends are shown in Figure 5.16 for sorption data determined in this work and solubility data taken from the literature. As seen. for almost all of the BTEX compounds there is a minimum in solubility within the temperature range of the $\mathrm{K}_{\mathrm{d}}$ data. If $\Delta H_{a q}$ was the only factor contributing to $\Delta H_{s}^{\text {net }}$, these $\Delta H_{s}^{\text {net }}$ should follow the inverse trend of solubility. This trend was not apparent in our data or in Dewulf and coworker data (1999). If Schwarzenbach et al.'s (1993) hypothesis holds true, BTEX would have a maximum sorption capacity between 15 and $20^{\circ} \mathrm{C}$ and the plots of $\ln K_{d}$ vs. $1 / T$ should not be linear as shown in Figure 5.16. 


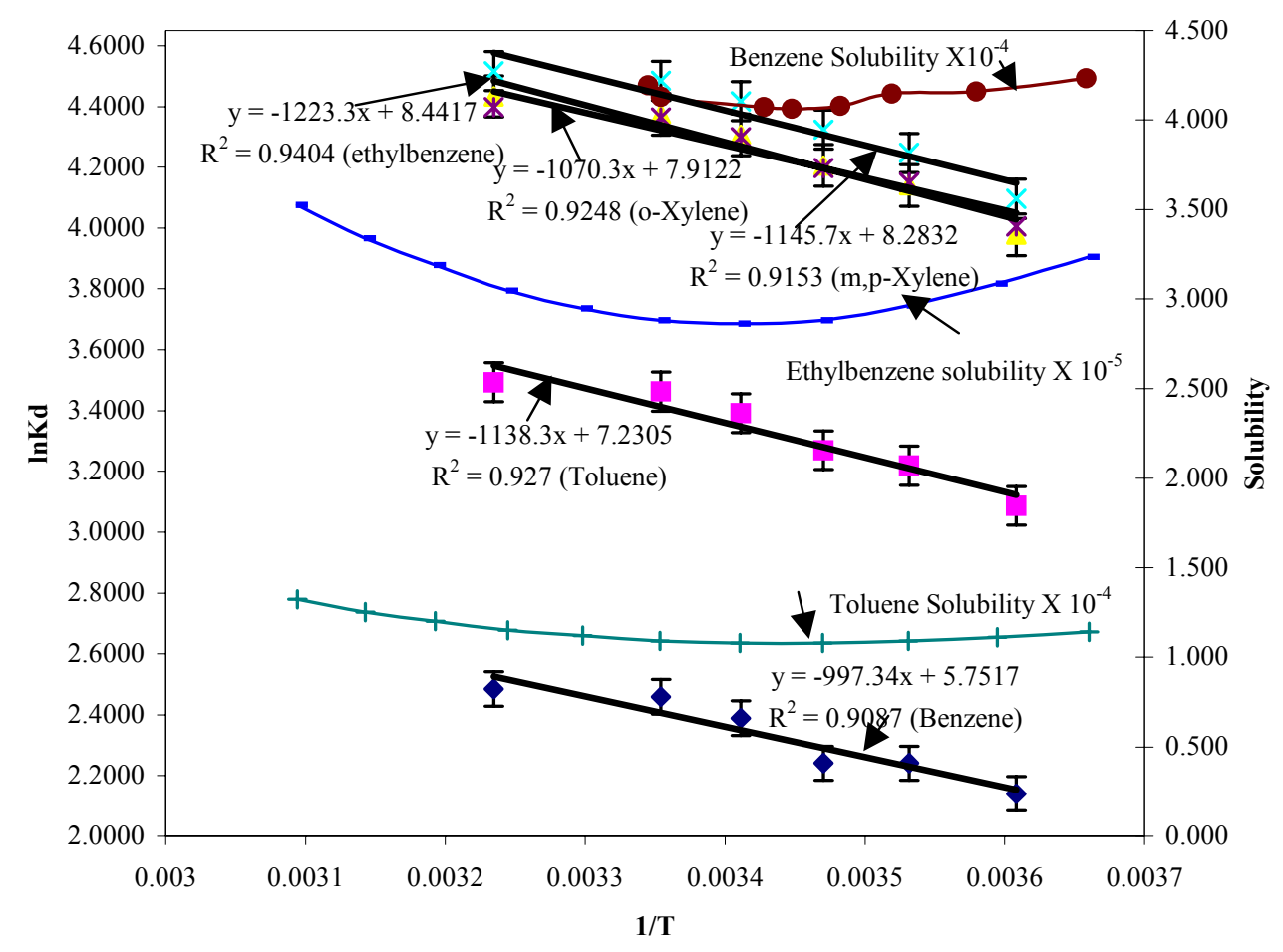

Figure 5.18 Comparison of BTEX sorption onto SMZ vs. BTEX solubility (Benzene solubility data are from May et al. (1983) and toluene and ethylbenzene solubility data are from Sawamura et al. 2001)

\subsubsection{Conclusions Derived from the BTEX Sorption Temperature Study}

The distribution coefficients found for all of the BTEX compounds sorbed onto SMZ increased with increasing temperatures from $4{ }^{\circ} \mathrm{C}$ to $36^{\circ} \mathrm{C}$. Regressions performed on the observed distribution coefficients for the BTEX compounds at all temperatures resulted in excellent correlations. Therefore, this relationship can be used to estimate distribution coefficients at field-scale. The sorption enthalpies were positive and ranged from 8.26 for benzene to $10.17 \mathrm{~kJ} / \mathrm{mol}$ for ethylbenzene. The sorption process is endothermic which means the sorption capacities increase with increasing temperature. The magnitude of the change in the distribution coefficients as a function of temperature was smallest for benzene. Changes in the BTEX distribution coefficients as a function of temperature cannot be explained by examining the BTEX solubilities because $\Delta H_{o c}$ were not insignificant. A partitioning sorption mechanism was confirmed based on the sorption enthalpies. 


\subsubsection{Studies with Produced Water}

Preliminary batch tests using produced water obtained by Crystal Solutions, LLC. from the Wamsutter, WY site holding tank suggested that a fraction of TDS, Barium and BTEX could be removed from solution using SMZ. Formal studies confirmed the BTEX results using produced water from the Wamsutter site with initial BTEX concentrations shown in Table 5.28. Produced water BTEX concentrations from the oil/water separation tank reported in Table 5.28 were determined at the University of Texas at Austin. Room temperature batch isotherms conducted using this produced water and $14 \times 40 \mathrm{SMZ}$ produced linear isotherms that followed the same trends as the ultrapure water isotherms.

Table 5.28 BTEX Concentrations in Produced Water from the Wamsutter, WY Site

\begin{tabular}{|l|l|}
\hline Compound & $\begin{array}{l}\text { Oil/Water Separation } \\
\text { Tank (mg/L) }\end{array}$ \\
\hline Benzene & 15.4 \\
Toluene & 27.5 \\
Ethylbenzene & 1.4 \\
m- \& p-Xylene & 9.0 \\
o-Xylene & 3.0 \\
\hline
\end{tabular}

Note: These analyses were conducted at the University of Texas.

As shown in Figure 5.19, the isotherms remain linear for the isotherm range considered. Distribution coefficients for each isotherm are presented in Table 5.29.

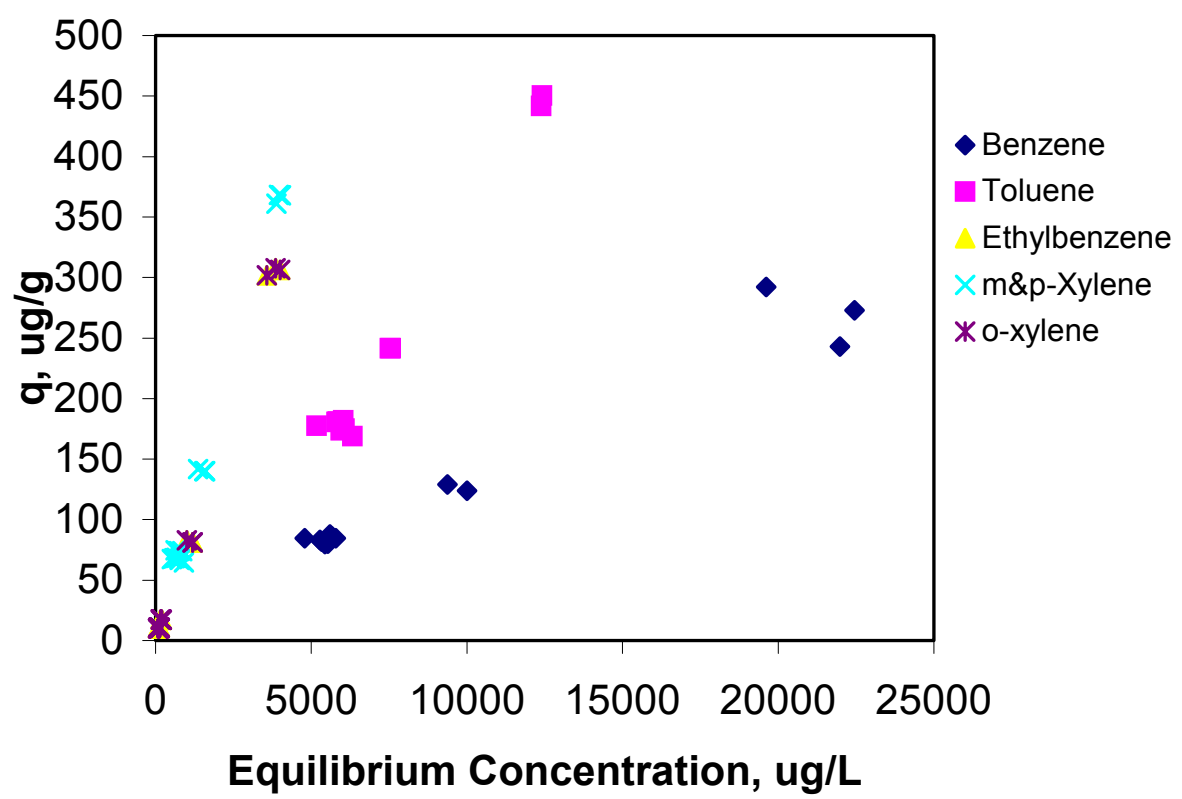

Figure 5.19 Sorption Isotherms for BTEX Compounds in a Produced Water Matrix 
Table 5.29 Comparison of $K_{d}$ values from Batch Isotherm Studies using Ultrapure and Produced Water Background using Hypothesis Testing

\begin{tabular}{|l|c|l|l|l|l|l|}
\hline Compound & $\begin{array}{l}\mathbf{K}_{\mathbf{d}} \mathbf{( L / K g} \\
\text { SMZ) } \\
\text { Ultrapure } \\
\text { Water }\end{array}$ & $\mathbf{R}^{\mathbf{2}}$ & $\begin{array}{l}\mathbf{K}_{\mathbf{d}}(\mathbf{L} / \mathbf{K g} \\
\text { SMZ) } \\
\text { Produced } \\
\text { Water }\end{array}$ & $\mathbf{R}^{\mathbf{2}}$ & $\begin{array}{l}\mathbf{T}- \\
\text { Value }\end{array}$ & $\begin{array}{l}\text { Result for } \\
\text { Null } \\
\text { Hypothesis }\end{array}$ \\
\hline Benzene & 10.9 & 0.988 & 13 & 0.93 & 2.20 & Reject \\
Toluene & 29.7 & 6 & 32.7 & 34 & 1.08 & Retain \\
Ethylbenzene & 74.2 & 0.990 & 79.4 & 0.93 & 1.82 & Retain \\
m, p-Xylene & 82.9 & 3 & 92.6 & 95 & 2.70 & Reject \\
o-Xylene & 73.6 & 0.989 & 77.4 & 0.99 & 1.34 & Retain \\
& & 6 & & 52 & & \\
& & 0.989 & & 0.99 & & \\
& & 5 & & 19 & & \\
& & 0.988 & & 0.99 & & \\
& & 7 & & 62 & & \\
\hline
\end{tabular}

Note: the experiments were conducted at $20^{\circ} \mathrm{C}$.

The SMZ mesh size is $14 \times 40$.

The null hypothesis is that the distribution coefficients are equal.

Comparison of the $\mathrm{K}_{\mathrm{d}}$ values from produced water and ultrapure water suggest that produced water increases BTEX sorption to SMZ. However, hypothesis testing for the null hypothesis that the $\mathrm{K}_{\mathrm{d}}$ values are equal generated mixed results. The isotherms developed in produced water for benzene and $\mathrm{m}-\& \mathrm{p}$ - xylene were found to have greater slopes than the isotherms generated in ultrapure water. However, the null hypothesis was valid for the remaining BTEX compounds.

\subsubsection{Batch Studies with Different Size SMZ Particles}

Two particle sizes of SMZ were used in this research. Particles in the $14 \times 40$ mesh size range were used for field column studies. Particles in the $80 \times 100$ mesh size range were used in the lab scale column study. The $\mathrm{K}_{\mathrm{d}}$ values for both mesh sizes were obtained from batch studies and the results are shown in Table 5.30.

Table 5.30 Comparison of $K_{d}$ Values for Different Sizes of SMZ

\begin{tabular}{|l|c|c|}
\hline Compounds & $\begin{array}{l}\mathbf{K}_{\mathbf{d}}(\mathbf{L} / \mathbf{K g}) \text { for } \mathbf{8 0} \times \mathbf{1 0 0} \\
\text { Mesh Size SMZ }\end{array}$ & $\begin{array}{l}\mathbf{K}_{\mathbf{d}}(\mathbf{L} / \mathbf{K g}) \text { for } \mathbf{1 4} \times \mathbf{4 0} \\
\text { Mesh Size SMZ }\end{array}$ \\
\hline Benzene & 5.7 & 9.7 \\
\hline Toluene & 16.1 & 26.7 \\
\hline Ethylbenzene & 40.9 & 65.9 \\
\hline m- \& p- Xylene & 46.5 & 73.5 \\
\hline o-Xylene & 38.2 & 64.2 \\
\hline
\end{tabular}

The $14 \times 40 \mathrm{SMZ}$ exhibited higher sorption capacities for all of the BTEX compounds compared to the $80 \times 100 \mathrm{SMZ}$. While this result is not intuitive, it can be understood if the HDTMA loading onto each mesh size is compared. Results obtained from 
measurements of the supernatant obtained during SMZ preparation indicate that more surfactant was adsorbed to the $14 \times 40$ mesh size SMZ. The loading rate of HDTMA was $180 \mathrm{mmol} / \mathrm{kg}$ for $14 \times 40 \mathrm{SMZ}$ compared to $157 \mathrm{mmol} / \mathrm{kg}$ for the $80 \times 100 \mathrm{SMZ}$. The higher loading rate of HDTMA is likely responsible for the increase in sorption capacity for the larger particle size SMZ. Thus, particle size is less important than the amount of HDTMA sorbed.

\subsection{Column Adsorption Studies}

A lab scale column study was conducted to confirm the validity of $K_{d}$ values for BTEX obtained in the batch studies and to evaluate whether mass transfer limitations were significant. This latter objective was addressed by comparing the data from the column studies to a one-dimensional model that assumes local equilibrium. The assumption used for this analysis is that a reasonable fit to the data using a model that assumes local equilibrium would support the contention that mass transfer limitations are negligible for this system.

\subsubsection{Column Study in Ultrapure Water Background}

A column study was performed using ultrapure water as a background solution to determine the basic breakthrough behavior of BTEX compounds in water. The results of this experiment are shown in Figure 5.20. As expected based on the batch isotherm $\mathrm{K}_{d}$ values, benzene was the first solute to appear in the column effluent (breakthrough) and m- \& p- xylene were the last.

The initial assumption made in modeling BTEX sorption in the laboratory scale columns was that BTEX sorption follows local equilibrium behavior with minimal mass transfer limitations. Using CXTFIT2, the predicted breakthrough curves using the batch isotherm parameters for 80x100 mesh size SMZ are shown in Figure 5.21. The distribution coefficients for BTEX sorption used in predicting the breakthrough curves in ultrapure water are listed in Table 5.30. The input parameters for predicting the breakthrough curves using CXTFIT2 are shown in Table 5.31. As shown on Figure 5.21, the projected breakthrough curves based on the $\mathrm{K}_{\mathrm{d}}$ values from batch study correlate well with the actual data. These results suggest that the initial assumption regarding the lack of mass transfer limitations in this process is valid. 


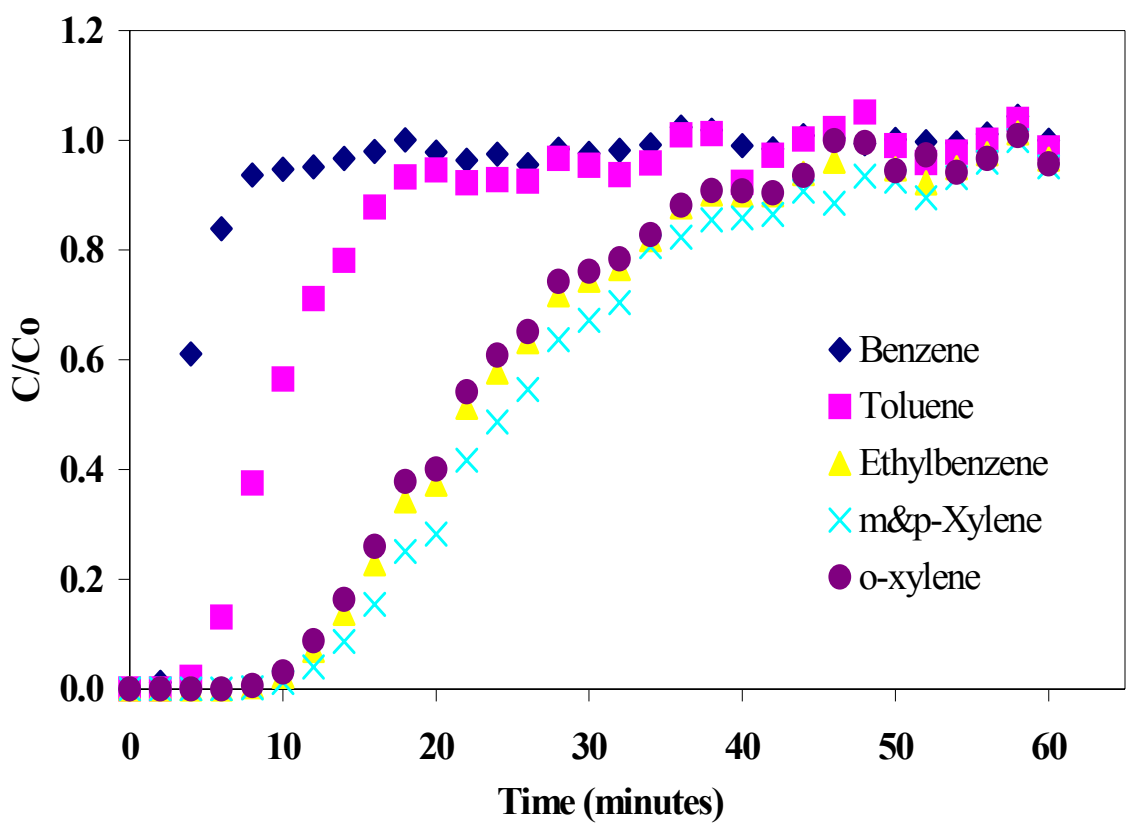

Figure 5.20 Breakthrough Curves for BTEX Sorbed onto SMZ in Ultrapure Water (The column flowrate was $22 \mathrm{~mL} / \mathrm{min}$, the porosity was 0.52 , and the bulk density of the SMZ was $1 \mathrm{~g} / \mathrm{cm}^{3}$ )

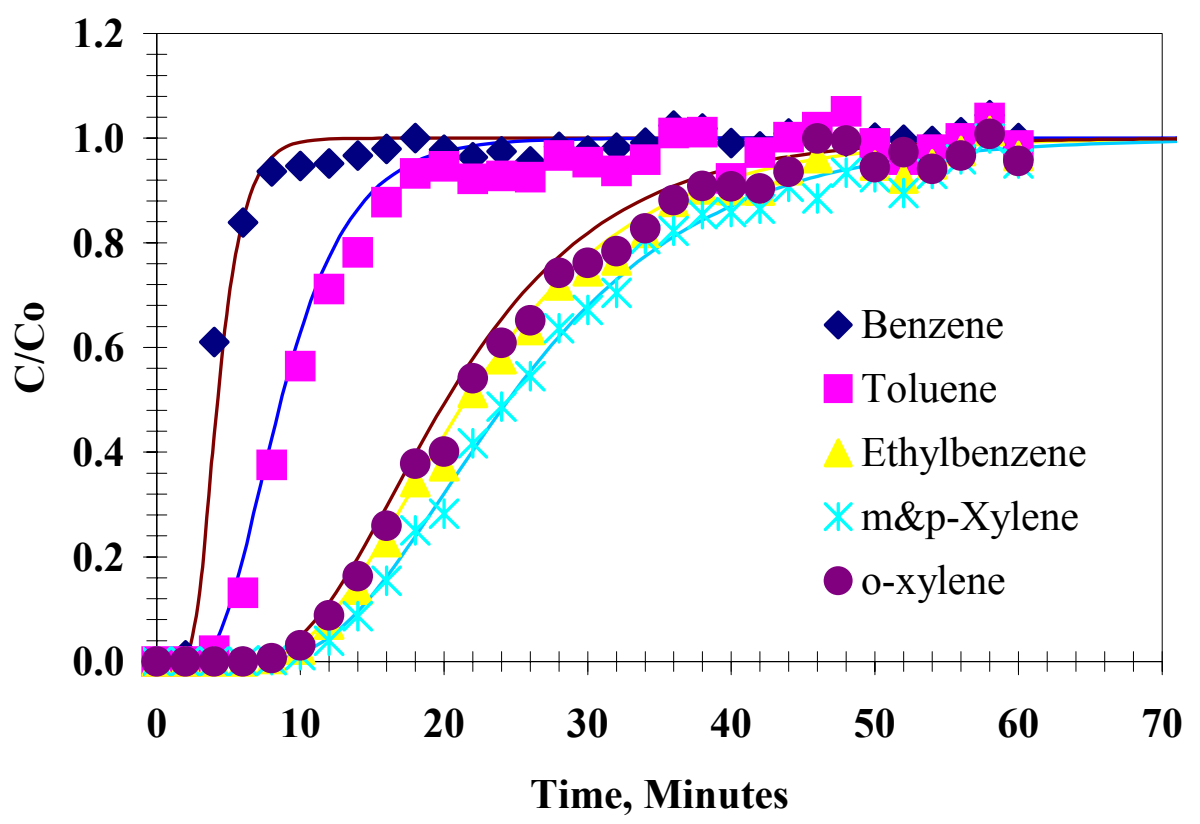

Figure 5.21 Comparison of Breakthrough Curves from Column Data and CXTFIT2 Predictions. Solid lines are from CXTFIT2 Predictions. 
Table 5.31 Parameters Applied in CXTFIT2 for Predicting BTEX Breakthrough Curves in Ultrapure Water

\begin{tabular}{|l|c|c|c|c|c|}
\hline & Benzene & Toluene & Ethylbenzene & m,p-Xylene & o-Xylene \\
\hline $\begin{array}{l}\text { Seepage } \\
\begin{array}{l}\text { Velocity } \\
\left(\mathrm{cm}^{3} / \mathrm{min}\right)\end{array}\end{array}$ & 84 & 84 & 84 & 84 & 84 \\
\hline $\begin{array}{l}\text { Dispersion } \\
\text { Coefficient }\end{array}$ & 210 & 210 & 210 & 210 & 210 \\
\hline $\begin{array}{l}\text { Retardation } \\
\text { Factor }\end{array}$ & 11.9 & 32 & 74.1 & 82.9 & 73.2 \\
\hline
\end{tabular}

\subsubsection{Column Study in Saline Water Background}

Batch experiments suggested that salinity increases sorption capacity for salt concentrations exceeding $100,000 \mathrm{ppm}$. A second column study was conducted to confirm the batch findings. A solution containing 100,000 ppm total dissolved solids was chosen for this experiment. The column parameters used in this experiment are shown in Table 5.32 and the column effluent data are presented in Figure 5.22 along with CXTFIT2 calibration results.

Table 5.32 Parameters Used in CXTFIT2 to Calibrate $K_{d}$ Values in Saline Water Column Study

\begin{tabular}{|l|c|c|c|c|c|}
\hline & Benzene & Toluene & Ethylbenzene & m,p-Xylene & o-Xylene \\
\hline $\begin{array}{l}\text { Seepage } \\
\begin{array}{l}\text { Velocity } \\
\left(\mathrm{cm}^{3} / \mathrm{min}\right)\end{array}\end{array}$ & 84 & 84 & 84 & 84 & 84 \\
\hline $\begin{array}{l}\text { Dispersion } \\
\text { Coefficient }\end{array}$ & 210 & 210 & 210 & 210 & 210 \\
\hline
\end{tabular}




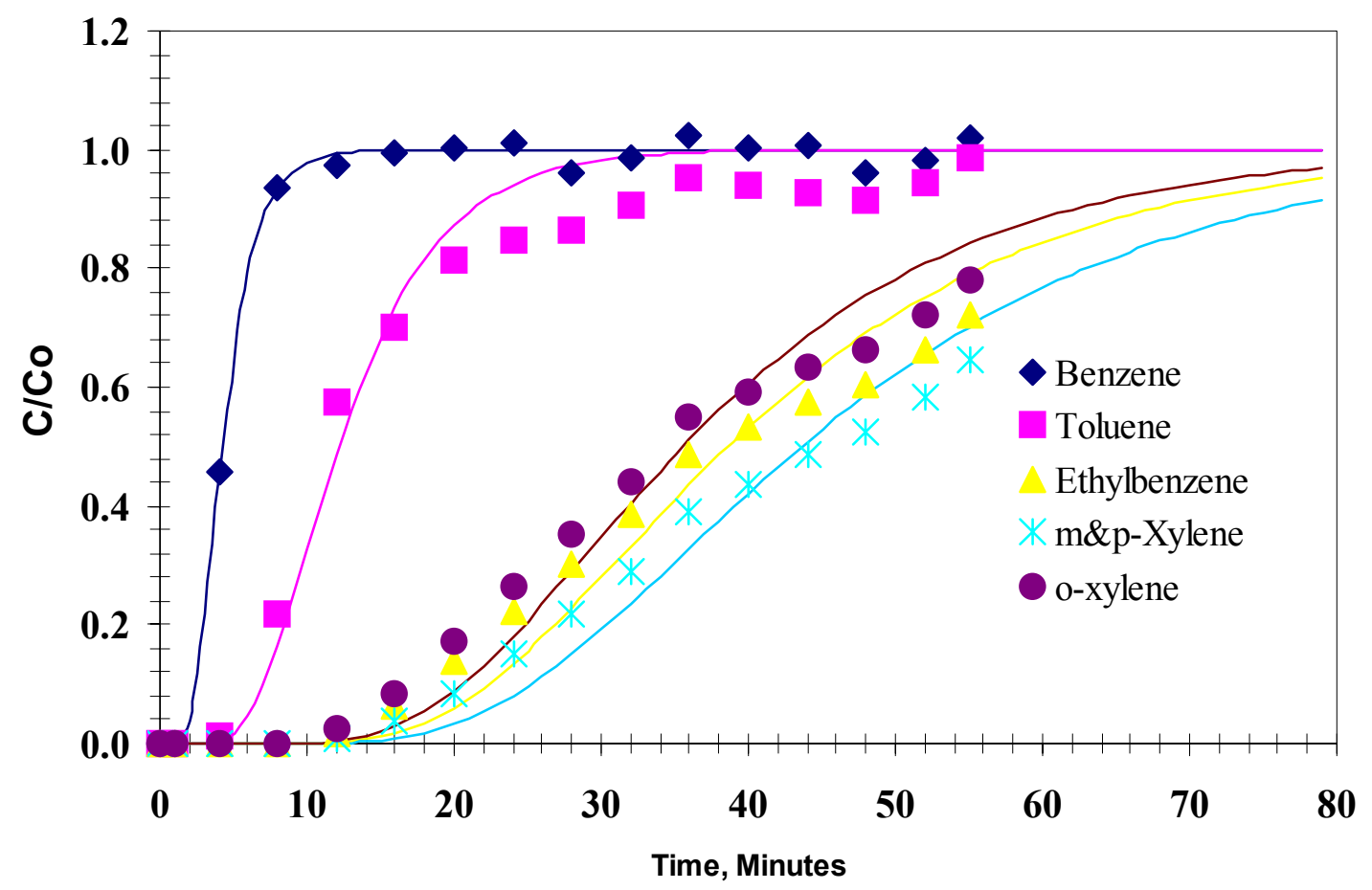

Figure 5.22 Breakthrough Curves for BTEX Sorbed onto SMZ in 100,000 Saline Water

Batch $\mathrm{K}_{\mathrm{d}}$ values for sorption of BTEX to $80 \times 100 \mathrm{SMZ}$ in 100,000 saline water were not available. Therefore, CXTFIT2 was used to calculate $\mathrm{K}_{\mathrm{d}}$ values for the column breakthrough data (Table 5.33). The $\mathrm{K}_{\mathrm{d}}$ values for $100,000 \mathrm{ppm}$ saline water and ultrapure water were compared with the data from the batch study using $14 \times 40 \mathrm{SMZ}$ in 100,000 ppm salinity water.

Table 5.33 Calculated Retardation Factors and Distribution Coefficients Determined using CXTFIT2 for BTEX Column Studies in Saline Water

\begin{tabular}{|l|c|c|c|}
\hline Compound & $\begin{array}{l}\text { Retardation Factor } \\
\text { R from CXTFIT2 }\end{array}$ & $\begin{array}{c}\text { Calculated } \mathbf{K}_{\mathbf{d}} \mathbf{b y} \\
\text { CXTFIT2 } \mathbf{( L / k g )}\end{array}$ & $\mathbf{R}^{\mathbf{2}}$ \\
\hline Benzene & $15.5(15.45,15.53)$ & 8.7 & 0.997 \\
Toluene & $44.9(44.71,44.99)$ & 26.4 & 0.970 \\
Ethylbenzene & $142.6(142.5,142.7)$ & 84.9 & 0.956 \\
m,p-Xylene & $161.1(161.0,161.2)$ & 96.4 & 0.962 \\
o-Xylene & $131.3(131.1,131.4)$ & 78.2 & 0.964 \\
\hline
\end{tabular}


As shown in Table 5.34, increases in sorption capacities with increasing ionic strength were on the same order of magnitude for batch and column studies and for the two particle sizes.

Table 5.34 Comparison of BTEX $K_{d}$ Values for Ultrapure Water and 100,000 ppm Saline Water

\begin{tabular}{|c|c|c|c|c|}
\hline Compounds & $\begin{array}{l}\text { Mesh } \\
\text { size }\end{array}$ & $\begin{array}{l}\mathrm{K}_{\mathrm{d}}(\mathrm{L} / \mathrm{Kg}) \text { Values } \\
\text { in ultrapure Water } \\
\text { Background }^{1}\end{array}$ & $\begin{array}{l}\mathrm{K}_{\mathrm{d}}(\mathrm{L} / \mathrm{Kg}) \text { Values } \\
\text { from } 100,000 \mathrm{ppm} \\
\text { Saline Water } \\
\text { Background }\end{array}$ & $\begin{array}{l}\text { Percentage } \\
\text { Increase }\end{array}$ \\
\hline \multirow[t]{2}{*}{ Benzene } & $80 \times 100$ & 5.7 & $8.7^{3}$ & $152 \%$ \\
\hline & $14 \times 40$ & 9.7 & $14.6^{2}$ & $150 \%$ \\
\hline \multirow[t]{2}{*}{ Toluene } & $80 \times 100$ & 16.1 & $26.4^{3}$ & $164 \%$ \\
\hline & $14 \times 40$ & 26.7 & $44.4^{2}$ & $166 \%$ \\
\hline \multirow[t]{2}{*}{ Ethylbenzene } & $80 \times 100$ & 40.9 & $84.9^{3}$ & $207 \%$ \\
\hline & $14 \times 40$ & 65.9 & $124^{2}$ & $188 \%$ \\
\hline \multirow[t]{2}{*}{ m,p-Xylene } & $80 \times 100$ & 46.5 & $96.4^{3}$ & $207 \%$ \\
\hline & $14 \times 40$ & 73.5 & $143^{2}$ & $194 \%$ \\
\hline \multirow[t]{2}{*}{ o-Xylene } & $80 \times 100$ & 38.2 & $78.2^{3}$ & $204 \%$ \\
\hline & $14 \times 40$ & 64.2 & $119^{1}$ & $185 \%$ \\
\hline
\end{tabular}

${ }^{1} \mathrm{~K}_{\mathrm{d}}$ values obtained from batch isotherm data

${ }^{2} \mathrm{~K}_{\mathrm{d}}$ values obtained from batch isotherm data in saline water

${ }^{3} \mathrm{~K}_{\mathrm{d}}$ values obtained from column data

\subsubsection{Column Study in Produced Water Background}

The final lab scale column test for the research involved evaluation of BTEX sorption with produced water from the Wamsutter Site owned by BC Technologies and operated by Crystal Solutions, LLC. The produced water was first extracted from Zero Headspace Extractor (ZHE) to a one-liter Tedlar bag. Bubbles were extracted from the valve on the Tedlar bag. The column study was then conducted using the same flowrate as used in the other column experiments. The BTEX breakthrough curves with produced water are shown on Figure 5.23. 


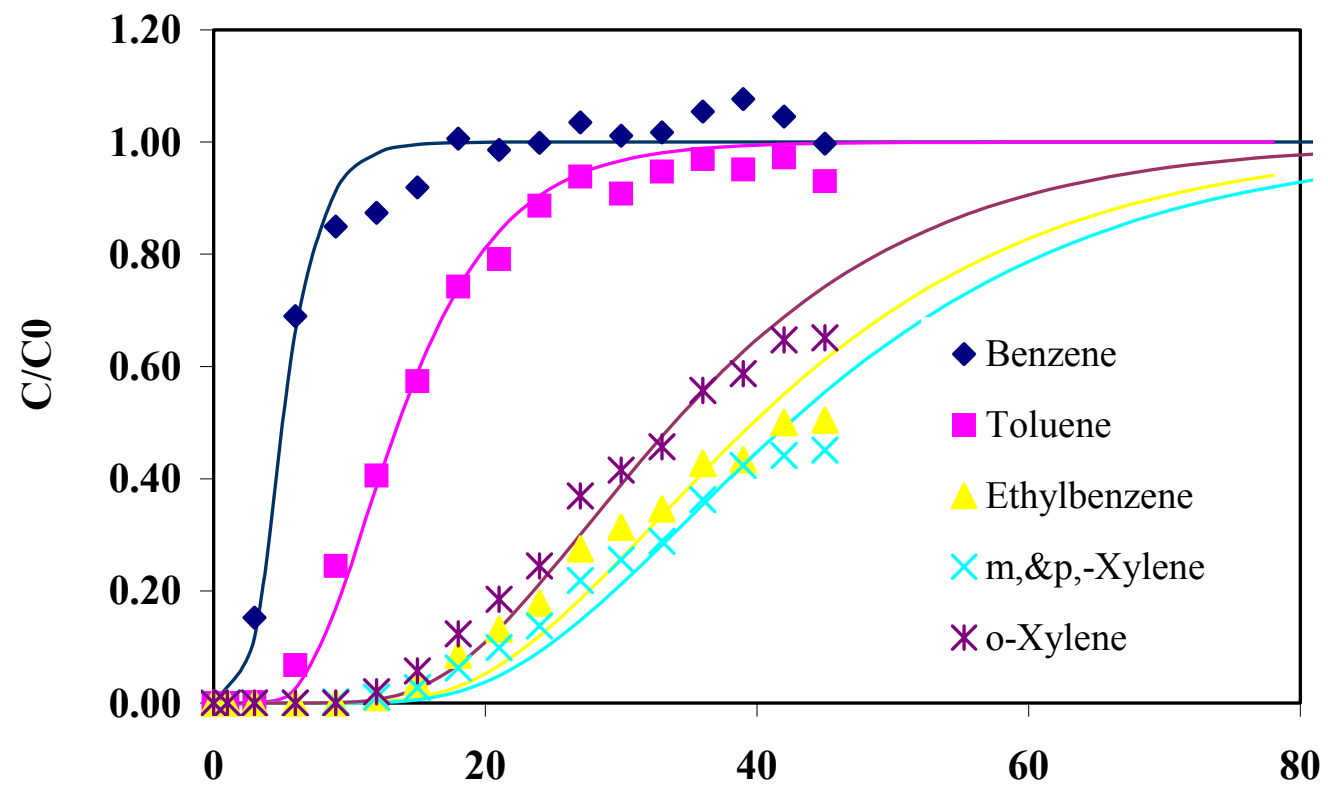

Time, minutes

Figure 5.23 Breakthrough Curves for BTEX sorbed onto SMZ in Produced Water

CXTFIT2 was used to calculate the $\mathrm{K}_{\mathrm{d}}$ values based on the column effluent data. Table 5.35 lists the input parameters for CXTFIT2 to calculate the retardation factors. See appendix B for the CXTFIT2 input file to calculate the distribution coefficients of BTEX in produced water. The resultant retardation factors, distribution coefficients, correlation coefficients and 95\% confidence limits are shown in Table 5.36.

Table 5.35 Parameters Used in CXTFIT2 Calculating Retardation Factor $\left(\mathrm{K}_{\mathrm{d}}\right.$ Values) in Produced Water in Column Study

\begin{tabular}{|l|c|c|c|c|c|}
\hline & Benzene & Toluene & Ethylbenzene & m,p-Xylene & o-Xylene \\
\hline $\begin{array}{l}\text { Seepage } \\
\begin{array}{l}\text { Velocity } \\
\left(\mathrm{cm}^{3} / \mathrm{min}\right)\end{array}\end{array}$ & 84 & 84 & 84 & 84 & 84 \\
\hline $\begin{array}{l}\text { Dispersion } \\
\text { Coefficient }\end{array}$ & 210 & 210 & 210 & 210 & 210 \\
\hline
\end{tabular}


Table 5.36 Calculated Retardation Factors and Distribution Coefficients, for CXTFIT2 for Produced Water Column Studies.

\begin{tabular}{|l|c|c|c|c|}
\hline Compound & $\begin{array}{l}\text { Retardation Factor, } \\
\mathbf{R}, \\
\text { from CXTFIT2 }\end{array}$ & $\begin{array}{l}\text { Calculated } \\
\mathbf{K}_{\mathbf{d}} \mathbf{( L / k g )}\end{array}$ & $\mathbf{R}^{\mathbf{2}}$ & $\begin{array}{l}\left.\text { Batch } \mathbf{K}_{\mathbf{d}} \mathbf{( L / K g}\right) \\
\text { in Ultrapure } \\
\text { Water }\end{array}$ \\
\hline Benzene & 18.46 & 8.2 & 0.9841 & 5.7 \\
Toluene & 50.21 & 23.1 & 0.9909 & 16.1 \\
Ethylbenzene & 146.7 & 68.3 & 0.9338 & 40.9 \\
m,p-Xylene & 156.5 & 72.9 & 0.9420 & 46.5 \\
o-Xylene & 125.1 & 58.2 & 0.9755 & 38.2 \\
\hline
\end{tabular}

Note: bulk density $\rho_{\mathrm{b}}=1.067 \mathrm{~g} / \mathrm{cm}^{3}$ in this column study

Porosity $\theta=0.5$

Flow rate $=22 \mathrm{~mL} / \mathrm{min}$

$\mathrm{R}=1+\rho_{\mathrm{b}} * \mathrm{~K}_{\mathrm{d}} / \theta$

Distribution coefficients using produced water were greater than those obtained using ultrapure water for the same mesh size SMZ. However, the data were not statistically compared. The salt effect was thought to be one factor for the increase in sorption capacity observed in the presence of produced water. However, the TDS concentration for produced water the Wamsutter site was only 11,400 ppm which is lower than the threshold value observed in the saline water batch experiments. While the salt composition may be different for produced water, it is unlikely that the salt effect is responsible for the increase in sorption observed for produced water. It is possible that the increase in sorption may result from sorption of other produced water components into the SMZ organic matter which provides a more favorable sorption environment for BTEX.

\section{$\underline{\text { Summary of Column Adsorption Results }}$}

Column studies confirmed that the distribution coefficients of BTEX sorption onto SMZ increased with increasing compound hydrophobicity. The column study with 100,000 ppm saline water also confirmed previous research suggesting that higher ionic strength increases BTEX sorption distribution coefficients. The magnitude of increase for the $100,000 \mathrm{ppm}$ salt concentration in the column study was comparable to the batch results for ultrapure water and the same salt concentration for 14x40 mesh SMZ.

Produced water may have enhanced the sorption capacity of SMZ toward BTEX as compared with ultrapure water. Batch isotherm tests showed a significant increase in BTEX sorption, but the increase in sorption for several of the other components was not statistically significant. The column study with produced water provided greater distribution coefficients for BTEX sorption onto SMZ as compared with ultrapure water.

Finally, the ability of CTXFIT2 to provide reasonable predictions of BTEX sorption in ultrapure water and excellent calibration fits to breakthrough data obtained in the presence of saline and produced water suggests that mass transfer limitations were relatively low for the system studied. 


\subsubsection{Regeneration Tests}

Figure 5.24 shows the results of the breakthrough of BTEX on virgin SMZ. Because of its low octanol-water partition coefficient $\left(\mathrm{K}_{\mathrm{ow}}\right)$ and high solubility in water, benzene breakthrough occurs first, while compounds with higher $\mathrm{K}_{\mathrm{ow}}$ and lower water solubility breakthrough later. The estimated amount of BTEX mass sorbed to the SMZ and estimated distribution coefficient $\left(\mathrm{K}_{\mathrm{d}}\right)$ values are shown in Table 5.37. The $\mathrm{K}_{\mathrm{d}}$ values determined in this experiment are similar and in some cases higher than those determined from batch experiments. A higher $\mathrm{K}_{\mathrm{d}}$ indicates enhanced sorption of the compound.

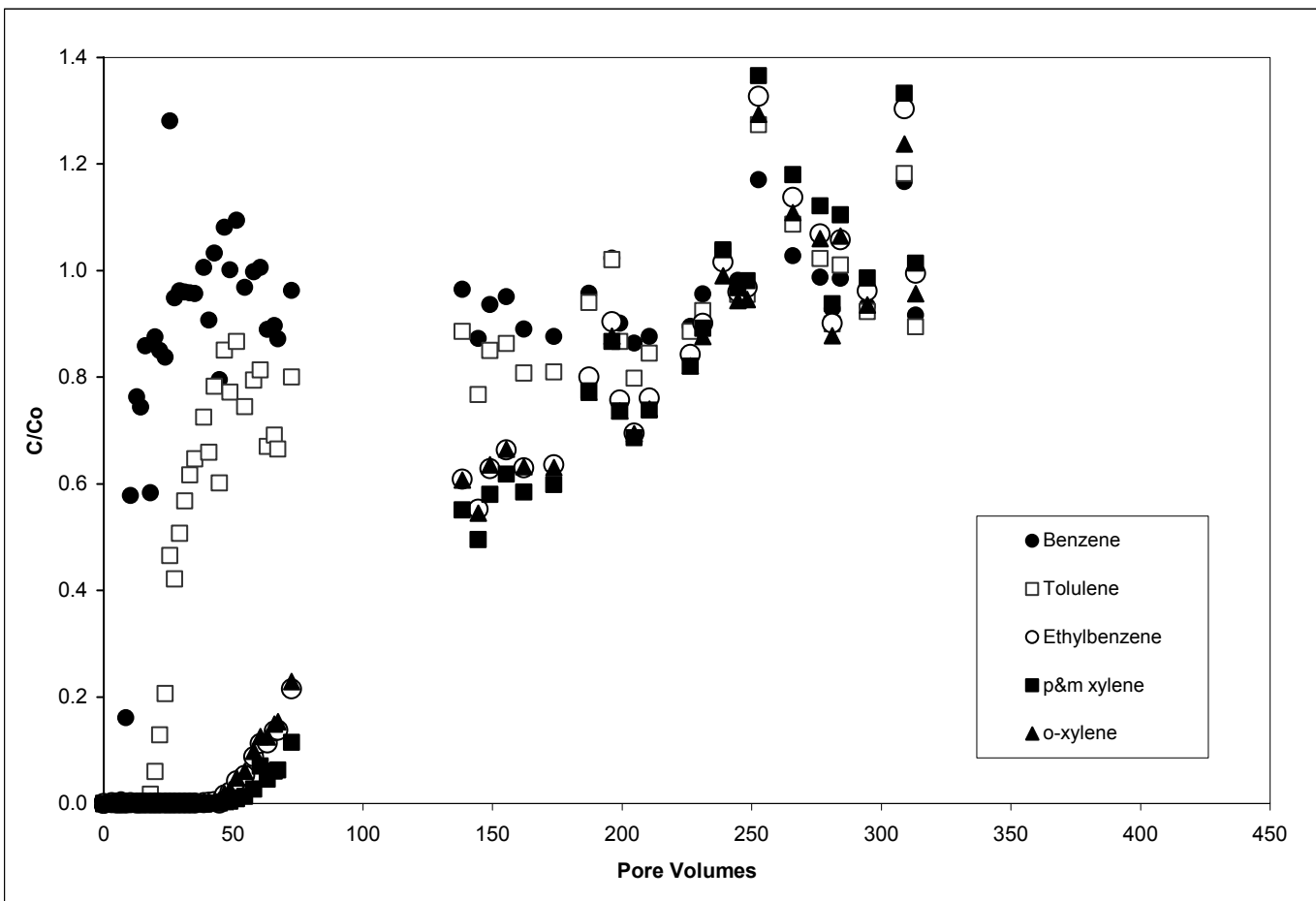

Figure 5.24 BTEX Breakthrough in a Laboratory Column Packed with Virgin SMZ

Figure 5.25 shows the cumulative masses of BTEX removed by air-sparging after the first column experiment. The compounds with the lowest $\mathrm{K}_{\mathrm{ow}}$ were the most readily removed. While air sparging was effective in stripping all of the benzene and toluene from the column, not all of the ethylbenzene and the xylenes were removed under these conditions (data not shown). 


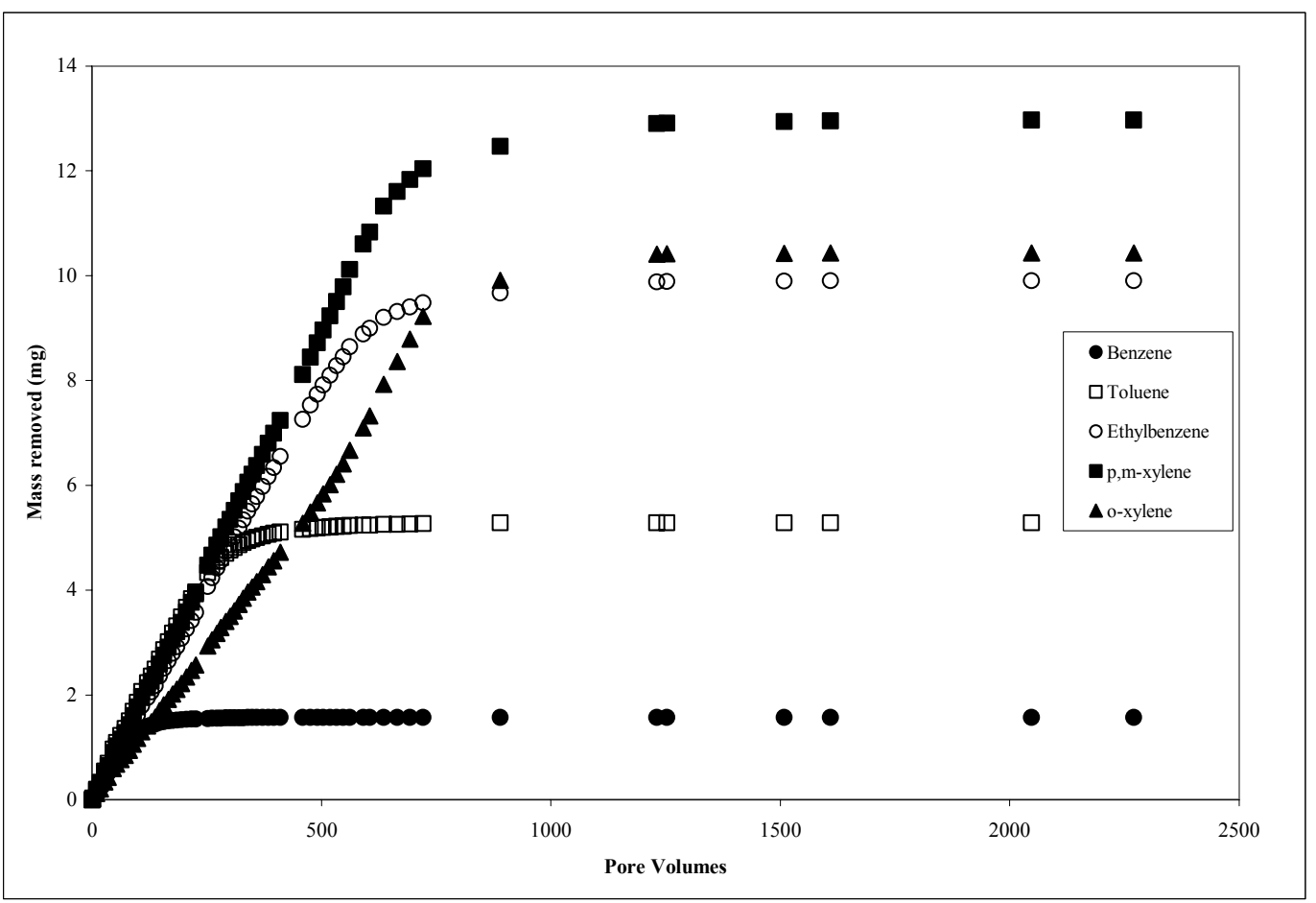

Figure 5.25 BTEX Mass Removed from SMZ in the Lab Column by Air-Sparging.

BTEX breakthrough in the regenerated column is shown in Figure 5.26. The estimated mass of BTEX sorbed to the SMZ and estimated $\mathrm{K}_{\mathrm{d}}$ values are shown in Table 5.37. The breakthroughs of benzene and toluene for the regenerated SMZ are similar to their breakthroughs with virgin SMZ. Figure 5.27 shows a comparison of benzene breakthrough in the two columns. The breakthrough curves for ethylbenzene and the xylenes seem to plateau at a relative concentration of 0.8 . We hypothesize the low plateau concentrations to be a result of enhanced cosorption effects in the regenerated columns. Others have noted that an increase of bound organic carbon due to BTEX sorption will enhance partitioning of additional BTEX (Jaynes and Vance, 1996; Sharmasardar et al., 2000). These effects would be more significant in the regenerated column since there is a higher hydrocarbon content on the SMZ, as not all of the BTEX mass was removed during air-sparging. These effects are most pronounced on the compounds with highest $\mathrm{K}_{\mathrm{ow}}$ and lowest $\mathrm{S}_{\mathrm{w}}$. Because the relative concentrations indicate that equilibrium between the SMZ and these compounds was not reached, $\mathrm{K}_{\mathrm{d}}$ values were not calculated for ethylbenzene and xylenes in the regenerated column. 


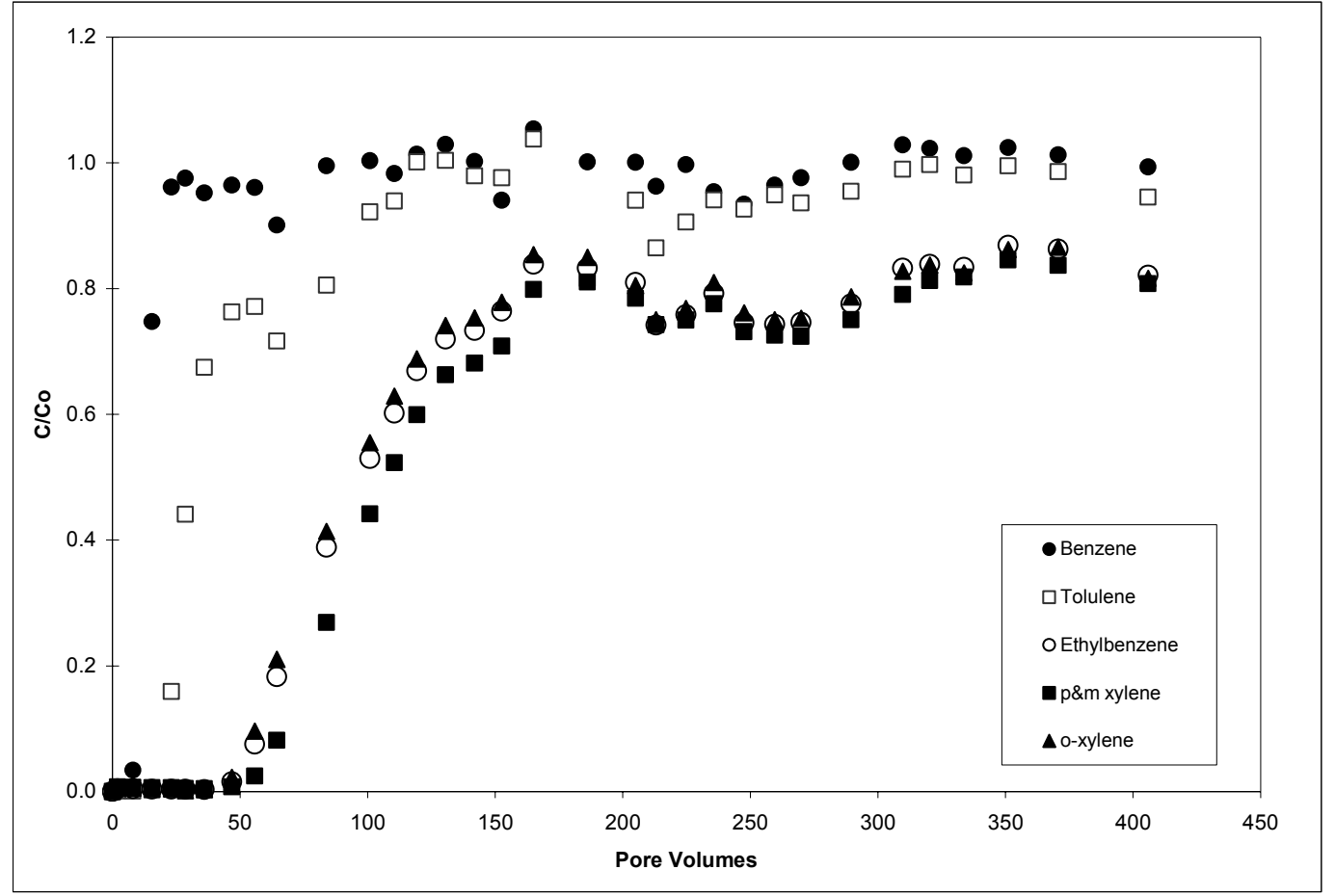

Figure 5.26 BTEX Breakthrough in the Lab Column with Regenerated SMZ

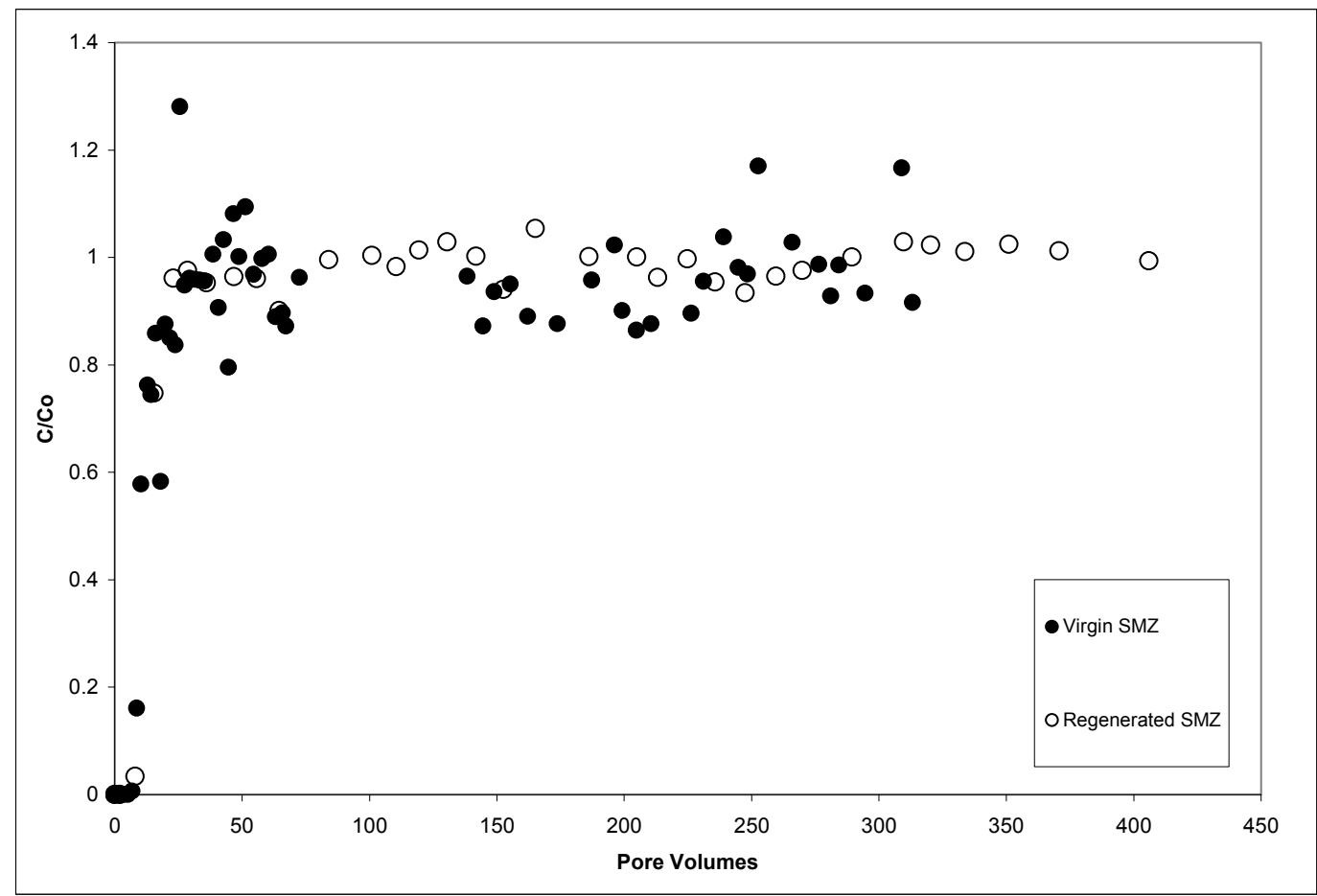

Figure 5.27 Comparison of Benzene Breakthrough in Lab Column for Virgin and Regenerated SMZ 
Table 5.37 Amount of BTEX Sorbed in Laboratory Columns and Comparison of $K_{d}$ Values

\begin{tabular}{|l|c|c|c|c|c|}
\hline & $\begin{array}{l}\text { Mass sorbed } \\
\text { to virgin } \\
\text { SMZ (mg) }\end{array}$ & $\begin{array}{l}\text { Virgin } \\
\text { SMZ } \\
\text { Kd (L/kg) }\end{array}$ & $\begin{array}{l}\text { Mass sorbed } \\
\text { to regen. } \\
\text { SMZ (mg) }\end{array}$ & $\begin{array}{l}\text { Regen. SMZ } \\
\text { Kd (L/kg) }\end{array}$ & $\begin{array}{l}\text { Batch } \\
\text { Kd (L/kg) }\end{array}$ \\
\hline Benzene & 1.9 & 7.8 & 1.8 & 8.2 & 9.9 \\
\hline Toluene & 4.4 & 23 & 4.2 & 23.0 & 27 \\
\hline Ethylbenzene & 15.5 & 85 & 12.6 & -- & 69 \\
\hline p\&m-xylene & 15.1 & 90 & 12.8 & -- & 75 \\
\hline o-xylene & 16.1 & 85 & 12.8 & -- & 66 \\
\hline
\end{tabular}

\subsection{Field Experiments}

The BTEX concentrations in the produced water used in the field testing varied over time. Table 5.38 shows the average and range of values of the BTEX component concentrations throughout the duration of the test of the field-scale columns. The breakthrough of BTEX in the virgin 14-inch field system is shown in Figure 5.28. The effluent concentrations of all compounds remained below the influent concentrations for the duration of the test. Little ethylbenzene or xylene had appeared in the effluent after 80 pore volumes. Benzene and toluene concentrations in the effluent appeared to plateau at relative concentrations of 0.8 and 0.6 , respectively. A possible reason for the failure of benzene and toluene to reach saturation may be the cosorption described above. The dissolved organic carbon of this produced water was $470 \mathrm{mg} / \mathrm{L}$, of which only $110 \mathrm{mg} / \mathrm{L}$ was BTEX, thus providing additional hydrocarbons that were not present in the laboratory experiments. These additional, primarily higher molecular weight hydrocarbons may have added to the cosorption effects. Laboratory batch tests comparing BTEX sorption to SMZ in both pure and produced waters showed similar results. The $\mathrm{K}_{\mathrm{d}}$ values were higher in produced water, which contained higher dissolved organic carbon.

Table 5.38 Average and range of BTEX component concentrations in WY Produced Water

\begin{tabular}{|l|c|c|}
\hline & $\begin{array}{l}\text { Average concentration in } \\
\text { WY Produced water } \mathbf{( m g / L )}\end{array}$ & $\begin{array}{l}\text { Range of concentration } \\
(\mathbf{m g} / \mathbf{L})\end{array}$ \\
\hline Benzene & 25.1 & $18.9-36.4$ \\
\hline Toluene & 40.7 & $31.0-61.3$ \\
\hline Ethylbenzene & 4.7 & $1.8-19.9$ \\
\hline p\&m-xylene & 30.6 & $8.8-78.9$ \\
\hline o-xylene & 9.5 & $3.7-40.8$ \\
\hline
\end{tabular}




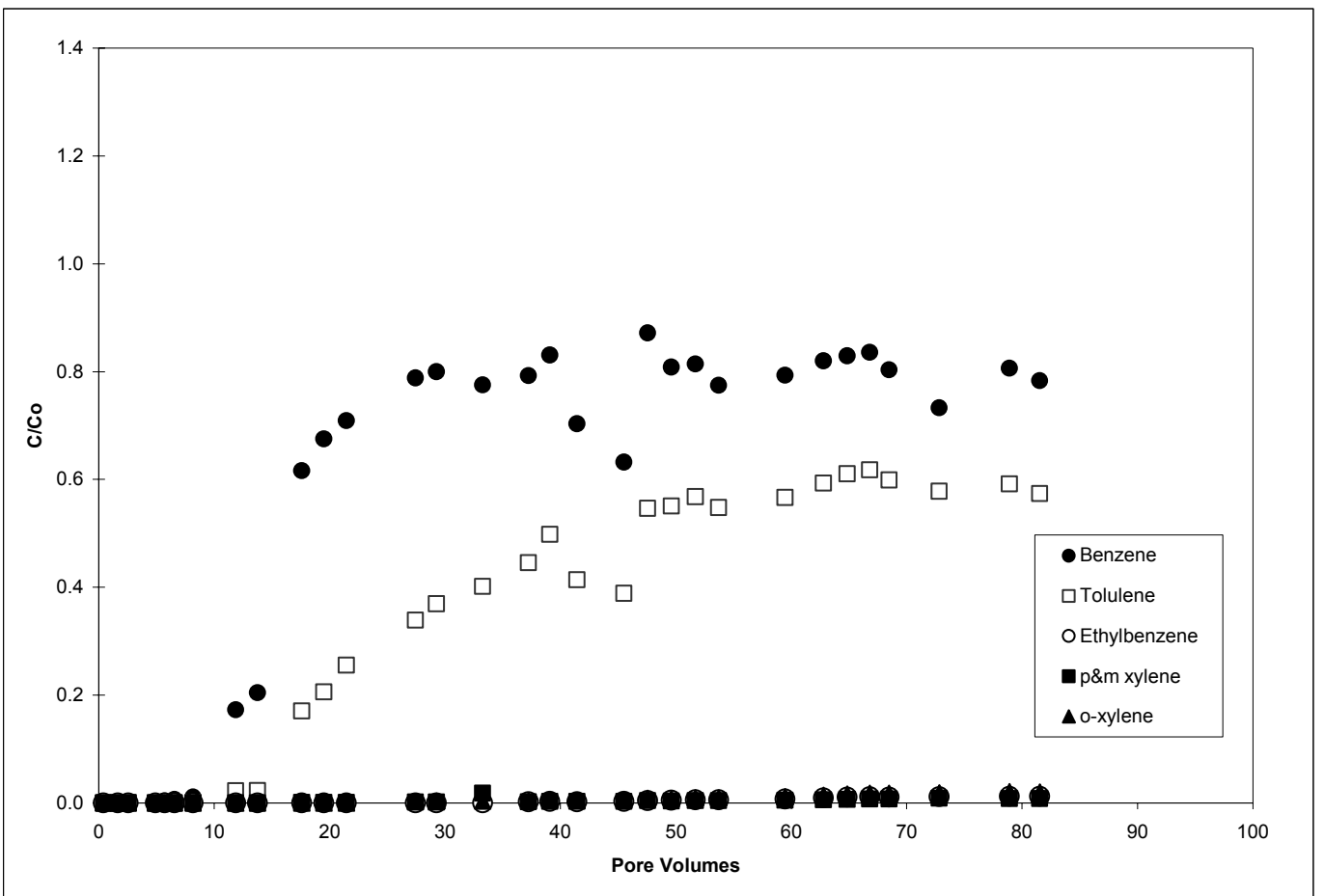

Figure 5.28 BTEX Breakthrough in the 14-inch Field Column with Virgin SMZ

Figure 5.29 shows a comparison of benzene sorption between the lab trial and 14-inch column field trial, both with virgin SMZ. Benzene breakthrough is later in the field column and does not reach the influent value. The results of the 12-inch column with virgin SMZ are similar. Figure 5.30 shows a comparison of toluene sorption between the lab trial and 12-inch field column with virgin SMZ.

Regeneration of the 14-inch column showed results similar to regeneration of the lab column, as shown in Figure 5.31 Benzene was the first to be removed, and was the only compound that fully stripped from the column. As mentioned above, air-sparging of the field column was terminated sooner than desired due to equipment failure. 


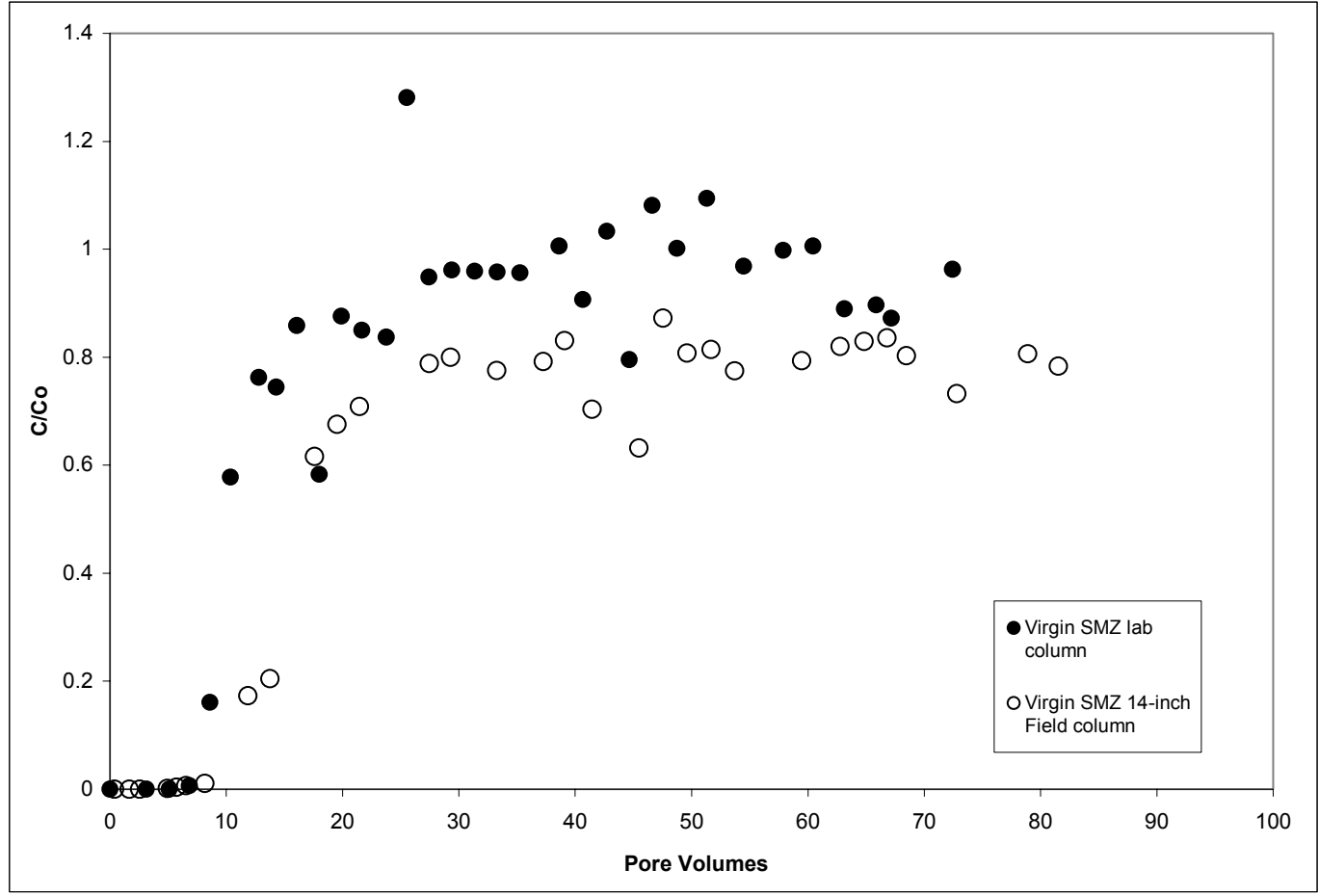

Figure 5.29 Comparison of Benzene Breakthrough in Lab Column with Virgin SMZ and 14-inch Field Column with Virgin SMZ.

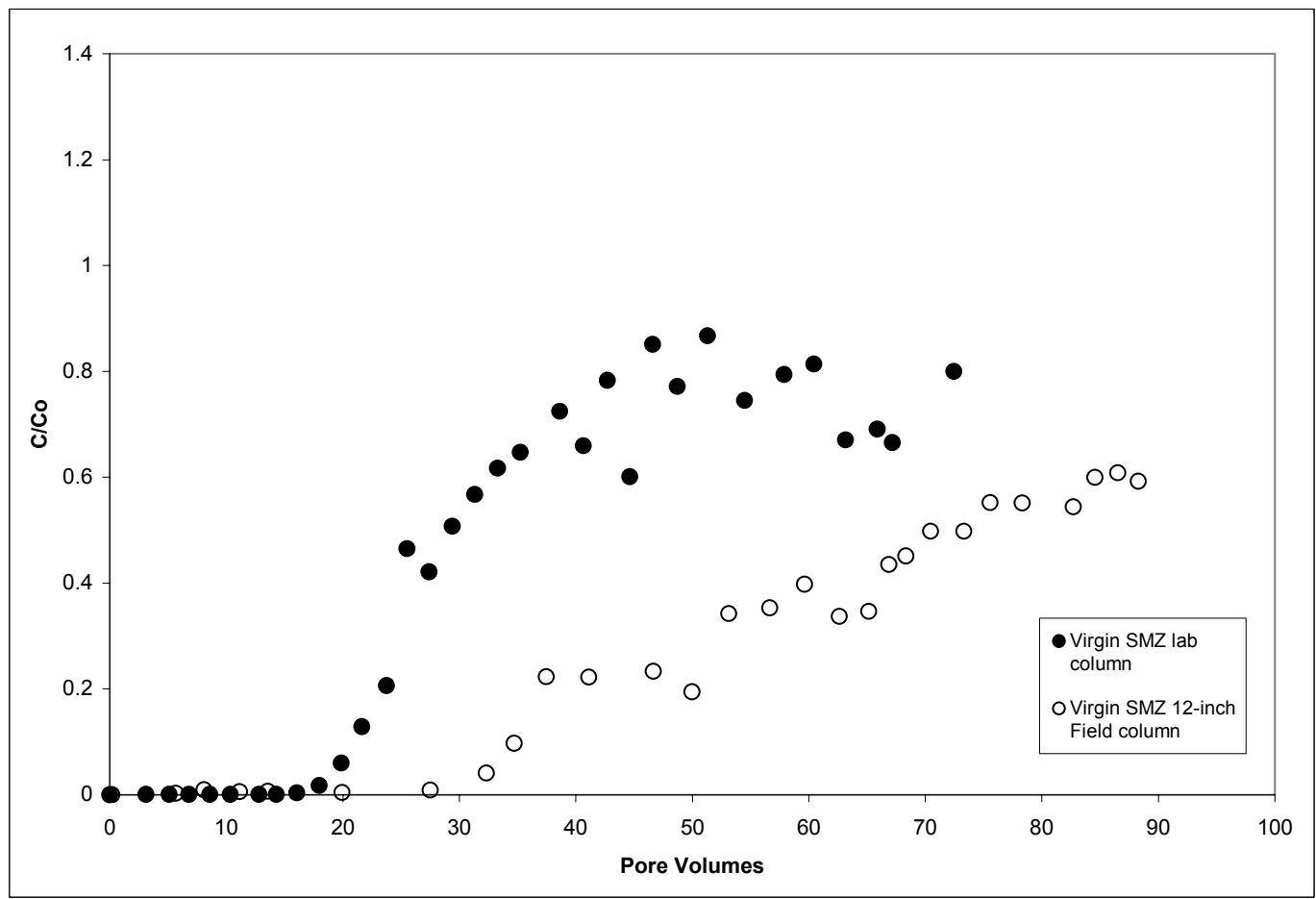

Figure 5.30 Comparison of Toluene Breakthrough in Lab Column with Virgin SMZ and 12-inch Field Column with Virgin SMZ 


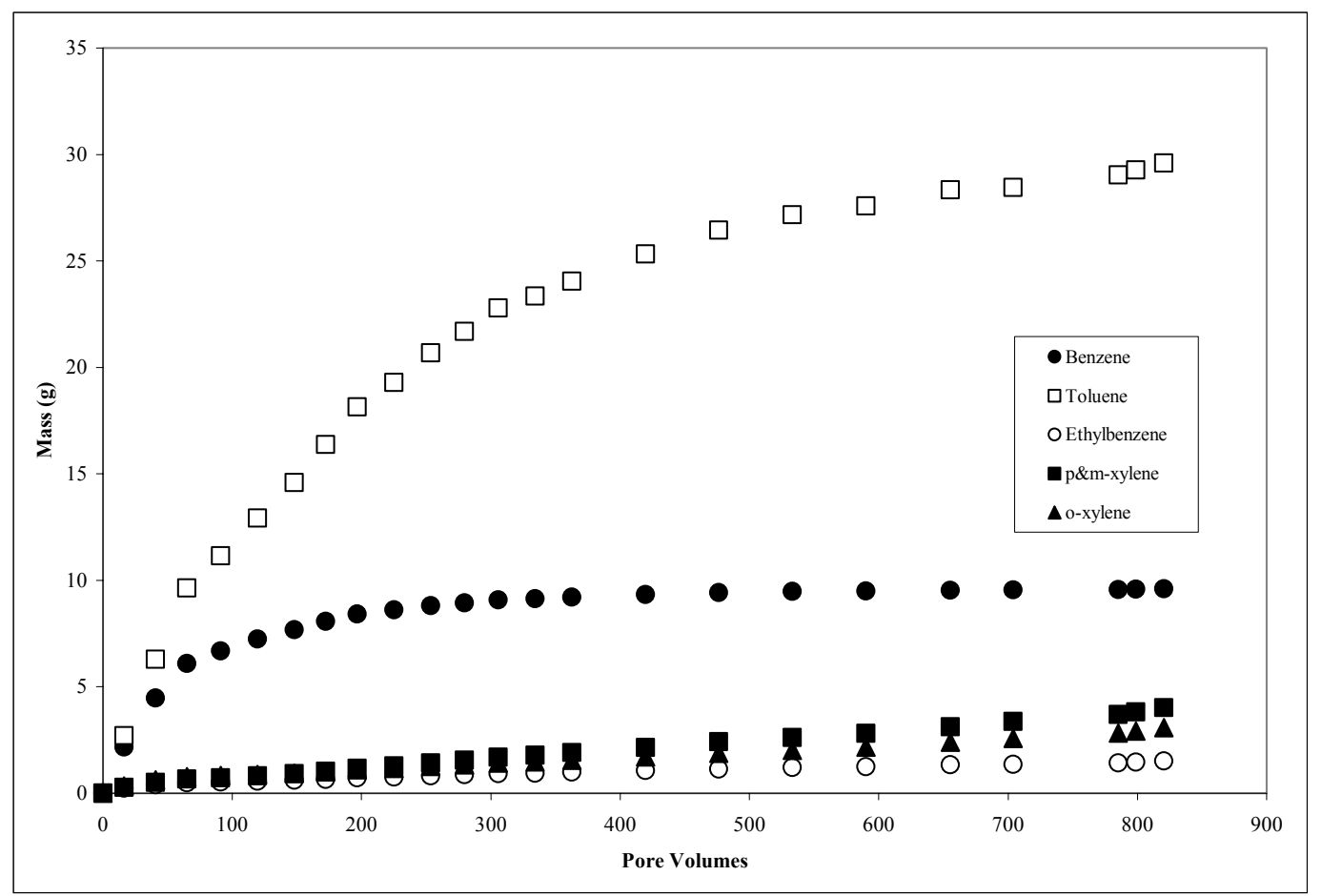

Figure 5.31 BTEX Mass Removed from SMZ in 14-inch Field Column by Airsparging.

Figure 5.32 shows the breakthrough of BTEX in the regenerated 14-inch column. The relative concentrations of all of the compounds except for benzene are above background (and higher for ethylbenzene and the xylenes than during any stage of the initial sorption experiment). We believe the high initial concentrations were due to the incomplete regeneration of the SMZ. During regeneration, air was pushed into the column in the same flow direction as water. Therefore, the influent end of the column was regenerated first and the BTEX was pushed toward the effluent end of the column. The compounds with higher $\mathrm{K}_{\mathrm{ow}}$ are less readily air sparged from the SMZ and were not completely removed from the column when regeneration terminated, but instead concentrated near the effluent end. Thus, when produced water was again flushed through the column, these higher concentrations eluted. If flow was reversed during regeneration, residual BTEX would be concentrated towards the influent end of the column and less readily eluted during the next saturation step.

Except for the high initial concentrations, the regenerated SMZ was even more effective than the virgin SMZ at BTEX removal. A comparison of toluene removal from the virgin and regenerated 14-inch column trials is shown in Figure 5.33. As was noted in the lab columns, the regenerated column removes higher amounts of BTEX from the water than the original column. 


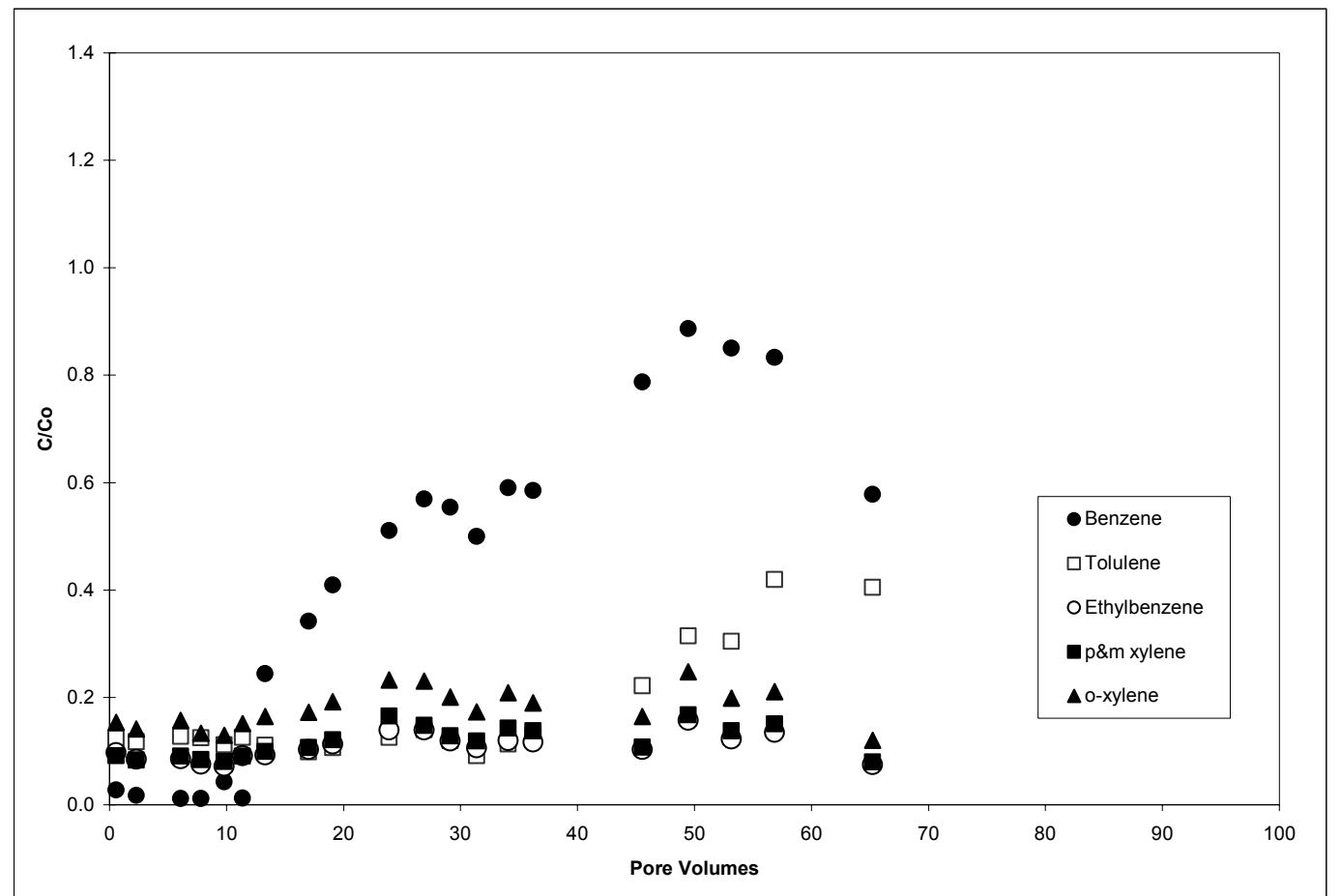

Figure 5.32 BTEX Breakthrough in 14-inch Field Column with Regenerated SMZ

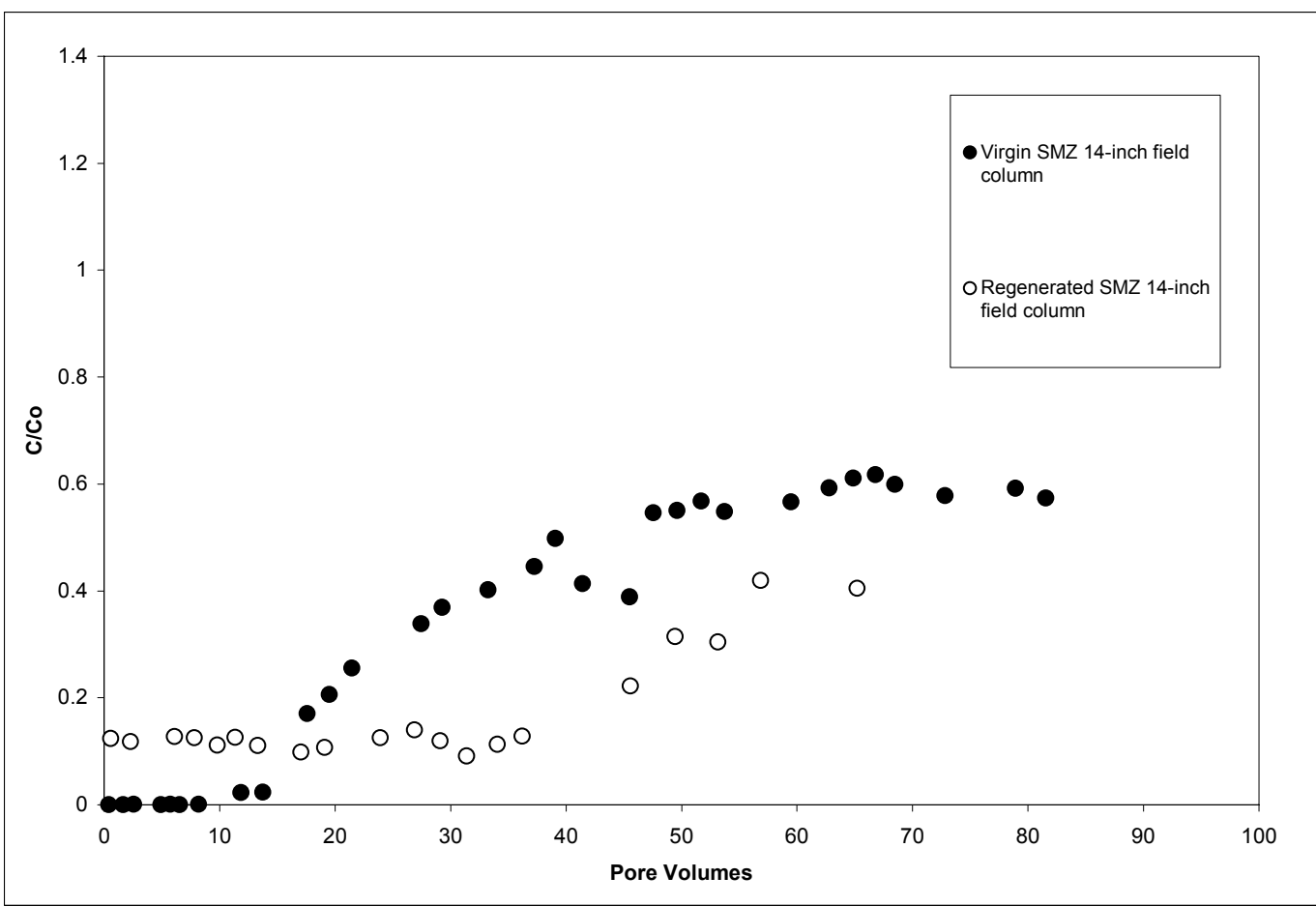

Figure 5.33 Comparison of Toluene Breakthrough in 14-inch Field Column with Virgin SMZ and 14-inch Field Column with Regenerated SMZ 


\subsection{Cost Analyses}

The original pilot scale system used for the Wyoming tests considered two columns: one 14" diameter and 48" in height, and one 12" diameter and 44" in height. These columns were run with average flow rates of 25 and 19 gph respectively as described above. According to the U.S. Department of Energy, as of 1996 the state of Wyoming discharges approximately $121,300 \mathrm{bbl}$ per day of produced water amongst 586 permits (Doyle and Brown, 1997). According to the American Petroleum Institute, the average offshore oil platform produces between 2,500 and 5,000 barrels of produced water per day (API, 1995). Thus, an industrial scale treatment system would need to be able to handle an average flow rate of 362 gph onshore and between 4375 and 8750 gph for offshore use. These flow values are summarized in Table 5.39.

Table 5.39 Industrial Produced Water Discharge Flow Rates

\begin{tabular}{|c|c|c|c|}
\hline \multirow{2}{*}{$\begin{array}{l}\text { Flowrate, } \\
\text { Q }\end{array}$} & \multirow[b]{2}{*}{ Onshore } & \multicolumn{2}{|c|}{ Offshore } \\
\hline & & Low & High \\
\hline bbls/d & 207 & 2500 & 5000 \\
\hline gph & 362 & 4375 & 8750 \\
\hline Iph & 1371 & 16559 & 33119 \\
\hline
\end{tabular}

The field test prototypes had an average hydraulic loading rate in the columns of approximately $0.5 \mathrm{gpm} / \mathrm{ft}^{2}$. It was found from this work that this hydraulic loading rate provided good flow, and gave an average of almost 100 percent benzene removal after 6 hours. As such, the industrial columns were designed to operate at a similar hydraulic loading rate in order to provide a reasonable time before regeneration would be required. For the purposes of this project, the columns were designed to be regenerated at the point of near 100 percent benzene removal. Since benzene broke through much sooner than the other components of BTEX, their removal rate was near 100 percent as well. For the prototype SMZ system, the columns were obtained from a local Culligan distributor in Austin, TX. The columns were originally deigned for ion exchange systems and were used by substituting the ion exchange resin for SMZ. Culligan produces the same type of columns for industrial scale use, and the recommended size available for the flow rates presented in Table 5.39 would be columns 36 " in diameter and 72 " in height (personal communication).

The prototype test showed that an air flow rate of $3-3.5 \mathrm{scfm}$ provided by an air compressor was sufficient to regenerate the columns over a time period of 10 hours. For the larger, industrial scale system, an air compressor would need to provide approximately $25-30 \mathrm{scfm}$ in order to provide the same air-flow rate through the column. In order to meet these requirements, a 7.5 horsepower rotary screw compressor is recommended, and can be purchased from various vendors, including Kaeser Compressors, Inc (personal communication).

Finally, the industrial scale SMZ system would require columns in series so that produced water could be treated continuously while the one set of columns is being regenerated. Thus, the system on which the cost analysis was based consisted of three 36 " diameter by 72 " height columns in series, with each set of columns being run for 6-8 hours followed by a 12 hour regeneration by air sparging with an air compressor. 


\subsubsection{Cost Analysis for Industrial Scale SMZ System}

Based on an example onshore produced water treatment facility with flow rates given in Table 5.39, a series of 3 columns could be used to treat water continuously. This example industrial treatment system would therefore consist of 3 columns filled with SMZ and one industrial size air compressor for regeneration. As one column reached the benzene breakthrough point at $6-8$ hours, it could be switched off and regenerated for 12 hours while the other columns continue to treat the influent flow. Thus, this system would allow continuous treatment.

In order for the SMZ filtration system to work effectively, pretreatment of the produced water is necessary. In particular, the use of an oil/water separation process is necessary to avoid fouling the SMZ. Due to the need for pretreatment and the large flow rates of produced water associated with offshore oil platforms, the SMZ system is most likely not a viable treatment option for offshore applications. Therefore, the preliminary design presented here is recommended for onshore use.

The initial capital costs for the SMZ system comprise the bulk of the costs. The costs of the columns are approximately $\$ 4500$ per column including fittings and filters (Culligan International Company). Furthermore, the initial cost of the air compressors required to regenerate the columns is $\$ 5000$ per air compressor (Kaeser Compressors, Inc.). Amortized over ten years at an interest rate of 5 percent, the yearly capital expenditures for a three-column system would be approximately $\$ 2400$. This figure includes the capital costs of the columns and air compressor for regeneration, but does not include treatment costs.

Power and energy costs associated with the SMZ system would be potentially very low. Head loss through the columns was calculated to be approximately 6 feet $\mathrm{H}_{2} \mathrm{O}$, so no pumping would be required if the influent of the system was connected to the bottom of a separation tank as it was in the pilot test. Moreover, the cost of running the air compressors to regenerate the columns was also low, at approximately $\$ 10$ per day. The capital costs and operating costs are summarized in Table 5.40.

Table 5.40 Capital and Operating Costs of Industrial SMZ Column

\begin{tabular}{|l|l|}
\hline Component & Cost \\
\hline Adsorption column & $\$ 4500$ \\
\hline SMZ fill & $\$ 500$ \\
\hline Air Compressor & $\$ 5000$ \\
\hline Daily Power Use & $\$ 10 /$ day \\
\hline
\end{tabular}

The total treatment costs of such a system would depend on the frequency that the SMZ is replaced or re-flushed with surfactant. Each column would contain approximately $1100 \mathrm{~kg}$ of SMZ at a cost of $\$ 460$ per metric ton, resulting in a total material cost of about $\$ 500$ per column. Table 5.41 summarizes the cost of an industrial- 
scale SMZ system based on different replacement intervals of the SMZ fill. The replacement intervals are based on 350 operating days per year. It is likely these costs would be lower if the SMZ were renewed by pumping surfactant through the columns rather than merely replacing the bulk of the zeolite.

Table 5.41 Total Cost of Industrial SMZ System

\begin{tabular}{|l|l|l|}
\hline $\begin{array}{l}\text { Replacement } \\
\text { Interval }\end{array}$ & $\begin{array}{l}\text { Capitol } \\
\text { Costs }\end{array}$ & $\begin{array}{l}\text { Treatment Costs } \\
/ \mathbf{1 0 0 0} \text { gal }\end{array}$ \\
\hline 1 month & $\$ 18,500$ & $\$ 5.80$ \\
\hline 3 months & $\$ 18,500$ & $\$ 1.96$ \\
\hline 6 months & $\$ 18,500$ & $\$ 0.98$ \\
\hline 1 year & $\$ 18,500$ & $\$ 0.49$ \\
\hline
\end{tabular}

When compared to other existing treatment technologies, the cost of the SMZ system is very competitive. In 1995, the American Petroleum Institute organized a workshop to analyze technologies for treating produced water toxicity (API, 1995). Table 5.42 provides a brief summary of the treatment technologies discussed, including the estimated costs associated with each. Of the technologies presented, the use of SMZ has the potential of being one of the most cost effective treatment options available. Furthermore, the SMZ system is relatively compact, does not require the storage of potentially hazardous chemicals, and could be readily adapted to an automated system. When compared with the most common offshore treatment method, reinjection, the use of SMZ would be substantially cheaper. Finally, the cost analysis performed here is based on removing all BTEX compounds to nearly undetectable levels, the total cost of such a system could be potentially much lower if it were used to treat to "acceptable" levels in order to meet any state of federal guidelines. 
Table 5.42 Summary of Treatment Costs of Other Technologies (API, 1995)

\begin{tabular}{|c|c|c|}
\hline Technology & Comments & Treatment Costs \\
\hline $\begin{array}{l}\text { Membrane } \\
\text { Filtration }\end{array}$ & Likely to require pretreatment & $\$ 1.90-2.38 / 1000 \mathrm{gal}$ \\
\hline $\begin{array}{l}\text { Carbon } \\
\text { Adsorption }\end{array}$ & $\begin{array}{l}\text { Requires deoiling pretreatment of } \\
\text { water to avoid fouling media, } \\
\text { costs w/ pretreatment estimated } \\
\text { by PWMOM }\end{array}$ & $\$ 1.19-8.33$ / $1000 \mathrm{gal}$ \\
\hline $\begin{array}{l}\text { Chemical } \\
\text { Oxidation }\end{array}$ & $\begin{array}{l}\text { Cost estimated for Hydrogen } \\
\text { Peroxide system at } 50 \mathrm{ppm} \\
\text { dosage rate, ozone would be } \\
\text { double this cost }\end{array}$ & $\$ 0.20-0.40 / 1000 \mathrm{gal}$ \\
\hline Air Stripping & Off gas treatment required & $\begin{array}{l}\$ 0.03-0.05 \text { plus } \$ 0.50-1.00 / \\
1000 \text { gal }\end{array}$ \\
\hline UV Oxidation & $\begin{array}{l}\text { Designed to treat } 10,000 \text { barrels } \\
\text { per day at } 350 \text { days per year }\end{array}$ & $\begin{array}{l}\$ 350,000-\$ 600,000 \text { capital } \\
\text { costs plus } \$ 0.60 / 1000 \text { gal }\end{array}$ \\
\hline Reinjection & $\begin{array}{l}\text { Most common treatment for } \\
\text { offshore use, cost estimated by } \\
\text { the API SWIM model }\end{array}$ & $\begin{array}{l}\$ 3.00-5.00 \text { with up to over } \$ 72 \\
\text { per } 1000 \text { gal in some cases }\end{array}$ \\
\hline
\end{tabular}




\section{Conclusions}

\subsection{Batch Equilibrium Studies}

\subsubsection{Batch Equilibrium Sorption Studies Conducted in Ultrapure Water}

Single-solute and multi-solute sorption tests showed that the partitioning of BTEX compounds remained linear through concentrations ranging over five orders of magnitude. As proven through hypothesis testing, the distribution coefficients for benzene and toluene were not significantly changed by the addition of the remaining BTEX compounds. Distribution coefficients for ethylbenzene and the xylenes were substantially greater than those for benzene and toluene which is typical for sorption of hydrophobic compounds onto organic carbon surfaces. Due to their lower aqueous solubilities, the driving force for partitioning of ethylbenzene and the xylenes out of the aqueous phase was greater. As a result, ethylbenzene and the xylenes will be removed to a higher extent than the remaining BTEX compounds in SMZ adsorption systems. Because benzene demonstrated the least affinity for SMZ and effluent criteria for benzene are generally more stringent, this compound was used as the target compound for design of the SMZ treatment system.

The distribution coefficients for benzene and toluene were underestimated by typical published correlations relating organic carbon normalized partition coefficients to either aqueous solubility or octanol water partition coefficients. These published correlations were developed for soils that contain organic matter which acts as an adsorbent for nonpolar organic compounds. The failure of the correlations to validate results from sorption onto SMZ signifies the chemical and physical differences between soil organic matter and SMZ. Hence, correlations specific to SMZ were developed with the data generated during this project. These correlations are:

$$
\begin{array}{ll}
\log K_{d}=0.84 \log K_{\text {ow }}-0.81 & \mathrm{R}^{2}=0.9987 \\
\log K_{d}=-0.75 \log S-0.26 & \mathrm{R}^{2}=0.9868
\end{array}
$$

where $\mathrm{K}_{\mathrm{d}}$ is expressed in $\mathrm{L} / \mathrm{kg} \mathrm{SMZ,} \mathrm{K}_{\mathrm{ow}}$ in $\mathrm{L}$ octanol/L water, and $\mathrm{S}$ in mol/L.

\subsubsection{Batch Equilibrium Sorption Studies Conducted in Saline Solutions}

The sorption isotherms for every BTEX compound in the saline solutions continued to show strong linearity as demonstrated by high correlation coefficients for isotherms on SMZ and by the y-intercepts that were not statistically different from zero. Hypothesis testing showed that all of the BTEX compounds demonstrated increased affinity for SMZ when the salt concentration in solution was increased to $100,000 \mathrm{ppm}$. Thus, the presence of high levels of salts did enhance linear partitioning of the BTEX compounds.

However, results comparing isotherms generated in ultrapure water and those generated in a 30,000 ppm saline solution were mixed. Statistical differences between the two isotherms were found for benzene and toluene, but the isotherms for the 
ethylbenzene and the xylenes were determined to be statistically equivalent. Hence, a baseline salt concentration may be required to yield a significant increase in sorption of BTEX compounds.

Attempts to predict distribution coefficients with the Setchenow equation and regressions developed both through this research and by Schwarzenbach, et al. (1993) were unsuccessful. As a result, empirical regression equations were developed based on observed distribution coefficient values and corresponding salt concentrations. These regressions fit the collected data well, as demonstrated by correlation coefficient values. Hence, these regressions can be used to provide estimates of the salt concentration required for BTEX effluent standards to be met. The general regression is:

$$
\log K_{d, \text { salt,observed }}=a[\text { salt }]_{M}+b
$$

The specific parameters, $a$ and $b$, for each BTEX compound are included in Table 6.1.

Table 6.1 Calculated Values for $a$ and $b$

\begin{tabular}{|c|c|c|}
\hline Compound & $\boldsymbol{a}\left(\mathbf{M}^{-\mathbf{1}}\right)$ & $\boldsymbol{b}$ \\
\hline Benzene & 0.118 & 0.948 \\
\hline Toluene & 0.135 & 1.39 \\
\hline Ethylbenzene & 0.155 & 1.79 \\
\hline m- \& p-Xylenes & 0.159 & 1.83 \\
\hline o-Xylene & 0.154 & 1.78 \\
\hline
\end{tabular}

\subsubsection{Batch Equilibrium Sorption Studies Conducted in Produced Water}

The methods used for sorption studies in produced water were similar to those used in the studies conducted in ultrapure water and saline solutions. However, small differences in these methods were present because of the unique nature of produced water. These differences could have affected the accuracy of the results for the batch studies. Nevertheless, the sorption isotherms for all of the compounds remained linear throughout at least two orders of magnitude.

Comparison of BTEX sorption in produced water and ultrapure water suggested that BTEX compounds had a higher affinity for SMZ in produced water than ultrapure water. In all cases, the distribution coefficients increased in the produced water background. However, hypothesis testing indicated that the differences in distribution coefficients were only significant for benzene and $\mathrm{m}$ and $\mathrm{p}$-xylene.

\subsubsection{Studies of Temperature Effects on Batch Equilibrium Sorption}

The distribution coefficients for BTEX compounds sorbed onto SMZ increased with increasing temperature. This means that for BTEX compounds temperature does have to be considered when designing field scale systems. Van't Hoff plots of $\ln K_{d}$ vs. $1 /$ T were used to estimate enthalpy values for the same mesh size material considered. The process 
proved to be endothermic and consistent with a partitioning mechanism for sorption. Greater sorption capacity of SMZ for BTEX compounds can be achieved by increasing temperature. This finding is of particular interest because produced water temperatures can be extremely high for some off-shore operations.

\subsection{Laboratory Scale Column Studies and Field Studies}

\subsubsection{Column Studies with Ultrapure Water, Saline Water, and Produced Water}

A summary of the distribution coefficients for BTEX sorption to SMZ obtained from column studies in ultrapure water, saline water and produced water are shown in Table 6.2 .

Table 6.2 $\mathrm{K}_{\mathrm{d}}$ Values from Ultrapure, Saline, and Produced Water Column Studies

\begin{tabular}{|l|l|l|l|}
\hline Compounds & $\begin{array}{l}\mathrm{K}_{\mathrm{d}} \text { from Ultrapure } \\
\text { Water }(\mathrm{L} / \mathrm{Kg})\end{array}$ & $\begin{array}{l}\mathrm{K}_{\mathrm{d}} \text { from Produced } \\
\text { Water }(\mathrm{L} / \mathrm{Kg})\end{array}$ & $\begin{array}{l}\mathrm{K}_{\mathrm{d}} \text { from Saline } \\
{\text { Water }(\mathrm{L} / \mathrm{Kg})^{\mathrm{a}}}\end{array}$ \\
\hline Benzene & 5.7 & 8.2 & 8.7 \\
Toluene & 16.1 & 23.1 & 26.4 \\
Ethylbenzene & 40.9 & 68.3 & 84.9 \\
m- \& p- Xylene & 46.5 & 72.9 & 96.4 \\
o-Xylene & 38.2 & 58.2 & 78.2 \\
\hline
\end{tabular}

${ }^{a}$ Salt concentration was $100,000 \mathrm{ppm}$

Note: SMZ mesh size was 80x100 in all laboratory column experiments.

Comparison of the $\mathrm{K}_{\mathrm{d}}$ values obtained from the ultrapure batch isotherms and the ultrapure column breakthrough curve showed good agreement between the two experimental methods. In addition, breakthrough curves derived from the breakthrough data using CTXFIT2 matched the experimental data reasonably well for both the produced water and saline water backgrounds. These results suggest that the local equilibrium assumption provided a reasonable fit to the data for the conditions tested.

As shown in Table 6.2, the $\mathrm{K}_{\mathrm{d}}$ values for the tests conducted in different background waters increased from ultrapure water to produced water to water containing 100,000 ppm TDS. While the increase in sorption capacity for the saline water can be attributed to a salting out effect, this phenomenon can not explain the increase in BTEX sorption for produced water since the TDS concentration in the produced water was relatively low.

The column studies laid the foundation for the design of pilot-scale column design. based on benzene sorption capacities and assumed local equilibrium kinetics. Benzene was selected for the design basis because it is the weakest sorbing BTEX species and typically has the most stringent regulatory limits.

\subsubsection{Regeneration Studies with Ultrapure Water}

Regeneration was successfully achieved using an air stripping approach. Upon completion of the adsorption phase of a laboratory column experiment, regeneration successfully removed both the benzene and toluene. Indeed, the compounds with the 
lowest $\mathrm{K}_{\mathrm{ow}}$ were the most readily removed. While air sparging was effective in stripping all of the benzene and toluene from the column, not all of the ethylbenzene and the xylenes were removed under the conditions employed.

The breakthrough profiles of benzene and toluene for the regenerated SMZ were similar to their breakthroughs with virgin SMZ; however, the breakthrough curves for ethylbenzene and the xylenes plateaued at $\mathrm{C} / \mathrm{Co}=0.8$. Others have noted that an increase of bound organic carbon due to BTEX sorption will enhance partitioning of additional BTEX (Jaynes and Vance, 1996; Sharmasardar et al., 2000). These effects would be more significant in the regenerated column since there is a higher hydrocarbon content on the SMZ, as not all of the BTEX mass was removed during air-sparging. These effects are most pronounced on the compounds with highest $\mathrm{K}_{\mathrm{ow}}$ and lowest $\mathrm{S}_{\mathrm{w}}$.

\subsubsection{Summary of Field Test}

The field test conducted at the BC Technologies site in Wamsutter, WY successfully verified the laboratory findings. The SMZ treatment system removed BTEX using virgin SMZ and regenerated SMZ. Benzene breakthrough in the field column occurred after a greater number of pore volumes than observed in the laboratory columns, suggesting that the background produced water increased the sorption capacity of the SMZ for benzene.

Regeneration of a 14-inch column showed results similar to regeneration of the lab column. Benzene was the first compound to be removed from the spent SMZ, and was the only compound that fully stripped from the column. Air sparging of the field column was terminated sooner than desired due to equipment failure; therefore, the more hydrophobic BTEX compounds were not completely stripped from the column.

Comparison of breakthrough profiles from the regenerated SMZ to the virgin SMZ suggested that the regenerated SMZ had a greater capacity for benzene. This result was consistent with a cosorption effect observed for the more hydrophobic compounds in the laboratory columns.

\subsection{Cost Analysis}

When compared to other existing treatment technologies, the cost of the SMZ system is very competitive. In comparison to other technologies including carbon adsorption, membrane filtration and oxidation, the use of SMZ has the potential to be one of the most cost effective treatment options available. Furthermore, the SMZ system is relatively compact, does not require the storage of potentially hazardous chemicals, and could be readily adapted to an automated system.

The analysis also demonstrated that the cost of the system would depend on the need for off-gas treatment and the replacement interval for the SMZ. 


\section{References}

Abdul, A.S.; Gibson, T.L., Rai, D.N. "Statistical Correlations for Predicting the Partition Coefficient for Nonpolar Organic Contaminants Between Aquifer Organic Carbon and Water." Hazardous Waste and Hazardous Materials. 4 (1987) 211.

Allen D.T. and Rosselot K.S. "Pollution Prevention at the Macro Scale - Flows of Wastes, Industrial Ecology and Life-Cycle Analyses” Waste Management. 14 (1994) 317328

American Petroleum Institute, Oil and Gas Industry Exploration and Production Wastes. 1987.

American Petroleum Institute. 1995. "Proceedings: Workshop to Identify Promising Technologies for the Treatment of Produced Water Toxicity." Health and Environmental Sciences Departmental Report No. DR351. Parsons Engineering Science, Fairfax, Va.

Barrer, R.M.; Papadopoulos, R.; Rees, L.V.C. "Exchange of Sodium in Clinoptilolite by Organic Cations.” Journal of Inorganic and Nuclear Chemistry. 29 (1967) 20472063.

Bessa, E.; Sant'Anna, G.L. Jr.; Dezotti, M. "Photocatalytic/ $\mathrm{H}_{2} \mathrm{O}_{2}$ Treatment of Oil Field Produced Waters.” Applied Catalysis B: Environmental. 29 (2001) 125-134.

Bilstad, T.; Espedal, E. "Membrane Separation of Produced Water." Water Science and Technology. 34 (9) (1996) 239-246.

Boethling, R.S.; Mackay, D.; "Soil and Sediment Sorption Coefficient." Handbook of Property Estimation Methods for Chemicals, Envrironmental and Health Sciences, 2000, CRC Press, New York

Borisover M. D.; Graber E. R. "Organic Compound Sorption Enthalpy and Sorption Mechanisam in Soil Organic Matter” Journal of Environmental Quality 27 (2): 3123171998.

Bowman, R.S.; Flynn, M.; Haggerty, G.M.; Huddleston, RG.; Neel, D. “Organo-zeolites for Sorption of Nonpolar Organics, Inorganic Cations, and Inorganic Anions.” In Proceedings of the 1993 Joint CSCE-ASCE Conference on Environmental Engineering. Montreal, Quebec. July 12-14, 1993; Geotechnical Research Center of McGill University: Montreal, Canada, 1993: 1103-1109.

Bowman, R.S.; Sullivan, E.J.; Li, Z. "Mechanisms of Contaminant Sorption by Surfactant-Modified Zeolite" In Proceedings of the WERC/HSRC 1997 Joint Conference on the Environment. April 22-24, 1997. Albuquerque, New Mexico. 104-108.

California MTBE Research Partnership. "Evaluation of the Applicability of Synthetic Resin Sorbents for MTBE Removal from Water.” Ed. G. Melin of National Water Research Institute. December 1999.

Casaday, A.L. "Advances in Flotation Unit Design for Produced Water Treatment." Paper Presented at Production Operations Symposium. Oklahoma City, Oklahoma. March 21-23, 1993. SPE 25472.

Caudle D. D. "Produced Water: Its Properties, Composition and Potential Environmental Impact" July 21, 1995 
Chen H.; Wagner J., "Mutual Solubility of Alkylbenzene + Water System at Temp. from 303 to $373 \mathrm{~K}$, Ethylbenzene, p-Xylene, 1,3,5-Trimethylbenezen, and Butylbenzene" J. Chem. Eng. Data 39, no. 4 (1994): 679-84.

Chiou, C. T. Theoretical Considerations of the Partition Uptake of Nonionic Organic Compounds by Soil Organic Matter. In B. L. Shawyney and K. Brown, Eds, Reactions and Movement of Organic Chemiclas in Soils, Soil Science Society of America, Madison, WI. 1989.

Chiou, C. T.; Peters L. J.; and Freed V. H. "A Physical Concept of Soil-Water Equilibria for Nonionic Organic Compounds" Science 206 (16) 1979: 831-832

Chiou, C.T.; Porter, P.E.; Schemdding, D.W. "Partition Equilibria of Nonionic Organic Compounds Between Soil Organic Matter and Water." Environmental Science and Technology. 17 (1983) 227.

Dewulf, J.; Van Langenhove H.; Grare S. "Sediment / Water and Octanol / Water Equilibrium Partitioning of Volatile Organic Compounds: Temperature Dependence in the $2-25^{\circ} \mathrm{C}$ Range" Water Research 33 (10) (1999) 2424-2436.

Dewulf, J., Drijvers D. and Van Langenhove H.'Measurement of Henry's Law Constant as Function of Temperature and Salinity for the Low Temperature Range" Atmos. Environ. 29 (1995), 323-331

Doyle, D.H., and Brown, A.B., "Field Test of Produced Water Treatment with Polymer Modified Bentonite," paper presented at the 1997 SPE Rocky Mountain Regional Meeting, Casper, WY, May 18-21.

Fillo, J.P.; Koraido, S.M.; Evans, J.M. "Sources, Characteristics, and Management of Produced Waters from Natural Gas Production and Storage Operations." Produced Water. Eds. J.P. Ray and F.R. Engelhart. Plenum Press. New York, New York. 1992, 151-161.

Fucik, K.W. "Toxicity Identification and Characteristics of Produced Water Discharges From Colorado and Wyoming.” Produced Water. Eds. J.P. Ray and F.R. Engelhart. Plenum Press. New York, New York. 1992. 187-197.

Gallup, D.L.; Isacoff, E.G.; Smith, D.N.III. "Use of Ambersorb® Carbonaceous Adsorbent for Removal of BTEX Compounds from Oil-Field Produced Water." Environmental Progress. 15 (3) (1996) 197-203.

Gilbert, P.; Al-taae. A. Lett. Appl. Microbiol. 1 (1985) 101-104.

Haggerty, G.M.; Bowman, R.S. "Sorption of Chromate and Other Inorganic Anions by Organo-zeolite." Environmental Science and Technology. 28 (3) (1994) 452-458.

Hand, D.W., Crittenden, J.C., and Thacker, W.E. "Simplified Models for Design of Fixed-Bed Adsorption Systems" Journal of Environmental Engineering. 110(2) (1984) 440-456

Hashimoto, Y.; Tokura, K.; Kishi, H.; Strachan, W.M.J. "Prediction of Seawater Solubility of Aromatic Compounds.” Chemosphere. 13 (1984) 881-888.

Huang W.; Weber W. J.; "Thermodynamic Considerations in the Sorption of Organic Contaminants by Soils and Sediments. 1. The Isosteric Heat Approach and Its Application to Model Inorganic Sorbents” Environ. Sci. Technol. 31 (1997) 32383243

Isachoff, E.G.; Bortko, S.M.; Parker, G.R. "The Removal of Regulated Compounds from Groundwater and Wastewater Using Ambersorb 563 Carbonaceous Adsorbent." 
Presented at the American Institute of Chemical Engineers Annual Conference. Miami Beach, Florida. November 1992.

Jacobs, R.P.W.M.; Grant, R.O.H.; Kwant, J.; Marquenie, J.M.; Mentzer, E. “The Composition of Produced Water From Shell Operated Oil and Gas Production in the North Sea." Produced Water. Eds. J.P. Ray and F.R. Engelhart. Plenum Press. New York, New York. 1992. 13-21.

Janks, J.S.; Cadena, F. "Investigations into the Use of Modified Zeolites for Removing Benzene, Toluene, and Xylene From Saline Produced Water." Produced Water. Eds. J.P. Ray and F.R. Engelhart. Plenum Press. New York, New York. 1992. 473-487.

Jaynes, W.F., and Vance, G. F., "BTEX Sorption by Organo-Clays: Cosorptive Enhancement and Equivalence of Interlayer Complexes," Soil Sci. Soc. Am. J., 60, 1742-1749 (1996).

Karickhoff, S.W.; Brown, D.S.; Scott, T.A. "Sorption of Hydrophobic Pollutants on Natural Sediments." Water Research. 13 (1979) 241.

Karickhoff, S.W. "Semi-Empirical Estimation of Sorption of Hydrophobic Pollutants on Natural Sediments and Soils." Chemosphere. 10 (1981) 833.

Kleinbaum, D. G.; Kupper, L. L.; Muller, K. E. "Applied Regression Analysis and Other Multivariable Methods" Second Edition. PWS-Kent Publishing Co. Boston, Massachusetts. 1988. 266-268.

Lawrence, A.W.; Miller, J.A.; Miller, D.L.; Hayes, T.D. "Regional Assessment of Produced Water Treatment and Disposal Practices and Research Needs." Presented at SPE/EPA Exploration and Production Environmental Conference. Houston, Texas. March 27-29. 1995. SPE 029729.

Li, Z.; Bowman, R.S. "Counterion Effects on the Sorption of Cationic Surfactant and Chromate on Natural Clinoptilolite." Environmental Science and Technology. 31 (8) (1997) 2407-2412.

Li, Z; Bowman; R.S. "Sorption of Perchloroethylene by Surfactant-Modified Zeolite as Controlled by Surfactant Loading." Environmental Science and Technology. 32 (15) (1998) 2278-2282.

Li, Z.; Bowman, R.S. "Regeneration of Surfactant-Modified Zeolite After Saturation with Chromate and Perchloroethylene." Water Research. 35 (1) (1997) 322-326.

Li, Z.; Burt, T.; Bowman, R.S. "Sorption of Ionizable Organic Solutes by SurfactantModified Zeolite." Environmental Science and Technology. 34 (17) (2000) 37563760 .

Li, Z.; Roy, S.J.; Zou, Y.; Bowman, R.S. "Long-Term Chemical and Biological Stability of Surfactant-Modified Zeolite." Environmental Science and Technology. 32 (17) (1998) 2628-2632.

Lüers F.; ten Hulscher Th. E. M. "Temperature Effect on the Partitioning of Polycyclic Aromatic Hydrocarbons Between Natural Organic Carbon and Water"Chemosphere 33 (4) (1996) 643-657.

May, W. E, S. P. Wasik, M. M. Miller, Y. B. Tewari, J. M. Brown-Thomas, and R. N. Goldberg, "Solution Thermodynamics of Some Slightly Soluble Hydrocarbons in Water," J. Chem. Eng. Data, 28 (1983)197-200

McCarty, P.L.; Reinhard, M.; Rittman, B.E. "Trace Organics in Groundwater." Environmental Science and Technology. 15 (1981) 40-51. 
Ming, D.W.; Dixon, J.B. "Quantitative Determination of Clinoptilolite in Soils by a Cation-Exchange Capacity Method." Clays and Clay Minerals. 35 (1987) 463-368.

Mount, D.R.; Drottar, K.R.; Gulley, D.D.; Fillo, J.P.; O’Neil, P.E. 'Use of Laboratory Toxicity Data for Evaluating the Environmental Acceptability of Produced Water Discharge to Surface Waters." Produced Water. Eds. J.P. Ray and F.R. Engelhart. Plenum Press. New York, New York. 1992. 175-185.

Neel, D.; Bowman, R.S. "Sorption of Organics to Surface-Altered Zeolites." In Proceedings of New Mexico $36^{\text {th }}$ Annual Water Conference. Albuquerque, New Mexico. November 7-8, (1991) 57-61.

Negri, M.C.; Hinchman R.C. "Biotreatment of Produced Waters for Volume Reduction and Contaminant Removal." Paper Presented at the $4^{\text {th }}$ Annual International Petroleum Environmental Conference: Issues and Solutions, Production and Refining. San Antonio, Texas. September 9-12, 1997.

Parker, G.R. "Comparison of Ambersorb 563 Carbonaceous Adsorbent and Granular Activated Carbon for the Removal of TCE from Water at Short Empty Bed Contact Times." Presented at the American Institute of Chemical Engineers Annual Conference. Miami Beach, Florida. November 1992.

Peng, J.; Wan, A. "Effect of Ionic Strength on Henry's Constant of Volatile Organic Compounds." Chemosphere. 36 (13) (1998) 2731-2740.

Piatt J. J., Backhus D. A., Capel P. D. and Eisenreich S. J. ( 1996) “TemperatureDependent Sorption of Naphthalene, Phenanthrene and Pyrene to Low Organic Carbon Aquifer Sediments", Environ. Sci. Technol. 30 (1996) 751-760

Pinal, R.; Rao, P.S.C.; Lee, L.S.; Cline, P. "Cosolvency of Partially Miscible Organic Solvents on the Solubility of Hydrophobic Organic Chemicals.” Environmental Science and Technology 24 (5) (1990) 639-647.

Pussemier, L; Szabo, G.; Bulman, R.A. "Prediction of the Soil Adsorption Coefficient $\mathrm{K}_{\mathrm{oc}}$ for Aromatic Pollutants.” Chemosphere. 21 (1990) 1199.

Rohm and Haas, Inc. Manufacturer Literature. 100 Independence Mall West, Philadelphia, Pennsylvania. 19106-2399. 1992-1999.

Santos, S.M.; Wiesner, M.R. "Ultrafiltration of Water Generated in Oil and Gas Production." Water Environment Research. 69 (6) (1997) 1120-1127.

Sauer, T.C. Jr.; Ward, T.J.; Brown, J.S.; O’Neil, S.; Wade, M.J. "Identification of Toxicity in Low-TDS Produced Waters.” Produced Water. Eds. J.P. Ray and F.R. Engelhart. Plenum Press. New York, New York. 1992. 209-221.

Sawamura, S., Nagaoka K., and Machikawa T., "Effects of Pressure and Temperature on the Solubility of Alkylbenzene in Water: Volumetric Property of Hydrophobic Hydration" J. Phys. Chem. B 105 (12) (2001): 2429-2436

Schiff, K.C.; Reish, D.J.; Anderson, J.W.; Bay, S.M. "A Comparative Evaluation of Produced Water Toxicity." Produced Water. Eds. J.P. Ray and F.R. Engelhart. Plenum Press. New York, New York. 1992. 199-207.

Schwarzenbach, R.P.; Gschwend, P.M.; Imboden, D.M. Environmental Organic Chemistry. John Wiley \& Sons, Inc. New York, New York. 1993.

Schwarzenbach, R.P. Westall, J. "Transport of Nonpolar Organic Compounds from Surface Water to Groundwater, Laboratory Sorption Studies.” Environmental Science and Technology. 15 (1981) 1360. 
Setschenow, J. "Uber die Konstitution der Salzlosungen auf Grund ihres Verhaltens zu Kohlensaure.” Z. Phys. Chem., Vierter Band. 1 (1889) 117-125.

Sharmasarkar, S., Jaynes, W. F., and Vance, G. F., "BTEX Sorption by Montmorillonite Organo-Clays: TMPA, ADAM, HDTMA.,"Water, Air, and Soil Pollution, 119, 257-273 (2000).

Smith, J.P.; Tyler, A.O.; Rymell, M.C.; Sidharta, H. "Environmental Impact of Produced Waters in the Java Sea, Indonesia." Presented at 1996 SPE Asia Pacific Oil and Gas Conference. Adelaide, Australia. October 28-30, 1996. SPE 37002.

Sontheimer, H.; Crittenden, J.C.; Summers, R.S. Activated Carbon for Water Treatment. DVGW-Forschungsstelle. Karlsruhe, Germany. 1988.

Standard Methods for the Examination of Water and Wastewater, Seventeenth Edition, American Public Health Association, Washington, DC, 1989.

Stephenson, M.T. "Components of Produced Water: A Compilation of Industry Studies." Journal of Petroleum Technology. May 1992. 548-603. SPE 23313.

Stumm W. and Morgan J. J. (1981) “An Introduction Emphasizing Chemical Equilibria in Natural Waters" Aquatic Chemistry, Wiley, New York, pp. 38-55

Stuart, B.J.; Bowlen, G.F.; Kosson, D.S. "Competitive Sorption of Benzene, Toluene, and the Xylenes onto Soil.” Environmental Progress. 10 (1991) 104.

Sullivan, E.J.; Hunter, D.B.; Bowman, R.S. "Topological and Thermal Properties of Surfactant-Modified Clinoptilolite Studied by Tapping Mode ${ }^{\mathrm{TM}}$ Atomic Force Microscopy and High-Resolution Thermogravimetric Analyses." Clays and Clay Minerals. 45 (1997) 42-53.

Szecsody J. E. and Bales R. C. "Temperature effects on Chlorinated-Benzene Sorption to Hydrophobic Surfaces" Chemosphere, 22 (12) (1991) 1141-1151.

Tao, F.T.; Curtice, S.; Hobbs, R.D.; Sides, J.L.; Wieser, J.D.; Dyke, C.A.; Tuohey, D.; Pilger, P.F. "Reverse Osmosis Process Successfully Converts Oil Field Brine into Freshwater." Oil and Gas Journal. September 20, 1993. 88-91.

Ten Hulscher Th. E. M.; Cornelissen G. "Effect of Temperature on Sorption Equilibrium and Sorption Kinetics of Organic Micropollutants - A Review" Chemosphere, Vol. 32 (4) (1996) 609-626

Thoma, G.J.; Bowen, M.L.; Hollensworth, D. "Dissolved Air Precipitation/Solvent Sublation for Oil-Field Produced Water Treatment." Separation and Purification Technology. 16 (1999) 101-107.

Toride, N., Leij F. J., and Van Genuchten M. Th. "The CXTFIT Code for Estimating Transport Parameters from Laboratory or Field Tracer Experiments, Version 2.0”, Research Report No. 137. US Salinity Laboratory, USDA, ARS: Riverside, CA, 1995

van Ginkel, C.G.; van Dijk, J.B.; Kroon, A.G.M. Appl. Environ. Microbiol. 58 (1992) 3083-3087.

Vowles, P.D.; Mantoura, R.F.C. "Sediment-Water Partition Coefficients and HPLC Factors of Aromatic Hydrocarbons." Chemosphere. 16 (1987) 109.

Weber, W.J. Jr.; Digiano, F.A. Process Dynamic in Environmental Systems, John Wiley \& Sons, Inc. New York, New York. 1996.

Weber, W.J. and van Vliet, B.M. "Synthetic adsorbents and activated carbons for water treatment: overview and experimental comparisons." Journal of the American Waterworks Association (AWWA). 73 (8) (1981) 420-426. 


\section{Appendices}

\section{Appendix A: Input and Output Files in Column Studies}

Appendix A-1: Input Files for Predicting BTEX Breakthrough Curves in the Column Study Conducted with ultrapure Water

The distribution coefficients $\mathrm{K}_{\mathrm{d}}$ and retardation factors $\mathrm{R}$ applied in the CXTFIT direct problem are:

\begin{tabular}{|c|c|c|}
\hline Compounds & $\mathrm{K}_{\mathrm{d}}(\mathrm{L} / \mathrm{Kg})$ & $\begin{array}{c}\text { Retardation Factor } \\
(\mathrm{R})\end{array}$ \\
\hline Benzene & 5.7 & 11.9 \\
Toluene & 16.1 & 15.6 \\
Ethylbenzene & 40.9 & 38.4 \\
m,p-Xylene & 46.5 & 43 \\
o-Xylene & 38.2 & 37.9 \\
\hline
\end{tabular}




\section{Benzene breakthrough curve prediction.}

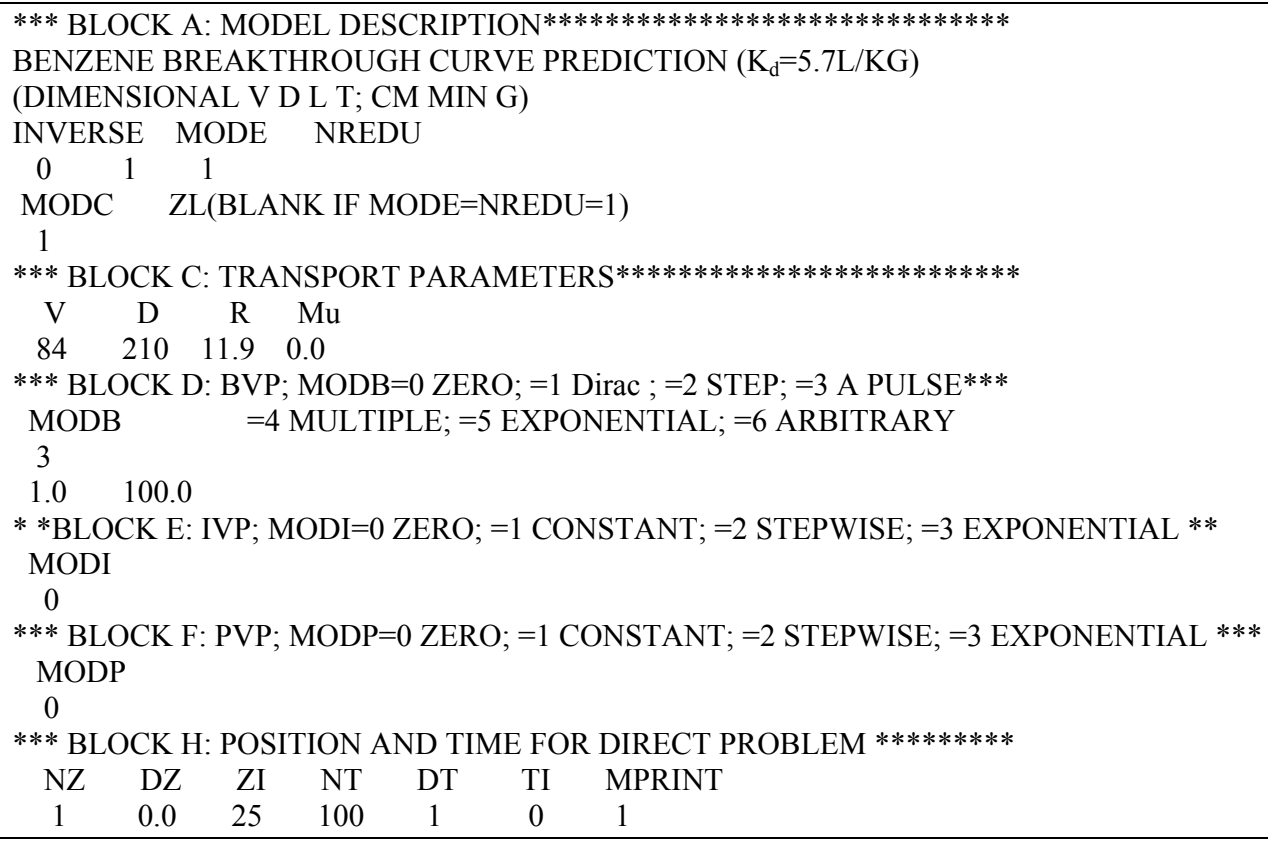

\section{Toluene breakthrough curve prediction.}

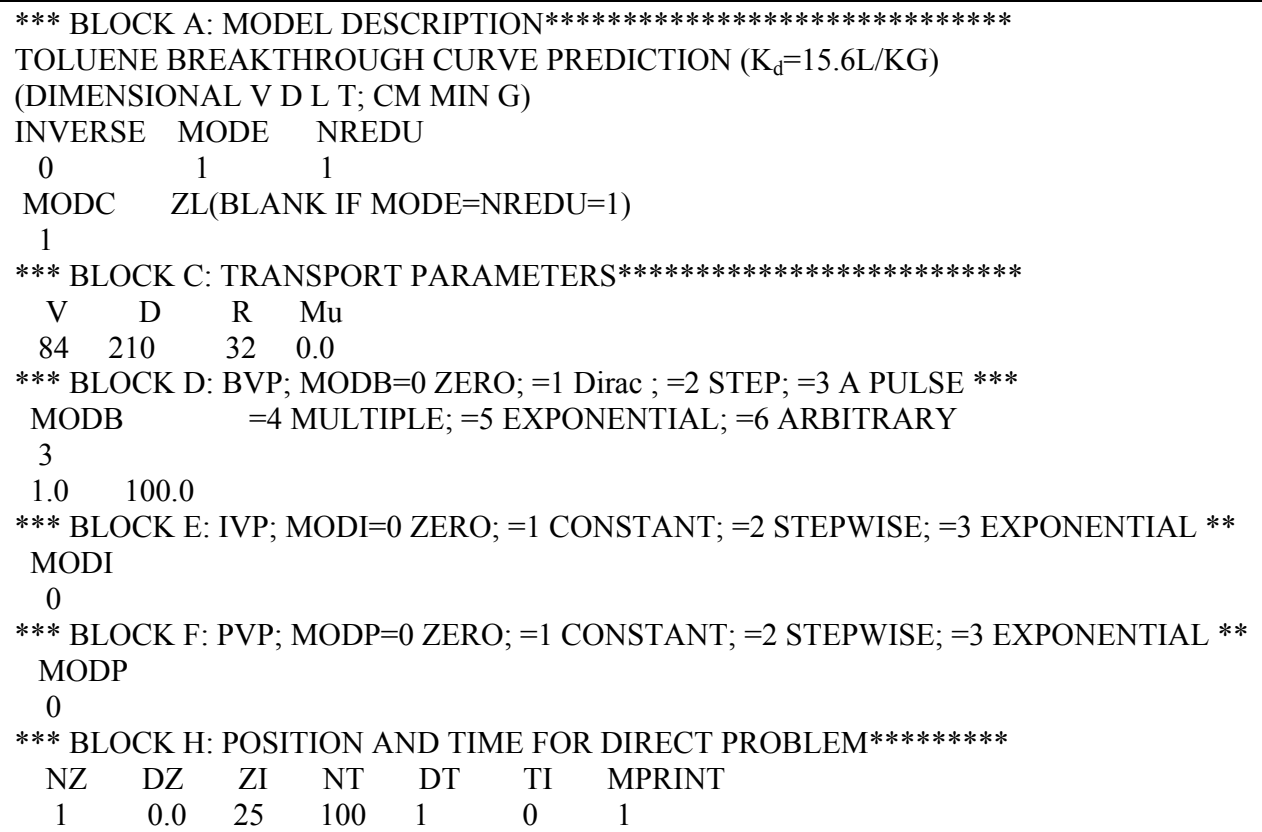




\section{Ethylbenzene breakthrough curve prediction.}

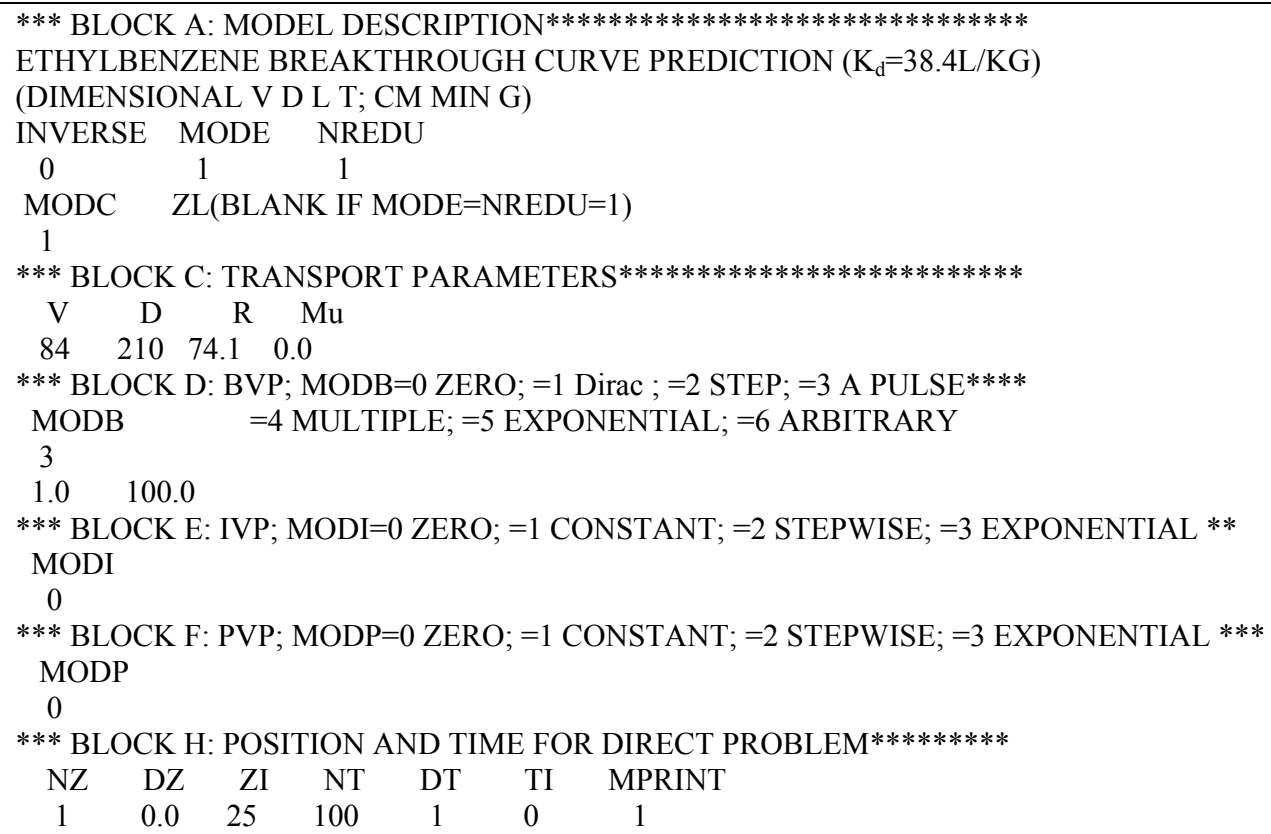

\section{M-P-xylene breakthrough curve prediction}

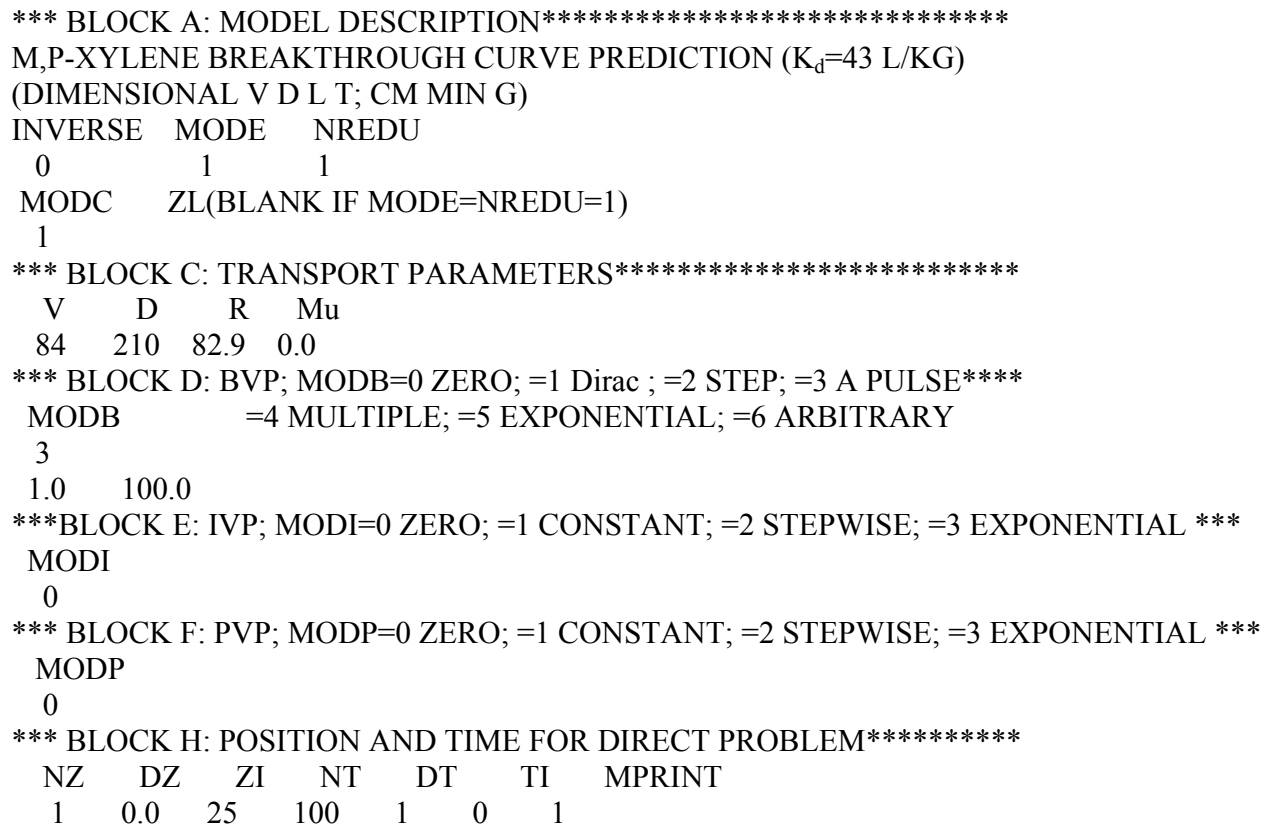




\section{O-xylene breakthrough curve prediction}

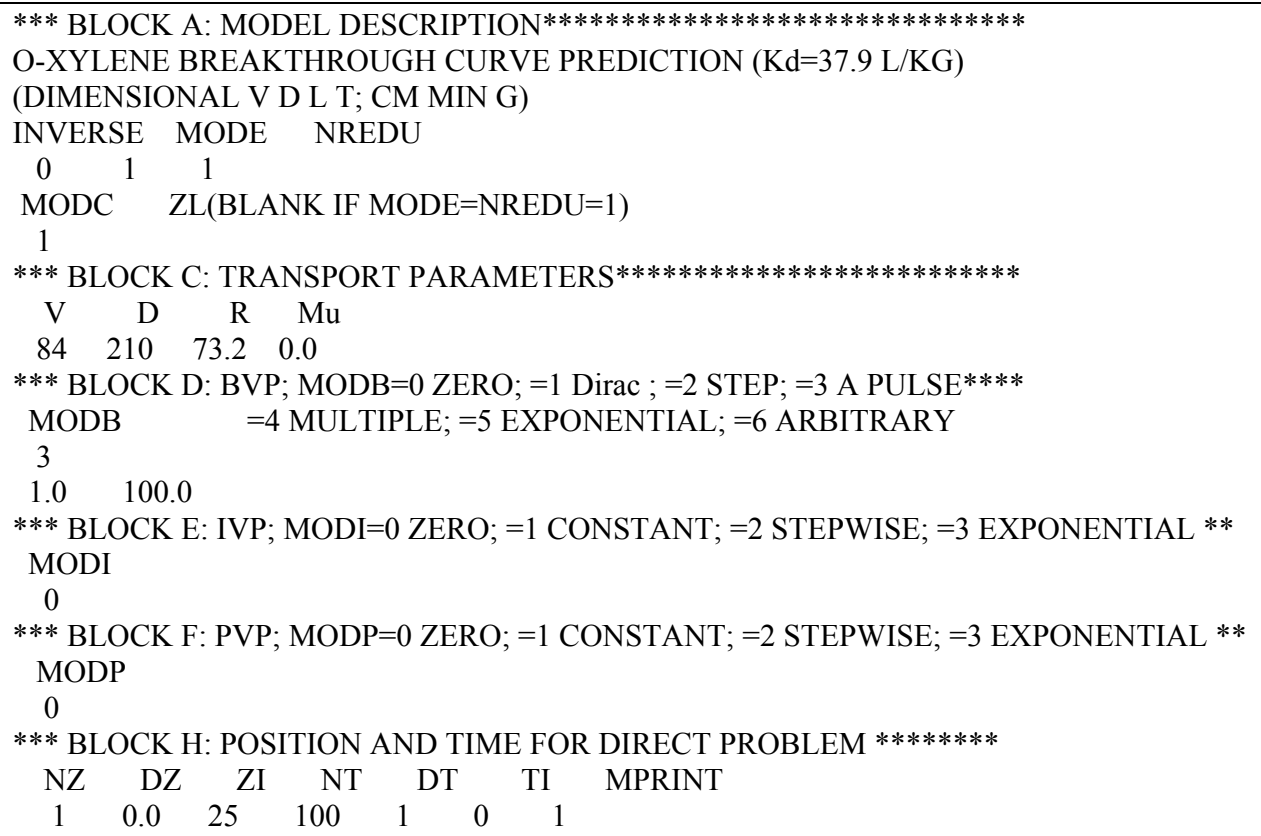


Appendix A-2: Output files of BTEX Breakthrough Curve in Column Study in ultrapure $\underline{\text { Water }}$

\section{Benzene breakthrough curve prediction}

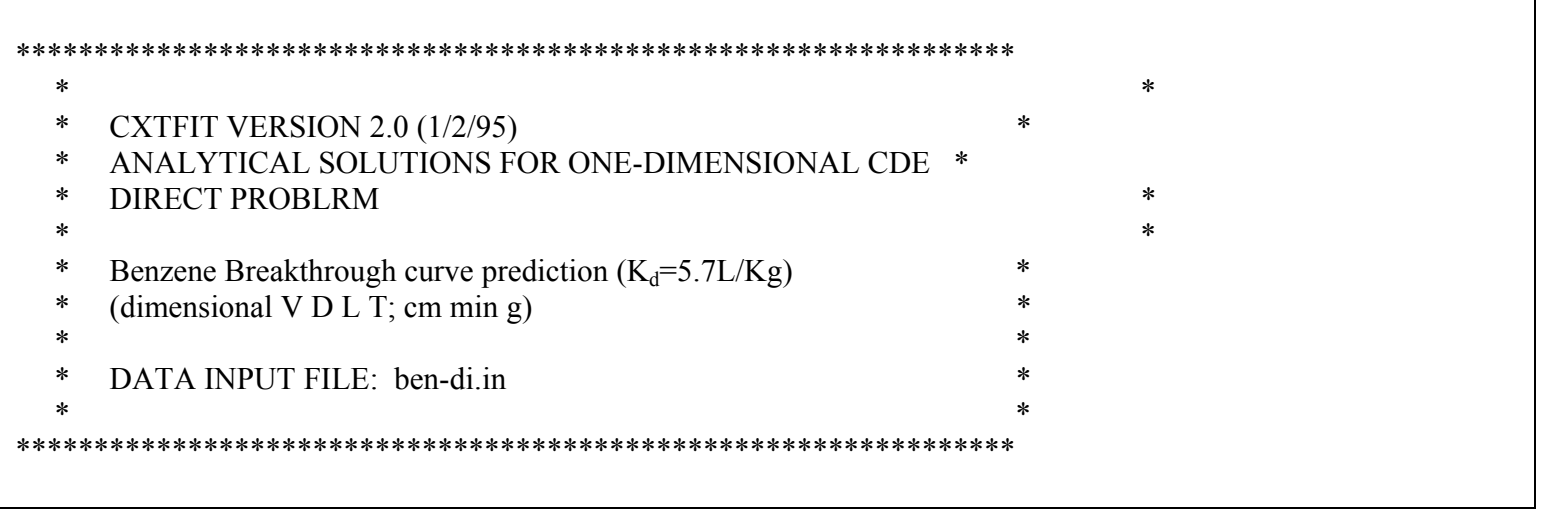

\section{Model Description}

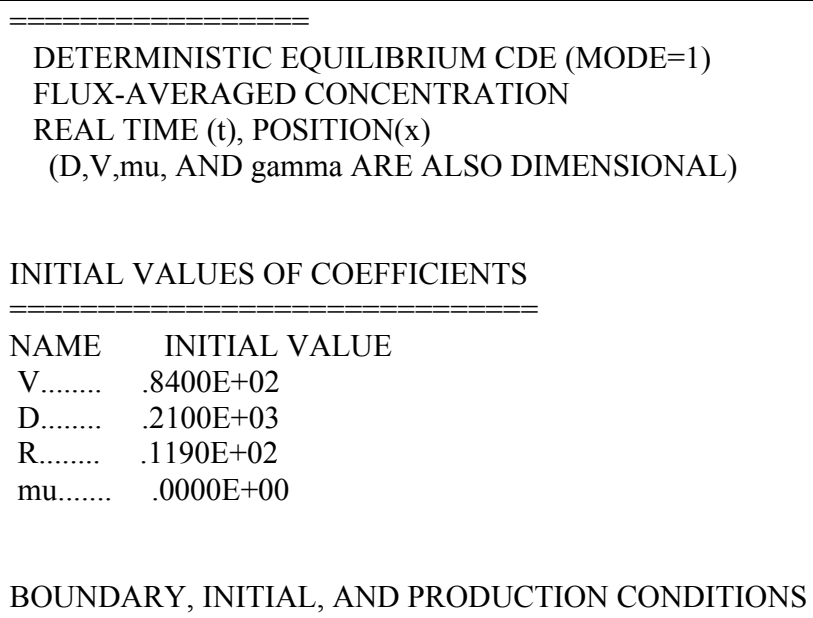

BOUNDARY, INITIAL, AND PRODUCTION CONDITIONS

SINGLE PULSE OF CONC. $=1.0000 \&$ DURATION $=100.0000$ SOLUTE FREE INITIAL CONDITION NO PRODUCTION TERM 
$\$ Z=25.0000 \quad$ (FLUX CONC. VS. TIME)

$\$ \operatorname{Sum}\left(C^{*} \mathrm{dT}\right)=95.4587$

\$TIME C

$.0000 \quad .00000 \mathrm{E}+00$

$1.0000 \quad .20134 \mathrm{E}-02$

$2.0000 \quad .13313 \mathrm{E}+00$

$3.0000 \quad .43445 \mathrm{E}+00$

$4.0000 \quad .68934 \mathrm{E}+00$

$5.0000 \quad .84312 \mathrm{E}+00$

$6.0000 \quad .92405 \mathrm{E}+00$

$7.0000 \quad .96403 \mathrm{E}+00$

$8.0000 \quad .98316 \mathrm{E}+00$

$9.0000 \quad .99216 \mathrm{E}+00$

$10.0000 \quad .99636 \mathrm{E}+00$

$11.0000 \quad .99831 \mathrm{E}+00$

$12.0000 \quad .99922 \mathrm{E}+00$

$13.0000 \quad .99964 \mathrm{E}+00$

$14.0000 \quad .99983 \mathrm{E}+00$

$15.0000 \quad .99992 \mathrm{E}+00$

$16.0000 \quad .99996 \mathrm{E}+00$

$17.0000 \quad .99998 \mathrm{E}+00$

$\begin{array}{ll}18.0000 & .99999 \mathrm{E}+00\end{array}$

$19.0000 \quad .10000 \mathrm{E}+01$

$20.0000 \quad .10000 \mathrm{E}+01$

$21.0000 \quad .10000 \mathrm{E}+01$

$22.0000 \quad .10000 \mathrm{E}+01$

$23.0000 \quad .10000 \mathrm{E}+01$

$24.0000 \quad .10000 \mathrm{E}+01$

$25.0000 \quad .10000 \mathrm{E}+01$

$26.0000 \quad .10000 \mathrm{E}+01$

$27.0000 \quad .10000 \mathrm{E}+01$

$28.0000 \quad .10000 \mathrm{E}+01$

$29.0000 \quad .10000 \mathrm{E}+01$

$30.0000 \quad .10000 \mathrm{E}+01$

$31.0000 \quad .10000 \mathrm{E}+01$

$32.0000 \quad .10000 \mathrm{E}+01$

$33.0000 \quad .10000 \mathrm{E}+01$

$34.0000 \quad .10000 \mathrm{E}+01$

$35.0000 \quad .10000 \mathrm{E}+01$

$36.0000 \quad .10000 \mathrm{E}+01$

$37.0000 \quad .10000 \mathrm{E}+01$

$38.0000 \quad .10000 \mathrm{E}+01$

$39.0000 \quad .10000 \mathrm{E}+01$

$40.0000 \quad .10000 \mathrm{E}+01$

$41.0000 \quad .10000 \mathrm{E}+01$

$42.0000 \quad .10000 \mathrm{E}+01$

$43.0000 \quad .10000 \mathrm{E}+01$

$44.0000 \quad .10000 \mathrm{E}+01$

$45.0000 \quad .10000 \mathrm{E}+01$

$46.0000 \quad .10000 \mathrm{E}+01$

$47.0000 \quad .10000 \mathrm{E}+01$

$48.0000 \quad .10000 \mathrm{E}+01$

$49.0000 \quad .10000 \mathrm{E}+01$

$\$ Z=25.0000 \quad$ (FLUX CONC. VS. TIME)

$\$ \operatorname{Sum}\left(C^{*} \mathrm{dT}\right)=95.4587$

\$TIME C

$50.0000 \quad .10000 \mathrm{E}+01$

$51.0000 \quad .10000 \mathrm{E}+01$

$52.0000 \quad .10000 \mathrm{E}+01$

$53.0000 \quad .10000 \mathrm{E}+01$ 


$\begin{array}{ll}54.0000 & .10000 \mathrm{E}+01 \\ 55.0000 & .10000 \mathrm{E}+01 \\ 56.0000 & .10000 \mathrm{E}+01 \\ 57.0000 & .10000 \mathrm{E}+01 \\ 58.0000 & .10000 \mathrm{E}+01 \\ 59.0000 & .10000 \mathrm{E}+01 \\ 60.0000 & .10000 \mathrm{E}+01 \\ 61.0000 & .10000 \mathrm{E}+01 \\ 62.0000 & .10000 \mathrm{E}+01 \\ 63.0000 & .10000 \mathrm{E}+01 \\ 64.0000 & .10000 \mathrm{E}+01 \\ 65.0000 & .10000 \mathrm{E}+01 \\ 66.0000 & .10000 \mathrm{E}+01 \\ 67.0000 & .10000 \mathrm{E}+01 \\ 68.0000 & .10000 \mathrm{E}+01 \\ 69.0000 & .10000 \mathrm{E}+01 \\ 70.0000 & .10000 \mathrm{E}+01 \\ 71.0000 & .10000 \mathrm{E}+01 \\ 72.0000 & .10000 \mathrm{E}+01 \\ 73.0000 & .10000 \mathrm{E}+01 \\ 74.0000 & .10000 \mathrm{E}+01 \\ 75.0000 & .10000 \mathrm{E}+01 \\ 76.0000 & .10000 \mathrm{E}+01 \\ 77.0000 & .10000 \mathrm{E}+01 \\ 78.0000 & .10000 \mathrm{E}+01 \\ 79.0000 & .10000 \mathrm{E}+01 \\ 80.0000 & .10000 \mathrm{E}+01 \\ 81.0000 & .10000 \mathrm{E}+01 \\ 82.0000 & .10000 \mathrm{E}+01 \\ 83.0000 & .10000 \mathrm{E}+01 \\ 84.0000 & .10000 \mathrm{E}+01 \\ 85.0000 & .10000 \mathrm{E}+01 \\ 86.0000 & .10000 \mathrm{E}+01 \\ 87.0000 & .10000 \mathrm{E}+01 \\ 88.0000 & .10000 \mathrm{E}+01 \\ 89.0000 & .10000 \mathrm{E}+01 \\ 90.0000 & .10000 \mathrm{E}+01 \\ 91.0000 & .10000 \mathrm{E}+01 \\ 92.0000 & .10000 \mathrm{E}+01 \\ 93.0000 & .10000 \mathrm{E}+01 \\ 94.0000 & .10000 \mathrm{E}+01 \\ 95.0000 & .10000 \mathrm{E}+01 \\ 96.0000 & .10000 \mathrm{E}+01 \\ 97.0000 & .10000 \mathrm{E}+01 \\ 98.0000 & .10000 \mathrm{E}+01 \\ 99.0000 & .10000 \mathrm{E}+01 \\ \end{array}$




\section{Toluene breakthrough curve prediction.}

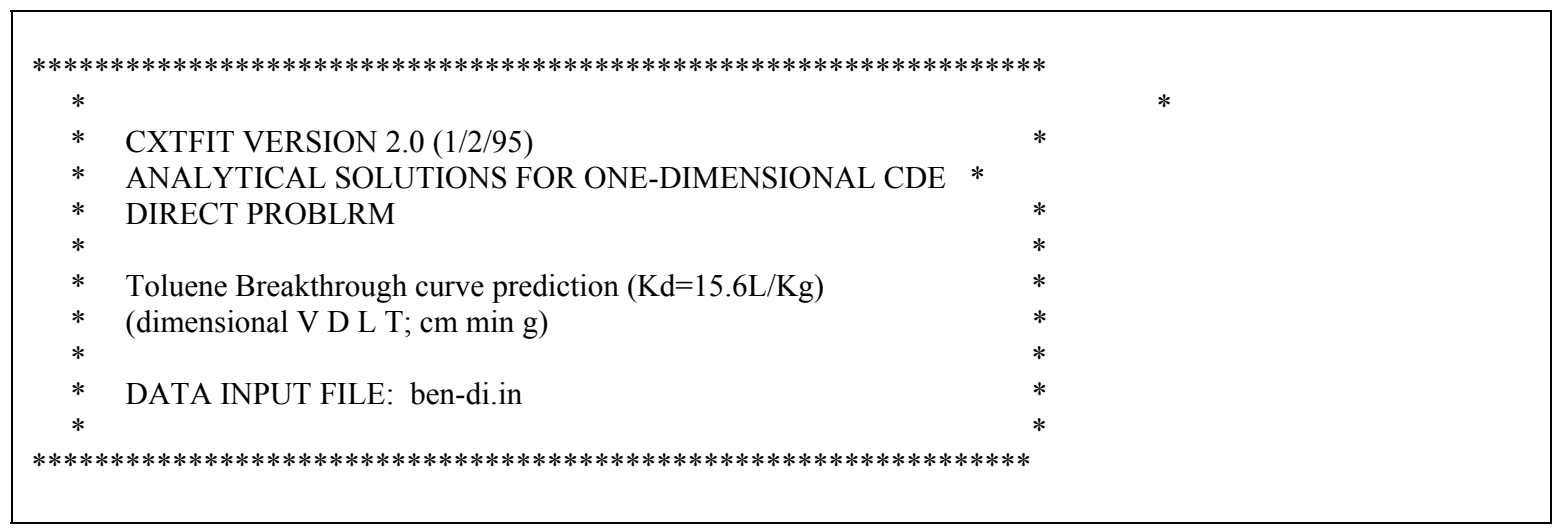

\section{Model Description}

DETERMINISTIC EQUILIBRIUM CDE (MODE=1)

FLUX-AVERAGED CONCENTRATION

REAL TIME (t), POSITION(x)

(D,V,mu, AND gamma ARE ALSO DIMENSIONAL)

INITIAL VALUES OF COEFFICIENTS

$================$
NAME INITIAL VALUE

$\mathrm{V}$........ .8400E+02

D........ .2100E+03

R........ .3200E +02

mu....... .0000E+00

BOUNDARY, INITIAL, AND PRODUCTION CONDITIONS

SINGLE PULSE OF CONC. $=1.0000 \&$ DURATION $=100.0000$

SOLUTE FREE INITIAL CONDITION

NO PRODUCTION TERM 


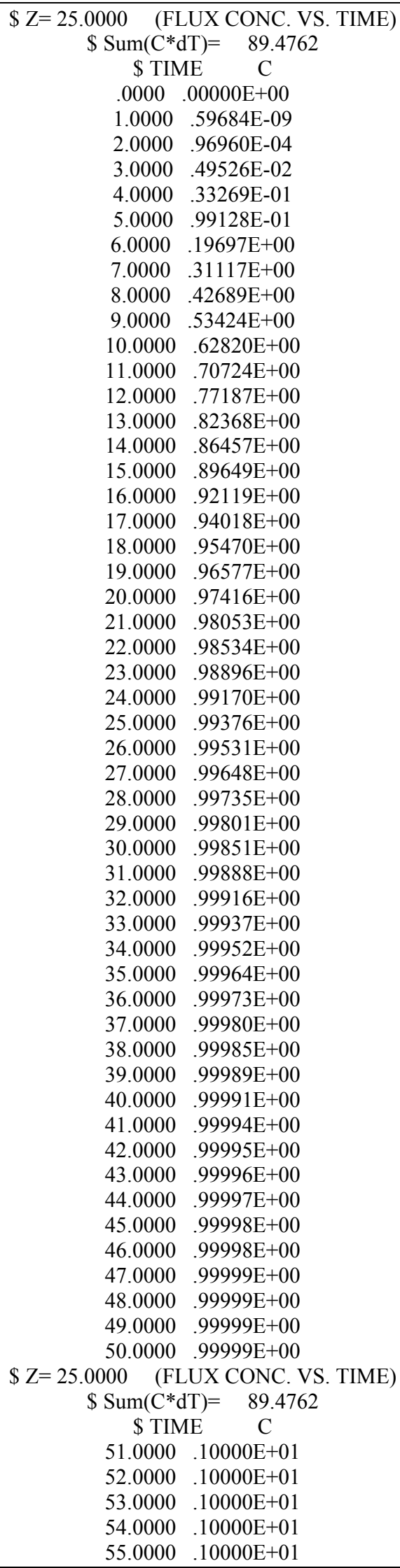




\begin{tabular}{ll|}
56.0000 & $.10000 \mathrm{E}+01$ \\
57.0000 & $.10000 \mathrm{E}+01$ \\
58.0000 & $.10000 \mathrm{E}+01$ \\
59.0000 & $.10000 \mathrm{E}+01$ \\
60.0000 & $.10000 \mathrm{E}+01$ \\
61.0000 & $.10000 \mathrm{E}+01$ \\
62.0000 & $.10000 \mathrm{E}+01$ \\
63.0000 & $.10000 \mathrm{E}+01$ \\
64.0000 & $.10000 \mathrm{E}+01$ \\
65.0000 & $.10000 \mathrm{E}+01$ \\
66.0000 & $.10000 \mathrm{E}+01$ \\
67.0000 & $.10000 \mathrm{E}+01$ \\
68.0000 & $.10000 \mathrm{E}+01$ \\
69.0000 & $.10000 \mathrm{E}+01$ \\
70.0000 & $.10000 \mathrm{E}+01$ \\
71.0000 & $.10000 \mathrm{E}+01$ \\
72.0000 & $.10000 \mathrm{E}+01$ \\
73.0000 & $.10000 \mathrm{E}+01$ \\
74.0000 & $.10000 \mathrm{E}+01$ \\
75.0000 & $.10000 \mathrm{E}+01$ \\
76.0000 & $.10000 \mathrm{E}+01$ \\
77.0000 & $.10000 \mathrm{E}+01$ \\
78.0000 & $.10000 \mathrm{E}+01$ \\
79.0000 & $.10000 \mathrm{E}+01$ \\
80.0000 & $.10000 \mathrm{E}+01$ \\
81.0000 & $.10000 \mathrm{E}+01$ \\
82.0000 & $.10000 \mathrm{E}+01$ \\
83.0000 & $.10000 \mathrm{E}+01$ \\
84.0000 & $.10000 \mathrm{E}+01$ \\
85.0000 & $.10000 \mathrm{E}+01$ \\
86.0000 & $.10000 \mathrm{E}+01$ \\
87.0000 & $.10000 \mathrm{E}+01$ \\
88.0000 & $.10000 \mathrm{E}+01$ \\
89.0000 & $.10000 \mathrm{E}+01$ \\
90.0000 & $.10000 \mathrm{E}+01$ \\
91.0000 & $.10000 \mathrm{E}+01$ \\
92.0000 & $.10000 \mathrm{E}+01$ \\
93.0000 & $.10000 \mathrm{E}+01$ \\
94.0000 & $.10000 \mathrm{E}+01$ \\
95.0000 & $.10000 \mathrm{E}+01$ \\
96.0000 & $.10000 \mathrm{E}+01$ \\
97.0000 & $.10000 \mathrm{E}+01$ \\
98.0000 & $.10000 \mathrm{E}+01$ \\
99.0000 & $.10000 \mathrm{E}+01$ \\
\hline
\end{tabular}




\section{Ethylbenzene breakthrough curve prediction.}

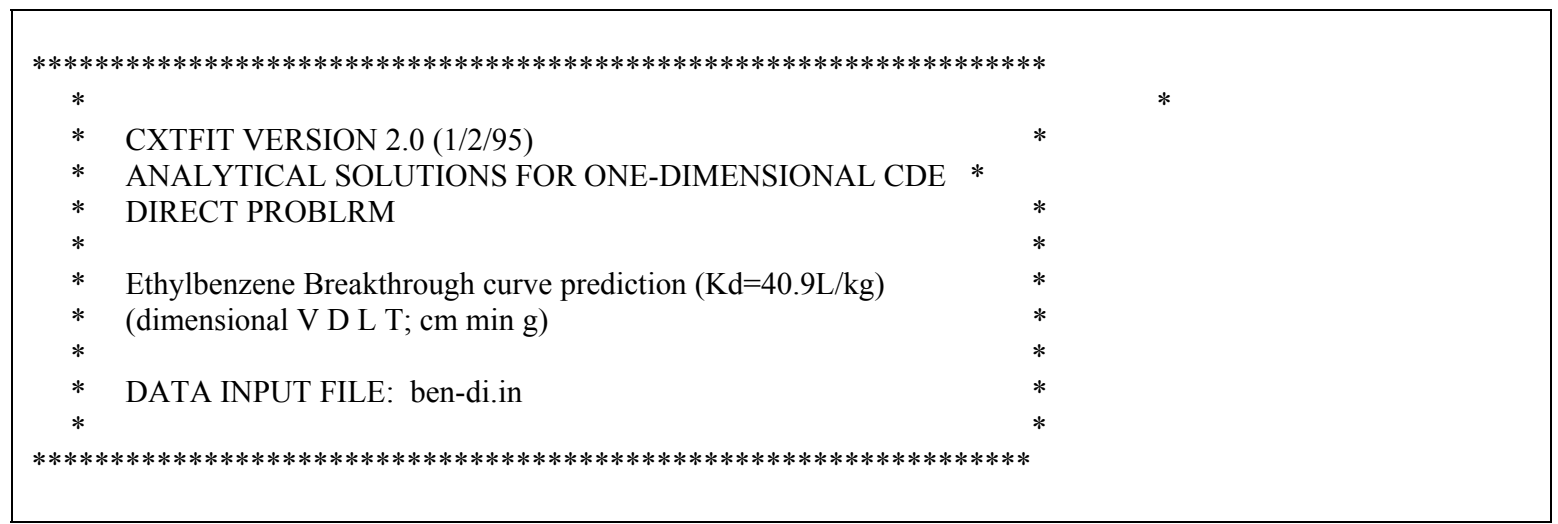

\section{Model Description}

DETERMINISTIC EQUILIBRIUM CDE (MODE=1)

FLUX-AVERAGED CONCENTRATION

REAL TIME (t), POSITION(x)

(D,V,mu, AND gamma ARE ALSO DIMENSIONAL)

INITIAL VALUES OF COEFFICIENTS

\begin{tabular}{|c|c|}
\hline NAME & INITIAL VALUE \\
\hline V... & $.8400 \mathrm{E}+02$ \\
\hline D......... & $.2100 \mathrm{E}+03$ \\
\hline R..... & $.7960 \mathrm{E}+02$ \\
\hline mu... & $.0000 \mathrm{E}+00$ \\
\hline
\end{tabular}

BOUNDARY, INITIAL, AND PRODUCTION CONDITIONS

SINGLE PULSE OF CONC. $=1.0000 \&$ DURATION $=100.0000$ SOLUTE FREE INITIAL CONDITION

NO PRODUCTION TERM 


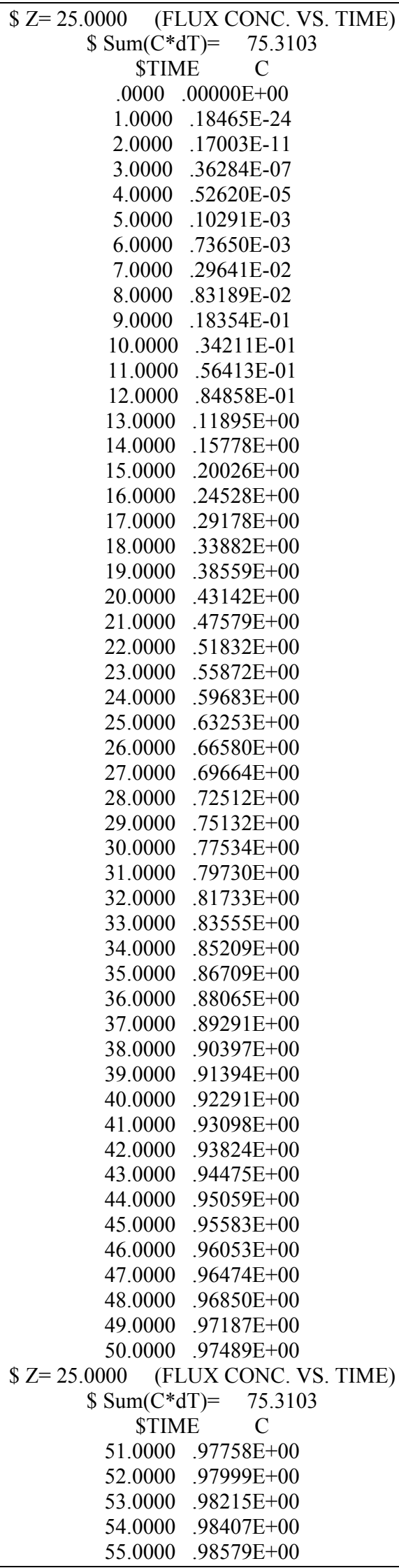




$\begin{array}{ll}56.0000 & .98732 \mathrm{E}+00 \\ 57.0000 & .98869 \mathrm{E}+00 \\ 58.0000 & .98992 \mathrm{E}+00 \\ 59.0000 & .99101 \mathrm{E}+00 \\ 60.0000 & .99198 \mathrm{E}+00 \\ 61.0000 & .99285 \mathrm{E}+00 \\ 62.0000 & .99362 \mathrm{E}+00 \\ 63.0000 & .99432 \mathrm{E}+00 \\ 64.0000 & .99493 \mathrm{E}+00 \\ 65.0000 & .99548 \mathrm{E}+00 \\ 66.0000 & .99597 \mathrm{E}+00 \\ 67.0000 & .99641 \mathrm{E}+00 \\ 68.0000 & .99680 \mathrm{E}+00 \\ 69.0000 & .99715 \mathrm{E}+00 \\ 70.0000 & .99746 \mathrm{E}+00 \\ 71.0000 & .99773 \mathrm{E}+00 \\ 72.0000 & .99798 \mathrm{E}+00 \\ 73.0000 & .99820 \mathrm{E}+00 \\ 74.0000 & .99839 \mathrm{E}+00 \\ 75.0000 & .99857 \mathrm{E}+00 \\ 76.0000 & .99872 \mathrm{E}+00 \\ 77.0000 & .99886 \mathrm{E}+00 \\ 78.0000 & .99899 \mathrm{E}+00 \\ 79.0000 & .99910 \mathrm{E}+00 \\ 80.0000 & .99919 \mathrm{E}+00 \\ 81.0000 & .99928 \mathrm{E}+00 \\ 82.0000 & .99936 \mathrm{E}+00 \\ 83.0000 & .99943 \mathrm{E}+00 \\ 84.0000 & .99949 \mathrm{E}+00 \\ 85.0000 & .99955 \mathrm{E}+00 \\ 86.0000 & .99960 \mathrm{E}+00 \\ 87.0000 & .99964 \mathrm{E}+00 \\ 88.0000 & .99968 \mathrm{E}+00 \\ 89.0000 & .99971 \mathrm{E}+00 \\ 90.0000 & .99974 \mathrm{E}+00 \\ 91.0000 & .99977 \mathrm{E}+00 \\ 92.0000 & .99980 \mathrm{E}+00 \\ 93.0000 & .99982 \mathrm{E}+00 \\ 94.0000 & .99984 \mathrm{E}+00 \\ 95.0000 & .99986 \mathrm{E}+00 \\ 96.0000 & .99987 \mathrm{E}+00 \\ 97.0000 & .99989 \mathrm{E}+00 \\ 98.0000 & .99990 \mathrm{E}+00 \\ 99.0000 & .99991 \mathrm{E}+00\end{array}$




\section{M-P-xylene breakthrough curve prediction}

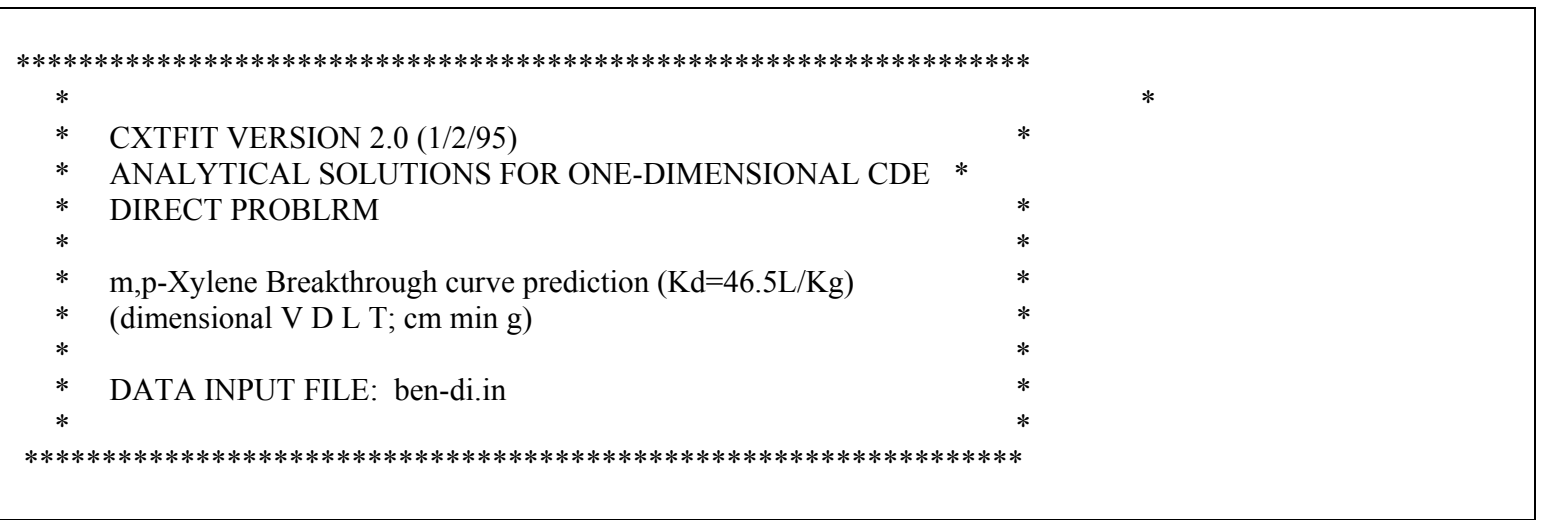

\section{Model Description}

DETERMINISTIC EQUILIBRIUM CDE $($ MODE=1)

FLUX-AVERAGED CONCENTRATION

REAL TIME ( $\mathrm{t})$, POSITION(x)

(D,V,mu, AND gamma ARE ALSO DIMENSIONAL)

INITIAL VALUES OF COEFFICIENTS

$\begin{array}{cc}=================== \\ \text { NAME } & \text { INITIAL VALUE } \\ \text { V........ } & .8400 \mathrm{E}+02 \\ \text { D........ } & .2100 \mathrm{E}+03 \\ \text { R........ } & .9040 \mathrm{E}+02 \\ \text { mu....... } & .0000 \mathrm{E}+00\end{array}$

BOUNDARY, INITIAL, AND PRODUCTION CONDITIONS

SINGLE PULSE OF CONC. $=1.0000 \&$ DURATION $=100.0000$ SOLUTE FREE INITIAL CONDITION NO PRODUCTION TERM 


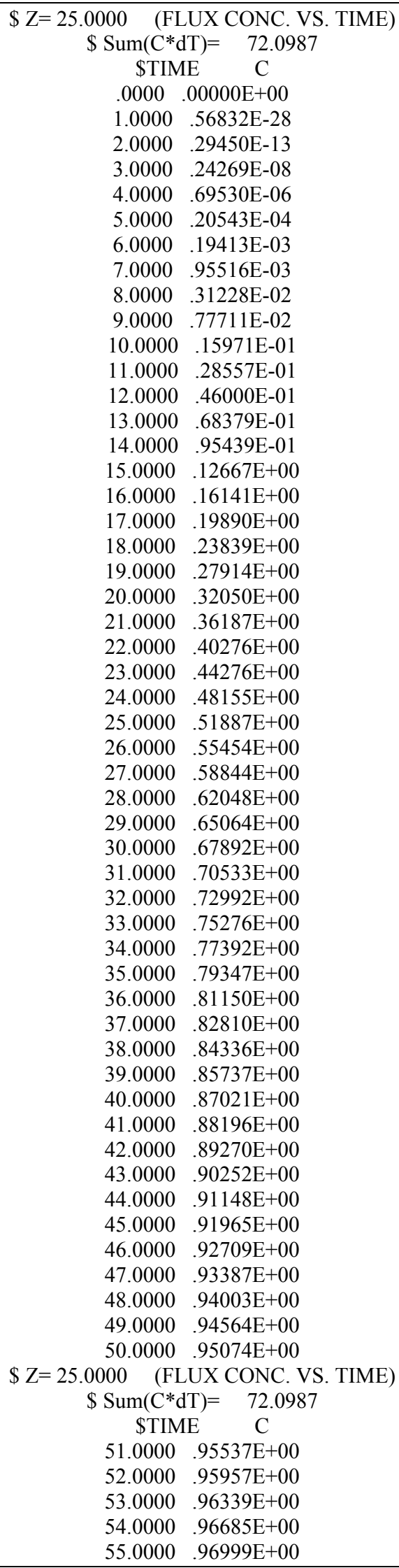




$\begin{array}{ll}56.0000 & .97284 \mathrm{E}+00 \\ 57.0000 & .97542 \mathrm{E}+00 \\ 58.0000 & .97776 \mathrm{E}+00 \\ 59.0000 & .97988 \mathrm{E}+00 \\ 60.0000 & .98180 \mathrm{E}+00 \\ 61.0000 & .98354 \mathrm{E}+00 \\ 62.0000 & .98511 \mathrm{E}+00 \\ 63.0000 & .98654 \mathrm{E}+00 \\ 64.0000 & .98783 \mathrm{E}+00 \\ 65.0000 & .98899 \mathrm{E}+00 \\ 66.0000 & .99005 \mathrm{E}+00 \\ 67.0000 & .99100 \mathrm{E}+00 \\ 68.0000 & .99187 \mathrm{E}+00 \\ 69.0000 & .99265 \mathrm{E}+00 \\ 70.0000 & .99335 \mathrm{E}+00 \\ 71.0000 & .99399 \mathrm{E}+00 \\ 72.0000 & .99457 \mathrm{E}+00 \\ 73.0000 & .99509 \mathrm{E}+00 \\ 74.0000 & .99556 \mathrm{E}+00 \\ 75.0000 & .99599 \mathrm{E}+00 \\ 76.0000 & .99638 \mathrm{E}+00 \\ 77.0000 & .99672 \mathrm{E}+00 \\ 78.0000 & .99704 \mathrm{E}+00 \\ 79.0000 & .99732 \mathrm{E}+00 \\ 80.0000 & .99758 \mathrm{E}+00 \\ 81.0000 & .99781 \mathrm{E}+00 \\ 82.0000 & .99803 \mathrm{E}+00 \\ 83.0000 & .99822 \mathrm{E}+00 \\ 84.0000 & .99839 \mathrm{E}+00 \\ 85.0000 & .99854 \mathrm{E}+00 \\ 86.0000 & .99868 \mathrm{E}+00 \\ 87.0000 & .99881 \mathrm{E}+00 \\ 88.0000 & .99892 \mathrm{E}+00 \\ 89.0000 & .99903 \mathrm{E}+00 \\ 90.0000 & .99912 \mathrm{E}+00 \\ 91.0000 & .99921 \mathrm{E}+00 \\ 92.0000 & .99928 \mathrm{E}+00 \\ 93.0000 & .99935 \mathrm{E}+00 \\ 94.0000 & .99941 \mathrm{E}+00 \\ 95.0000 & .99947 \mathrm{E}+00 \\ 96.0000 & .99952 \mathrm{E}+00 \\ 97.0000 & .99957 \mathrm{E}+00 \\ 98.0000 & .99961 \mathrm{E}+00 \\ 99.0000 & .99965 \mathrm{E}+00\end{array}$




\section{O-xylene breakthrough curve prediction}

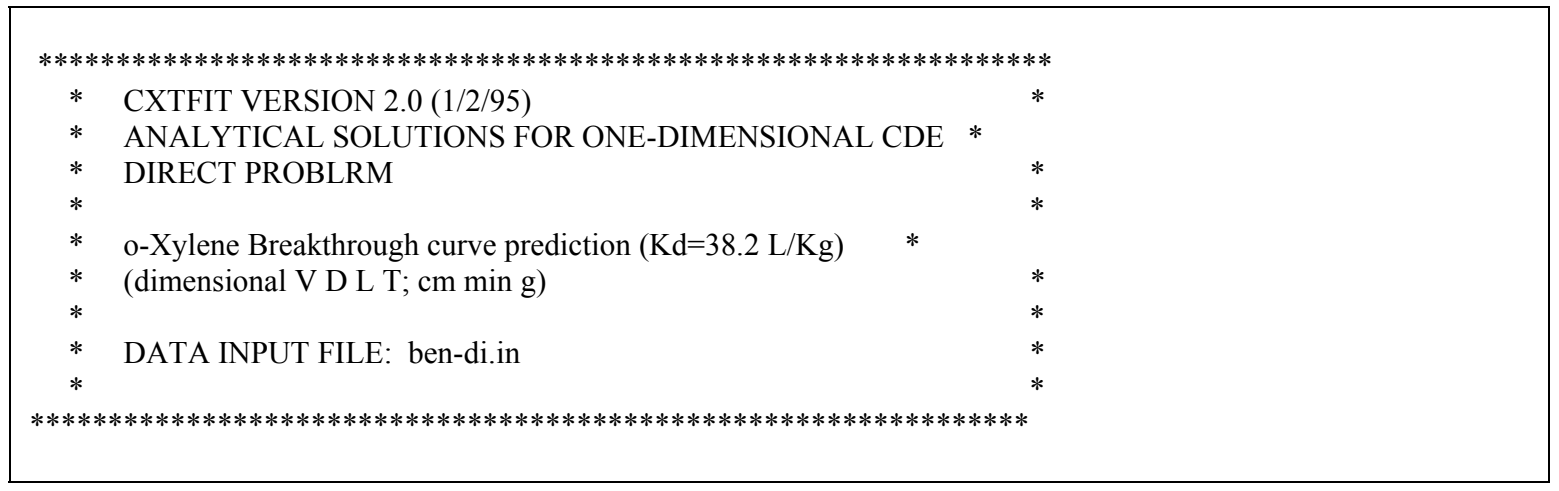

\section{Model Description}

DETERMINISTIC EQUILIBRIUM CDE (MODE=1)

FLUX-AVERAGED CONCENTRATION

REAL TIME (t), POSITION(x)

(D,V,mu, AND gamma ARE ALSO DIMENSIONAL)

INITIAL VALUES OF COEFFICIENTS

$\begin{array}{cc}\text { NAME } & \text { INITIAL VALUE } \\ \text { V ........ } & .8400 \mathrm{E}+02 \\ \mathrm{D} \ldots \ldots . . & .2100 \mathrm{E}+03 \\ \mathrm{R} . . . . . . . & .7450 \mathrm{E}+02 \\ \text { mu...... } & .0000 \mathrm{E}+00\end{array}$

BOUNDARY, INITIAL, AND PRODUCTION CONDITIONS

SINGLE PULSE OF CONC. $=1.0000 \&$ DURATION $=100.0000$

SOLUTE FREE INITIAL CONDITION

NO PRODUCTION TERM 


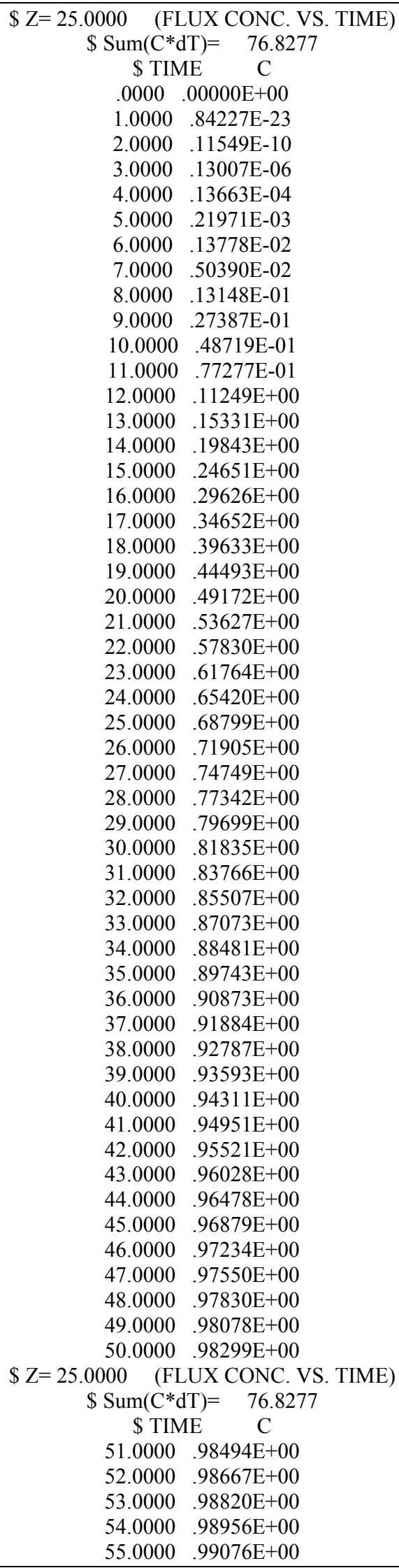




$\begin{array}{ll}56.0000 & .99183 \mathrm{E}+00 \\ 57.0000 & .99277 \mathrm{E}+00 \\ 58.0000 & .99360 \mathrm{E}+00 \\ 59.0000 & .99434 \mathrm{E}+00 \\ 60.0000 & .99499 \mathrm{E}+00 \\ 61.0000 & .99557 \mathrm{E}+00 \\ 62.0000 & .99608 \mathrm{E}+00 \\ 63.0000 & .99654 \mathrm{E}+00 \\ 64.0000 & .99694 \mathrm{E}+00 \\ 65.0000 & .99729 \mathrm{E}+00 \\ 66.0000 & .99760 \mathrm{E}+00 \\ 67.0000 & .99788 \mathrm{E}+00 \\ 68.0000 & .99813 \mathrm{E}+00 \\ 69.0000 & .99834 \mathrm{E}+00 \\ 70.0000 & .99853 \mathrm{E}+00 \\ 71.0000 & .99870 \mathrm{E}+00 \\ 72.0000 & .99885 \mathrm{E}+00 \\ 73.0000 & .99899 \mathrm{E}+00 \\ 74.0000 & .99910 \mathrm{E}+00 \\ 75.0000 & .99921 \mathrm{E}+00 \\ 76.0000 & .99930 \mathrm{E}+00 \\ 77.0000 & .99938 \mathrm{E}+00 \\ 78.0000 & .99945 \mathrm{E}+00 \\ 79.0000 & .99951 \mathrm{E}+00 \\ 80.0000 & .99957 \mathrm{E}+00 \\ 81.0000 & .99962 \mathrm{E}+00 \\ 82.0000 & .99966 \mathrm{E}+00 \\ 83.0000 & .99970 \mathrm{E}+00 \\ 84.0000 & .99974 \mathrm{E}+00 \\ 85.0000 & .99977 \mathrm{E}+00 \\ 86.0000 & .99979 \mathrm{E}+00 \\ 87.0000 & .99982 \mathrm{E}+00 \\ 88.0000 & .99984 \mathrm{E}+00 \\ 89.0000 & .99986 \mathrm{E}+00 \\ 90.0000 & .99987 \mathrm{E}+00 \\ 91.0000 & .99989 \mathrm{E}+00 \\ 92.0000 & .99990 \mathrm{E}+00 \\ 93.0000 & .99991 \mathrm{E}+00 \\ 94.0000 & .99992 \mathrm{E}+00 \\ 95.0000 & .99993 \mathrm{E}+00 \\ 96.0000 & .99994 \mathrm{E}+00 \\ 97.0000 & .99995 \mathrm{E}+00 \\ 98.0000 & .99995 \mathrm{E}+00 \\ 99.0000 & 99996 \mathrm{E}+00\end{array}$


Appendix A-3: Input Files for Predicting BTEX Sorption Distribution Coefficients in Column Study with Saline Water

\section{Benzene sorption coefficient $\mathrm{Kd}$ in 100,000 PPM salt water evaluation}

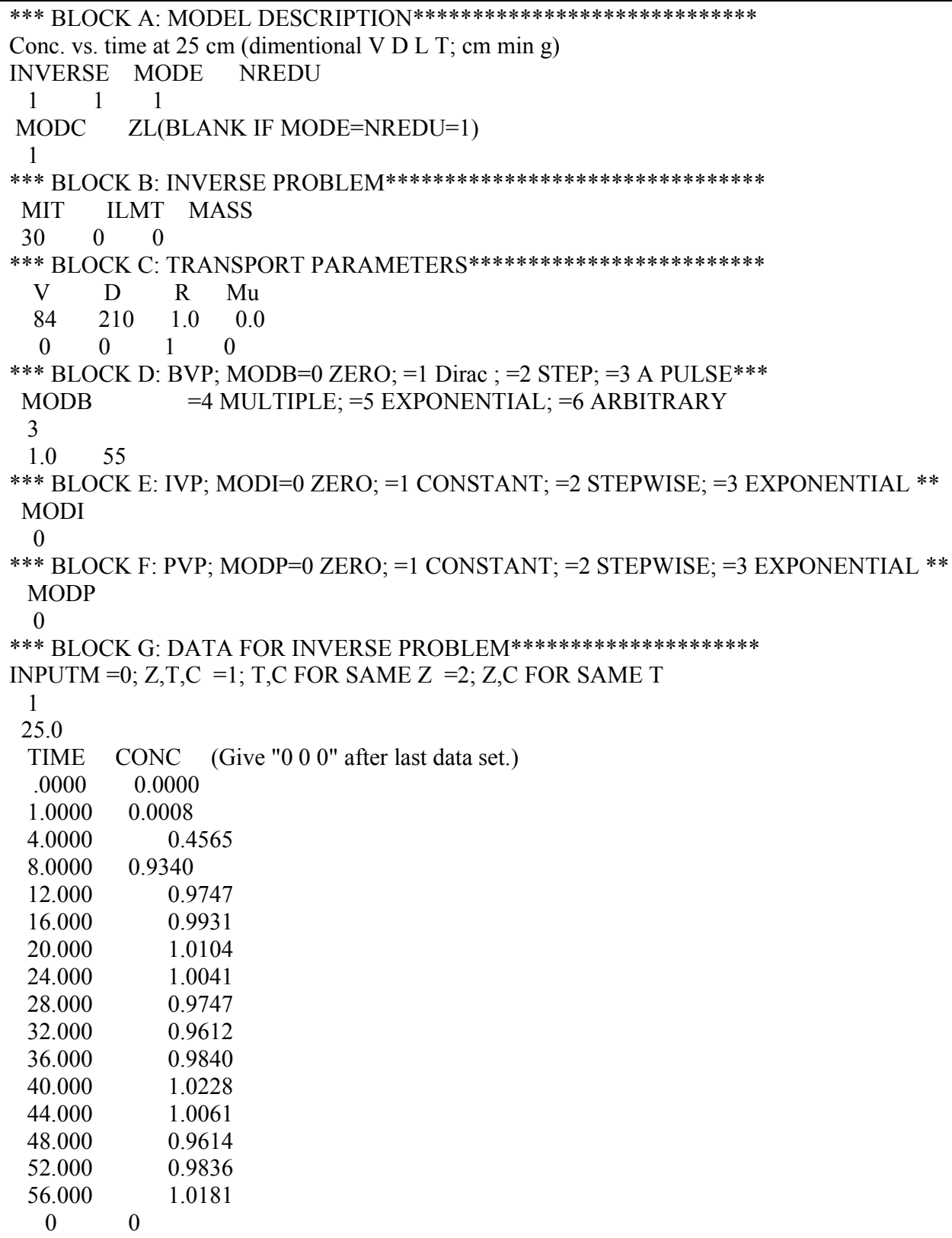




\section{Toluene sorption coefficient $\mathrm{Kd}$ in 100,000 PPM salt water evaluation}

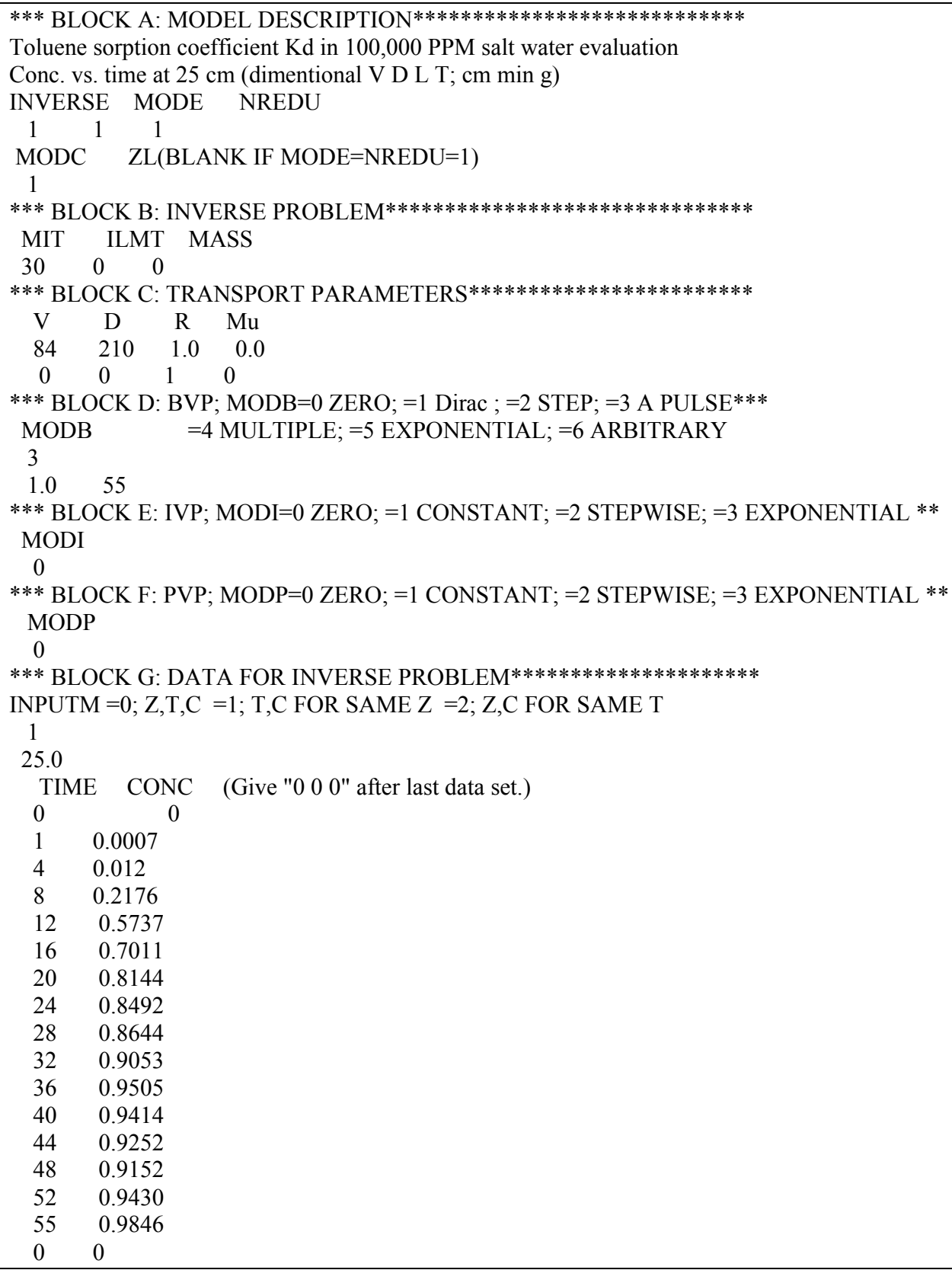




\section{Ethylbenzene sorption coefficient Kd in 100,000 PPM salt water evaluation}

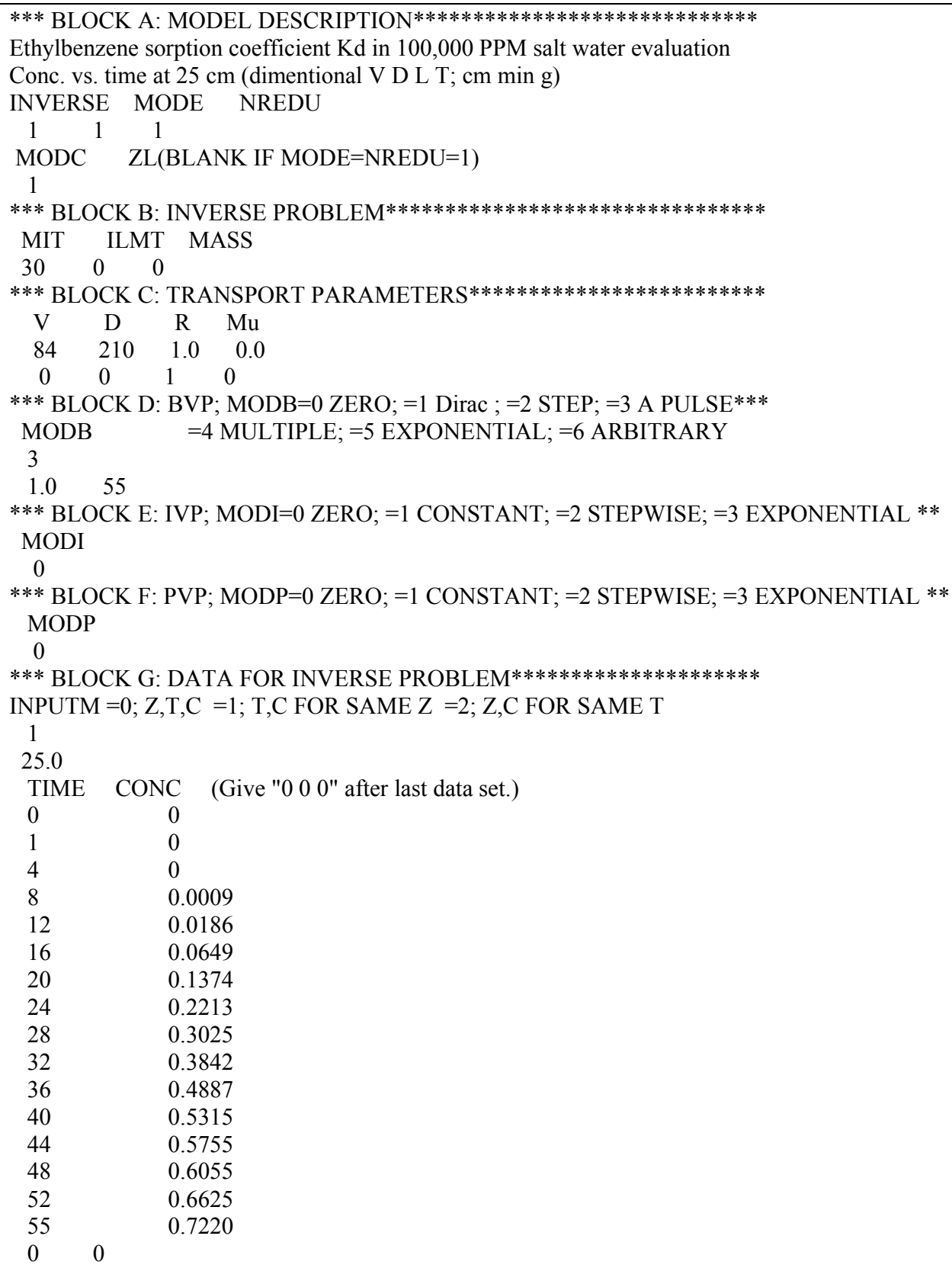




\section{m,p-Xylene sorption coefficient Kd in 100,000 PPM salt water evaluation}

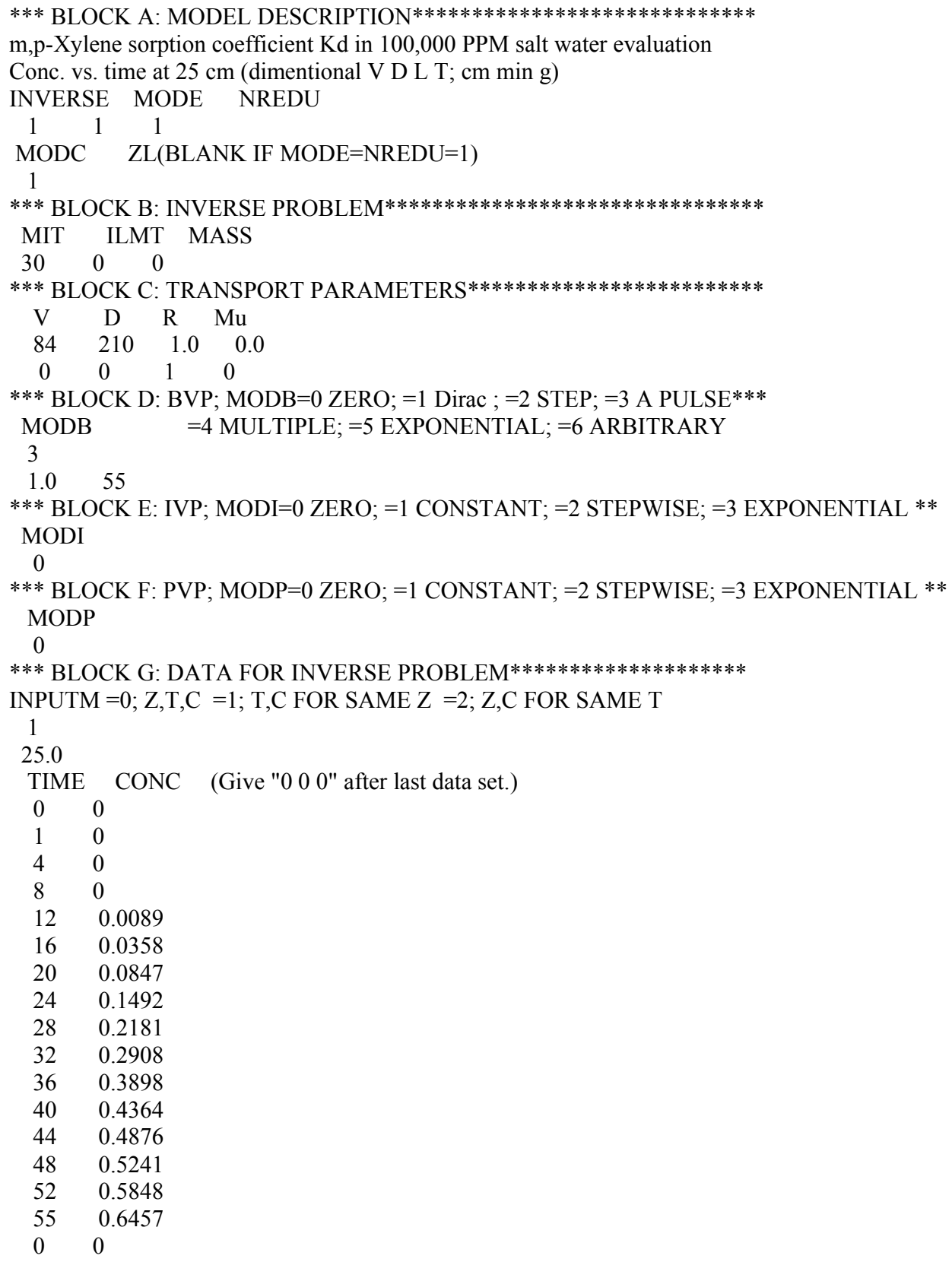




\section{o-Xylene sorption coefficient $\mathrm{Kd}$ in 100,000 PPM salt water evaluation}

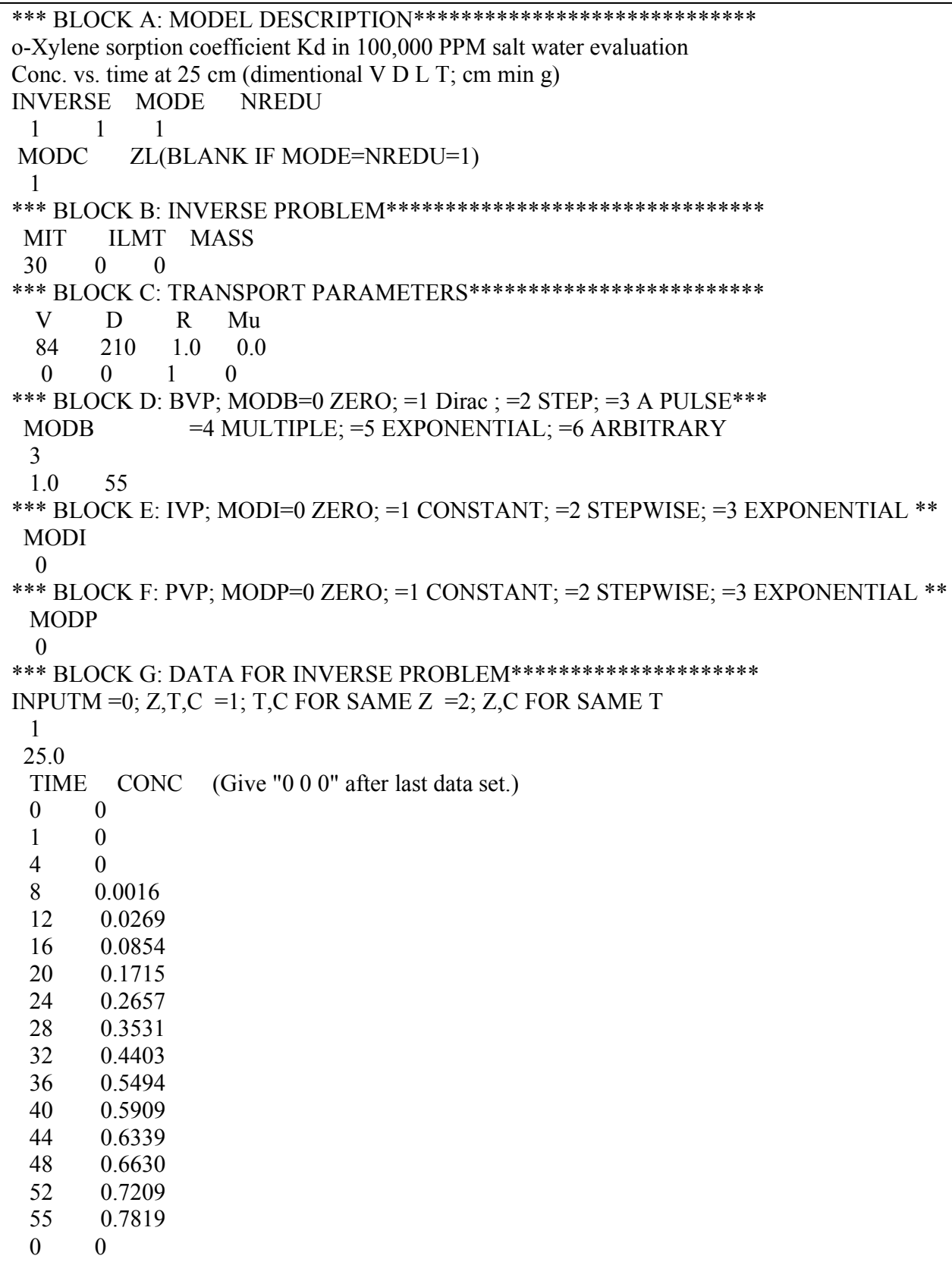


Appendix A-4: Output files for Predicting BTEX Sorption Distribution Coefficients in Column Study with Saline Water.

Predicting benzene sorption coefficient $K_{d}$ in 100,000 PPM salt water

\section{Model Description}

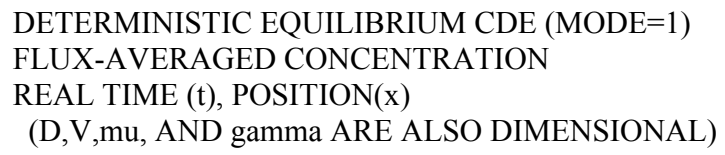

BOUNDARY, INITIAL, AND PRODUCTION CONDITIONS

SINGLE PULSE OF CONC. $=1.0000 \&$ DURATION $=55.0000$ SOLUTE FREE INITIAL CONDITION NO PRODUCTION TERM

PARAMETER ESTIMATION MODE

$$
\text { MAXIMUM NUMBER OF ITERATIONS }=30
$$

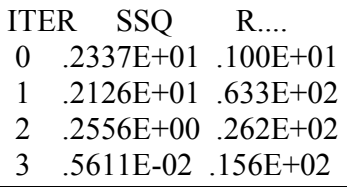




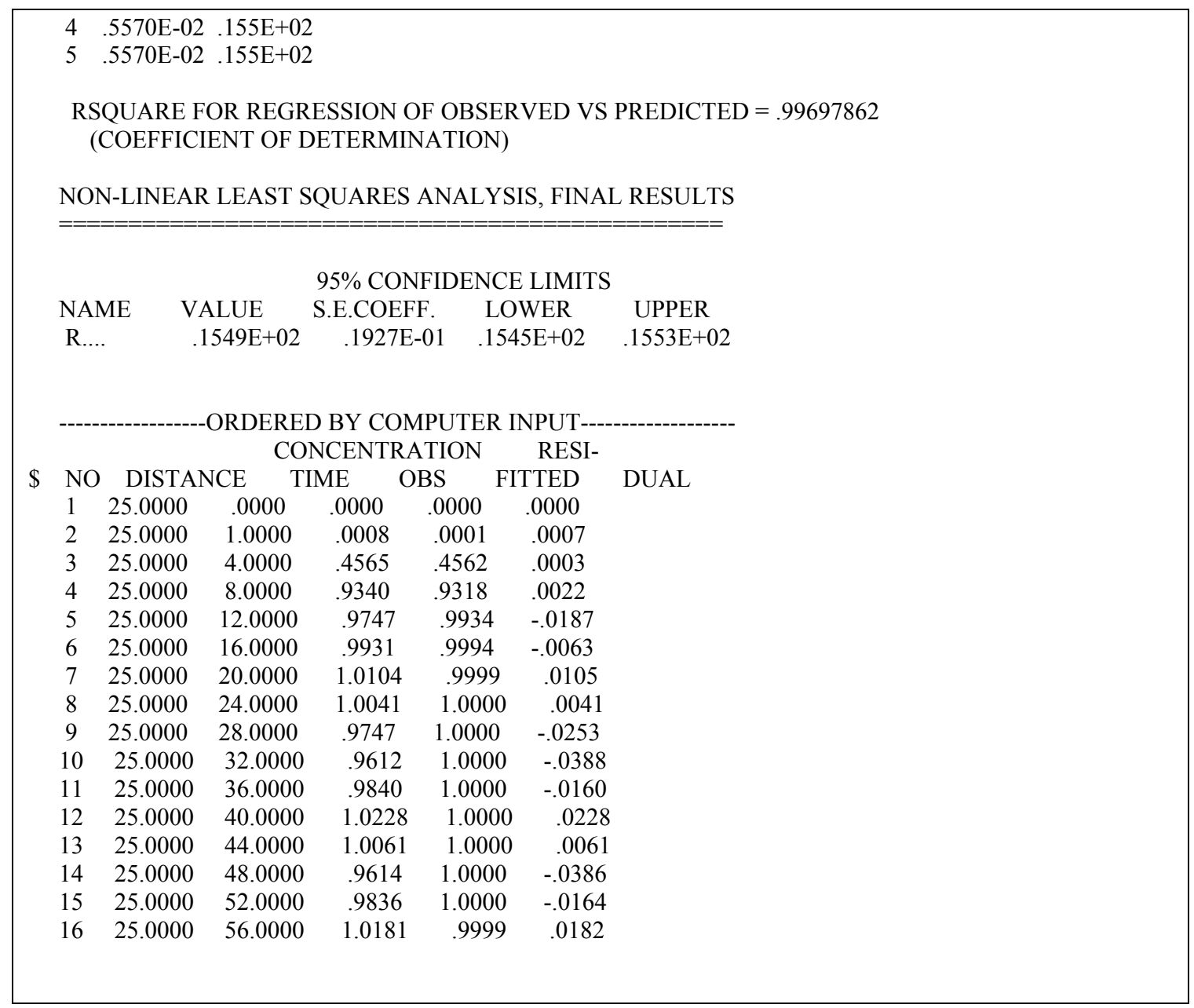




\section{Predicting toluene $K_{d}$ in 100,000 PPM saline water}

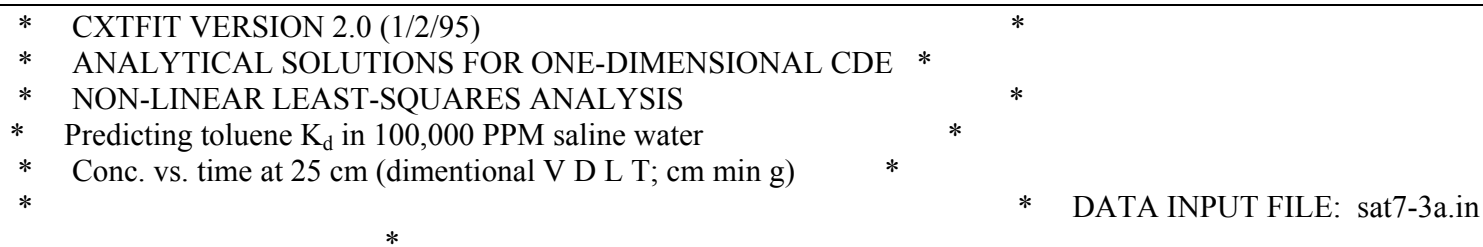

\section{Model Description}

DETERMINISTIC EQUILIBRIUM CDE $(\mathrm{MODE}=1)$

FLUX-AVERAGED CONCENTRATION

REAL TIME (t), POSITION(x)

(D,V,mu, AND gamma ARE ALSO DIMENSIONAL)

INITIAL VALUES OF COEFFICIENTS

$========================$
NAME INITIAL VALUE FITTING

$\mathrm{V}$........ .8400E+02 N

D....... .2100E+03 N

R....... .1000E+01 Y

mu....... .0000E+00 N

BOUNDARY, INITIAL, AND PRODUCTION CONDITIONS

SINGLE PULSE OF CONC. $=1.0000 \&$ DURATION $=55.0000$

SOLUTE FREE INITIAL CONDITION

NO PRODUCTION TERM

PARAMETER ESTIMATION MODE

MAXIMUM NUMBER OF ITERATIONS $=30$

ITER SSQ R....

$\begin{array}{lll}0 & .2963 \mathrm{E}+01 \quad .100 \mathrm{E}+01\end{array}$

$1 \quad .2504 \mathrm{E}+01 \quad .124 \mathrm{E}+03$

$2 \quad .2632 \mathrm{E}+00 \quad .620 \mathrm{E}+02$

$\begin{array}{lll}3 & .7319 \mathrm{E}-01 \quad .483 \mathrm{E}+02\end{array}$

$4 \quad .6391 \mathrm{E}-01 \quad .455 \mathrm{E}+02$

$5 \quad .6349 \mathrm{E}-01 \quad .450 \mathrm{E}+02$

$\begin{array}{lll}6 & .6347 \mathrm{E}-01 \quad .449 \mathrm{E}+02\end{array}$

$\begin{array}{llll}7 & .6346 \mathrm{E}-01 & .449 \mathrm{E}+02\end{array}$

$8 \quad .6346 \mathrm{E}-01 \quad .449 \mathrm{E}+02$

RSQUARE FOR REGRESSION OF OBSERVED VS PREDICTED $=.97035822$ (COEFFICIENT OF DETERMINATION)

NON-LINEAR LEAST SQUARES ANALYSIS, FINAL RESULTS 


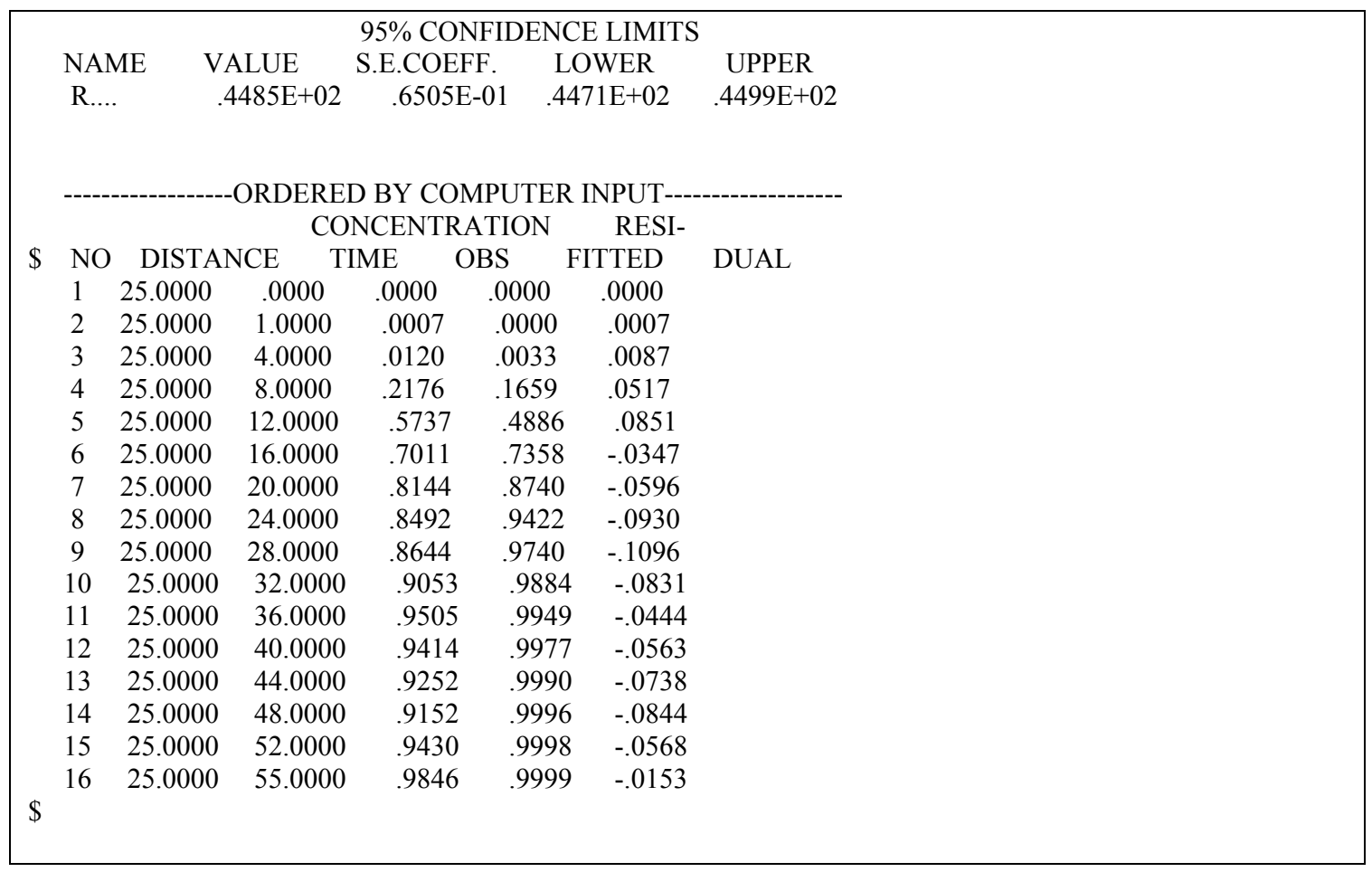




\section{Predicting ethylbenzene $K_{d}$ in $100,000 p p m$ salt water}

\begin{tabular}{|clc|}
\hline$*$ & CXTFIT VERSION $2.0(1 / 2 / 95)$ & $*$ \\
$*$ & ANALYTICAL SOLUTIONS FOR ONE-DIMENSIONAL CDE & $*$ \\
$*$ & NON-LINEAR LEAST-SQUARES ANALYSIS & $*$ \\
$*$ & Predicting ethylbenzene $\mathrm{K}_{\mathrm{d}}$ in $100,000 \mathrm{ppm}$ salt water & $*$ \\
$*$ & Conc. vs. time at $25 \mathrm{~cm}($ dimentional V D L T; cm min g) & $*$ \\
$*$ & DATA INPUT FILE: sat7-3a.in & $*$ \\
$*$ & & \\
$* * * * * * * * * * * * * * * * * * * * * * * * * * * * * * * * * * * * * * * * * * * * * * * * * * * * * * * * * * *$
\end{tabular}

\section{Model Description}

DETERMINISTIC EQUILIBRIUM CDE $(\mathrm{MODE}=1)$

FLUX-AVERAGED CONCENTRATION

REAL TIME ( $\mathrm{t}$ ), POSITION(x)

(D,V,mu, AND gamma ARE ALSO DIMENSIONAL)

INITIAL VALUES OF COEFFICIENTS

$============================$
NAME INITIAL VALUE FITTING

$\mathrm{V}$........ .8400E+02 N

D....... .2100E+03 N

R....... .1000E+01 Y

mu....... .0000E $+00 \quad \mathrm{~N}$

BOUNDARY, INITIAL, AND PRODUCTION CONDITIONS

SINGLE PULSE OF CONC.$=1.0000 \&$ DURATION $=55.0000$

SOLUTE FREE INITIAL CONDITION

NO PRODUCTION TERM

PARAMETER ESTIMATION MODE

$===================$

MAXIMUM NUMBER OF ITERATIONS $=30$

ITER SSQ R....

$\begin{array}{llll}0 & .8058 \mathrm{E}+01 \quad .100 \mathrm{E}+01\end{array}$

$1 \quad .1370 \mathrm{E}+00 \quad .125 \mathrm{E}+03$

$2 \quad .5120 \mathrm{E}-01 \quad .139 \mathrm{E}+03$

$3 \quad .4879 \mathrm{E}-01.142 \mathrm{E}+03$

$4 \quad .4877 \mathrm{E}-01 \quad .143 \mathrm{E}+03$

$5 \quad .4877 \mathrm{E}-01 \quad .143 \mathrm{E}+03$

RSQUARE FOR REGRESSION OF OBSERVED VS PREDICTED $=.95571232$ (COEFFICIENT OF DETERMINATION)

NON-LINEAR LEAST SQUARES ANALYSIS, FINAL RESULTS

\begin{tabular}{|c|c|c|c|c|}
\hline \multirow{2}{*}{ NAME } & \multicolumn{4}{|c|}{ 95\% CONFIDENCE LIMITS } \\
\hline & VALUE & S.E.COEFF. & LOWER & UPPER \\
\hline $\mathrm{R} \ldots .$. & $.1426 \mathrm{E}+03$ & $.5702 \mathrm{E}-01$ & $.1425 \mathrm{E}+03$ & $.1427 \mathrm{E}+03$ \\
\hline
\end{tabular}




\begin{tabular}{|ccccccc|}
\hline \multicolumn{8}{c|}{ CONCENTRATION } & RESI- \\
\$ & \multicolumn{8}{c|}{ NO } & DISTANCE & TIME & OBS & FITTED & DUAL \\
1 & 25.0000 & .0000 & .0000 & .0000 & .0000 & \\
2 & 25.0000 & 1.0000 & .0000 & .0000 & .0000 \\
3 & 25.0000 & 4.0000 & .0000 & .0000 & .0000 \\
4 & 25.0000 & 8.0000 & .0009 & .0000 & .0009 \\
5 & 25.0000 & 12.0000 & .0186 & .0020 & .0166 \\
6 & 25.0000 & 16.0000 & .0649 & .0175 & .0474 \\
7 & 25.0000 & 20.0000 & .1374 & .0607 & .0767 \\
8 & 25.0000 & 24.0000 & .2213 & .1338 & .0875 \\
9 & 25.0000 & 28.0000 & .3025 & .2284 & .0741 \\
10 & 25.0000 & 32.0000 & .3842 & .3323 & .0519 \\
11 & 25.0000 & 36.0000 & .4887 & .4357 & .0530 \\
12 & 25.0000 & 40.0000 & .5315 & .5318 & -.0003 \\
13 & 25.0000 & 44.0000 & .5755 & .6171 & -.0416 \\
14 & 25.0000 & 48.0000 & .6055 & .6904 & -.0849 \\
15 & 25.0000 & 52.0000 & .6625 & .7520 & -.0895 \\
16 & 25.0000 & 55.0000 & .7220 & .7909 & -.0689 \\
$\$$ & & & & & \\
\hline
\end{tabular}




\section{Predicting m,p-xylene $K_{d}$ in 100,000 PPM saline water}

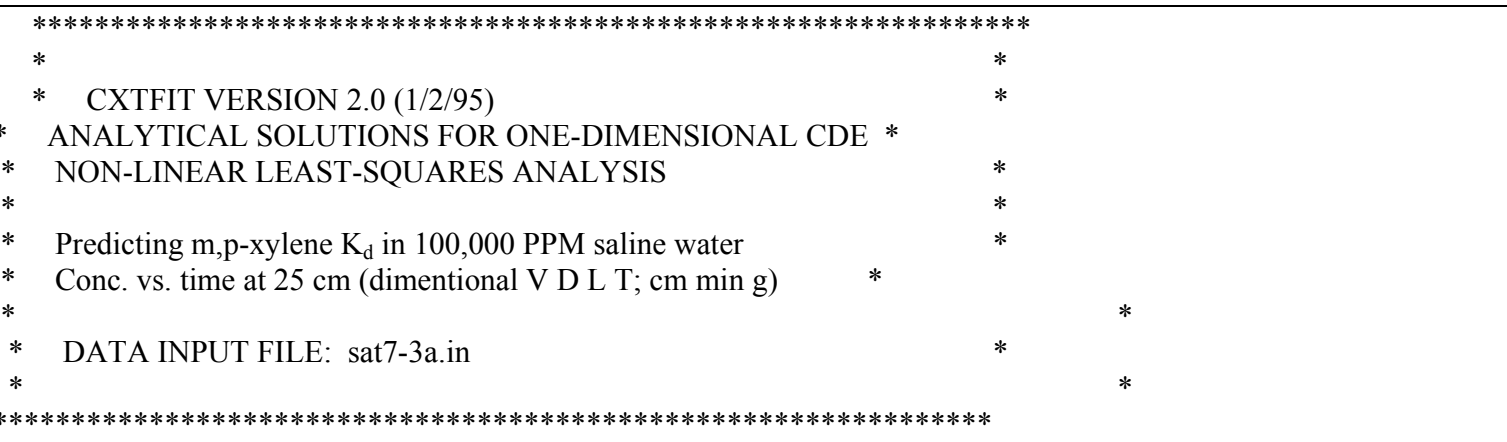

\section{Model Description}

DETERMINISTIC EQUILIBRIUM CDE (MODE=1)

FLUX-AVERAGED CONCENTRATION

REAL TIME (t), POSITION(x)

(D,V,mu, AND gamma ARE ALSO DIMENSIONAL)

INITIAL VALUES OF COEFFICIENTS

\begin{tabular}{cccc}
$==========================$ \\
NAME & \multicolumn{1}{c}{ INITIAL VALUE } & FITTING \\
V........ & $.8400 \mathrm{E}+02$ & $\mathrm{~N}$ & \\
D........ & $.2100 \mathrm{E}+03$ & $\mathrm{~N}$ & \\
R........ & $.1000 \mathrm{E}+01$ & $\mathrm{Y}$ & \\
mu........ & $.0000 \mathrm{E}+00$ & $\mathrm{~N}$ &
\end{tabular}

BOUNDARY, INITIAL, AND PRODUCTION CONDITIONS

\begin{tabular}{|c|c|c|}
\hline \multicolumn{3}{|c|}{$\begin{array}{l}\text { SINGLE PULSE OF CON } \\
\text { SOLUTE FREE INITIAL } \\
\text { NO PRODUCTION TER }\end{array}$} \\
\hline \multicolumn{3}{|c|}{ PARAMETER ESTIMAT } \\
\hline \multicolumn{3}{|c|}{ MAXIMUM NUMBER } \\
\hline ITER & R SSQ & R.... \\
\hline & $.9063 \mathrm{E}+01$ & $100 \mathrm{E}+0$ \\
\hline & $.3628 \mathrm{E}+00$ & $.125 \mathrm{E}+03$ \\
\hline & $.4419 \mathrm{E}-01$ & $.153 \mathrm{E}+03$ \\
\hline & $.3234 \mathrm{E}-01$ & $.160 \mathrm{E}+03$ \\
\hline & $.3221 \mathrm{E}-01$ & $.161 \mathrm{E}+03$ \\
\hline & $.3221 \mathrm{E}-01$ & $.161 \mathrm{E}+0$ \\
\hline
\end{tabular}

RSQUARE FOR REGRESSION OF OBSERVED VS PREDICTED $=.96199420$ (COEFFICIENT OF DETERMINATION)

NON-LINEAR LEAST SQUARES ANALYSIS, FINAL RESULTS 


\begin{tabular}{|c|c|c|c|c|c|c|c|}
\hline & \multicolumn{2}{|c|}{$\begin{array}{l}\text { NAME } \\
\text { R.... }\end{array}$} & $\begin{array}{l}\text { VALUE } \\
.1611 \mathrm{E}+03\end{array}$ & \multicolumn{2}{|c|}{$\begin{array}{l}\text { S.E.COEFF. } \\
.4634 \mathrm{E}-01\end{array}$} & $\begin{array}{l}\text { LOWER } \\
.1610 \mathrm{E}+03\end{array}$ & $\begin{array}{l}\text { UPPER } \\
.1612 \mathrm{E}+03\end{array}$ \\
\hline \multirow{17}{*}{$\$$} & & ------------ & $\begin{array}{r}\text { ORDEREI } \\
\mathrm{CO}\end{array}$ & $\begin{array}{l}\mathrm{D} \text { BY CO } \\
\text { NCENTR }\end{array}$ & $\begin{array}{l}\text { MPUTER } \\
\text { RATION }\end{array}$ & $\begin{array}{l}\text { INPUT--- } \\
\text { RESI- }\end{array}$ & ---------------- \\
\hline & $\mathrm{NO}$ & DISTAI & ICE & IME & OBS & FITTED & DUAL \\
\hline & 1 & 25.0000 & .0000 & .0000 & .0000 & .0000 & \\
\hline & 2 & 25.0000 & 1.0000 & .0000 & .0000 & .0000 & \\
\hline & 3 & 25.0000 & 4.0000 & .0000 & .0000 & .0000 & \\
\hline & 4 & 25.0000 & 8.0000 & .0000 & .0000 & .0000 & \\
\hline & 5 & 25.0000 & 12.0000 & .0089 & .0007 & .0082 & \\
\hline & 6 & 25.0000 & 16.0000 & .0358 & .0076 & .0282 & \\
\hline & 7 & 25.0000 & 20.0000 & .0847 & .0320 & .0527 & \\
\hline & 8 & 25.0000 & 24.0000 & .1492 & .0804 & .0688 & \\
\hline & 9 & 25.0000 & 28.0000 & .2181 & .1510 & .0671 & \\
\hline & 10 & 25.0000 & 32.0000 & .2908 & .2366 & .0542 & \\
\hline & 11 & 25.0000 & 36.0000 & .3898 & .3287 & .0611 & \\
\hline & 12 & 25.0000 & 40.0000 & .4364 & .4206 & .0158 & \\
\hline & 13 & 25.0000 & 44.0000 & .4876 & .5074 & -.0198 & \\
\hline & 14 & 25.0000 & 48.0000 & .5241 & .5862 & -.0621 & \\
\hline & 15 & 25.0000 & 52.0000 & .5848 & .6558 & -.0710 & \\
\hline$\$$ & 16 & 25.0000 & 55.0000 & .6457 & .7017 & -.0560 & \\
\hline
\end{tabular}




\section{o-Xylene sorption coefficient $\mathrm{Kd}$ in 100,000 PPM salt water}

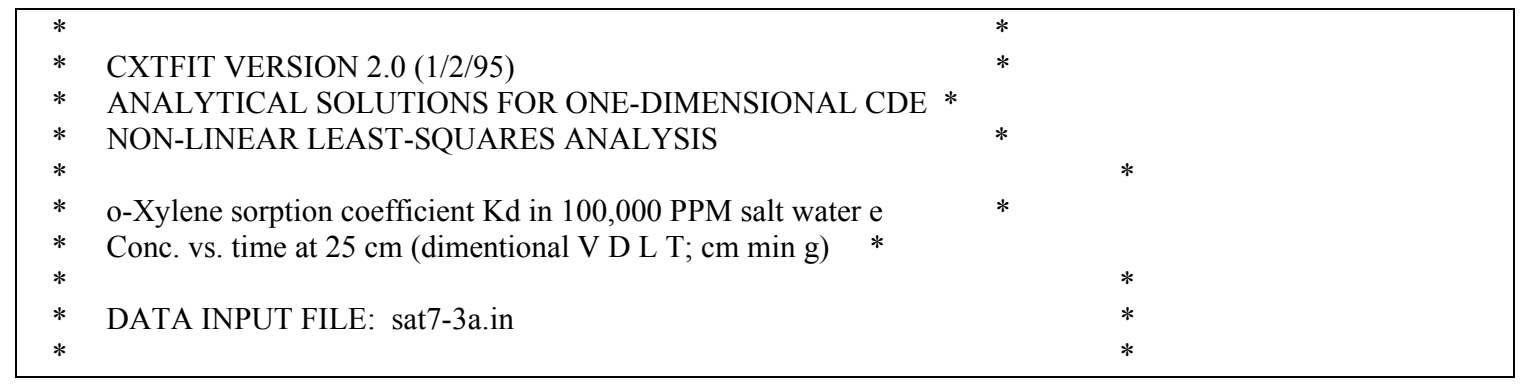

\section{Model Description}

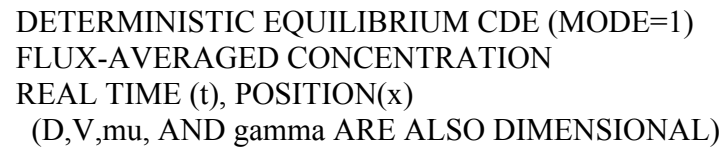

BOUNDARY, INITIAL, AND PRODUCTION CONDITIONS

SINGLE PULSE OF CONC. $=1.0000 \&$ DURATION $=55.0000$ SOLUTE FREE INITIAL CONDITION NO PRODUCTION TERM

PARAMETER ESTIMATION MODE

MAXIMUM NUMBER OF ITERATIONS $=30$

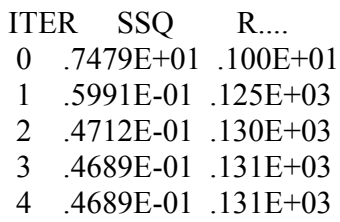

RSQUARE FOR REGRESSION OF OBSERVED VS PREDICTED $=.96406136$ (COEFFICIENT OF DETERMINATION)

NON-LINEAR LEAST SQUARES ANALYSIS, FINAL RESULTS

95\% CONFIDENCE LIMITS

NAME VALUE S.E.COEFF. LOWER UPPER 


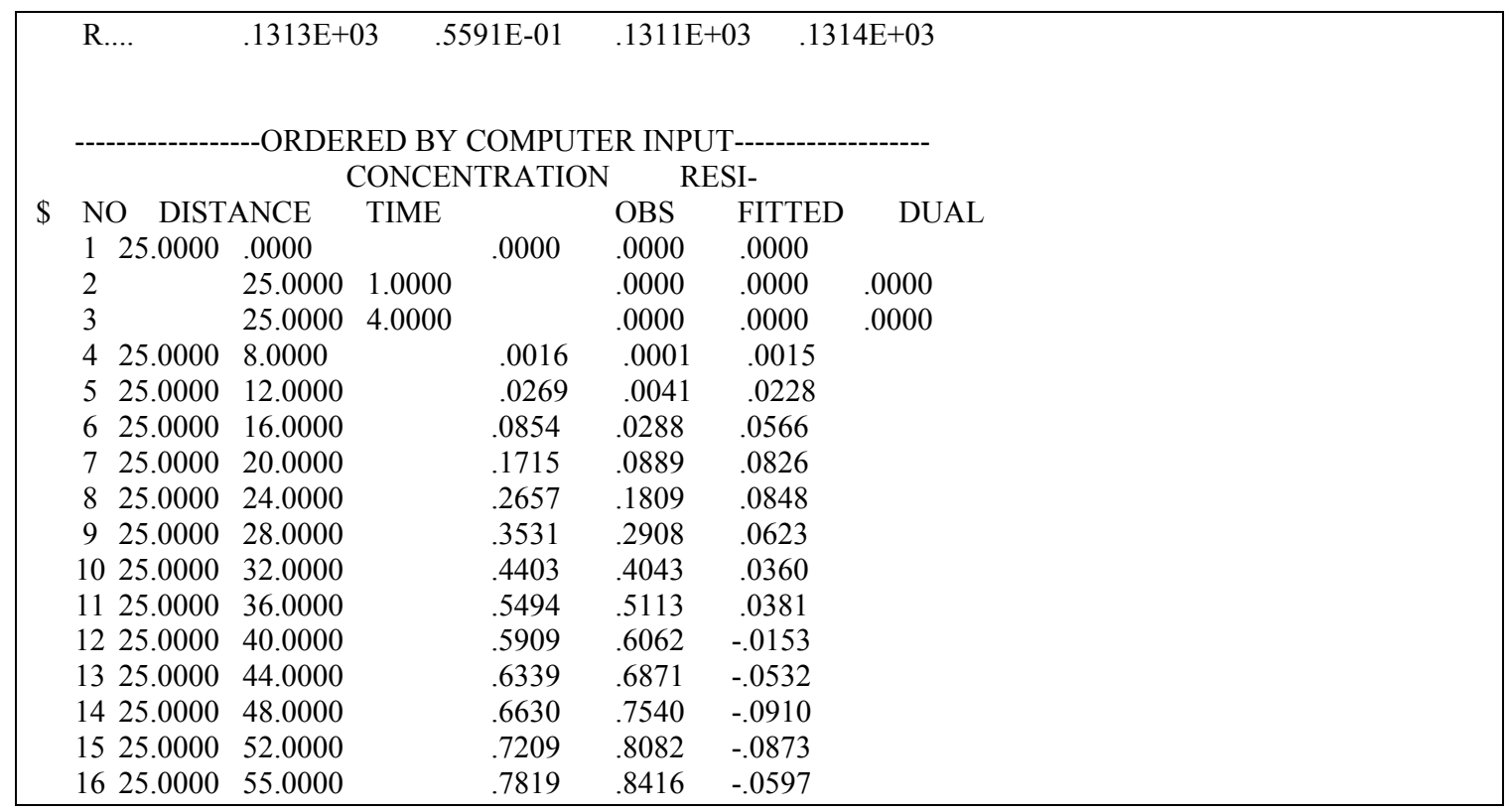


Appendix A-5: Output files for Predicting BTEX Sorption Distribution Coefficients in Column Study with Produced Water.

\section{Benzene sorption coefficient $\mathrm{Kd}$ in produced water}

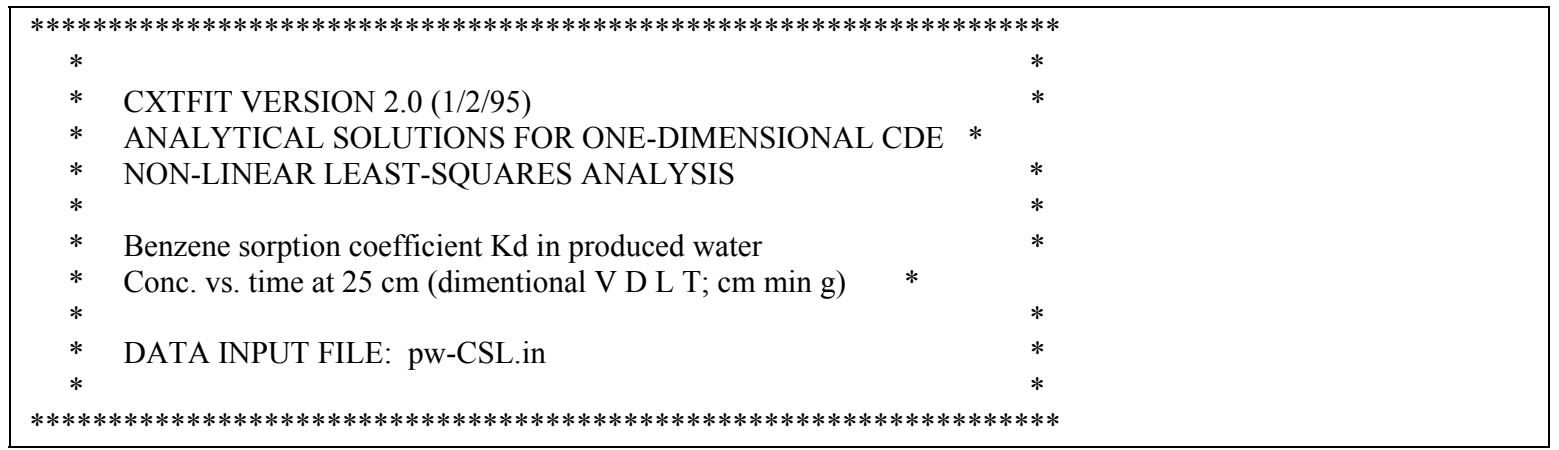

\section{Model Description}

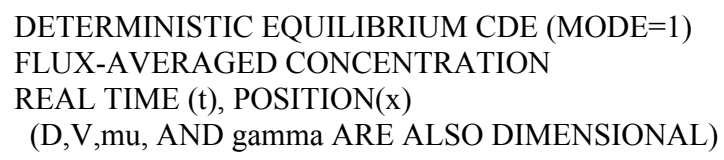

\begin{tabular}{cccc} 
NAME & \multicolumn{2}{c}{ INITIAL VALUE } & FITTING \\
V........ & $.8400 \mathrm{E}+02$ & $\mathrm{~N}$ & \\
$\mathrm{D} \ldots \ldots . .$. & $.2100 \mathrm{E}+03$ & $\mathrm{~N}$ & \\
R........ & $.1000 \mathrm{E}+01$ & $\mathrm{Y}$ & \\
mu....... & $.0000 \mathrm{E}+00$ & $\mathrm{~N}$ &
\end{tabular}

BOUNDARY, INITIAL, AND PRODUCTION CONDITIONS

SINGLE PULSE OF CONC. $=1.0000 \&$ DURATION $=55.0000$ SOLUTE FREE INITIAL CONDITION NO PRODUCTION TERM

PARAMETER ESTIMATION MODE

MAXIMUM NUMBER OF ITERATIONS $=30$

$\begin{array}{ccc}\text { ITER } & \text { SSQ } & \text { R.... } \\ 0 & .1872 \mathrm{E}+01 & .100 \mathrm{E}+01 \\ 1 & .3848 \mathrm{E}+00 & .319 \mathrm{E}+02 \\ 2 & .4842 \mathrm{E}-01 & .207 \mathrm{E}+02 \\ 3 & .3604 \mathrm{E}-01 & .188 \mathrm{E}+02 \\ 4 & .3566 \mathrm{E}-01 & .185 \mathrm{E}+02 \\ 5 & .3565 \mathrm{E}-01 & .185 \mathrm{E}+02\end{array}$




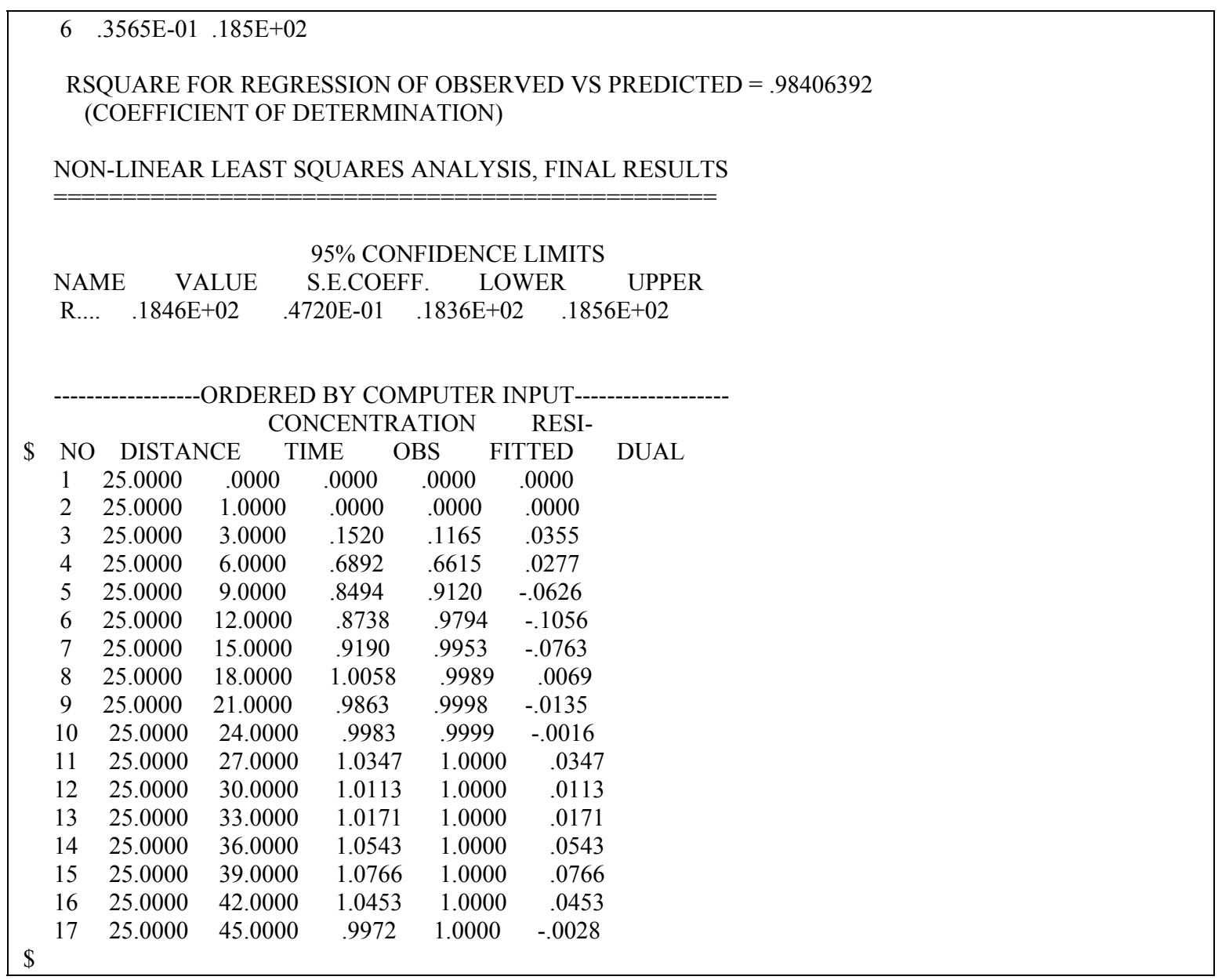




\section{Toluene sorption coefficient $\mathrm{Kd}$ in produced water}

\begin{tabular}{|clc|}
\hline$*$ & $*$ \\
$*$ & CXTFIT VERSION $2.0(1 / 2 / 95)$ & $*$ \\
$*$ & ANALYTICAL SOLUTIONS FOR ONE-DIMENSIONAL CDE & $*$ \\
$*$ & NON-LINEAR LEAST-SQUARES ANALYSIS & $*$ \\
$*$ & & $*$ \\
$*$ & Toluene sorption coefficient Kd in produced water & $*$ \\
$*$ & Conc. vs. time at $25 \mathrm{~cm}($ dimentional V D L T; cm min g) & $*$ \\
$*$ & & $*$ \\
$*$ & DATA INPUT FILE: pw-CSL.in & $*$ \\
$* * * * * * * * * * * * * * * * * * * * * * * * * * * * * * * * * * * * * * * * * * * * * * * * * * * * * * * * * * * *$
\end{tabular}

\section{Model Description}

DETERMINISTIC EQUILIBRIUM CDE (MODE=1)

FLUX-AVERAGED CONCENTRATION

REAL TIME (t), POSITION(x)

(D,V,mu, AND gamma ARE ALSO DIMENSIONAL)

INITIAL VALUES OF COEFFICIENTS

NAME INITIAL VALUE FITTING

$\mathrm{V}$........ .8400E+02 N

D........ .2100E+03 N

R....... .1000E+01 Y

mu...... . .0000E $+00 \quad \mathrm{~N}$

BOUNDARY, INITIAL, AND PRODUCTION CONDITIONS

SINGLE PULSE OF CONC. $=1.0000 \&$ DURATION $=55.0000$

SOLUTE FREE INITIAL CONDITION

NO PRODUCTION TERM

PARAMETER ESTIMATION MODE

$====================$
MAXIMUM NUMBER OF ITERATIONS $=30$

$$
\begin{array}{ccc}
\text { ITER } & \text { SSQ } & \text { R.... } \\
0 & .4116 \mathrm{E}+01 & .100 \mathrm{E}+01 \\
1 & .3126 \mathrm{E}+01 & .125 \mathrm{E}+03 \\
2 & .2293 \mathrm{E}-01 & .506 \mathrm{E}+02 \\
3 & .2274 \mathrm{E}-01 & .503 \mathrm{E}+02 \\
4 & .2273 \mathrm{E}-01 & .502 \mathrm{E}+02 \\
5 & .2273 \mathrm{E}-01 & .502 \mathrm{E}+02
\end{array}
$$

RSQUARE FOR REGRESSION OF OBSERVED VS PREDICTED $=.99091125$ (COEFFICIENT OF DETERMINATION) 


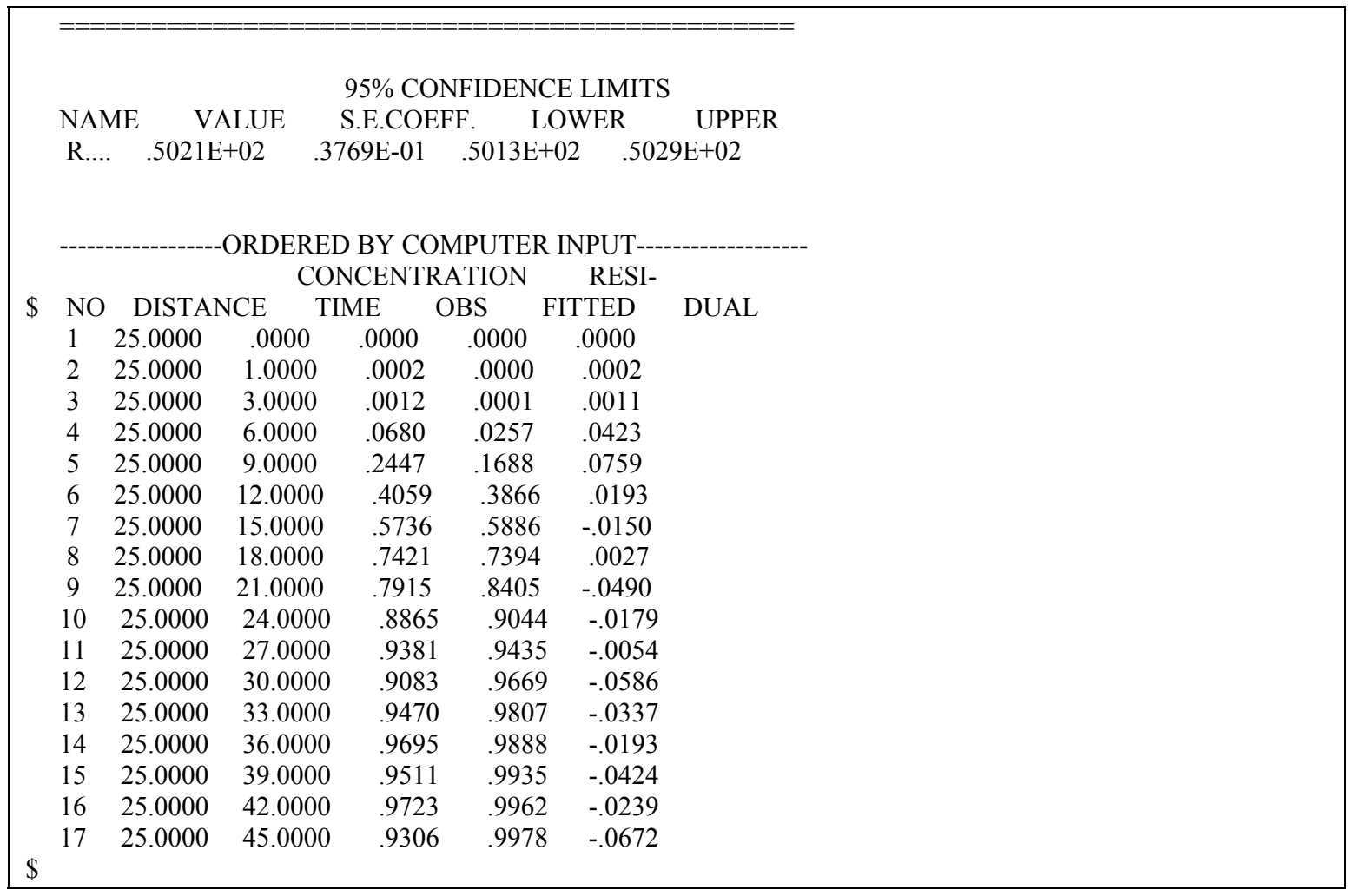




\section{Ethylbenzene sorption coefficient $\mathrm{Kd}$ in produced water}

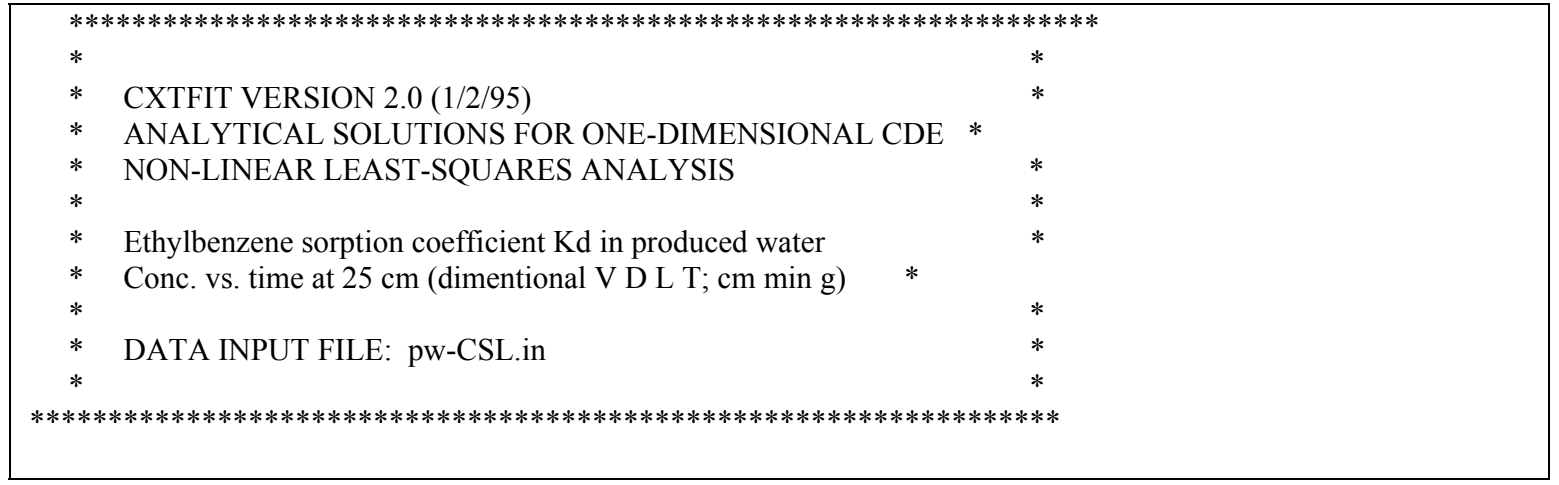

\section{Model Description}

DETERMINISTIC EQUILIBRIUM CDE (MODE=1)

FLUX-AVERAGED CONCENTRATION

REAL TIME (t), POSITION(x)

(D,V,mu, AND gamma ARE ALSO DIMENSIONAL)

INITIAL VALUES OF COEFFICIENTS

NAME INITIAL VALUE FITTING

V....... .8400E+02 N

D........ .2100E+03 N

R........ .1000E+01 Y

mu....... .0000E $+00 \quad \mathrm{~N}$

BOUNDARY, INITIAL, AND PRODUCTION CONDITIONS

SINGLE PULSE OF CONC. $=1.0000 \&$ DURATION $=55.0000$

SOLUTE FREE INITIAL CONDITION

NO PRODUCTION TERM

PARAMETER ESTIMATION MODE

MAXIMUM NUMBER OF ITERATIONS $=30$

$$
\begin{array}{ccc}
\text { ITER } & \text { SSQ } & \text { R... } \\
0 & .1073 \mathrm{E}+02 & .100 \mathrm{E}+01 \\
1 & .1769 \mathrm{E}+00 & .125 \mathrm{E}+03 \\
2 & .4429 \mathrm{E}-01 & .143 \mathrm{E}+03 \\
3 & .4039 \mathrm{E}-01 & .146 \mathrm{E}+03 \\
4 & .4035 \mathrm{E}-01 & .147 \mathrm{E}+03 \\
5 & .4035 \mathrm{E}-01 & .147 \mathrm{E}+03
\end{array}
$$

RSQUARE FOR REGRESSION OF OBSERVED VS PREDICTED $=.93377468$ (COEFFICIENT OF DETERMINATION)

NON-LINEAR LEAST SQUARES ANALYSIS, FINAL RESULTS 


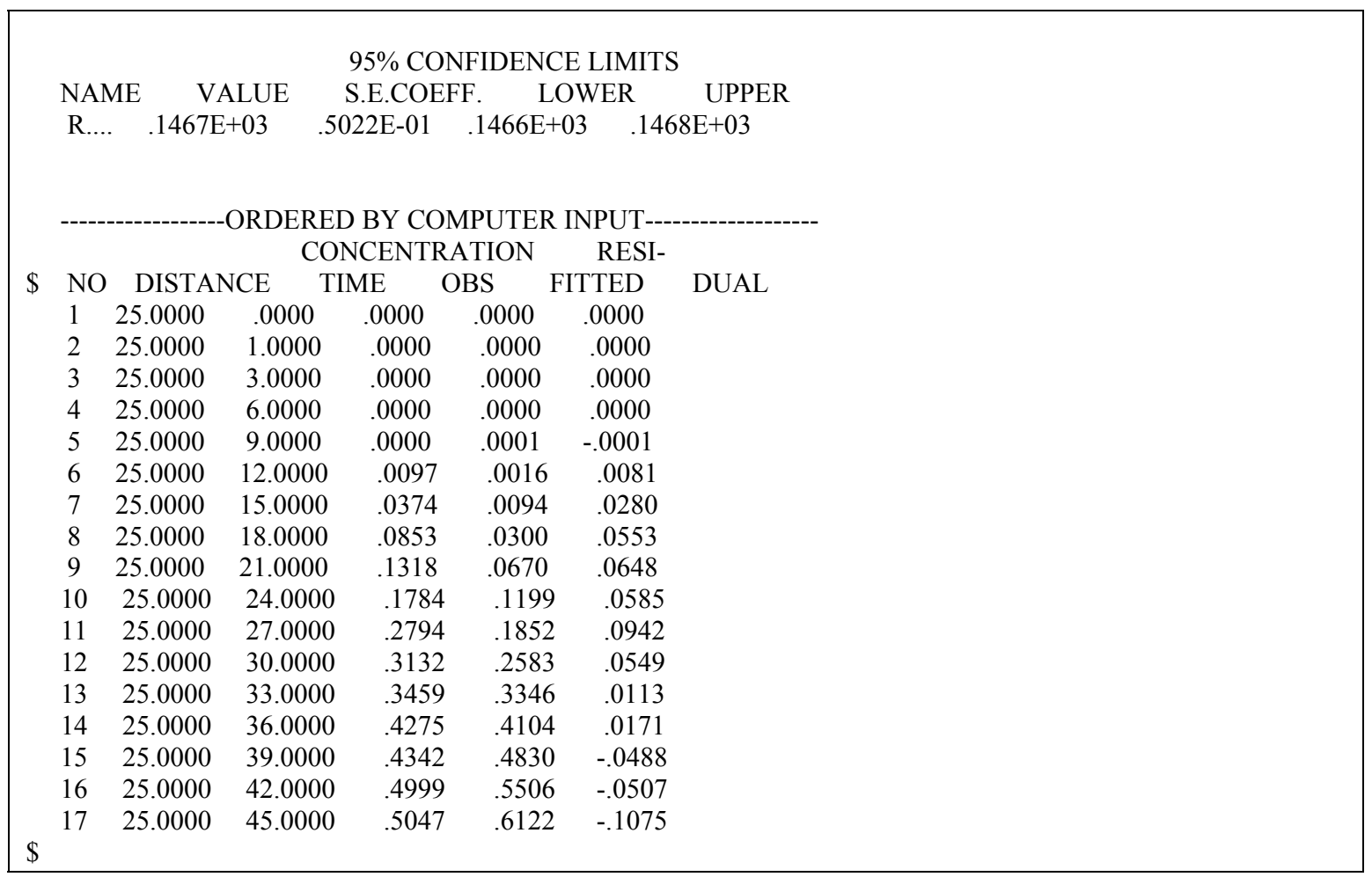




\section{m,p-Xylene sorption coefficient $\mathrm{Kd}$ in produced water}

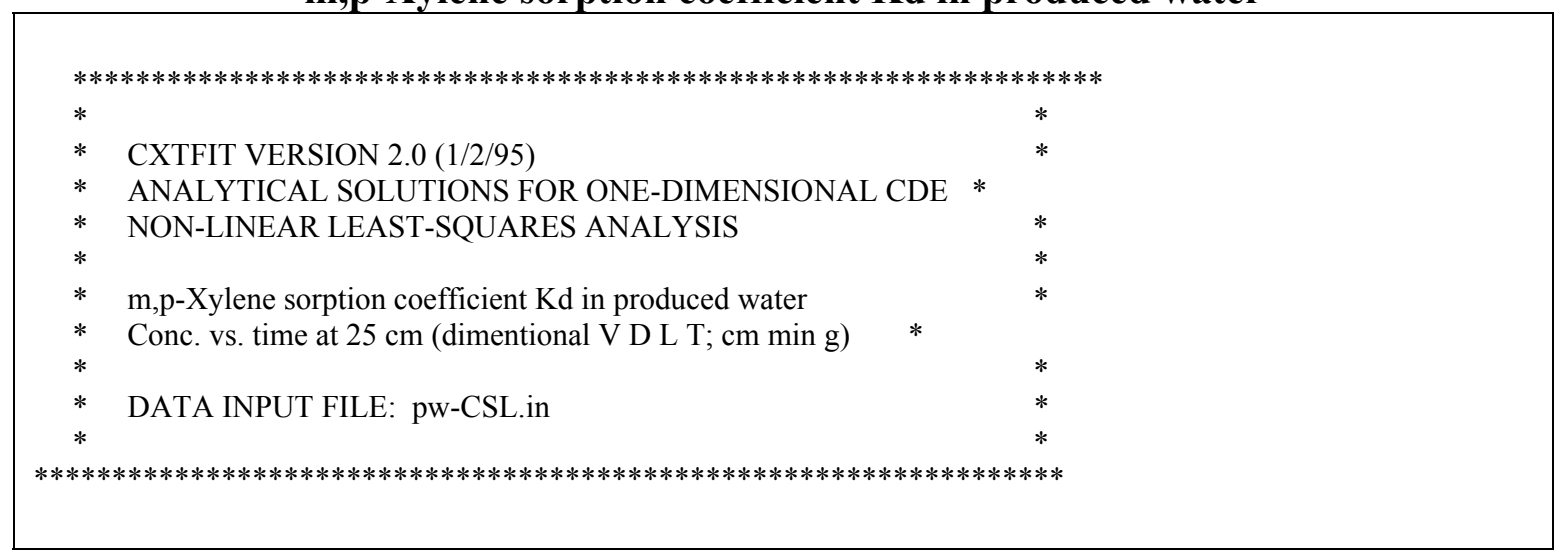

\section{Model Description}

DETERMINISTIC EQUILIBRIUM CDE (MODE=1)

FLUX-AVERAGED CONCENTRATION

REAL TIME (t), POSITION(x)

(D,V,mu, AND gamma ARE ALSO DIMENSIONAL)

INITIAL VALUES OF COEFFICIENTS

\begin{tabular}{cccc} 
NAME & \multicolumn{2}{c}{ INITIAL VALUE } & FITTING \\
V........ & $.8400 \mathrm{E}+02$ & $\mathrm{~N}$ & \\
D........ & $.2100 \mathrm{E}+03$ & $\mathrm{~N}$ & \\
R........ & $.1000 \mathrm{E}+01$ & $\mathrm{Y}$ & \\
mu....... & $.0000 \mathrm{E}+00$ & $\mathrm{~N}$ &
\end{tabular}

BOUNDARY, INITIAL, AND PRODUCTION CONDITIONS

SINGLE PULSE OF CONC. $=1.0000 \&$ DURATION $=55.0000$

SOLUTE FREE INITIAL CONDITION

NO PRODUCTION TERM

PARAMETER ESTIMATION MODE

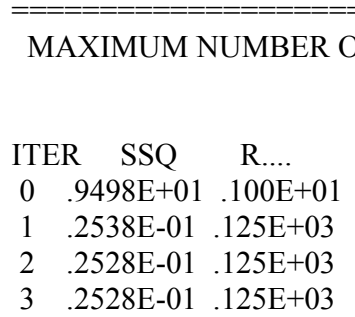

RSQUARE FOR REGRESSION OF OBSERVED VS PREDICTED $=.97553946$ (COEFFICIENT OF DETERMINATION)

NON-LINEAR LEAST SQUARES ANALYSIS, FINAL RESULTS

95\% CONFIDENCE LIMITS

NAME VALUE S.E.COEFF. LOWER UPPER 


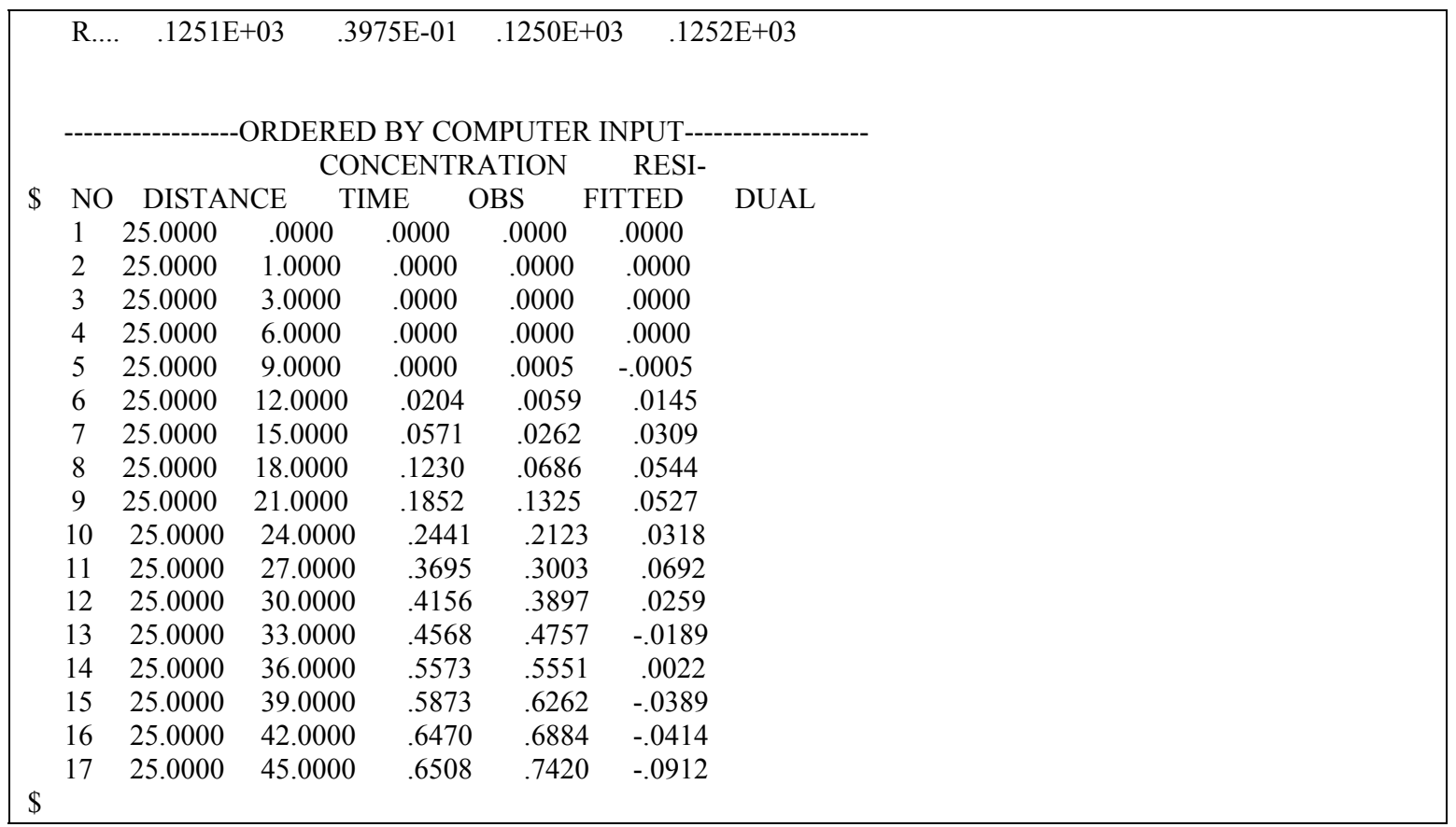




\section{o-Xylene sorption coefficient $\mathrm{Kd}$ in produced water}

\begin{tabular}{|c|c|c|c|}
\hline$*$ & & & * \\
\hline * & CXTFIT VERSION $2.0(1 / 2 / 95)$ & & * \\
\hline * & ANALYTICAL SOLUTIONS FOR ONE-DIMENSIONAL & $\mathrm{CDE} *$ & \\
\hline$*$ & NON-LINEAR LEAST-SQUARES ANALYSIS & & $*$ \\
\hline$*$ & & & * \\
\hline$*$ & $\mathrm{o}$-Xylene sorption coefficient $\mathrm{Kd}$ in produced water & & $*$ \\
\hline$*$ & Conc. vs. time at $25 \mathrm{~cm}$ (dimentional V D L T; $\mathrm{cm} \min \mathrm{g}$ ) & * & \\
\hline * & & & * \\
\hline$*$ & DATA INPUT FILE: pw-CSL.in & & $*$ \\
\hline * & & & * \\
\hline \multicolumn{4}{|c|}{$* * * * * * * * * * * * * * * * * * * * * * * * * * * * * * * * * * * * * * * * * * * * * * * * * * * * * * * * * * * * * * * * * * * * *$} \\
\hline
\end{tabular}

\section{Model Description}

DETERMINISTIC EQUILIBRIUM CDE (MODE=1)

FLUX-AVERAGED CONCENTRATION

REAL TIME (t), POSITION(x)

(D,V,mu, AND gamma ARE ALSO DIMENSIONAL)

INITIAL VALUES OF COEFFICIENTS

NAME INITIAL VALUE FITTING

$\mathrm{V}$........ $.8400 \mathrm{E}+02 \quad \mathrm{~N}$

D......... .2100E+03 N

R........ . .1000E+01 Y

mu...... .0000E+00 N

BOUNDARY, INITIAL, AND PRODUCTION CONDITIONS

SINGLE PULSE OF CONC. $=1.0000 \&$ DURATION $=55.0000$

SOLUTE FREE INITIAL CONDITION

NO PRODUCTION TERM

PARAMETER ESTIMATION MODE

MAXIMUM NUMBER OF ITERATIONS $=30$
ITER SSQ R...
$\begin{array}{lll}0 & .9498 \mathrm{E}+01 \quad .100 \mathrm{E}+01\end{array}$
$1 \quad .2538 \mathrm{E}-01 \quad .125 \mathrm{E}+03$
$2 \quad .2528 \mathrm{E}-01.125 \mathrm{E}+03$
$3 \quad .2528 \mathrm{E}-01 \quad .125 \mathrm{E}+03$

RSQUARE FOR REGRESSION OF OBSERVED VS PREDICTED $=.97553946$ (COEFFICIENT OF DETERMINATION)

NON-LINEAR LEAST SQUARES ANALYSIS, FINAL RESULTS 


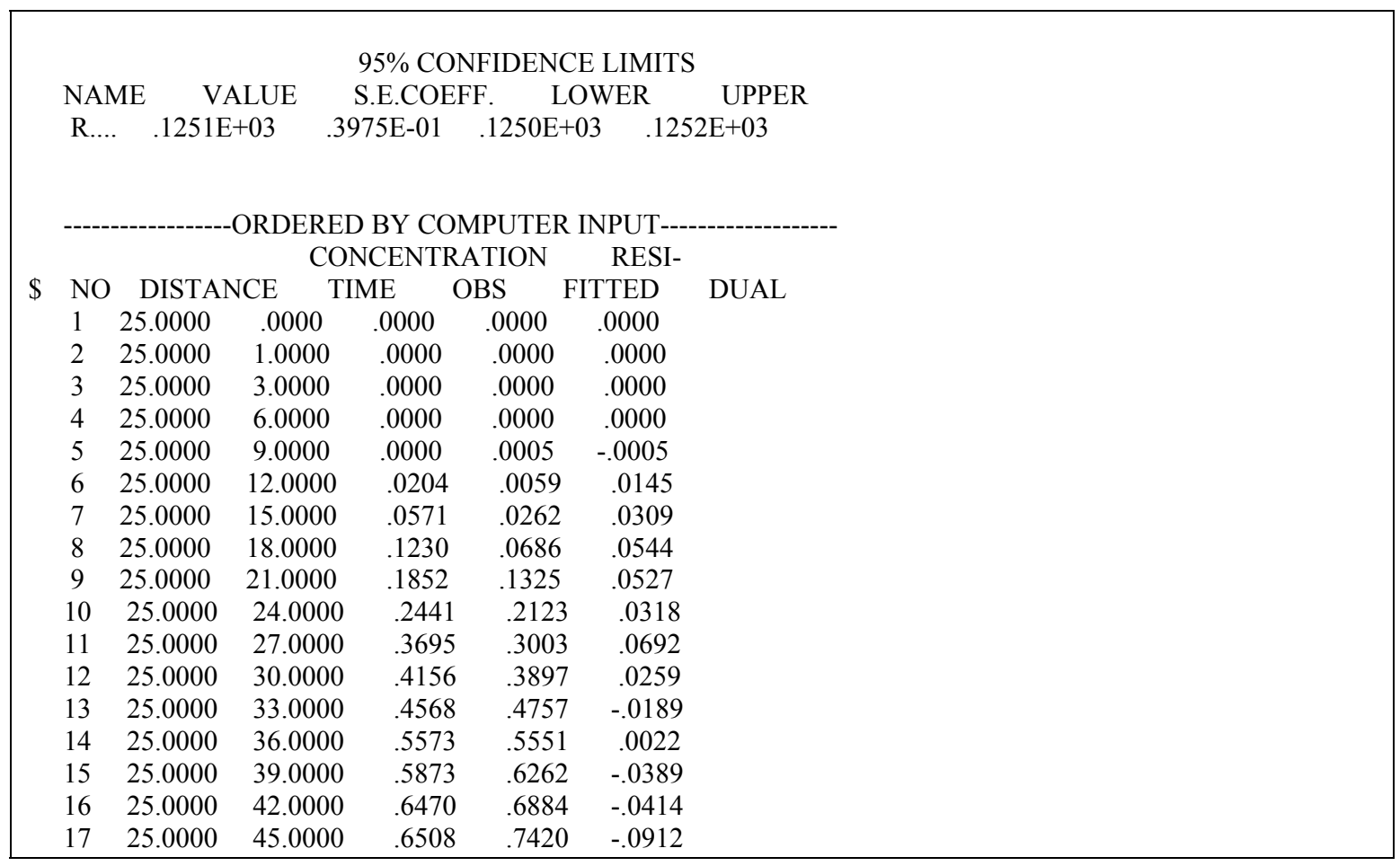




\section{Appendix B: Batch Studies}

Appendix B-1: Isotherm Data and Percent Differences for Single-Solute $\underline{\text { Test }}$

Table B.1 Isotherm Data for Benzene in Saline Solutions

\begin{tabular}{|c|c|c|c|c|c|}
\hline \multicolumn{2}{|c|}{ Millipore Water } & \multicolumn{2}{|c|}{$30,000 \mathrm{ppm}$} & \multicolumn{2}{|c|}{$231,000 \mathrm{ppm}$} \\
\hline $\begin{array}{c}\mathrm{C}_{\mathrm{e}} \\
\mu \mathrm{g} / \mathrm{L}\end{array}$ & $\begin{array}{c}\mathrm{q}_{\mathrm{e}} \\
\mu \mathrm{g} / \mathrm{g}\end{array}$ & $\begin{array}{c}C_{e} \\
\mu \mathrm{g} / \mathrm{L}\end{array}$ & $\begin{array}{c}\mathrm{q}_{\mathrm{e}} \\
\mu \mathrm{g} / \mathrm{g}\end{array}$ & $\begin{array}{c}C_{e} \\
\mu \mathrm{g} / \mathrm{L}\end{array}$ & $\begin{array}{c}\mathrm{q}_{\mathrm{e}} \\
\mu \mathrm{g} / \mathrm{g}\end{array}$ \\
\hline 4.5 & 0.05 & 0 & 0 & 0 & 0 \\
\hline 45 & 0.44 & 0 & 0 & 0 & 0 \\
\hline 4642 & 44.07 & 2.5 & 0.02 & 0.86 & 0.03 \\
\hline 32130 & 337.64 & 2.6 & 0.02 & 0.86 & 0.03 \\
\hline & & 4.5 & 0.05 & 1.8 & 0.07 \\
\hline & & 4.7 & 0.04 & 1.7 & 0.07 \\
\hline & & 47 & 0.43 & 18 & 0.66 \\
\hline & & 47 & 0.42 & 17 & 0.65 \\
\hline & & 480 & 4.28 & 187 & 6.65 \\
\hline & & 474 & 4.19 & 182 & 6.74 \\
\hline & & 4716 & 43.20 & 1844 & 67.91 \\
\hline & & 4690 & 43.78 & 1761 & 67.75 \\
\hline & & 18783 & 173.23 & 6915 & 259.45 \\
\hline & & 19692 & 167.76 & 7118 & 271.73 \\
\hline & & 35148 & 316.29 & 12203 & 497.97 \\
\hline & & broken & broken & 11661 & 500.07 \\
\hline
\end{tabular}

Table B.2 Percent Differences Between Duplicates

\begin{tabular}{|c|cc|cc|}
\hline \multirow{2}{*}{$\begin{array}{c}\mathrm{C}_{\circ} \\
\mu \mathrm{g} / \mathrm{L}\end{array}$} & \multicolumn{2}{|c|}{$30,000 \mathrm{ppm}$} & \multicolumn{2}{c|}{$231,000 \mathrm{ppm}$} \\
\cline { 2 - 5 } & $\begin{array}{c}\mathrm{C}_{\mathrm{e}} \\
\mu \mathrm{g} / \mathrm{L}\end{array}$ & $\begin{array}{c}\mathrm{q}_{\mathrm{e}} \\
\mu \mathrm{g} / \mathrm{g}\end{array}$ & $\begin{array}{c}\mathrm{C}_{\mathrm{e}} \\
\mu \mathrm{g} / \mathrm{L}\end{array}$ & $\begin{array}{c}\mathrm{q}_{\mathrm{e}} \\
\mu \mathrm{g} / \mathrm{g}\end{array}$ \\
\hline 5 & 1.8 & 4.5 & 0.2 & 1.9 \\
\hline 10 & 5.1 & 5.7 & 5.4 & 2.0 \\
\hline 100 & 1.3 & 2.1 & 3.0 & 0.5 \\
\hline 1000 & 1.2 & 2.3 & 2.6 & 1.2 \\
\hline 10000 & 0.5 & 1.3 & 4.5 & 0.2 \\
\hline 40000 & 4.8 & 3.2 & 2.9 & 4.7 \\
\hline 75000 & broken & broken & 4.4 & 0.4 \\
\hline
\end{tabular}


Appendix B-2: Isotherm Data and Percent Differences for Multi-Solute Test

Table B.3 - Isotherm Data for Multi-Solutes in Saline Solutions

\begin{tabular}{|c|c|c|c|c|c|c|c|c|}
\hline \multirow[t]{2}{*}{ Compound } & \multicolumn{2}{|c|}{ Millipore Water } & \multicolumn{2}{|c|}{$30,000 \mathrm{ppm}$} & \multicolumn{2}{|c|}{100,000 ppm } & \multicolumn{2}{|c|}{200,000 ppm } \\
\hline & $\begin{array}{c}\mathrm{C}_{\mathrm{e}} \\
\mu \mathrm{g} / \mathrm{L}\end{array}$ & $\begin{array}{c}\mathrm{q}_{\mathrm{e}} \\
\mu \mathrm{g} / \mathrm{g}\end{array}$ & 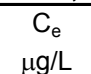 & $\begin{array}{c}\mathrm{q}_{\mathrm{e}} \\
\mu \mathrm{g} / \mathrm{g}\end{array}$ & $\begin{array}{c}\mathrm{C}_{\mathrm{e}} \\
\mu \mathrm{g} / \mathrm{L}\end{array}$ & $\begin{array}{c}\mathrm{q}_{\mathrm{e}} \\
\mu \mathrm{g} / \mathrm{g}\end{array}$ & $\begin{array}{c}\mathrm{C}_{\mathrm{e}} \\
\mu \mathrm{g} / \mathrm{L}\end{array}$ & $\begin{array}{c}\mathrm{q}_{\mathrm{e}} \\
\mu \mathrm{g} / \mathrm{g}\end{array}$ \\
\hline \multirow[t]{8}{*}{ Benzene } & 7 & 0.06 & 0 & 0 & 0 & 0 & 0 & 0 \\
\hline & 453 & 4.34 & 0 & 0 & 0 & 0 & 0 & 0 \\
\hline & 4597 & 44.58 & 7 & 0.06 & 6 & 0.07 & 3 & 0.10 \\
\hline & & & 7 & 0.06 & 6 & 0.07 & 3 & 0.10 \\
\hline & & & 470 & 4.20 & 369 & 5.22 & 200 & 6.51 \\
\hline & & & 477 & 4.34 & 377 & 5.09 & & \\
\hline & & & 4644 & 43.94 & 3590 & 53.27 & & \\
\hline & & & 4720 & 43.57 & 3628 & 52.46 & & \\
\hline \multirow[t]{8}{*}{ Toluene } & 4 & 0.09 & 0 & 0 & 0 & 0 & 0 & 0 \\
\hline & 237 & 6.07 & 0 & 0 & 0 & 0 & 0 & 0 \\
\hline & 2351 & 62.72 & 5 & 0.08 & 3 & 0.10 & 2 & 0.11 \\
\hline & & & 5 & 0.08 & 3 & 0.10 & 2 & 0.10 \\
\hline & & & 247 & 5.98 & 167 & 6.87 & 71 & 7.54 \\
\hline & & & 249 & 6.19 & 171 & 6.74 & & \\
\hline & & & 2392 & 62.25 & 1569 & 69.65 & & \\
\hline & & & 2388 & 62.42 & 1561 & 69.32 & & \\
\hline \multirow[t]{8}{*}{ Ethylbenzene } & 1 & 0.11 & 0 & 0 & 0 & 0 & 0 & 0 \\
\hline & 113 & 7.08 & 0 & 0 & 0 & 0 & 0 & 0 \\
\hline & 1106 & 72.94 & 1.0 & 0.11 & 0 & 0.12 & 0 & 0.12 \\
\hline & & & 1.0 & 0.11 & 0 & 0.12 & 0 & 0.12 \\
\hline & & & 115.9 & 7.03 & 68 & 7.70 & 24 & 7.93 \\
\hline & & & 116.8 & 7.28 & 69 & 7.57 & & \\
\hline & & & 1071.5 & 73.16 & 620 & 77.51 & & \\
\hline & & & 1088.0 & 73.08 & 626 & 77.10 & & \\
\hline \multirow[t]{8}{*}{$\mathrm{m}$ - and $\mathrm{p}$-Xylenes } & 2 & 0.11 & 0 & 0 & 0 & 0 & 0 & 0 \\
\hline & 102 & 7.15 & 0 & 0 & 0 & 0 & 0 & 0 \\
\hline & 1001 & 73.61 & 2 & 0.11 & 0.55 & 0.11 & 0 & 0.12 \\
\hline & & & 2 & 0.11 & 0.64 & 0.11 & 0 & 0.12 \\
\hline & & & 104 & 7.11 & 59 & 7.75 & 21 & 7.94 \\
\hline & & & 105 & 7.36 & 60 & 7.62 & & \\
\hline & & & 962 & 73.87 & 542 & 77.96 & & \\
\hline & & & 975 & 73.82 & 546 & 77.58 & & \\
\hline \multirow[t]{8}{*}{ o-Xylene } & 0 & 0.12 & 0 & 0 & 0 & 0 & 0 & 0 \\
\hline & 115 & 7.06 & 0 & 0 & 0 & 0 & 0 & 0 \\
\hline & 1132 & 72.66 & 0 & 0.12 & 0 & 0.12 & 0 & 0.12 \\
\hline & & & 0 & 0.12 & 0 & 0.12 & 0 & 0.12 \\
\hline & & & 117 & 7.02 & 70 & 7.68 & 25 & 7.92 \\
\hline & & & 119 & 7.25 & 71 & 7.55 & & \\
\hline & & & 1094 & 72.90 & 647 & 77.22 & & \\
\hline & & & 1117 & 72.77 & 652 & 76.81 & & \\
\hline
\end{tabular}


Table B.4 - Percent Differences Between Replicates in Multi-Solute Salinity Studies

\begin{tabular}{|c|c|c|c|c|c|c|c|}
\hline \multirow[b]{2}{*}{ Compound } & \multirow[b]{2}{*}{$\begin{array}{c}C_{o} \\
\mu g / L\end{array}$} & \multicolumn{2}{|c|}{$30,000 \mathrm{ppm}$} & \multicolumn{2}{|c|}{100,000 ppm } & \multicolumn{2}{|c|}{200,000 ppm } \\
\hline & & $\begin{array}{c}C_{e} \\
\mu g / L\end{array}$ & $\begin{array}{c}q_{e} \\
\mu g / g\end{array}$ & $\begin{array}{c}C_{e} \\
\mu g / L\end{array}$ & $\begin{array}{c}q_{e} \\
\mu g / g\end{array}$ & $\begin{array}{c}C_{e} \\
\mu g / L\end{array}$ & $\begin{array}{c}q_{e} \\
\mu g / g\end{array}$ \\
\hline Benzene & 15 & 4 & 4 & 0 & 2 & 10 & 2 \\
\hline Toluene & 15 & 1 & 1 & 0 & 1 & 16 & 2 \\
\hline Ethylbenzene & 15 & 3 & 1 & - & 1 & - & 0 \\
\hline m- \& p-Xylenes & 15 & 1 & 1 & 18 & 1 & - & 0 \\
\hline o-Xylene & 15 & - & 1 & - & 1 & - & 0 \\
\hline Benzene & 1000 & 2 & 3 & 2 & 3 & - & - \\
\hline Toluene & 1000 & 1 & 4 & 2 & 2 & - & - \\
\hline Ethylbenzene & 1000 & 1 & 3 & 2 & 2 & - & - \\
\hline m- \& p-Xylenes & 1000 & 1 & 3 & 1 & 2 & - & - \\
\hline o-Xylene & 1000 & 1 & 3 & 1 & 2 & - & - \\
\hline Benzene & 10000 & 2 & 1 & 1 & 2 & - & - \\
\hline Toluene & 10000 & 0 & 0 & 1 & 0 & - & - \\
\hline Ethylbenzene & 10000 & 2 & 0 & 1 & 1 & - & - \\
\hline m- \& p-Xylenes & 10000 & 1 & 0 & 1 & 0 & - & - \\
\hline o-Xylene & 10000 & 2 & 0 & 1 & 1 & - & - \\
\hline
\end{tabular}


Appendix B-3: Multi-Solute Isotherms for Ethylbenzene, m- \& p-Xylenes, and o-Xylene

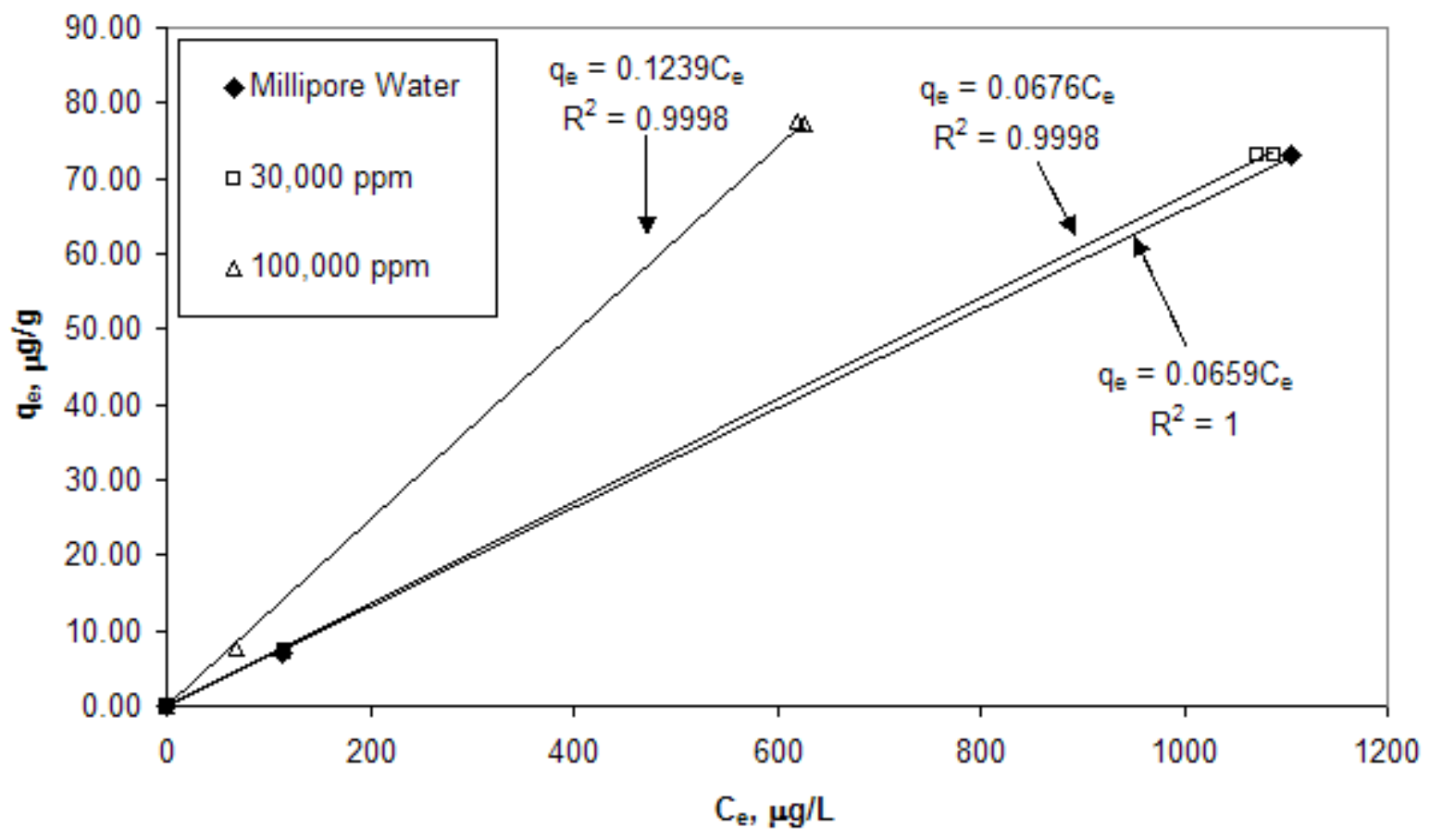

Figure B.1 - Ethylbenzene Sorption Isotherms in Aqueous Solutions of Varying Salinities 
Appendix B-4: Isotherm Data for Benzene, Toluene, Ethylbenzene, m- \& p-Xylene, and o-Xylene at Different Temperature in ultrapure Water

Table B.5 - Isotherm Data at $4^{\circ} \mathrm{C}$

\begin{tabular}{|c|c|c|c|c|c|c|c|c|c|}
\hline \multicolumn{2}{|c|}{ Benzene } & \multicolumn{2}{|c|}{ Toluene } & \multicolumn{2}{|c|}{ Ethylbenzene } & \multicolumn{2}{|c|}{ m- \& p-Xylene } & \multicolumn{2}{|c|}{ o-Xylene } \\
\hline $\begin{array}{c}\mathrm{C}_{\mathrm{e}} \\
\mu \mathrm{g} / \mathrm{L}\end{array}$ & $\begin{array}{c}\mathrm{q}_{\mathrm{e}} \\
\mu \mathrm{g} / \mathrm{g}\end{array}$ & $\begin{array}{c}\mathrm{C}_{\mathrm{e}} \\
\mu \mathrm{g} / \mathrm{L}\end{array}$ & $\begin{array}{c}\mathrm{q}_{\mathrm{e}} \\
\mu \mathrm{g} / \mathrm{g}\end{array}$ & $\begin{array}{c}\mathrm{C}_{\mathrm{e}} \\
\mu \mathrm{g} / \mathrm{L}\end{array}$ & $\begin{array}{c}\mathrm{q}_{\mathrm{e}} \\
\mu \mathrm{g} / \mathrm{g}\end{array}$ & $\begin{array}{c}\mathrm{C}_{\mathrm{e}} \\
\mu \mathrm{g} / \mathrm{L}\end{array}$ & $\begin{array}{c}\mathrm{q}_{\mathrm{e}} \\
\mu \mathrm{g} / \mathrm{g}\end{array}$ & $\begin{array}{c}C_{e} \\
\mu \mathrm{g} / \mathrm{L}\end{array}$ & $\begin{array}{c}\mathrm{q}_{\mathrm{e}} \\
\mu \mathrm{g} / \mathrm{g}\end{array}$ \\
\hline 0.00 & 0.00 & 0.00 & 0.00 & 0.00 & 0.00 & 0.00 & 0.00 & 0.00 & 0.00 \\
\hline 0.00 & 0.00 & 0.00 & 0.00 & 0.00 & 0.00 & 0.00 & 0.00 & 0.00 & 0.00 \\
\hline 0.00 & 0.00 & 0.00 & 0.00 & 0.00 & 0.00 & 0.00 & 0.00 & 0.00 & 0.00 \\
\hline 44.57 & 0.44 & 27.36 & 0.58 & 12.95 & 0.70 & 12.40 & 0.70 & 13.17 & 0.69 \\
\hline 52.53 & 0.37 & 32.47 & 0.54 & 16.23 & 0.67 & 15.16 & 0.68 & 16.15 & 0.67 \\
\hline 52.14 & 0.38 & 32.22 & 0.54 & 15.88 & 0.67 & 14.99 & 0.68 & 15.70 & 0.67 \\
\hline 570.80 & 3.66 & 351.73 & 5.49 & 189.65 & 6.80 & 169.91 & 6.96 & 184.98 & 6.84 \\
\hline 581.61 & 3.59 & 358.89 & 5.44 & 193.78 & 6.77 & 173.57 & 6.93 & 188.42 & 6.81 \\
\hline 552.22 & 3.47 & 339.05 & 5.24 & 182.60 & 6.50 & 163.30 & 6.66 & 177.68 & 6.54 \\
\hline 5564.44 & 33.92 & 3374.67 & 52.09 & 1791.94 & 64.90 & 1598.58 & 66.48 & 1731.49 & 65.40 \\
\hline 5570.72 & 34.32 & 3350.22 & 52.69 & 1783.01 & 65.33 & 1594.93 & 66.87 & 1731.81 & 65.75 \\
\hline 5569.82 & 33.99 & 3327.55 & 52.55 & 1742.98 & 65.34 & 1553.34 & 66.88 & 1686.55 & 65.80 \\
\hline 18907.82 & 165.66 & 10447.82 & 234.79 & 5053.02 & 277.63 & 4574.03 & 281.47 & 5000.21 & 278.06 \\
\hline 18920.37 & 165.77 & 10409.61 & 235.79 & 5006.01 & 279.00 & 4526.59 & 282.87 & 4863.60 & 280.16 \\
\hline 19499.09 & 168.66 & 10753.41 & 240.79 & 5134.34 & 285.85 & 4617.98 & 290.02 & 4988.30 & 287.04 \\
\hline
\end{tabular}


Table B.6 - Isotherm Data at $10^{\circ} \mathrm{C}$

\begin{tabular}{|cc|cc|cc|cc|cc|}
\hline \multicolumn{2}{|c|}{ Benzene } & \multicolumn{2}{|c|}{ Toluene } & \multicolumn{2}{c|}{ Ethylbenzene } & \multicolumn{2}{c|}{$\mathrm{m}$ - \& p-Xylene } & \multicolumn{2}{c|}{ o-Xylene } \\
\hline $\mathrm{C}_{\mathrm{e}}$ & $\mathrm{q}_{\mathrm{e}}$ & $\mathrm{C}_{\mathrm{e}}$ & $\mathrm{q}_{\mathrm{e}}$ & $\mathrm{C}_{\mathrm{e}}$ & $\mathrm{q}_{\mathrm{e}}$ & $\mathrm{C}_{\mathrm{e}}$ & $\mathrm{q}_{\mathrm{e}}$ & $\mathrm{C}_{\mathrm{e}}$ & $\mathrm{q}_{\mathrm{e}}$ \\
$\mu \mathrm{g} / \mathrm{L}$ & $\mu \mathrm{g} / \mathrm{g}$ & $\mu \mathrm{g} / \mathrm{L}$ & $\mu \mathrm{g} / \mathrm{g}$ & $\mu \mathrm{g} / \mathrm{L}$ & $\mu \mathrm{g} / \mathrm{g}$ & $\mu \mathrm{g} / \mathrm{L}$ & $\mu \mathrm{g} / \mathrm{g}$ & $\mu \mathrm{g} / \mathrm{L}$ & $\mu \mathrm{g} / \mathrm{g}$ \\
\hline 0.00 & 0.00 & 0.00 & 0.00 & 0.00 & 0.00 & 0.00 & 0.00 & 0.00 & 0.00 \\
0.00 & 0.00 & 0.00 & 0.00 & 0.00 & 0.00 & 0.00 & 0.00 & 0.00 & 0.00 \\
0.00 & 0.00 & 0.00 & 0.00 & 0.00 & 0.00 & 0.00 & 0.00 & 0.00 & 0.00 \\
53.41 & 0.36 & 32.62 & 0.53 & 15.59 & 0.67 & 14.79 & 0.68 & 15.52 & 0.67 \\
52.13 & 0.38 & 31.65 & 0.54 & 15.11 & 0.68 & 14.38 & 0.68 & 15.18 & 0.68 \\
52.42 & 0.37 & 32.03 & 0.54 & 15.77 & 0.67 & 14.54 & 0.68 & 15.34 & 0.67 \\
538.44 & 3.95 & 319.61 & 5.78 & 166.06 & 7.02 & 148.97 & 7.16 & 163.11 & 7.05 \\
519.70 & 3.79 & 306.23 & 5.54 & 157.42 & 6.72 & 141.79 & 6.85 & 156.01 & 6.73 \\
515.51 & 3.82 & 300.08 & 5.57 & 153.17 & 6.73 & 137.99 & 6.85 & 152.11 & 6.74 \\
5399.90 & 35.34 & 3092.21 & 54.73 & 1560.12 & 67.28 & 1401.06 & 68.59 & 1539.72 & 67.45 \\
5320.82 & 35.77 & 3042.70 & 54.73 & 1526.58 & 67.04 & 1368.57 & 68.33 & 1505.86 & 67.21 \\
5220.52 & 37.18 & 2950.51 & 55.82 & 1479.66 & 67.59 & 1326.47 & 68.83 & 1457.07 & 67.77 \\
18431.70 & 176.66 & 9733.65 & 248.11 & 4536.74 & 289.56 & 4139.82 & 292.75 & 4517.20 & 289.72 \\
18035.25 & 180.02 & 9536.54 & 250.41 & 4409.31 & 291.62 & 4018.48 & 294.78 & 4357.75 & 292.04 \\
18522.08 & 174.47 & 9762.21 & 247.74 & 4473.17 & 290.72 & 4065.93 & 294.05 & 4439.25 & 291.00 \\
\hline
\end{tabular}

Table B.7 - Isotherm Data at $15^{\circ} \mathrm{C}$

\begin{tabular}{|cc|cc|cc|cc|cc|}
\hline \multicolumn{2}{|c|}{ Benzene } & \multicolumn{2}{|c|}{ Toluene } & \multicolumn{2}{c|}{ Ethylbenzene } & \multicolumn{2}{c|}{$\mathrm{m}-\& \mathrm{p}-$ Xylene } & \multicolumn{2}{c|}{ o-Xylene } \\
\hline $\mathrm{C}_{\mathrm{e}}$ & $\mathrm{q}_{\mathrm{e}}$ & $\mathrm{C}_{\mathrm{e}}$ & $\mathrm{q}_{\mathrm{e}}$ & $\mathrm{C}_{\mathrm{e}}$ & $\mathrm{q}_{\mathrm{e}}$ & $\mathrm{C}_{\mathrm{e}}$ & $\mathrm{q}_{\mathrm{e}}$ & $\mathrm{C}_{\mathrm{e}}$ & $\mathrm{q}_{\mathrm{e}}$ \\
$\mu \mathrm{g} / \mathrm{L}$ & $\mu \mathrm{g} / \mathrm{g}$ & $\mu \mathrm{g} / \mathrm{L}$ & $\mu \mathrm{g} / \mathrm{g}$ & $\mu \mathrm{g} / \mathrm{L}$ & $\mu \mathrm{g} / \mathrm{g}$ & $\mu \mathrm{g} / \mathrm{L}$ & $\mu \mathrm{g} / \mathrm{g}$ & $\mu \mathrm{g} / \mathrm{L}$ & $\mu \mathrm{g} / \mathrm{g}$ \\
\hline 0.00 & 0.00 & 0.00 & 0.00 & 0.00 & 0.00 & 0.00 & 0.00 & 0.00 & 0.00 \\
0.00 & 0.00 & 0.00 & 0.00 & 0.00 & 0.00 & 0.00 & 0.00 & 0.00 & 0.00 \\
0.00 & 0.00 & 0.00 & 0.00 & 0.00 & 0.00 & 0.00 & 0.00 & 0.00 & 0.00 \\
53.06 & 0.37 & 30.92 & 0.55 & 14.67 & 0.68 & 13.79 & 0.69 & 14.53 & 0.68 \\
50.28 & 0.39 & 29.73 & 0.56 & 14.00 & 0.68 & 13.16 & 0.69 & 13.72 & 0.68 \\
53.34 & 0.36 & 30.99 & 0.55 & 14.39 & 0.68 & 13.60 & 0.69 & 14.37 & 0.68 \\
538.51 & 3.60 & 305.50 & 5.53 & 152.48 & 6.77 & 137.45 & 6.90 & 152.58 & 6.77 \\
514.96 & 3.82 & 290.39 & 5.67 & 145.31 & 6.84 & 130.74 & 6.96 & 145.17 & 6.84 \\
514.66 & 4.15 & 283.92 & 6.07 & 138.90 & 7.25 & 124.99 & 7.36 & 139.76 & 7.24 \\
972.29 & 0.00 & 2842.82 & 56.90 & 1400.75 & 68.33 & 1260.28 & 69.45 & 1397.72 & 68.35 \\
5142.23 & 38.17 & 2840.63 & 57.04 & 1397.22 & 68.58 & 1256.32 & 69.72 & 1390.96 & 68.63 \\
5125.41 & 38.28 & 2899.00 & 56.36 & 1385.59 & 68.41 & 1246.00 & 69.53 & 1393.30 & 68.35 \\
17645.44 & 182.46 & 9246.04 & 252.39 & 4322.47 & 292.14 & 3892.13 & 295.65 & 4290.83 & 292.41 \\
18339.69 & 177.41 & 9199.87 & 253.10 & 4135.56 & 293.83 & 3707.57 & 297.30 & 4144.14 & 293.76 \\
19079.52 & 164.46 & 9347.59 & 243.77 & 4140.13 & 285.04 & 3726.43 & 288.35 & 4272.61 & 283.98 \\
\hline
\end{tabular}


Table B.8 - Isotherm Data at $20^{\circ} \mathrm{C}$

\begin{tabular}{|cc|cc|cc|cc|cc|}
\hline \multicolumn{2}{|c|}{ Benzene } & \multicolumn{2}{|c|}{ Toluene } & \multicolumn{2}{c|}{ Ethylbenzene } & \multicolumn{2}{c|}{$\mathrm{m}-\& \mathrm{p}-X y l e n e$} & \multicolumn{2}{c|}{ o-Xylene } \\
\hline $\mathrm{C}_{\mathrm{e}}$ & $\mathrm{q}_{\mathrm{e}}$ & $\mathrm{C}_{\mathrm{e}}$ & $\mathrm{q}_{\mathrm{e}}$ & $\mathrm{C}_{\mathrm{e}}$ & $\mathrm{q}_{\mathrm{e}}$ & $\mathrm{C}_{\mathrm{e}}$ & $\mathrm{q}_{\mathrm{e}}$ & $\mathrm{C}_{\mathrm{e}}$ & $\mathrm{q}_{\mathrm{e}}$ \\
$\mu \mathrm{g} / \mathrm{L}$ & $\mu \mathrm{g} / \mathrm{g}$ & $\mu \mathrm{g} / \mathrm{L}$ & $\mu \mathrm{g} / \mathrm{g}$ & $\mu \mathrm{g} / \mathrm{L}$ & $\mu \mathrm{g} / \mathrm{g}$ & $\mu \mathrm{g} / \mathrm{L}$ & $\mu \mathrm{g} / \mathrm{g}$ & $\mu \mathrm{g} / \mathrm{L}$ & $\mu \mathrm{g} / \mathrm{g}$ \\
\hline 0.00 & 0.00 & 0.00 & 0.00 & 0.00 & 0.00 & 0.00 & 0.00 & 0.00 & 0.00 \\
0.00 & 0.00 & 0.00 & 0.00 & 0.00 & 0.00 & 0.00 & 0.00 & 0.00 & 0.00 \\
0.00 & 0.00 & 0.00 & 0.00 & 0.00 & 0.00 & 0.00 & 0.00 & 0.00 & 0.00 \\
47.31 & 0.42 & 26.39 & 0.59 & 11.94 & 0.70 & 11.35 & 0.71 & 11.82 & 0.70 \\
47.95 & 0.41 & 26.89 & 0.58 & 11.83 & 0.70 & 11.25 & 0.71 & 12.08 & 0.70 \\
49.29 & 0.40 & 27.23 & 0.58 & 11.93 & 0.70 & 11.59 & 0.70 & 12.12 & 0.70 \\
498.60 & 4.27 & 270.37 & 6.18 & 130.86 & 7.31 & 118.37 & 7.41 & 132.34 & 7.30 \\
489.38 & 4.04 & 265.38 & 5.87 & 129.06 & 6.95 & 116.78 & 7.05 & 129.98 & 6.94 \\
489.80 & 4.06 & 264.61 & 5.87 & 128.20 & 6.94 & 115.94 & 7.04 & 129.40 & 6.93 \\
4831.43 & 41.30 & 2576.33 & 59.52 & 1242.19 & 70.00 & 1126.91 & 70.91 & 1248.09 & 69.95 \\
5035.76 & 38.44 & 2653.75 & 58.11 & 1257.20 & 69.34 & 1136.67 & 70.31 & 1282.77 & 69.13 \\
4811.27 & 40.32 & 2574.80 & 58.93 & 1236.38 & 69.76 & 1116.25 & 70.74 & 1240.30 & 69.72 \\
17242.80 & 179.60 & 8628.19 & 249.74 & 3930.08 & 286.81 & 3564.84 & 289.72 & 3994.33 & 286.30 \\
16779.73 & 191.11 & 8419.83 & 259.96 & 3838.81 & 296.47 & 3461.86 & 299.51 & 3843.40 & 296.44 \\
16465.36 & 194.00 & 8271.47 & 261.33 & 3787.00 & 296.97 & 3417.44 & 299.94 & 3797.36 & 296.89 \\
\hline
\end{tabular}

Table B.9 - Isotherm Data at $25^{\circ} \mathrm{C}$

\begin{tabular}{|cc|cc|cc|cc|cc|}
\hline \multicolumn{2}{|c|}{ Benzene } & \multicolumn{2}{c|}{ Toluene } & \multicolumn{2}{c|}{ Ethylbenzene } & \multicolumn{2}{c|}{$\mathrm{m}-\& \mathrm{p}-X y l e n e$} & \multicolumn{2}{c|}{ o-Xylene } \\
\hline $\mathrm{C}_{\mathrm{e}}$ & $\mathrm{q}_{\mathrm{e}}$ & $\mathrm{C}_{\mathrm{e}}$ & $\mathrm{q}_{\mathrm{e}}$ & $\mathrm{C}_{\mathrm{e}}$ & $\mathrm{q}_{\mathrm{e}}$ & $\mathrm{C}_{\mathrm{e}}$ & $\mathrm{q}_{\mathrm{e}}$ & $\mathrm{C}_{\mathrm{e}}$ & $\mathrm{q}_{\mathrm{e}}$ \\
$\mu \mathrm{g} / \mathrm{L}$ & $\mu \mathrm{g} / \mathrm{g}$ & $\mu \mathrm{g} / \mathrm{L}$ & $\mu \mathrm{g} / \mathrm{g}$ & $\mu \mathrm{g} / \mathrm{L}$ & $\mu \mathrm{g} / \mathrm{g}$ & $\mu \mathrm{g} / \mathrm{L}$ & $\mu \mathrm{g} / \mathrm{g}$ & $\mu \mathrm{g} / \mathrm{L}$ & $\mu \mathrm{g} / \mathrm{g}$ \\
\hline 0.00 & 0.00 & 0.00 & 0.00 & 0.00 & 0.00 & 0.00 & 0.00 & 0.00 & 0.00 \\
0.00 & 0.00 & 0.00 & 0.00 & 0.00 & 0.00 & 0.00 & 0.00 & 0.00 & 0.00 \\
0.00 & 0.00 & 0.00 & 0.00 & 0.00 & 0.00 & 0.00 & 0.00 & 0.00 & 0.00 \\
44.74 & 0.43 & 24.00 & 0.61 & 11.13 & 0.71 & 10.79 & 0.71 & 11.71 & 0.70 \\
45.15 & 0.43 & 24.43 & 0.60 & 10.62 & 0.71 & 10.52 & 0.71 & 11.09 & 0.71 \\
43.95 & 0.44 & 23.53 & 0.61 & 10.41 & 0.71 & 9.96 & 0.72 & 10.46 & 0.71 \\
451.11 & 4.31 & 233.68 & 6.11 & 110.29 & 7.09 & 99.78 & 7.18 & 111.93 & 7.08 \\
473.08 & 4.47 & 245.03 & 6.37 & 115.62 & 7.41 & 104.54 & 7.50 & 117.31 & 7.40 \\
456.49 & 4.26 & 235.79 & 6.07 & 111.11 & 7.06 & 100.66 & 7.14 & 112.94 & 7.04 \\
4662.81 & 42.11 & 2398.05 & 60.83 & 1136.53 & 70.96 & 1026.92 & 71.85 & 1148.97 & 70.86 \\
4673.76 & 41.37 & 2397.56 & 60.34 & 1122.49 & 70.67 & 1015.61 & 71.54 & 1137.22 & 70.55 \\
4608.59 & 41.94 & 2383.32 & 60.63 & 1128.77 & 70.87 & 1019.67 & 71.77 & 1144.47 & 70.74 \\
16115.36 & 197.06 & 7960.02 & 263.97 & 3585.86 & 298.65 & 3240.74 & 301.42 & 3633.61 & 298.27 \\
16492.91 & 192.35 & 8254.15 & 260.75 & 3770.85 & 296.77 & 3414.57 & 299.66 & 3798.83 & 296.55 \\
16184.42 & 194.81 & 8006.08 & 261.44 & 3643.86 & 295.79 & 3298.46 & 298.53 & 3665.18 & 295.62 \\
\hline
\end{tabular}


Table B.10 - Isotherm Data at $36^{\circ} \mathrm{C}$

\begin{tabular}{|cc|cc|cc|cc|cc|}
\hline \multicolumn{2}{|c|}{ Benzene } & \multicolumn{2}{|c|}{ Toluene } & \multicolumn{2}{c|}{ Ethylbenzene } & \multicolumn{2}{c|}{ m- \& p-Xylene } & \multicolumn{2}{c|}{ o-Xylene } \\
\hline $\mathrm{C}_{\mathrm{e}}$ & $\mathrm{q}_{\mathrm{e}}$ & $\mathrm{C}_{\mathrm{e}}$ & $\mathrm{q}_{\mathrm{e}}$ & $\mathrm{C}_{\mathrm{e}}$ & $\mathrm{q}_{\mathrm{e}}$ & $\mathrm{C}_{\mathrm{e}}$ & $\mathrm{q}_{\mathrm{e}}$ & $\mathrm{C}_{\mathrm{e}}$ & $\mathrm{q}_{\mathrm{e}}$ \\
$\mu \mathrm{g} / \mathrm{L}$ & $\mu \mathrm{g} / \mathrm{g}$ & $\mu \mathrm{g} / \mathrm{L}$ & $\mu \mathrm{g} / \mathrm{g}$ & $\mu \mathrm{g} / \mathrm{L}$ & $\mu \mathrm{g} / \mathrm{g}$ & $\mu \mathrm{g} / \mathrm{L}$ & $\mu \mathrm{g} / \mathrm{g}$ & $\mu \mathrm{g} / \mathrm{L}$ & $\mu \mathrm{g} / \mathrm{g}$ \\
\hline 0.00 & 0.00 & 0.00 & 0.00 & 0.00 & 0.00 & 0.00 & 0.00 & 0.00 & 0.00 \\
0.00 & 0.00 & 0.00 & 0.00 & 0.00 & 0.00 & 0.00 & 0.00 & 0.00 & 0.00 \\
0.00 & 0.00 & 0.00 & 0.00 & 0.00 & 0.00 & 0.00 & 0.00 & 0.00 & 0.00 \\
42.83 & 0.45 & 22.13 & 0.62 & 9.30 & 0.72 & 9.00 & 0.72 & 9.44 & 0.72 \\
42.57 & 0.46 & 22.31 & 0.62 & 9.22 & 0.73 & 9.01 & 0.73 & 9.41 & 0.73 \\
41.98 & 0.45 & 21.62 & 0.62 & 9.03 & 0.73 & 8.83 & 0.73 & 9.18 & 0.72 \\
438.80 & 4.44 & 222.99 & 6.21 & 103.18 & 7.16 & 93.95 & 7.23 & 106.33 & 7.13 \\
449.43 & 4.70 & 227.94 & 6.56 & 105.68 & 7.55 & 96.16 & 7.63 & 108.51 & 7.53 \\
464.90 & 4.56 & 237.18 & 6.46 & 110.45 & 7.48 & 100.23 & 7.57 & 113.36 & 7.46 \\
4454.32 & 43.44 & 2261.84 & 61.43 & 1056.61 & 71.03 & 958.77 & 71.82 & 1080.07 & 70.84 \\
4590.72 & 42.83 & 2316.18 & 61.40 & 1067.14 & 71.31 & 968.33 & 72.10 & 1088.83 & 71.13 \\
4504.73 & 43.22 & 2267.86 & 61.64 & 1047.58 & 71.40 & 949.55 & 72.19 & 1064.77 & 71.26 \\
16010.21 & 194.44 & 7887.01 & 262.18 & 3492.10 & 297.63 & 3267.91 & 299.45 & 3652.93 & 296.31 \\
16081.88 & 195.27 & 7908.41 & 262.71 & 3479.38 & 298.05 & 3232.51 & 300.03 & 3578.93 & 297.24 \\
15930.95 & 197.78 & 7836.73 & 263.92 & 3450.54 & 298.56 & 3181.58 & 300.70 & 3546.81 & 297.78 \\
\hline
\end{tabular}


Appendix B-5: Isotherms for Benzene, Toluene, Ethylbenzene, m- \& p-Xylene and oXylene in Produced Water

\begin{tabular}{|c|c|c|c|c|c|c|c|c|c|}
\hline \multicolumn{2}{|c|}{ Benzene } & \multicolumn{2}{|c|}{ Toluene } & \multicolumn{2}{|c|}{ Ethylbenzene } & \multicolumn{2}{|c|}{ m- \& p- Xylene } & \multicolumn{2}{|c|}{ o-Xylene } \\
\hline $\begin{array}{c}\mathrm{C}_{\mathrm{e}} \\
\mu \mathrm{g} / \mathrm{L}\end{array}$ & $\begin{array}{c}\mathrm{q}_{\mathrm{e}} \\
\mu \mathrm{g} / \mathrm{g}\end{array}$ & $\begin{array}{c}\mathrm{C}_{\mathrm{e}} \\
\mu \mathrm{g} / \mathrm{L}\end{array}$ & $\begin{array}{c}\mathrm{q}_{\mathrm{e}} \\
\mu \mathrm{g} / \mathrm{g}\end{array}$ & $\begin{array}{c}\mathrm{C}_{\mathrm{e}} \\
\mu \mathrm{g} / \mathrm{L}\end{array}$ & $\begin{array}{c}\mathrm{q}_{\mathrm{e}} \\
\mu \mathrm{g} / \mathrm{g}\end{array}$ & $\begin{array}{c}C_{e} \\
\mu \mathrm{g} / \mathrm{L}\end{array}$ & $\begin{array}{c}\mathrm{q}_{\mathrm{e}} \\
\mu \mathrm{g} / \mathrm{g}\end{array}$ & $\begin{array}{c}\mathrm{C}_{\mathrm{e}} \\
\mu \mathrm{g} / \mathrm{L}\end{array}$ & $\begin{array}{c}\mathrm{q}_{\mathrm{e}} \\
\mu \mathrm{g} / \mathrm{g}\end{array}$ \\
\hline 5442 & 79.73 & 6324 & 168.83 & 116 & 9.83 & 906 & 64.61 & 410 & 20.29 \\
\hline 4793 & 84.74 & 5171 & 177.68 & 86 & 10.05 & 517 & 67.57 & 215 & . \\
\hline 5341 & 81.79 & 5977 & 174.25 & 81 & 10.26 & 776 & 66.66 & 334 & 21.22 \\
\hline 5459 & 81.71 & 6007 & 174.98 & 138 & 10.61 & 673 & 68.36 & 296 & 22.35 \\
\hline 5538 & 80.32 & 5947 & 173 & 131 & 10.58 & 604 & 68.28 & 293 & 2.17 \\
\hline 5285 & 83.37 & 6067 & 175.00 & 89 & 11.04 & 777 & 67.71 & 324 & 22.19 \\
\hline 5668 & 86.08 & 5861 & 180.88 & 195 & 17.21 & 755 & 73.93 & 376 & 28.60 \\
\hline 5602 & 87.75 & 6034 & 18 & 184 & 17.43 & 851 & 74.10 & 435 & 28.41 \\
\hline 5797 & 84.79 & 5824 & 180.57 & 167 & 17.40 & 648 & 74.55 & 369 & 28.58 \\
\hline & & & & 1196 & 81.16 & 1363 & 141.79 & 1270 & 93.56 \\
\hline 9382 & 129.01 & 7562 & 241.68 & 998 & 82.77 & 1596 & 140.00 & 1303 & 93.32 \\
\hline 10000 & 123.90 & 7532 & 241.53 & 1196 & 81.16 & 1572 & 140.05 & 1420 & 92.33 \\
\hline 21973 & 242.80 & 12383 & 441.97 & 3576 & 301.79 & 3881 & 360.91 & 3895 & 312.15 \\
\hline 22438 & 272.80 & 12416 & 450.37 & 3848 & 307.48 & 4026 & 367.94 & 4086 & 318.55 \\
\hline 19611 & 292.15 & & & 4003 & 306.36 & 3955 & 368.28 & 4112 & 318.40 \\
\hline
\end{tabular}




\section{Appendix C: Column Studies}

$\underline{\text { Appendix C-1: Breakthrough Data in Column Study Conducted with ultrapure Water }}$

\begin{tabular}{|c|c|c|c|c|c|}
\hline $\mathrm{T}$ & & & $\mathrm{C} / \mathrm{C} 0$ & & \\
\hline $\min$ & Benzene & Toluene & Ethylbenzene & m-\&p-Xylene & o-Xylene \\
\hline 0 & 0.0000 & 0.0000 & 0.0000 & 0.0000 & 0.0000 \\
\hline 2 & 0.0122 & 0.0000 & 0.0000 & 0.0000 & 0.0000 \\
\hline 4 & 0.6104 & 0.0210 & 0.0000 & 0.0000 & 0.0000 \\
\hline 6 & 0.8388 & 0.1312 & 0.0000 & 0.0000 & 0.0000 \\
\hline 8 & 0.9369 & 0.3756 & 0.0045 & 0.0024 & 0.0066 \\
\hline 10 & 0.9471 & 0.5645 & 0.0234 & 0.0119 & 0.0313 \\
\hline 12 & 0.9517 & 0.7116 & 0.0705 & 0.0401 & 0.0881 \\
\hline 14 & 0.9671 & 0.7813 & 0.1379 & 0.0868 & 0.1633 \\
\hline 16 & 0.9796 & 0.8779 & 0.2284 & 0.1544 & 0.2598 \\
\hline 18 & 1.0005 & 0.9328 & 0.3431 & 0.2510 & 0.3779 \\
\hline 20 & 0.9782 & 0.9461 & 0.3733 & 0.2823 & 0.4009 \\
\hline 22 & 0.9634 & 0.9226 & 0.5131 & 0.4169 & 0.5415 \\
\hline 24 & 0.9749 & 0.9281 & 0.5777 & 0.4870 & 0.6086 \\
\hline 26 & 0.9558 & 0.9253 & 0.6330 & 0.5455 & 0.6513 \\
\hline 28 & 0.9835 & 0.9672 & 0.7182 & 0.6365 & 0.7427 \\
\hline 30 & 0.9763 & 0.9543 & 0.7454 & 0.6715 & 0.7616 \\
\hline 32 & 0.9819 & 0.9373 & 0.7665 & 0.7041 & 0.7835 \\
\hline 34 & 0.9913 & 0.9588 & 0.8188 & 0.8067 & 0.8279 \\
\hline 36 & 1.0239 & 1.0098 & 0.8788 & 0.8232 & 0.8816 \\
\hline 38 & 1.0186 & 1.0118 & 0.9021 & 0.8546 & 0.9085 \\
\hline 40 & 0.9904 & 0.9233 & 0.9009 & 0.8587 & 0.9076 \\
\hline 42 & 0.9845 & 0.9724 & 0.9004 & 0.8650 & 0.9042 \\
\hline 44 & 1.0087 & 1.0018 & 0.9392 & 0.9069 & 0.9360 \\
\hline 46 & 1.0041 & 1.0210 & 0.9621 & 0.8851 & 0.9991 \\
\hline 48 & 0.9935 & 1.0511 & 8.4168 & 0.9345 & 0.9956 \\
\hline 50 & 1.0012 & 0.9902 & 0.9476 & 0.9251 & 0.9447 \\
\hline 52 & 0.9970 & 0.9592 & 0.9229 & 0.8949 & 0.9730 \\
\hline 54 & 0.9951 & 0.9784 & 0.9498 & 0.9318 & 0.9416 \\
\hline 56 & 1.0114 & 0.9997 & 0.9753 & 0.9598 & 0.9670 \\
\hline 58 & 1.0437 & 1.0383 & 1.0134 & 0.9996 & 1.0081 \\
\hline 60 & 1.0002 & 0.9862 & 0.9658 & 0.9517 & 0.9568 \\
\hline
\end{tabular}


Appendix C-2: Breakthrough Data in Column Study Conducted with Saline Water

\begin{tabular}{|c|ccccc|}
\hline $\mathrm{T}(\mathrm{min})$ & Benzene & Toluene & Ethylbenzene & $\mathrm{m}$-\&p-Xylene & o-Xylene \\
\hline 0 & 0.0000 & 0.0000 & 0.0000 & 0.0000 & 0.0000 \\
1 & 0.0008 & 0.0007 & 0.0000 & 0.0000 & 0.0000 \\
4 & 0.4565 & 0.0120 & 0.0000 & 0.0000 & 0.0000 \\
8 & 0.9340 & 0.2176 & 0.0009 & 0.0000 & 0.0016 \\
12 & 0.9747 & 0.5737 & 0.0186 & 0.0089 & 0.0269 \\
16 & 0.9931 & 0.7011 & 0.0649 & 0.0358 & 0.0854 \\
20 & 1.0041 & 0.8144 & 0.1374 & 0.0847 & 0.1715 \\
24 & 1.0104 & 0.8492 & 0.2213 & 0.1492 & 0.2657 \\
28 & 0.9612 & 0.8644 & 0.3025 & 0.2181 & 0.3531 \\
32 & 0.9840 & 0.9053 & 0.3842 & 0.2908 & 0.4403 \\
36 & 1.0228 & 0.9509 & 0.4887 & 0.3898 & 0.5494 \\
40 & 1.0041 & 0.9414 & 0.5315 & 0.4364 & 0.5909 \\
44 & 1.0061 & 0.9252 & 0.5755 & 0.4876 & 0.6339 \\
48 & 0.9614 & 0.9152 & 0.6055 & 0.5241 & 0.6630 \\
52 & 0.9836 & 0.9430 & 0.6625 & 0.5848 & 0.7209 \\
55 & 1.0181 & 0.9846 & 0.7220 & 0.6457 & 0.7819 \\
\hline
\end{tabular}

Note: the concentration is fractional. 
Appendix C-3: Breakthrough Data in Column Study Conducted with Produced Water

\begin{tabular}{|c|ccccc|}
\hline \multicolumn{1}{|l|}{ Min } & \multicolumn{5}{|c|}{$\mathrm{C} / \mathrm{C} 0$} \\
\hline 0 & 0.0000 & 0.0000 & 0.0000 & 0.0000 & 0.0000 \\
1 & 0.0000 & 0.0002 & 0.0000 & 0.0000 & 0.0000 \\
3 & 0.1520 & 0.0012 & 0.0000 & 0.0000 & 0.0000 \\
6 & 0.6892 & 0.0680 & 0.0000 & 0.0000 & 0.0000 \\
9 & 0.8494 & 0.2447 & 0.0000 & 0.0023 & 0.0000 \\
12 & 0.8738 & 0.4059 & 0.0097 & 0.0102 & 0.0204 \\
15 & 0.9190 & 0.5736 & 0.0374 & 0.0277 & 0.0571 \\
18 & 1.0058 & 0.7421 & 0.0853 & 0.0624 & 0.1230 \\
21 & 0.9863 & 0.7915 & 0.1318 & 0.0991 & 0.1852 \\
24 & 0.9983 & 0.8865 & 0.1784 & 0.1378 & 0.2441 \\
27 & 1.0347 & 0.9381 & 0.2749 & 0.2185 & 0.3695 \\
30 & 1.0113 & 0.9083 & 0.3132 & 0.2553 & 0.4156 \\
33 & 1.0171 & 0.9470 & 0.3459 & 0.2883 & 0.4568 \\
36 & 1.0543 & 0.9695 & 0.4275 & 0.3624 & 0.5573 \\
39 & 1.0766 & 0.9511 & 0.4342 & 0.4238 & 0.5873 \\
42 & 1.0453 & 0.9723 & 0.4999 & 0.4415 & 0.6470 \\
45 & 0.9972 & 0.9306 & 0.5047 & 0.4509 & 0.6508 \\
\hline
\end{tabular}

Note: the concentration is fractional. 
Appendix D Averages and Standard Deviations for BTEX Sorption Study in ultrapure Water at $20^{\circ} \mathrm{C}$

\begin{tabular}{|c|c|c|c|}
\hline Compounds & $\begin{array}{l}\text { Initial Concentration } \\
(\mu \mathrm{g} / \mathrm{L})\end{array}$ & $\begin{array}{l}\text { Final Concentration } \\
\qquad(\mu \mathrm{g} / \mathrm{L})\end{array}$ & $\begin{array}{l}\text { Sorption Density } \\
\qquad(\mu \mathrm{g} / \mathrm{g})\end{array}$ \\
\hline & & Average \pm Std. Dev. & Average \pm Std. Dev. \\
\hline Benzene & $\begin{array}{l}0 \\
100 \\
1000 \\
10000 \\
40000 \\
\end{array}$ & $\begin{array}{l}0 \pm 0 \\
48.2 \pm 1.01 \\
492.6 \pm 5.21 \\
4892.8 \pm 124.2 \\
16829.3 \pm 391.1\end{array}$ & $\begin{array}{l}0 \pm 0 \\
0.406 \pm 0.01 \\
4.12 \pm 0.129 \\
40.0 \pm 1.45 \\
188.2 \pm 7.62\end{array}$ \\
\hline Toluene & $\begin{array}{l}0 \\
100 \\
1000 \\
10000 \\
40000 \\
\end{array}$ & $\begin{array}{l}0 \pm 0 \\
26.8 \pm 0.42 \\
266.8 \pm 3.13 \\
2601.6 \pm 45.15 \\
8439.8 \pm 179.2 \\
\end{array}$ & $\begin{array}{l}0 \pm 0 \\
0.58 \pm 0.0047 \\
5.97 \pm 0.18 \\
58.85 \pm 0.71 \\
257.0 \pm 6.33 \\
\end{array}$ \\
\hline Ethylbenzene & $\begin{array}{l}0 \\
100 \\
1000 \\
10000 \\
40000 \\
\end{array}$ & $\begin{array}{l}0 \pm 0 \\
11.9 \pm 0.06 \\
129.4 \pm 1.40 \\
1245.3 \pm 10.7 \\
3852.0 \pm 72.4 \\
\end{array}$ & $\begin{array}{l}0 \pm 0 \\
0.70 \pm 0.0011 \\
7.07 \pm 0.21 \\
69.7 \pm 0.34 \\
293.4 \pm 5.70 \\
\end{array}$ \\
\hline m,p-Xylene & $\begin{array}{l}0 \\
100 \\
1000 \\
10000 \\
40000 \\
\end{array}$ & $\begin{array}{l}0 \pm 0 \\
11.4 \pm 0.17 \\
117.0 \pm 1.24 \\
1126.6 \pm 10.2 \\
3481.4 \pm 75.6 \\
\end{array}$ & $\begin{array}{l}0 \pm 0 \\
0.71 \pm 0.0015 \\
7.17 \pm 0.21 \\
70.6 \pm 0.31 \\
296.4 \pm 5.8 \\
\end{array}$ \\
\hline O-Xylene & $\begin{array}{l}0 \\
100 \\
1000 \\
10000 \\
40000\end{array}$ & $\begin{array}{l}0 \pm 0 \\
12 \pm 0.17 \\
130.6 \pm 1.56 \\
1257 \pm 22.6 \\
3878 \pm 103 \\
\end{array}$ & $\begin{array}{l}0 \pm 0 \\
0.7 \pm 0.0026 \\
7.06 \pm 0.21 \\
69.6 \pm 0.43 \\
293.2 \pm 6.0\end{array}$ \\
\hline
\end{tabular}

NOTE: SMZ'S MESH SIZE IS $14 \times 40$. 